Florida International University FIU Digital Commons

$11-8-2012$

\title{
Evaluation of the Evidential Value of the Elemental Composition of Glass, Ink and Paper by Laser- Based Micro-Spectrochemical Methods
}

Tatiana Trejos

Florida International University, trejost@fiu.edu

DOI: $10.25148 /$ etd.FI12113004

Follow this and additional works at: https://digitalcommons.fiu.edu/etd

\section{Recommended Citation}

Trejos, Tatiana, "Evaluation of the Evidential Value of the Elemental Composition of Glass, Ink and Paper by Laser-Based MicroSpectrochemical Methods" (2012). FIU Electronic Theses and Dissertations. 755.

https://digitalcommons.fiu.edu/etd/755 


\title{
FLORIDA INTERNATIONAL UNIVERSITY
}

Miami, Florida

\section{EVALUATION OF THE EVIDENTIAL VALUE OF THE ELEMENTAL COMPOSITION OF GLASS, INK AND PAPER BY LASER-BASED MICRO- SPECTROCHEMICAL METHODS}

\author{
A dissertation submitted in partial fulfillment of the \\ requirements for the degree of \\ DOCTOR OF PHILOSOPHY \\ in \\ CHEMISTRY \\ by \\ Tatiana Trejos
}


To: Dean Kenneth G. Furton

College of Arts and Sciences

This dissertation, written by Tatiana Trejos, and entitled Evaluation of the Evidential Value of the Elemental Comparison of Glass, Ink and Paper by Laser-based Microspectrochemical Methods, having been approved in respect to style and intellectual content, is referred to you for judgment.

We have read this dissertation and recommend that it be approved.

$\begin{array}{r}\hline \text { Yong Cai } \\ \hline \text { Piero Gardinali } \\ \hline \text { Jaroslava Miksovska } \\ \hline \text { William Anderson } \\ \hline \text { Jose Almirall, Major Professor }\end{array}$

Date of Defense: November 8, 2012

The dissertation of Tatiana Trejos is approved.

Dean Kenneth G. Furton College of Arts and Sciences

Dean Lakshmi N. Reddi University Graduate School

Florida International University, 2012 


\section{DEDICATION}

This dissertation is dedicated to my family, especially to my husband and my mom who are my day-to-day inspiration. I have learned from you both how to be perseverant and keep believing in our dreams. I also dedicate this work to my lovely

kids: Montserrat and Anthony, being your mom has been God's greatest gift and privilege. 


\section{ACKNOWLEDGMENTS}

I am grateful for the opportunity given to me to pursue my $\mathrm{PhD}$ at FIU. My sincere gratitude goes to my professors, lab-mates, colleagues and friends. It is impossible to have completed this project by my own; it is instead the result of a sum of efforts of many people that were very helpful to me.

Special thanks go to my mentor Dr. Jose Almirall. I am really proud to be part of your team as student and employee. You have inspired me in many ways, for your devotion, exceptional skills to guide the students and for your passion for your field. You have been a key person and model in my career.

My committee members Dr. Yong Cai, Dr. Piero Gardinali, Dr. Jaroslava Miksovska and Dr. William Anderson have also helped me during this project and I would like to thank them for their advice.

Many people have provided remarkable support throughout my time at FIU Thanks go to the College of Arts and Sciences, the Chemistry and Biochemistry Department, the International Forensic Research Institute, Pupi Tomassini and Dr. Almirall's entire group, who also offered me their friendship. Thanks to those students that were also involved in the research project: Benjamin Naes, Yaribey Rodriguez, Alejandra Flores, Linet Kamandulis and Ruth Corzo. It has been a real pleasure to work with you.

Thanks to Jack Gordon Institute for Public Policy and Citizenship Studies at FIU for the Graduate Student Research Award granted in 2009. This award gave me the opportunity to travel to forensic laboratories in Mexico and Dominican Republic and 
made possible to include Latin American forensic laboratories in inter-laboratory programs for the interpretation of trace evidemce.

Thanks to my husband, who has been my best friend and the most interesting colleague I would ever have. Thanks my love for been the greatest support in this adventure.

Outside FIU there are also several people that deserve many thanks. Dr. Robert Koons and Dr. Anthony Cantu, for their advice and contribution. Thanks to EAWG members for the numerous discussions and significant contribution to this research.

I would like to thank several people for their help in providing samples. Robert Ramatowski from the US Secret Service for facilitating writing ink samples and the International Paper Company for providing paper exemplars.

Thanks to INTERPOL and the EDEWG committee for the Young Scientist Award that allowed me to participate at the $7^{\text {th }}$ EDEWG meeting, it was a great learning experience.

Thank you to Applied Spectra for the LIBS instrument loan and for their expert technical support.

Last but not least, thanks to the National Institute of Justice for funding provided to both the EAWG project and the ink project. 


\section{ABSTRACT OF THE DISSERTATION \\ EVALUATION OF THE EVIDENTIAL VALUE OF THE ELEMENTAL COMPOSITION OF GLASS INK AND PAPER BY LASER-BASED MCIROSPECTROCHEMICAL METHODS}

by

\section{Tatiana Trejos}

Miami, FL

\section{Professor Jose R. Almirall, Major Professor}

Elemental analysis can become an important piece of evidence to assist the solution of a case. The work presented in this dissertation aims to evaluate the evidential value of the elemental composition of three particular matrices: ink, paper and glass.

In the first part of this study, the analytical performance of LIBS and LA-ICP-MS methods was evaluated for paper, writing inks and printing inks. A total of 350 ink specimens were examined including black and blue gel inks, ballpoint inks, inkjets and toners originating from several manufacturing sources and/or batches. The paper collection set consisted of over 200 paper specimens originating from 20 different paper sources produced by 10 different plants.

Micro-homogeneity studies show smaller variation of elemental compositions within a single source (i.e., sheet, pen or cartridge) than the observed variation between different sources (i.e., brands, types, batches). Significant and detectable differences in the elemental profile of the inks and paper were observed between samples originating from different sources (discrimination of $87-100 \%$ of samples, depending on the sample set under investigation and the method applied). These results support the use of 
elemental analysis, using LA-ICP-MS and LIBS, for the examination of documents and provide additional discrimination to the currently used techniques in document examination.

In the second part of this study, a direct comparison between four analytical methods ( $\mu$-XRF, solution-ICP-MS, LA-ICP-MS and LIBS) was conducted for glass analyses using interlaboratory studies. The data provided by 21 participants were used to assess the performance of the analytical methods in associating glass samples from the same source and differentiating different sources, as well as the use of different match criteria (confidence interval ( $\pm 6 \mathrm{~s}, \pm 5 \mathrm{~s}, \pm 4 \mathrm{~s}, \pm 3 \mathrm{~s}, \pm 2 \mathrm{~s})$, modified confidence interval, t-test (sequential univariate, $\mathrm{p}=0.05$ and $\mathrm{p}=0.01$ ), t-test with Bonferroni correction (for multivariate comparisons), range overlap, and Hotelling's $\mathrm{T}^{2}$ tests. Error rates (Type 1 and Type 2) are reported for the use of each of these match criteria and depend on the heterogeneity of the glass sources, the repeatability between analytical measurements, and the number of elements that were measured. The study provided recommendations for analytical performance-based parameters for $\mu$-XRF and LA-ICP-MS as well as the best performing match criteria for both analytical techniques, which can be applied now by forensic glass examiners. 


\section{TABLE OF CONTENTS}

CHAPTER

PAGE

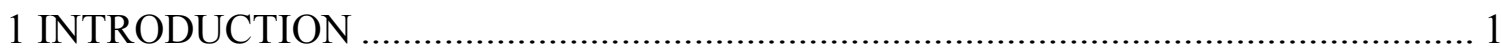

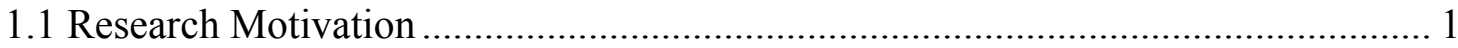

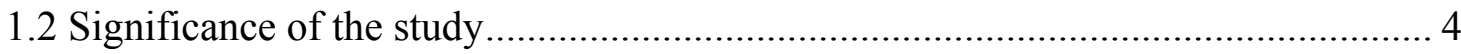

1.3 Utility of elemental analysis in trace evidence ................................................... 5

1.3.1 Utility of elemental analysis in forensic comparisons of man-made materials . 7

1.4 The composition, manufacture and forensic examination of paper.......................... 8

1.4.1 Raw materials and chemistry of paper....................................................... 8

1.4.2 Paper manufacturing ............................................................................... 12

1.4.3 Forensic Examination of paper .................................................................... 16

1.5 The composition, manufacture and forensic examination of ink .......................... 18

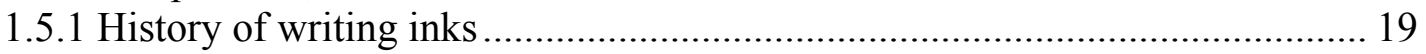

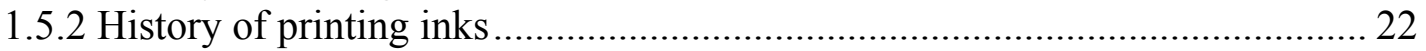

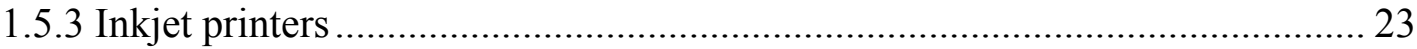

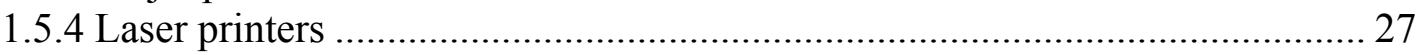

1.5.5 Raw materials and formulation of printing inks and writing inks ................... 30

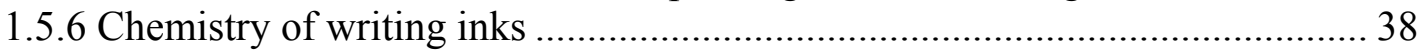

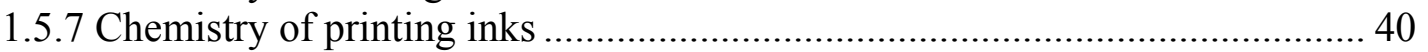

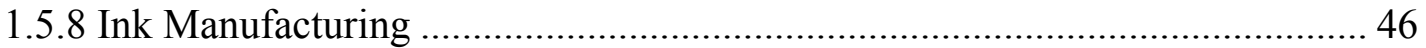

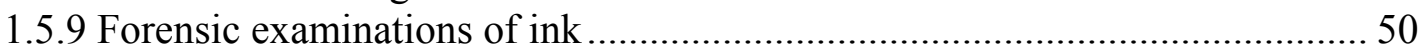

1.6 The composition, manufacture and forensic examination of glass ......................... 53

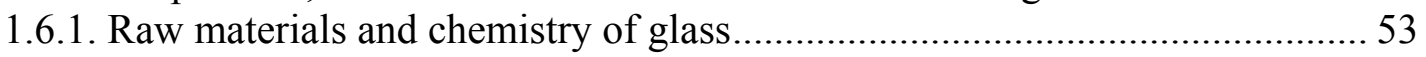

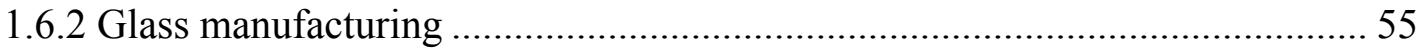

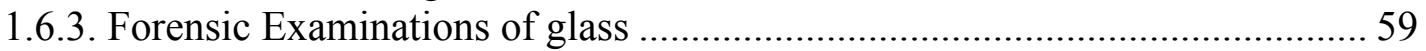

1.7 Fundamentals of laser-based spectrochemical methods for elemental analysis .... 65

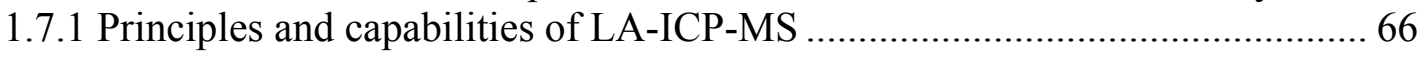

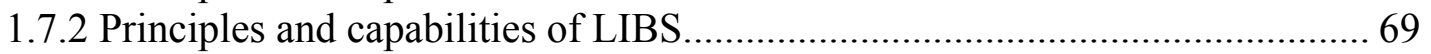

2 MICRO-SPECTROCHEMICAL ANALYSIS OF PAPER BY LA-ICP-MS AND LIBS

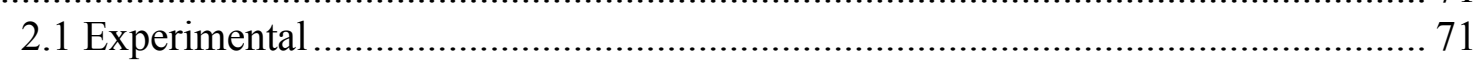

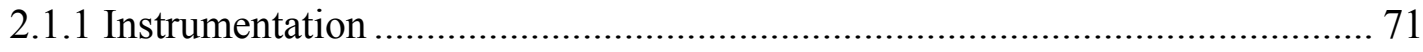

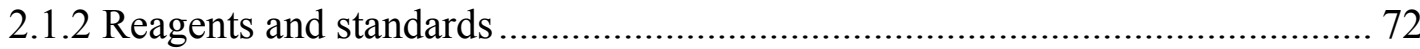

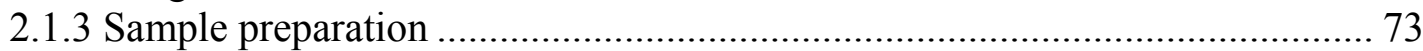

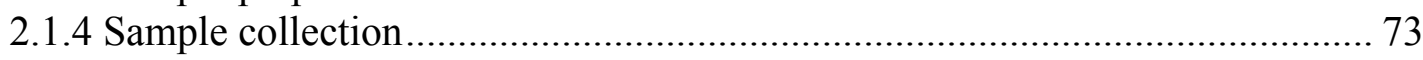

2.1.5 Data reduction and statistical analysis ........................................................ 74

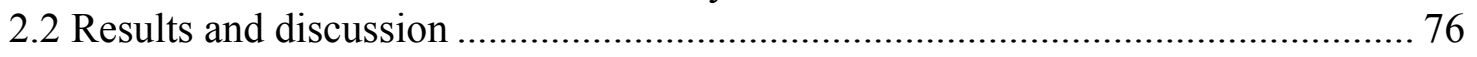

2.2.1 Development and optimization of LA-ICP-MS method for the elemental analysis of paper ………................................................................................. 76 2.2.2 Development and optimization of LIBS method for the elemental analysis of paper. 85 
2.2.3. Comparison of figures of merit of laser ablation methods for paper analysis 93

2.2.4 Evaluation of the discrimination potential of LIBS and LA-ICP-MS ............ 93

2.2.5 Results for differentiation and identification of paper.................................. 100

2.3. Conclusions for elemental analysis of paper by LA-ICP-MS and LIBS ............. 109

\section{FORENSIC ANALYSIS OF WRITING INKS AND PRINTING INKS BY LA-ICP-}

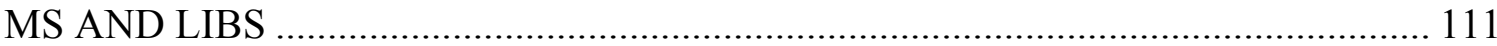

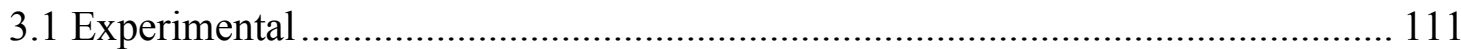

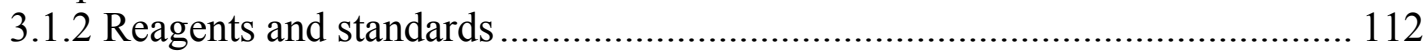

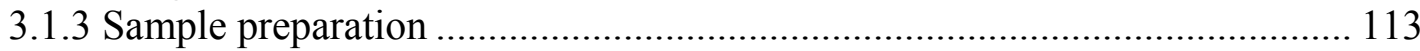

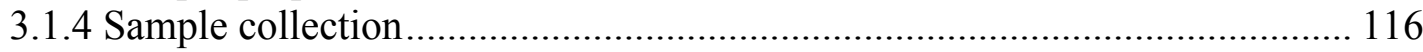

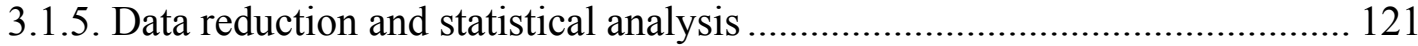

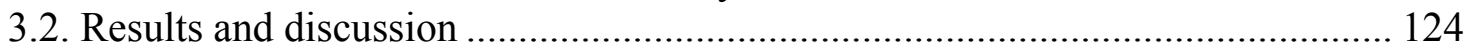

3.2.1 Development and optimization of a LA-ICP-MS method for the analysis of writing inks ................................................................................................... 124

3.2.2 Development and optimization of a LIBS method for the analysis of writing

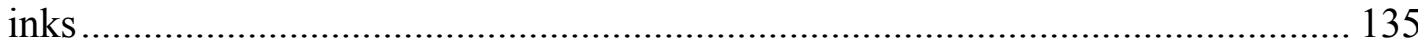

3.2.3 Comparison of figures of merit for the analysis of writing inks by LA-ICP-MS

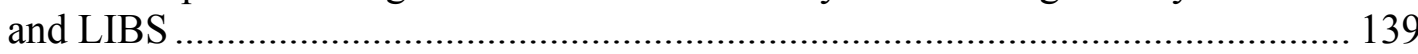

3.2.4. Development and optimization of a LA-ICP-MS method for the analysis of

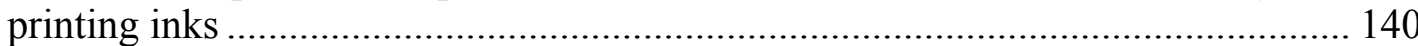

3.2.5 Development and optimization of a method for the analysis of printing inks by

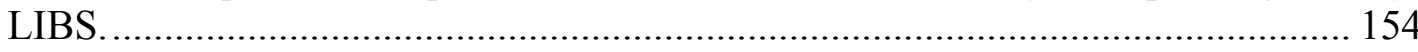

3.2.6 Comparison of the figures of merit of LA-ICP-MS and LIBS for the analysis

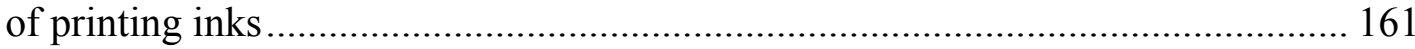

3.2.7 Evaluation of the discrimination capabilities of laser ablation methods for the analysis of writing and printing inks....................................................................... 163 3.2.8 Evaluation of usefulness of molecular emissions in the discrimination of inks

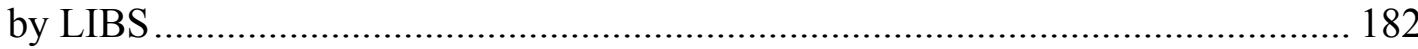
3.2.9 Determination of mass of ink removed by laser ablation methods................. 187

3.3 Conclusions for the elemental analysis of ink by laser ablation methods ............ 192

4 PERFORMANCE OF STANDARDIZED METHODS FOR THE FORENSIC ELEMENTAL ANALYSIS OF GLASS BY $\mu$-XRF, ICP-MS, LA-ICP-MS AND LIBS.

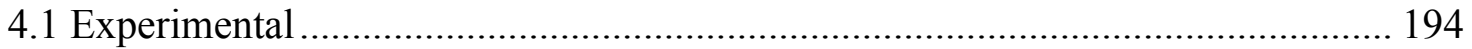

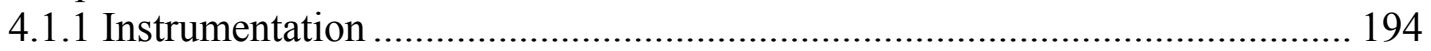

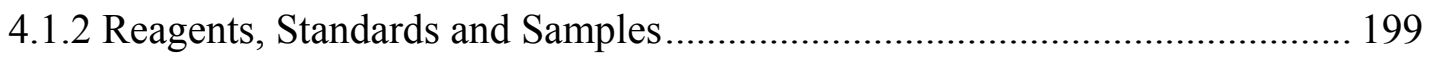

4.1.3 Analytical protocols and descriptions of interlaboratory tests........................ 199

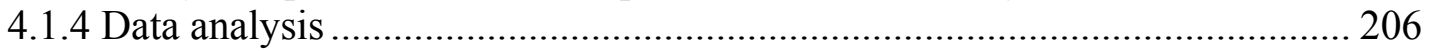

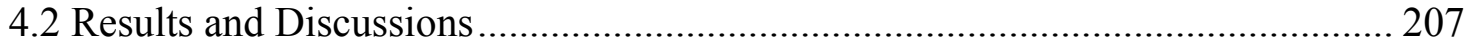

4.2.1 Results from the first and second interlaboratory test: method standardization 
4.2.2 Results and discussion for interlaboratory tests 2, 3 and 4: Evaluation of the performance of different criteria for comparing elemental composition................ 235 4.3 Conclusions for the evaluation of the performance of different match criteria for the comparison of elemental composition of glass ..................................................... 266

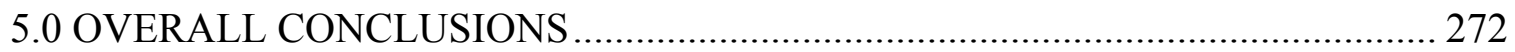

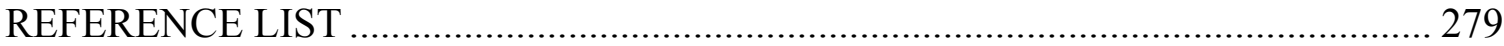

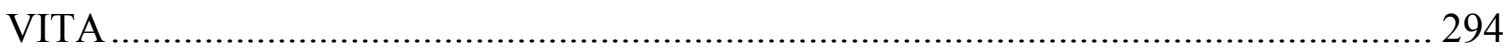




\section{LIST OF TABLES}

TABLE

PAGE

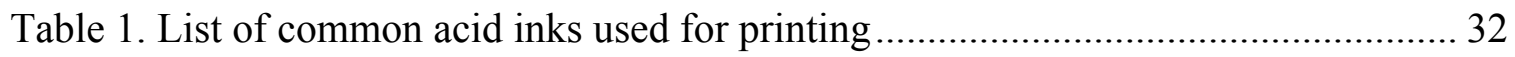

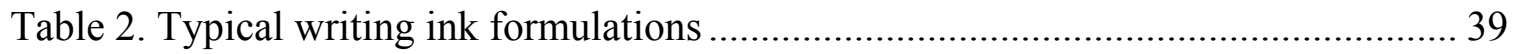

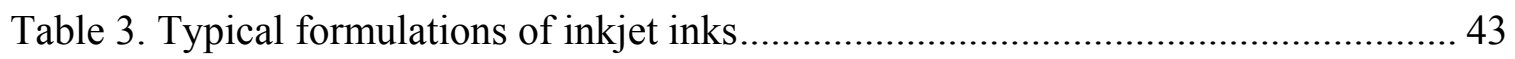

Table 4. Description of paper samples analyzed by LA-ICP-MS and LIBS .................. 75

Table 5. Optimized instrumental parameters for the analysis of paper by LA-ICP-MS .. 77

Table 6. Optimized parameters for the analysis of paper by LA-ICP-MS and LIBS ....... 87

Table 7. Figures of merit for the methods used for paper analysis............................... 94

Table 8. Discrimination capabilities of elemental composition of paper by LA-ICP-MS

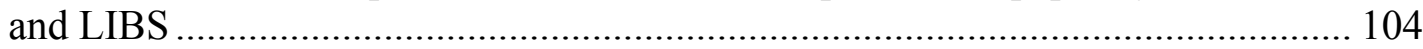

Table 9. Information of manufacturing and distribution of paper reams for the paper

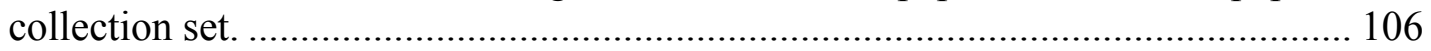

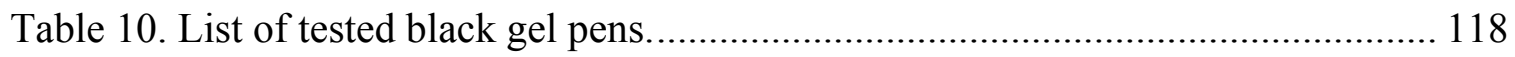

Table 11. List of tested black ballpoint refill inks ................................................ 119

Table 12. List of tested blue gel pens and refill inks. ............................................. 120

Table 13. List of tested inkjet printer inks. ........................................................ 122

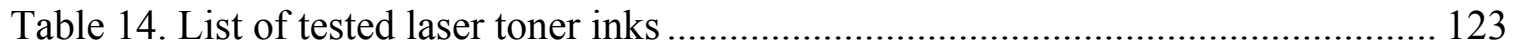

Table 15. Optimized instrumental parameters for the analysis of writing inks by LA-ICP-

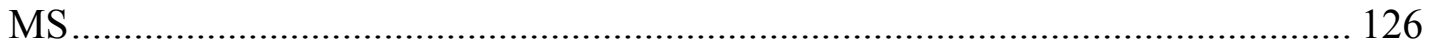

Table 16. Elemental composition of the tested fountain ink. .................................. 127

Table 17. Optimized instrumental parameters for the analysis of writing ink by LIBS. 136

Table 18. Figures of merit for laser-based methods for the analysis of writing ink...... 140

Table 19. Optimized instrumental parameters for the analysis of printing inks (inkjets and

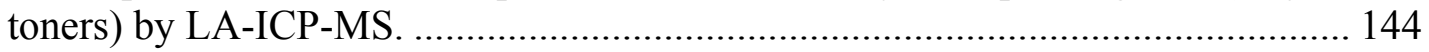


Table 20. Optimum instrumental parameters for the analysis of printing inks by LIBS.154

Table 21. Comparison of the elemental menu selected for the analysis of toners by LIBS

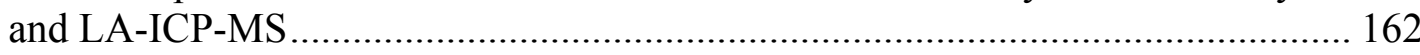

Table 22. Comparison of limits of detection of LA-ICP-MS and LIBS for the analysis of

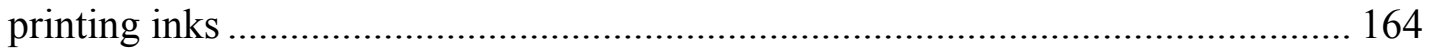

Table 23. Discrimination capabilities of LA-ICP-MS for writing inks........................ 167

Table 24. Discrimination capabilities of LIBS for the analysis of writing inks ............ 171

Table 25. Discrimination capabilities and error rates for the elemental analysis of inkjet

Table 26. Discrimination capabilities and error rates for the analysis of black toners by

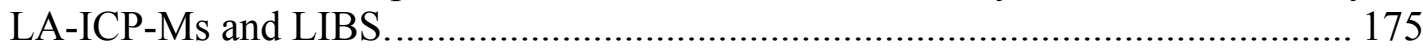

Table 27. List of emission species detected in the LIBS spectra of inks ...................... 183

Table 28. Discrimination capabilities of the LIBS molecular bands on inks ................ 184

Table 29. Comparison of mass removed during laser ablation experiments on inks. Mass

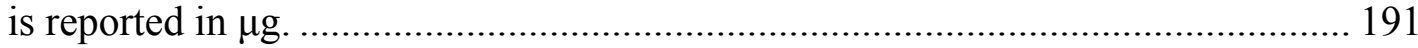

Table 30. Instrumental parameters used for the LA-ICP-MS or ICP-MS laboratories that

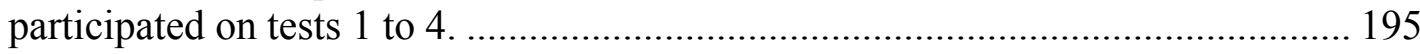

Table 31. Instrumental parameters used for the additional ICP participants in interlaboratory tests 3 and 4 .

Table 32. Instrumental parameters used for the elemental analysis of glass fragments by $\mu-\mathrm{XRF}$

Table 33. Instrumental parameters used for the elemental analysis of glass fragments by LIBS.

Table 34. Description of manufacturing dates of float glasses and the composition of the inter-laboratory test samples .......................................................................... 203

Table 35. Bias and precision obtained by ICP-methods for SRM NIST 1831 from the

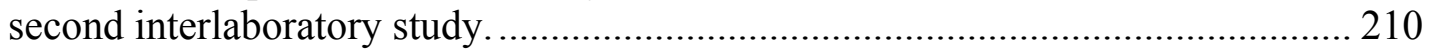

Table 36. Bias and precision obtained by ICP methods in FGS 1 from the second interlaboratory study. 
Table 37. Bias and precision obtained by ICP methods in FGS 2 from the second interlaboratory study

Table 38. Values of z-score obtained from the interlaboratory comparison of elemental ratios by $\mu$-XRF for FGS 1 and FGS 2 .

Table 39. Precision data obtained by $\mu$-XRF methods for FGS 1 and FGS 2.

220

Table 40. Expected Limits of Detection (LOD) for glass analysis by ICP-MS, LA-ICPMS, $\mu$-XRF and LIBS methods, respectively.

Table 41. Detail of elements with differences in elemental composition for full thickness vs small fragment of SRM NIST 1831 measured by LA-ICP-MS.

Table 42. Pairwise comparison of SRM NIST 1831 glass fragments using ANOVA $(p=0.05)$ and $4 \mathrm{~s}$ interval, respectively. Elements listed were significantly different using the specified match criteria.

Table 43. Results for the inter-laboratory test 2 sample comparisons as reported by each participant using their match criteria.

Table $44 \mathrm{XRF}$ and LIBS results for the inter-laboratory test 3 sample comparisons as reported by each participant using their match criteria.

Table 45 ICP results for the inter-laboratory test 3 sample comparisons as reported by each participant using their match criteria.

Table 46 Inter-laboratory test 4 results as reported by each $\mu \mathrm{XRF}$ participant using their selected match criteria.

Table 47. Interlaboratory test 4 results as reported by each ICP participant using their selected match criteria.

Table 48 Round robin $4^{\text {th }}$ results as reported by each LIBS participant using their selected match criteria. 250

Table 49. Results for the application of different match criteria on data acquired by XRF methods

Table 50. Results for the application of different match criteria on data acquired by ICP methods. 


\section{LIST OF FIGURES}

FIGURE

PAGE

Figure 1. Scheme of the main manufacturers of CIJ and DOD inkjet printers (modified

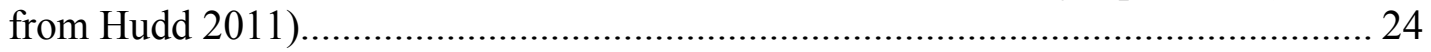

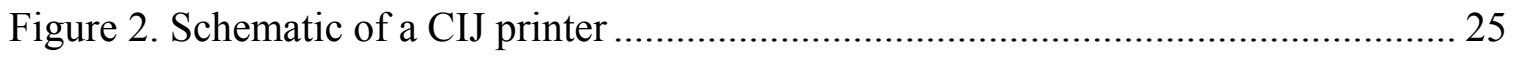

Figure 3. Schematic representation of a DOD printer ............................................. 27

Figure 4. Diagram of main components of a laser printer ............................................. 29

Figure 5. Comparison of precision $(\% \mathrm{RSD}, \mathrm{n}=7)$ of multipurpose paper using LA-ICP-

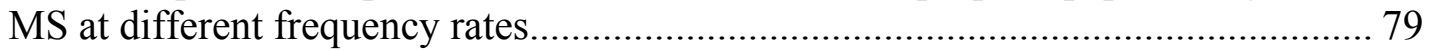

Figure 6. Comparison of signal intensity and signal stability of multipurpose paper using LA-ICP-MS at different frequency and ablation rates.................................... 79

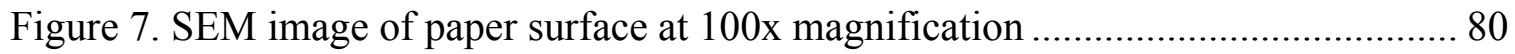

Figure 8. SEM image of ablation marks left on paper substrate after LA-ICP-MS at different energy levels. Image shown at 100x magnification ............................... 81

Figure 9. Calibration curves of spiked $\mathrm{Sr}$ in paper with and without internal standard ... 84

Figure 10. Optimization of gate delay for Sr spiked in paper (250 ng). Top to bottom: intensity response, precision (as \% RSD) and signal to noise ratio 88

Figure 11. Optimization of gate width for Sr spiked in paper (250ng). Top to bottom: intensity response, precision (as \% RSD) and signal to noise ratio.

Figure 12.LIBS signal for $\mathrm{Sr} 421.5 \mathrm{~nm}$ (II) (top) and $\mathrm{Sr} 407.7 \mathrm{~nm}$ (II) (bottom) with

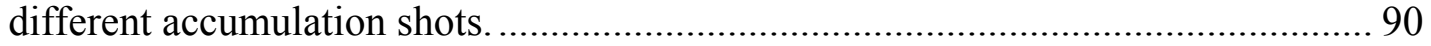

Figure 13. Variation of Strontium within a sheet of paper and between two sheets of

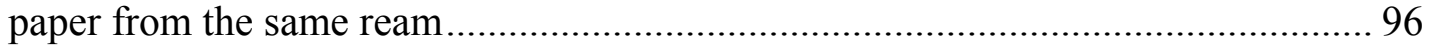

Figure 14. Normalized elemental profile from document paper collected from three different brands (brands $\mathrm{G}, \mathrm{B}$ and $\mathrm{A}$ ), processed in different mills and production batches. 98

Figure 15. Results from principal component analysis of LA-ICP-MS data, showing differentiation and grouping of the paper samples produced in different 
mills/batches. Principal component 1 (Prin1) and principal component 2 (Prin2) describe $51.5 \%$ and $26.1 \%$ of the total variance of the data, respectively. 100

Figure 16. Comparison of the variation of the elemental composition within and between the paper sources. Letters in paper ID represent the brand and the number identify the sample as reported elsewhere. Each brand is also grouped by color or pattern 103

Figure 17. Examples of templates for the collection of writing inks (top left) and printing inks (bottom left) and their respective subsamples after ablation (right). 115

Figure 18. Effect of the laser frequency in the precision of the measurements (\%RSD, $\mathrm{n}=5$ ) of the elemental composition of ink by LA-ICP-MS 125

Figure 19. Photomicrograph of an ink standard drop (25x magnification) and transient LA-ICP-MS signal across an ink drop spiked with $5 \mathrm{ng}$ of a mixture of elements 129

Figure 20. Reproducibility $(n=3)$ and repeatability $(n=5)$ obtained for ink standards spiked with $12.5 \mathrm{ng}$ of the elements of interest.

Figure 21. Calibration curve of matrix-matched spiked ink on paper for the analysis of $\mathrm{Sr}$ in writing inks by LA-ICP-MS. 130

Figure 22. Signal of ${ }^{13} \mathrm{C}$ (light blue) for the gas blank, the ablation of paper and the ablation of ink on paper by LA-ICP-MS. 133

Figure 23. Calibration curve of Mg deposited on ink analyzed by LIBS (Mg II, $280.2 \mathrm{~nm}$ )

Figure 24. Part of the LIBS spectra of six different black gel inks at 232-284nm (A-D) and $304-354 \mathrm{~nm}(\mathrm{E})$. 138

Figure 25. Laser ablation signals at different energy levels for $\mathrm{C}, \mathrm{Mg}, \mathrm{K}$ and $\mathrm{Cu}$. 142

Figure 26. Top: LA-ICP-MS transient signal for gas blank, paper and ink on paper, respectively, for laser energy at $0.9 \mathrm{~mJ}$ (left) and $1.3 \mathrm{~mJ}$ (right). Bottom: respective signals for $\mathrm{Cu}$ only. 143

Figure 27. Imaging of the laser interaction with inkjet and paper at different laser energies. Top: 3D imaging, Bottom: 2D image. 145

Figure 28. Microscopic images for ink on paper of inkjet (top images) and toner (bottom images). From left to right: cross section image of the deposition of ink on paper at 100x; top image of the ink deposited on the substrate at 500x; and image of the ablation patterns of ink of paper at 200x. 147 
Figure 29. Comparison of absorption patterns of inkjet inks on paper. A) IN 01(Hewlett Packard), B) IN06 (Hewlett Packard), C) IN 14 (Canon), D) IN 15 (Lexmark) and E) IN 18 (Brother). From left to right: magnification at 100x, 300x and 1000x, respectively 148

Figure 30. Comparison of deposition patterns of toners on paper. A) T01 (Hewlett Packard), B) T05 (Hewlett Packard), C) T06 14 (Hewlett Packard), D) T03 (Brother) and E) T02 (OKI). From left to right: magnification at 100x, 300x and 1000x, respectively. 149

Figure 31. Examples of morphology of toners at 300x (left) and 1000x (right) for toners of the same brand (A and $\mathrm{B}$ ) and toners from different brand $(\mathrm{C})$........................ 150

Figure 32. Signal increase at different spiked concentration levels (top) and its respective calibration curve (bottom) for the analysis of Li $670.7 \mathrm{~nm}$ (left) and $\mathrm{Sr} 460.7 \mathrm{~nm}$ (right) by LIBS. 156

Figure 33. Scheme for the systematic identification of peaks and comparison of LIBS ink spectra by spectral overlay. 159

Figure 34. LIBS spectra of region III for toner inks. From top to bottom: Toner samples \#T04 and T05, replicate measurements from toner \#T04 and toner samples \#T04 and T01. 160

Figure 35. Representation of the variation of aluminum on black gel ink at different percent use of the pen. 165

Figure 36. Photograph of $t$ different deposition patterns for the black gel blind sample set. 168

Figure 37. Variation of elemental composition on inkjets by LA-ICP-MS. Top to bottom: $\mathrm{Mg} /{ }^{13} \mathrm{C}, \mathrm{Cu} /{ }^{13} \mathrm{C}$ and $\mathrm{K} /{ }^{13} \mathrm{C}$. 176

Figure 38. Variation of the elemental composition of $\mathrm{Sr}$ on toner samples collected from the same cartridge at different time intervals.

Figure 39 Results from principal component analysis of LA-ICP-MS data, showing differentiation and grouping of the ink samples from different brands The 3 first principal components describe $56 \%$ of the total variance in the data. 179

Figure 40 Results from principal component analysis of LA-ICP-MS data, showing differentiation and grouping of the inkjet samples from different brands and/or cartridges. The 3 first principal components describe $99 \%$ of the total variance in the data. 180 
Figure 41 Results from principal component analysis of LA-ICP-MS data, showing differentiation and grouping of the toner samples from different brands and/or cartridges. The 3 first principal components describe $99 \%$ of the total variance in the data. 181

Figure 42. LIBS spectra for blue gels BB 17 (top) and BB18 (bottom) and their respective duplicate samples 184

Figure 43. LIBS spectra of emission lines at the 674-676 nm range for blue gel samples $\mathrm{BB} 01, \mathrm{BB} 10$ and the paper background. 185

Figure 44. Examples of LIBS spectra for the $\mathrm{CN}$ bands on blue gel inks (top, BB03 and BB08), and toners (T04, T01 and T01 Blind, respectively) 186

Figure 45. LIBS spectra for CN band in toner (top) and inkjet (bottom) and the respective background signal from paper substrate 187

Figure 46. Example of interlaboratory statistics of ICP-MS participants for strontium in FGS 1 215

Figure 47. Interlaboratory comparison of the $\mathrm{Ca} / \mathrm{Mg}$ ratio measured by $\mu$-XRF, for FGS1 without normalization (top) and after normalization (bottom) with SRM NIST 1831

Figure 48. Elemental variation of iron composition between samples manufactured at the

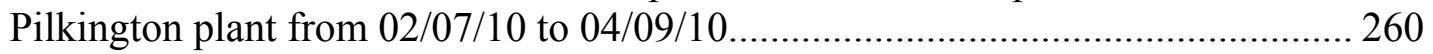

Figure 49. Sampling diagram used for the analysis of spatial elemental variation within a fragment. 262

Figure 50. Variation of iron content across different sampling areas within a single fragment. Top: glass manufactured at Pilkington plant on 03/03/10. Left: glass manufactured at Cardinal plant on 08/17/01 265 


\section{INTRODUCTION}

\subsection{Research Motivation}

Laser ablation is a leading technology for direct in-situ micro-sampling. The intrinsic advantages of laser ablation methods are very attractive for forensic analysis, especially for its micro-destructive nature, sub-micron spatial resolution and good discrimination potential [Almirall et al., 2010; Russo et al., 2011].

Laser ablation ICP-MS and LIBS have been used for several applications in the areas of trace evidence, drugs, explosives, forensic toxicology and environmental forensics [Almirall et al., 2010; Trejos et al., 2010].

My dissertation presents a comprehensive evaluation of the capabilities and limitations of these laser ablation techniques for the elemental analysis and comparison of paper, ink and glass samples. The ultimate goal is to evaluate the validity of these methods in the forensic context.

Document fraud is a criminal activity affecting the economy of both developed and developing countries. Crimes such as identity theft, altered contracts, falsified checks, insurance fraud and the use of counterfeit money, cost billions of dollars annually to the US government and citizens [Brunelle et al., 2003]. Examination of ink and paper has been the focus of many of these criminal investigations. Current analytical methods used to conduct examinations of questioned documents include the analysis of the ink and/or the paper by their physical properties, microscopic examination, optical methods, thin layer chromatography (TLC), FTIR, gas chromatography (GC, GC/MS), high pressure liquid chromatography (HPLC), microspectrophotometry, X-ray fluorescence 
(XRF) and/or capillary electrophoresis [ASTM E1422; Roux et al., 1999; Lewis 1996; Pfelferli 1983; Sensi et al.,1982; Sinor et al.,1986; Zimmerman et al., 1988].

Although the majority of these methods are useful to some extent to identify whether a document has been counterfeited or altered, counterfeiters are becoming more skilled and some fake documents have almost identical features as an authentic document, requiring more sophisticated and smarter methods of detection than are currently available. Moreover, as a result of new market requirements, environmental regulations and technological advances, the chemical composition of the formulations is changing continuously, also creating new analytical demands within the forensic community.

As a consequence, there is an increased interest in finding alternative and/or complementary methods of analysis for inks and paper to assist document examiners to overcome analytical challenges that otherwise are difficult to address using the conventional methods [Brunelle et al., 2003].

For instance, gel pen inks have become a prominent type of ink in forensic document examinations as a result of its widespread use and low cost of manufacture. Nonetheless, the analysis of gel pen inks constitutes a challenge for the forensic ink examiner since most of the gel inks are difficult to analyze by conventional techniques such as TLC and capillary electrophoresis [Wilson et al., 2004]. As a result, other methods such as Raman spectroscopy [Zieba-Palus et al., 2006; Zieba-Palus et al., 2008], infrared spectroscopy [Zieba-Palus et al., 2008], XRF [Zieba-Palus et al., 2008], ion paring HPLC/ MS/MS [Liu et al., 2006] and laser desorption mass spectrometry (LDI- 
MS) [Weyerman et al., 2010; Gallidabino et al., 2010; Weyerman et al., 2012] have been recently explored as alternative tools to cope with forensic comparisons of gel inks.

One of the purposes of the present work is to conduct method development and evaluation of the capabilities of laser-based micro-spectrochemical methods, Laser ablation Inductively Coupled Plasma Mass Spectrometry (LA-ICP-MS) and Laser Induced Breakdown Spectroscopy (LIBS), for its novel application to document paper, writing inks and printing inks.

Another key objective of my research consists of evaluating the meaning and value of the elemental composition in the comparison of trace evidence materials. Examinations such as elemental analysis generate quantitative data that permit the application of statistical tools for a better characterization of evidence to measure associations between variables, to calculate confidence intervals, to estimate systematic or random errors and to determine discrimination values.

Nevertheless, there is still a lack of uniformity in match or association criteria used among examiners to interpret and report conclusions on the basis of the elemental composition of materials. The deficiency of standardization has been recently identified by the National Academy of Sciences, and the NAS has encouraged the forensic community to find solutions to overcome this challenge [NRC report 2009]. My dissertation presents a systematic evaluation of the significance of the use of elemental analysis in glass, ink and paper evidence. 


\subsection{Significance of the study}

The main significance of this research will be to offer a thorough and critical evaluation of the evidential value of the elemental composition of glass, ink and paper by LA-ICP-MS and LIBS, including the study of the effect of match criteria selection on the interpretation of results and conclusions.

In this study, LIBS and LA-ICP-MS methods were developed, optimized and validated for the micro-chemical characterization of paper, printing inks and writing inks on the basis of their elemental composition. More than 350 ink specimens were collected and examined including black and blue gel inks, ballpoint inks, inkjets and laser toners originating from several manufacturing sources and/or batches. Moreover, the variation of the elemental composition in paper was studied within a single sheet, between pages from the same ream, between papers produced by the same plant at different time intervals and between papers produced by different plants. The paper sample collection is composed of $\sim 150$ samples, from 20 different types of paper, from 7 different brands, manufactured at 10 different plants, all in the US.

The analysis of these collection sets allowed the evaluation of the analytical performance of the methods as well as their discrimination capability and error rates, demonstrating for the first time the utility of both laser-based methods to provide additional discrimination to the currently used techniques for the forensic analysis of ink and paper.

My dissertation also presents important considerations in analytical method validation for $\mu$-XRF, LIBS and ICP-based methods for the elemental analysis of glass that may be used as guidance by scientists for the standardization of methods of analysis 
and for providing a better understanding of the capabilities of these techniques, including reporting figures of merit, match criteria and their informing power. The information provided will be especially useful in the context of quality management, accreditation and interpretation of the significance of evidence, which have become matters of increasing relevance in trace evidence examination in recent years.

\subsection{Utility of elemental analysis in trace evidence}

A large variety of man-made materials can become available as physical evidence of many criminal activities. Examinations such as elemental analysis can become a valuable piece of information to assist an investigation.

The inorganic or elemental composition of these materials can be used in forensic science for different purposes such as: a) chemical identification or characterization of the material, b) forensic comparison of known and questioned samples and c) tracing origin of the materials back to a geographical site and/or manufacturing place.

The chemical "characterization" of elements can be conducted qualitatively or quantitatively, depending on the aim of the analysis. In this type of forensic examinations, the main objective is to identify and characterize the target elements present in an item. For example, the presence and quantification of arsenic in biological specimens may be of utility to medical examiners to determine the cause of death. Elemental analysis can be also used for the detection of some elements such as $\mathrm{Pb}, \mathrm{Ba}$ and $\mathrm{Sb}$ to assist gunshot residue investigations. 
In the aforementioned examples, the main question to answer during the examination is whether a specific element is present and if so, at what levels of concentration and uncertainty.

On the other hand, forensic examinations that involve "comparisons" between a known and a questioned sample require the identification and characterization of the elemental profile of the samples to answer different questions such as: a) could two items (i.e., questioned and known source) have come from a common source of origin, and if so what does it mean? or b) is there evidence of falsification or forgery based on its chemical composition?

Examples of this type of examinations are the elemental analysis and comparison of glass, paint and questioned documents, to mention some. For instance, when two vehicles crash, small fragments of glass and paint chips are often transferred from one vehicle to the other. Elemental composition of glass and paint can then be used to show if there is an association or exclusion between the chemical characteristics of the glass and paint fragments recovered from the automobiles.

Finally, if there is enough information about geographical variation of the elemental composition of materials to generate and maintain databases, the elemental composition can be applied for tracing the materials to its geographical source of origin. Examples of this type of examinations are food authentication, gold and diamond provenance, sourcing of illicit drugs. Geographical provenance requires the use of comprehensive databases and therefore can be applied only to samples that meet specific requirements. This type of examination is outside of the scope of this research. 
In my dissertation, the utility of elemental composition will be explored for purposes of examinations related to "forensic comparisons" only, for matrices such as paper, ink and glass. Therefore, some aspects of this type of examinations are discussed in more detail below.

\subsubsection{Utility of elemental analysis in forensic comparisons of man-made materials}

When the elemental profile of some materials is used to do a comparison between a known source and a suspect source, it is fundamental to know what the evidential value of the findings is [Trejos et al., 2010].

The utility of elemental analysis for forensic comparisons depends on two main aspects; the capabilities of the analytical method(s) used for the analysis and also the variability of the elemental profile of the sample in the aimed population.

For instance, the analytical method used for the identification of elements in manmade materials must be sensitive enough to detect the chemical components added during the manufacturing process and also those relevant elements that are not added intentionally as part of the formulation but are present as impurities in the raw materials. The analytical method should also fit for purpose and ideally provide the required selectivity, precision, accuracy, speed of analysis, minimum sample consumption and good discrimination value.

The discrimination value or informing power of a method refers to the ability of a method to differentiate between samples that came from different sources (i.e., glass from vehicles of different brand, make or year) and to associate samples that came from the same source (i.e., glass from the same window pane) [Almirall et al., 2006]. 
For example, it is required to have a large variability of the elemental "fingerprint" within the population (i.e., large variability between glass produced in different manufacturing plants and different batches) and at the same time a small variability within the sample (i.e small variability of elements within a single glass sheet).

For forensic purposes, a clear understanding of other sample features is essential to assign the proper value to the evidence, such as a) chemical and physical nature of the sample, b) the manufacturing process and sources of trace elements, c) the variation of raw materials within different plants, different batches, different production lines and d) the warehouse, packaging and distribution processes after manufacture.

Forensic examiners should also be aware of the fact that the market is not static, it is dynamic instead, and therefore changes in formulations, technology and/or globalization of providers of raw materials may affect the relevance and value of the elemental analysis.

The following sections will illustrate the manufacture and chemical composition of the matrices of interest in this research and the different considerations taken to evaluate its applicability in the forensic field.

1.4 The composition, manufacture and forensic examination of paper

\subsubsection{Raw materials and chemistry of paper}

Paper is defined as an aqueous deposit of a vegetable fiber in sheet form. It can be made of a variety of fibers, including cotton, flax, manila, hemp, esparto, straw, banana and jute. However, the most common fiber used is wood paper [Smook 1992]. 
The wood used for papermaking is segregated into two main groups: softwood and hardwood. Softwood fibers are 3-7 mm long; they provide strength to the paper. Examples of softwood trees are pines, spruce and fir. Hardwood fiber produce short fibers of $\sim 1 \mathrm{~mm}$ long and are responsible for adding bulk and the desired thickness to the paper. Examples of trees that produce hardwood are birch, eucalyptus, beech, oak and maple [Bierman 1993].

Some paper plants have their own mills so the pulp can be directly pumped to the process. Otherwise, the dried pulp is packed into blocks and transported to the paper mill for further processing.

Recycled paper is an important raw material for the paper industry. It is used in the papermaking process, not only to reduce manufacturing costs but also to reduce the waste disposals. It is commonly named secondary fiber. Recycled paper is collected, sorted, graded, cleaned and processed before turning it into pulp [Scott 1996].

\subsubsection{Cellulose}

Cellulose fiber is a major constituent in fiber stems and therefore is a predominant constituent of paper. It is a polysaccharide with molecular formula of $\left(\mathrm{C}_{6} \mathrm{H}_{10} \mathrm{O}_{5}\right)_{\mathrm{n}}$, where the number of saccharide units can range from hundreds to thousands.

\subsubsection{Sizing agents}

Sizing agents are used to resist the penetration of liquids in the paper; they have key functional groups that allow orientation, anchoring or retention of molecules in the fiber. A common sizing agent is rosin soap, which is obtained from the tall oil and can be 
added to the paper at 1-5\% wt [Hubbe 2012]. One of the major components of rosin soap is the abietic acid [Hubbe 2012]. The carboxyl functional group can easily react with a coupling agent, such as aluminum sulfate, to form an anchoring hydroxyl group that adheres to the fiber [Isogai et al., 1997].

Some components such as alkenyl succinic anhydride (ASA) and alkylketene dimer (AKD) can form bonds to cellulose. The efficiency of any of these sizing agents is $\mathrm{pH}$ dependent. Rosin soap works under acidic conditions ( $\mathrm{pH}$ 4-5), while AKD and ASA operates at $\mathrm{pH}$ ranging from 6 to 9 [Isogai et al., 1997].

\subsubsection{Pigments and fillers}

These components are added to the paper to increase its brightness, opacity, smoothness, receptivity to the ink and to add bulk. They can be added to the fiber at amounts ranging from 1 to $10 \% \mathrm{wt}$ [Hubbe 2012].

Calcium carbonate is a common filler used to provide brightness and opacity to the paper, it also helps to control the $\mathrm{pH}$ of the formulation. It can be found as ground calcite from limestone or chalk, or as precipitated carbonate (calcite and aragonite) [Scott 1996].

Aluminum silicate $\left(\mathrm{Al}_{4} \mathrm{Si}_{4} \mathrm{O}_{10}(\mathrm{OH})_{8}\right)$ known as kaolin or china clay is used to reduce costs and to add gloss and air flow resistance to the paper. Depending on the particle size, kaolin can be used as filler or as coating of the paper. Other fillers found in the paper industry are sulfates $(\mathrm{Zn}, \mathrm{Ca}, \mathrm{Ba})$, oxides $(\mathrm{Zn})$, silica, alumina, talc and asbestos [Bierman 1993]. Titanium oxide is often used as pigment, however it is often used as a mixture with other pigments as a result of its higher price. 


\subsubsection{Coloring Dyes}

Although most of the multipurpose paper reaches the market as white paper, some colored paper is also marketed for specific purposes. Both dyes and pigments can be used to color the paper stock. Basic dyes are usually preferred for this purposes for their high affinity to the cellulose fibers [Bierman 1993].

\subsubsection{Other additives}

Starch, natural gums such as guar gum and polyacrylamide resins are used to increase the water resistant properties of the paper. Starch is typically used modified as amphoteric starch, with cationic and anionic groups that improve the adherence to the fiber [Pierre 1993].

Silicon-based antifoams are helpful to improve the drainage properties during the manufacture of paper. Their concentration has to be carefully controlled to avoid undesirable interactions with sizing agents and dry strength agents [Pierre 1993].

Fluorescent whitening agents are added to increase the white appearance of the paper by absorbing invisible UV light and re-emitting in the blue visible region. Direct dyes can be used for whitening purposes. They are usually added in the size-press formulation to avoid quenching and interaction with $\mathrm{TiO}_{2}$ [Hubbe 2012].

Biocides such as chlorine dioxide, hydrogen peroxide and thio-compounds are added to reduce the growth of bacteria. Because of their toxic nature, their concentration and addition has to be carefully controlled in the manufacture. Detackifiers reduce the pitch-like materials to reduce the deposition or agglomeration of components in the paper surface; the most widely used detackifier is talc $\left(\mathrm{Mg}_{3} \mathrm{SiO}_{4} \mathrm{O}_{10}(\mathrm{OH})_{2}\right)$ [Shetty 1994]. 


\subsubsection{Paper manufacturing}

Paper can be manufactured using mechanical pulping or chemical pulping. The main difference between these processes is that the former does not separate the lignin from the cellulose. In mechanical pulping, the wood is ground against stone rotating rollers softening the fibers by pressure and mechanical force. The paper produced by these methods is greyish or yellowish and less strong than paper produced by chemical pulping.

For chemical pulping, the wood chips are exposed to heat, pressure and chemical treatment to remove the lignin from the cellulose. These methods produce harder paper but the recovery yield of cellulose fibers is lower, having an effect in the production cost. There are three main chemical pulping processes: a) the Kraft process, b) the sulfite process and c) the soda pulping [Clark 1985].

In the Kraft process chemical liquor made of sodium hydroxide and sodium sulfide is used for the removal of the lignin. The wood is segregated in two main groups: soft wood and hard wood fiber. Both types of fibers are mixed in various proportions to produce the desired quality in the paper [Bierman 1993].

Round wood is sent to a debarking drum, then the log is sent to a chipper where it is cut into small wood chips. Once they are screened, the wood chips are stored in piles until they enter the pulping operation. During the pulping operation the cellulose fiber is separated from the lignin. The conversion of wood chips into fibers occurs in the digester, followed by washing, screening and bleaching where the fibers are brightened to white colors. Oxygen is used to remove any remaining lignin and extracts some color from the 
pulp. Nowadays, most milling plants use elemental chlorine free chemicals (ECF) for bleaching [Bierman 1993].

Although printing and writing paper often use the Kraft chemical process, other methods such as the sulfite or the soda pulping can be applied. The main sulfide process is fairly similar to the Kraft method, the main difference remain on the composition of the "liquor" chemicals. It uses a mixture of sulfurous acid and bisulfite ions $\mathrm{Ca}, \mathrm{Mg}, \mathrm{Na}, \mathrm{K}$ or $\mathrm{NH}_{4}$ ). The $\mathrm{pH}$ of the process is carefully controlled between 1.5 and 5 in order to avoid the emission of sulfuric acid. Most of the residual bisulfite ions can be recovered by different chemical methods. The sulfite process produce very strong paper but has the disadvantage that it can not be used in some wood species such as resinous softwoods and tannin-hardwoods [Hubbe 2012].

On the other hand, soda pulping uses sodium hydroxide as the main chemical to remove lignin. The caustic soda is easily recovered during this process. The method produces relatively bulky and soft paper. Soda pulping process is used with species such as straw and bagasse [Bierman 1993].

Some manufacturing plants have both the pulp mill and the paper mill in the same location, while other paper plants purchase the pulp from a mill and then the pulp is sent to a series of processes to form the paper.

In the paper plant, the first step in the paper making process is to refine the pulp. During refining process the pulp is shortened and weakened to give more surface area and to increase opacity. Both type of fibers are pumped into a blend chest where they are mixed together in certain proportions with other components such as clay, calcium carbonate ad titanium dioxide to improve surface and optical properties. Other chemicals 
can be added at this stage, including sizing agents, to control the penetration of liquids and optical features. The blended mixture of fiber and additives is called the furnish [Hubbe 2012].

The furnish flows from the blend chest to the fourdrinier of the paper machine. When the fiber reaches this stage, it is $\sim 99.5 \%$ water and $0.5 \%$ fiber, filler and additives. The paper is then passed to a series of steps until the water content is reduced to approximately 5\% [Bierman 1993].

Finally, the paper reaches the calender stock, where the paper is compressed to remove irregularities and produce smooth sheets. The paper can pass to high technology scanners that are able to detect variations in paper's weight, moisture, opacity, brightness and physical defects [Bierman 1993].

At the end of the paper machine, the paper undergoes a slitting and rewinding stage where the paper is wrapped in big rolls. Depending of the size of the paper machine these rolls can hold up to 15 tons of paper and measure over 25 feet long [Trejos, telephone survey 2012]. The paper is then slit into smaller rolls that can be more easily transported to a warehouse or other location in the mill where packaging operations take place. During the finishing step, smaller paper sheets are cut according to customer requirements and placed into reams for further shipping. Depending on the size of the plant, a ream may have paper from a single roll or from up to six different rolls produced in a time interval ranging from a day to weeks [Trejos, telephone survey 2012].

This information becomes critical later in this research for the design of sampling strategies and interpretation of results. 
Today paper is found everywhere; it is used for food packaging, paperboard, printing and writing paper, to mention few applications. Environmental regulations in the $21^{\text {st }}$ century have driven many changes in the paper industry and force the papermaking sector toward processes that use renewable sources and that minimize the wastewater and environmental emissions.

The largest consumers of wood paper in the world are Europe, North America and China [http://www.global-production.com/wood-pulp-paper/news/index.htm]. In 2010, the world annual production and consumption of paper was 330 million metric tons http://www.paperonweb.com/index.htm]. In that same year, the US used about $25 \%$ of the world paper production. The average American uses $\sim 740$ pounds of paper/year. About $28 \%$ of the paper consumed in the USA is used for printing/writing paper (approximately 24 million tons/year).

Paper is produced worldwide. In 2010 Paper on Web [http://www.paperonweb.com/index.htm] reported a total of 114 pulp manufacturers and 1210 paper manufacturers worldwide. For the pulp manufacturers, 35 pulp mills are located in the US, 17 in South America, 38 in Europe and 24 in Asia, Africa ad Australia.

For the paper manufacturers, 475 paper mills are located in Europe, 472 in Asia/Africa, 98 in South America and 10 in Australia. According to the Mills Online database [http://www.cpbis.gatech.edu/data/mills-online-new], there are 350 mills currently operating in the US. 


\subsubsection{Forensic Examination of paper}

Several methods such as FTIR, Raman, NMR, XRF, AA, ICP, XPS and LIBS have been used for purposes of characterization and restoration of cultural heritage paper [Manso et al., 2009]. In spite of the application to historical documents, forensic paper characterization has focused mainly on the measurement of physical properties, such as thickness, color, fluorescence, strength, fiber content and fiber morphology [Polk et al., 1977]. These methods are often deficient to detect differences between different brands of papers produced by the different manufacturers or to associate two sheets of paper with a high degree of certainty [Spence et al., 2000].

Quantitative elemental analysis of the inorganic components of paper has proven to provide added discrimination [Spence et al., 2000]. The forensic usefulness of elemental analysis of paper has been documented since 1970s and relies upon the premise that, despite technological standardization in the manufacture of paper, minor variations in the chemical composition remains between and within batches due to the natural trace contaminants of raw materials, such as the pulp fiber, fillers and additives.

Chemical identification of some elements has been used to discriminate sources of paper by several techniques such as NAA [Lukens et al., 1970], SEM-EDX [Polk et al., 1977], FTIR [Kuptsov et al., 1994], XRF [Rozic et al., 2005] and ICP-MS [Spence et al., 2000].

Each of these techniques has their own advantages and limitations. Nevertheless, ICP-MS provides significant advantages over the aforementioned methods. Mass spectrometry ICP allows for rapid quantitative multi-elemental analysis of elements with superior detection limits than FT-IR, SEM and XRF and therefore has the potential of 
detecting more elements; providing additional comparison points and improving the discrimination capabilities. [Spence et al., 2000]. Inductively coupled plasma mass spectrometry (ICP-MS) methods also offer excellent precision, reproducibility and selectivity. Additionally, this technique is generally more readily available to forensic laboratories than NAA.

Inductively coupled plasma mass spectrometry has proven to be particularly suitable for paper, whose major component is wood pulp, a natural product rich on elements whose distribution reflects its source of origin. Spence et al., showed that this technique can be effectively used for characterization and discrimination of white copy paper. The authors were able to distinguish 17 different brand of papers based on the trace elemental composition. Paper produced at the same plant, but manufactured a month apart was also discriminated [Spence et al., 2000].

Likewise, McGaw et al reported the evaluation of ICP-MS for the forensic comparison of paper originated from two different vendors [McGaw et al., 2009]. Moreover, ICP-MS has the potential to be coupled to different sample introduction systems, such as solution nebulization and laser ablation. In 2009 van Es et al reported the use of LA-ICP-MS, XRF and IRMS as complementary methods for paper examination [van Es et al., 2009].

Laser ablation has added advantages over solution methods. Since there is no need to digest the paper, the amount of sample will be drastically reduced. Spence et al, reported the use of solution ICP-MS that require the digestion of samples in the range of 100 to $110 \mathrm{mg}$ (approximate area of $3 \mathrm{~cm}$ by $4 \mathrm{~cm}$ ), which implies the destruction of the paper. [Spence et al., 2000]. In contrast, using LA-ICP-MS, fibers from the paper are just 
partially removed from microscopic areas of approximately 200 by $500 \mu \mathrm{m}(\sim 14 \mu \mathrm{g})$, leaving the paper almost intact after the analysis [Trejos et al., 2010]. Moreover, quantitative analysis of the inks is feasible, which represents a benefit for document examinations where differences on elemental composition between ink and paper samples of different origin are rather quantitative than qualitative [Zieba-Palus et al., 2008].

Elemental analysis of paper has been used in casework. In 2002, ICP-MS was successfully applied in a homicide. Document examiners were asked to compare a threatening letter received by a business partner of the victim with paper samples seized from the suspect. Quantitative elemental analysis of the concentration of nine elements (Na, Mg, Al, Mn, Sr, Y, Ba, La and $\mathrm{Ce}$ ) was conducted within the questioned and known documents. [Spence et al., 2002].

In 2010, as a result of the present research a paper was published describing the utility of laser ablation methods (LA-ICP-MS and LIBS) for the elemental analysis of paper [Trejos et al., 2010].

The development of these LA-ICP-MS and LIBS methods for the elemental analysis of paper will offer document examiners better tools to assist criminal investigations.

1.5 The composition, manufacture and forensic examination of ink

Ink can be defined as a colored liquid or paste used for writing, printing or drawing. Ink has an ancient origin and has influenced our civilization in many ways. One of its greatest contributions to our society was the spread of knowledge in writing and 
printed forms [Hickman et al., 1993]. The main components of modern inks are a) the coloring agent, b) the vehicle and c) additives. Their formulations can be composed of a large variety of natural and synthetic products, organic and/or inorganic components [Brunelle et al., 2003].

Inks can be classified according to the vehicle as a) aqueous, b) liquid, c) paste or d) powder form. Another common classification defined on the basis of their end-use, includes two major categories as writing inks and printing inks. The following sections will discus each of these two types of inks in more detail.

\subsubsection{History of writing inks}

The history of writing inks is important for forensic purposes because forensic examiners may be asked to estimate the date of an ink entry. Some formulations have been produced on specific time periods and therefore the identification of their chemical composition may assist the examiner with their opinion. For this reason the history of inks is briefly discussed here.

In early days, writing inks were commonly named based on its main composition such as Indian/carbon inks or iron gallotannate inks [Brunelle et al., 2003]. Nowadays writing ink formulations are typically classified according to its corresponding writing instrument, such as fountain pen inks, ballpoint inks, fiber/porous tip pen inks, rolling ball marking inks and gel pen inks.

The invention of writing inks goes parallel to the history of paper. The Romans created a form of fountain pen from stems of marsh grasses to write on parchment [Brunelle et al., 2003]. 
The chinese invented a basic ink formulation made of hide glue, carbon black and bone black pigment. The manufacture of this ink, later known as "Indian ink" or "carbon ink", was mastered in the 220 AD [Carvalho 1999].

By 600 A.D iron gallotannate inks were developed using a composite of iron salts, nutgalls and gum. Iron gallotannate ink became one of the most important writing inks used since Middle Ages until the $20^{\text {th }}$ century. One distinctive feature of these iron inks is that they induce degradation of the paper substrate. From a forensic perspective, this characteristic degradation is advantageous since it can be used for the purpose of dating documents [Carvalho 1999].

Modern washable fountain pen inks were introduced in the 1940s [Brunelle et al., 2003]. Although fountain pens only cover a small portion of the current pen market, they are commonly used to sign important documents and therefore they are encountered in forensic document examinations.

The hungarian Laszlo Biro developed the first ballpoint pen in Europe in 1939. He decided to create a pen that used the same type of ink that was in use to print the newspapers. In order to facilitate the flow of the ink in the writing pen, he designed a tiny ball bearing in its tip, which rotated as the pen moved along the substrate retrieving ink from the barrel. The ballpen invention reached the US market in 1945 and is still in use [Brunelle et al., 2003]

Numerous changes in the chemistry of ballpoint ink in the following decades provided a mean to link the chemical composition to specific periods of time. For example, the first ballpoint ink formulations contained natural oils such as mineral oil and linseed oil. In 1950 the ink formulation shifted from oil-based to glycol-based solvents. 
In 1954 more stable chelated metallized inks such as the blue-green copper phtalocyanine began to be used. Nine years later in 1963, pressurized ballpoint inks were introduced in the market. In 1978, ballpoints were formulated with a dye that is erasable and marketed as "erasable-ballpoints" with significant chemical differences in the dyes applied [Brunelle et al., 2003].

In 1962, Pentel, a manufacturing company from Japan, introduced a fiber tip writing pen. Three years later these types of pens were manufactured in the US. The inks used in fiber tip pens can be either water based or water resistant [Wilson et al., 2004].

The roller ball pen was marketed since 1978, having a similar ink composition to the fiber tip pens. Fiber diffusion is commonly observed in writing made with a roller pen, the ink usually flows freely into the fibers of the substrate eliminating the striations left by ballpoint pens. [Brunelle et al., 2003]

In 1975, the Bureau of Alcohol, Tobacco and Firearms initiated an ink-tagging program for intelligence purposes, where each manufacturer was asked to add chemical taggants such as rare earth elements to their formulations to be able to track the actual year and ink manufacturer. Unfortunately, this program only lasted 10 years. [Brunelle et al., 2003]

Finally, Sakura Color Products Corp in Japan first created the newest gel pen inks in 1984. They arrived to the US market in 1990s and very quickly became a common writing instrument in the US as a result of its smooth characteristics and inexpensive manufacture. It was not until 1996 that the first guide for the forensic identification of gel inks was published in a peer review paper [Gernandt et al., 1996]. In gel inks, as the name implies the ink is a gel, not a liquid and predominantly use pigments rather than 
organic dyes. However, some formulations manufactured after 1999 may contain both pigment and dye-based inks. [Wilson et al, 2004]

\subsubsection{History of printing inks}

The history of printing dates far back to the $\mathrm{BC}$ era, where the use of printing in cloth was documented in different regions including China, Europe and India. A major boost for the advance in printing was the availability of paper, near the 1400's, which led to the evolution from block printing to printing with casting in movable parts. [Hickman et al., 1993].

Germany had two notable inputs in the advancement of printing with the contribution of Johannes Gutenberg in the $15^{\text {th }}$ century and Friedrich Koenig in the $19^{\text {th }}$ century. Among Gutenberg's most outstanding inventions is the use of alloys in the metal-based movable printing technology, the formulation of more durable oil-based inks and the introduction of colored prints. Koenig developed the steam press that had a significant leap in the efficiency of printing. [Carvalho 1999]

The introduction of the personal computer and word processing in the $20^{\text {th }}$ century made printing more widely accessible to everyone. Since then, a number of technological innovations have evolved printing technology from dot matrix impact printers to offset lithography, laser printers and ink-jet printers [Hudd 2011].

Printers can be classified as impact and non-impact printers. Impact printers use a mechanical mechanism to bang a head against an ink ribbon to make the imprint; examples of this type of printers are lithographic offset, dot-matrix printers, daisy-wheel printers and line printers. On the other, non-impact printers are based on digital 
processes. Examples of non-impact printers are copy machines, inkjets and laser printers [Hudd 2011].

Two or the most common printers used in home and office are inkjet and laser printers; therefore it is not surprising that they are often found in questioned documents [Hudd 2011].

\subsubsection{Inkjet printers}

Inkjet technology relies on the efficient ejection of tiny drops of ink onto a substrate. It was developed in the 1950's and is currently the most popular type of computer printer used in personal and professional settings. There are two main types of industrial inkjet printers, the continuous (CIJ) and the drop-on demand (DOD). Figure 1 list the main type of inkjet printers available in the market and the main manufacturers. Hewlett-Packard (HP), followed by Canon, Epson and Lexmark, captures the majority of inkjet printer sales [Hudd 2011]. Most printer manufacturers produced their own brandspecific ink, nonetheless, the high cost of OEM ink cartridges have opened market opportunities to third-party ink suppliers.

\subsubsection{Continuous inkjet}

A CIJ delivers a continuous stream of ink to the material of interest. A vibrating piezoelectric crystal ejects the drops at high speed through microscopic nozzles. An electrostatic field then charges the small drops, which are later exposed to a deflection field to direct the drops to the final substrate. The charged droplets are deflected to a certain angle, while the un-deflected drops that do not reach the substrate can be directed 
to a recirculation container to reuse the ink [Hudd 2011]. Figure 2 shows a schematic representation of a CIJ system.

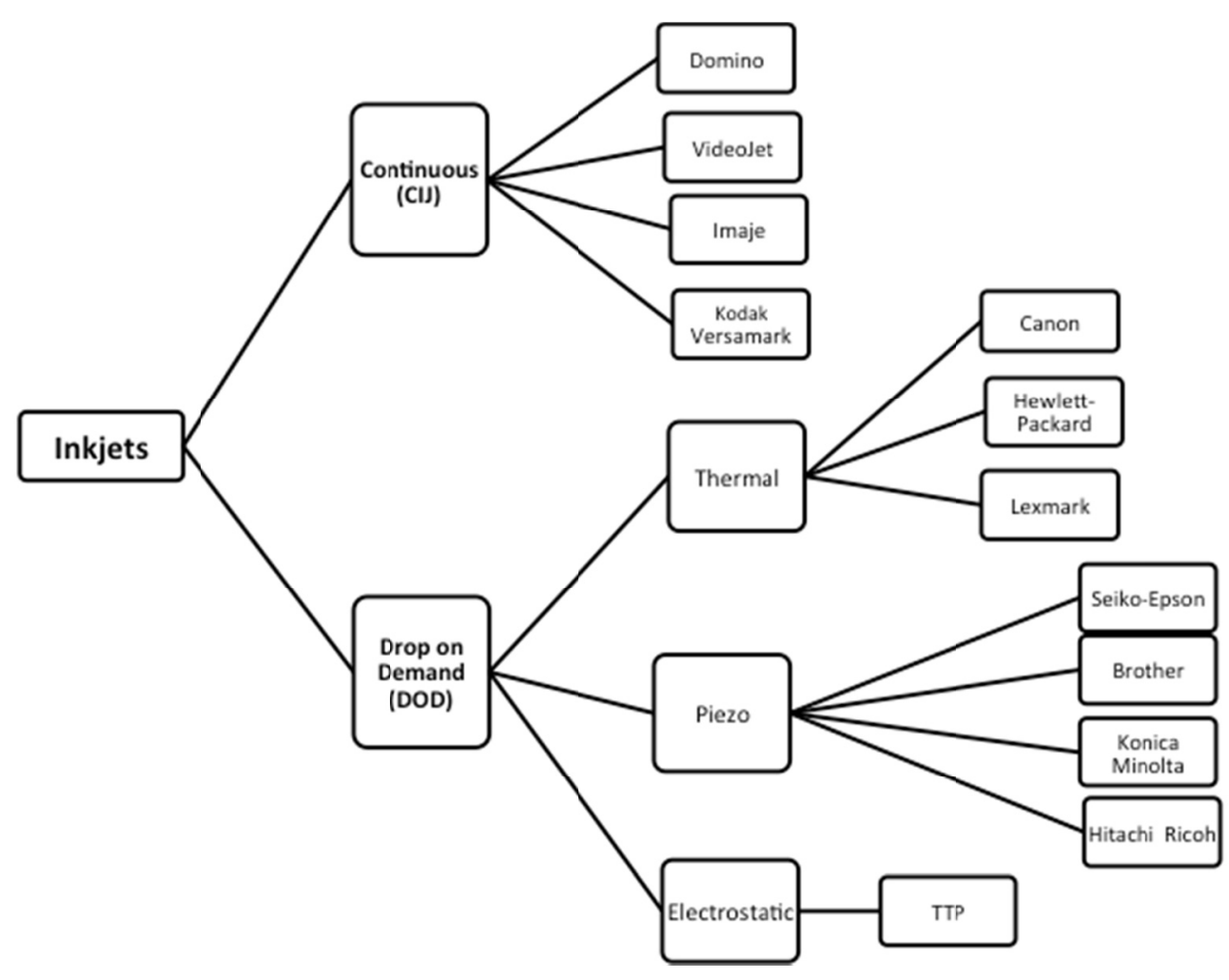

Figure 1. Scheme of the main manufacturers of CIJ and DOD inkjet printers (modified from Hudd 2011)

Although the print resolution of CIJ is low, it is widely used in labeling of packages and date coding because its high speed $(\sim 25-50 \mathrm{~m} / \mathrm{s})$ allows for convenient location between print head and the receptor material. Typically the inks used in CIJ are formulated in volatile solvents, such as ketones and alcohols, to aid the rapid drying required in industrial environments. [Hickman et at., 1993] 


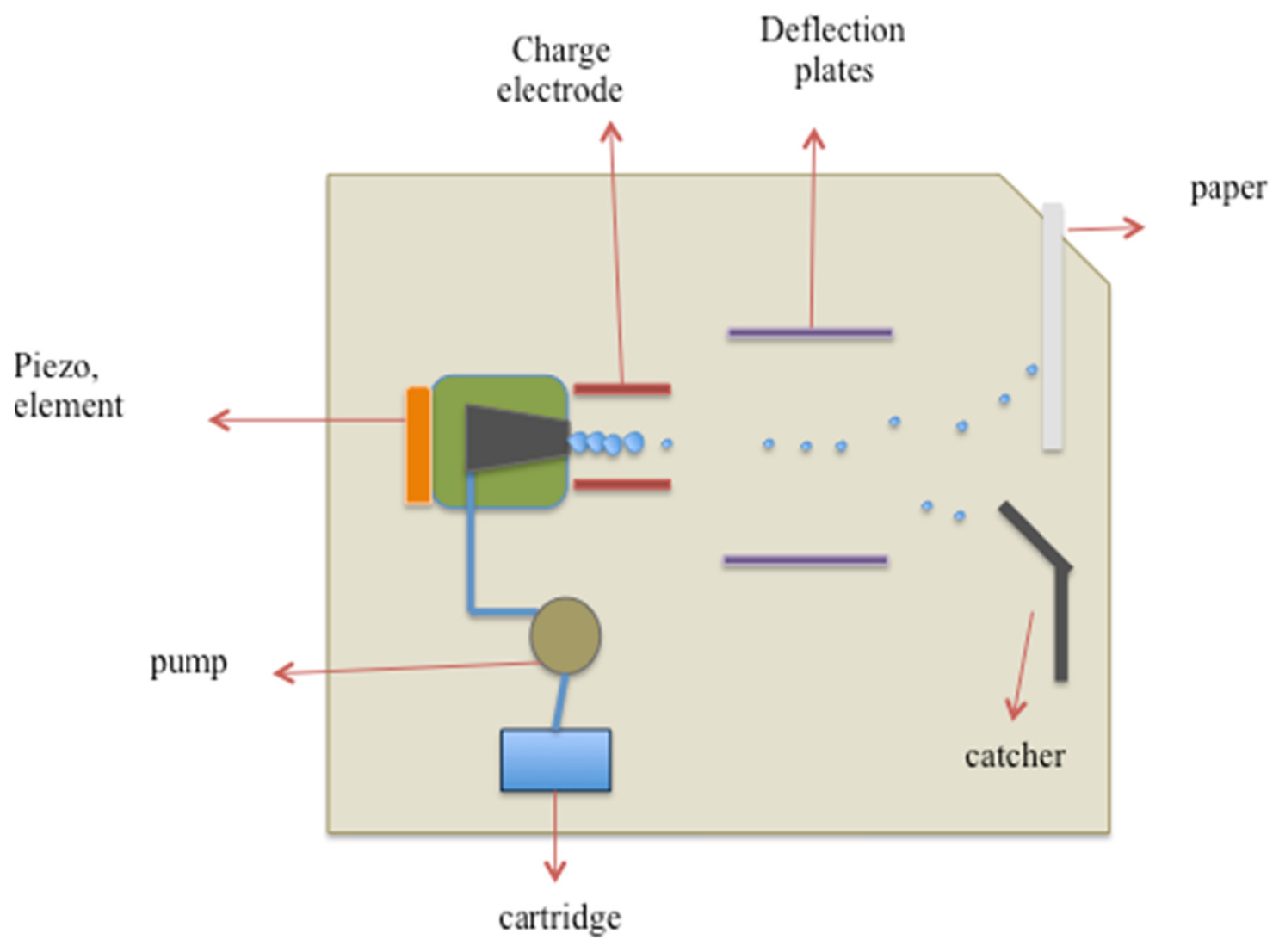

Figure 2. Schematic of a CIJ printer

\subsubsection{Drop on demand}

As the name implies, DOD inkjet ejects ink drops only when needed. A pressure pulse, which can be thermal, piezo or electrostatic, generates the drops [Hickman et al., 1993]. Figure 3 shows a typical scheme of a DOD printer.

\subsection{Thermal DOD inkjets}

Thermal DOD inkjets use a heating element in a small cavity to form the ink drops. A current is passed through the heating resistive element, which raises the temperature in the chamber to approximately $350-400{ }^{\circ} \mathrm{C}$. At that temperature, the ink 
rapidly vaporizes above the heater creating a bubble that force the ink drop to move through the nozzle [Hickman et al., 1993].

The main advantage of thermal DOD technology is its capability to use compact devices, which reduce manufacturing costs. In addition, the use of aqueous inks formulations reduces pollution of VOCs [Hudd 2011].

Thermal DOD is the most used in consumer desktop printers [Hudd 2011]. The main manufacturers of this type of printers are HP, Lexmark and Canon (see figure 1).

\subsection{Piezoelectric DOD inkjets}

The DOD printers use a piezo crystal to eject the ink droplets. The most common piezo crystal used in this technology is lead zirconium titanate, also called PZT for their respective chemical composition abbreviation $(\mathrm{Pb}, \mathrm{Zr}, \mathrm{Ti})$. As a result of its piezoelectric properties, this crystal physically changes shape when an external electric field is applied; creating a pressure pulse that causes the ejection of the droplet from the nozzle [Hickman et al., 1993].

The main advantages of this technology are the long life of the printing head and the outstanding capability of delivering tiny droplets of variable size only when needed.

Piezolectric DOD inkjets are the most used technology for commercial and industrial applications. They are also encountered in some consumer desktop printers manufactured by Epson and Brother [Hudd 2011]. However, they are more expensive to manufacture and therefore less common in low-end products. 


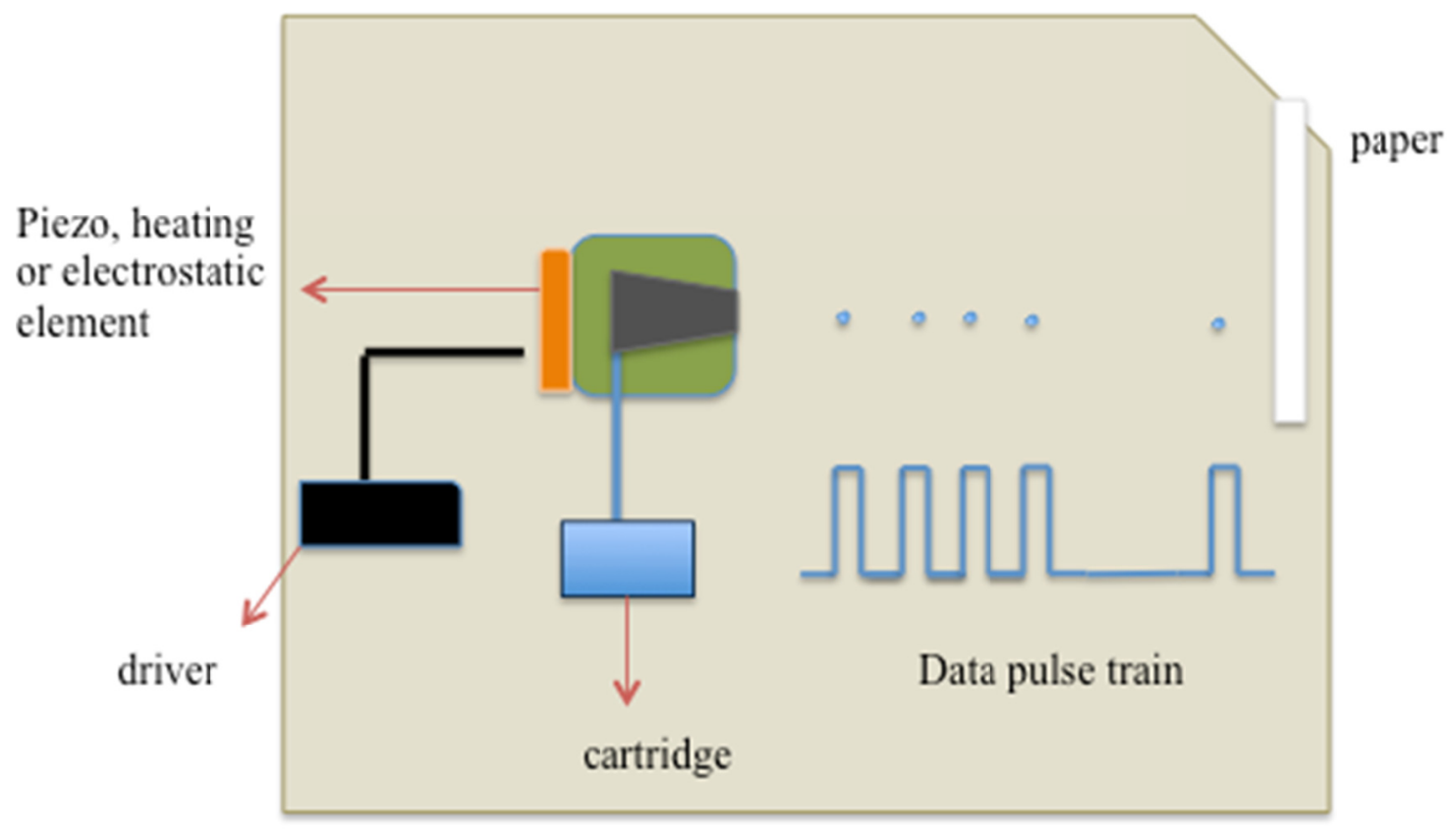

Figure 3. Schematic representation of a DOD printer

\subsubsection{Laser printers}

Laser printers are computer driven and use an electrostatic process to print. A laser printer can use different electrostatic processes such as: a) electrophotography, b) ion deposition, c) electrostatic, d) magnetograhic and e) electrographic. From these, the electrophotographic method is the most widely used in photocopiers and laser printers. This process was invented in 1938 by Xerox to reproduce documents in photocopiers [Hickman et al., 1993 Hickman et al., 1993].

\subsubsection{Electrophotography}

The main components of a laser printer that operate under this principle are a) the photoreceptor or drum, b) the fuser, c) the printer controller, d) the laser assembly and e) the toner. Figure 4 shows a scheme of the main components of a typical laser printer. 
The printer controller is the printer's main board that gathers and organizes data received by the host computer. In order to print the information sent by the printer controller, a photoreceptor is charged with static electricity by application of current through a corona wire. This photoreceptor has usually a drum or revolving cylinder shape which surface is sensitive to light. As this drum moves, a laser beam discharges certain areas of the photoreceptor creating a latent image to be printed called the electrostatic image [Hickman et al., 1993].

The photoreceptor uses chalcogenides (i.e. Se, Se-Te alloys, $\mathrm{As}_{2} \mathrm{Se}_{3}$ ) and/or organic photoconductors such as phtalocyanines, polyvinylcarbazole (PVK-TNG) charge transfer complex to promote the charging of the surface [Hickman et al., 1993].

The laser assembly is composed of a laser, a movable mirror and a lens. Together, they focus the laser beam across the surface of the drum, emitting light pulses for every dot to be printed. Some laser printers, such as OKI and Panasonic, use light emitting diodes (LEDs) instead of lasers to produce the electrostatic image [Hickman et al 1993]. In the next step, the printer coats the drum with a positively charged powder named the "toner" that attaches selectively to the electrostatic image but not to the positively charged background of the drum.

Then, the drum rolls over a sheet of paper at high speed and transfers the image by fusing the toner to the paper fibers. The fuser rollers are heated with quartz tube lamps to melt the toner particles to the substrate [Hickman et al., 1993]. 


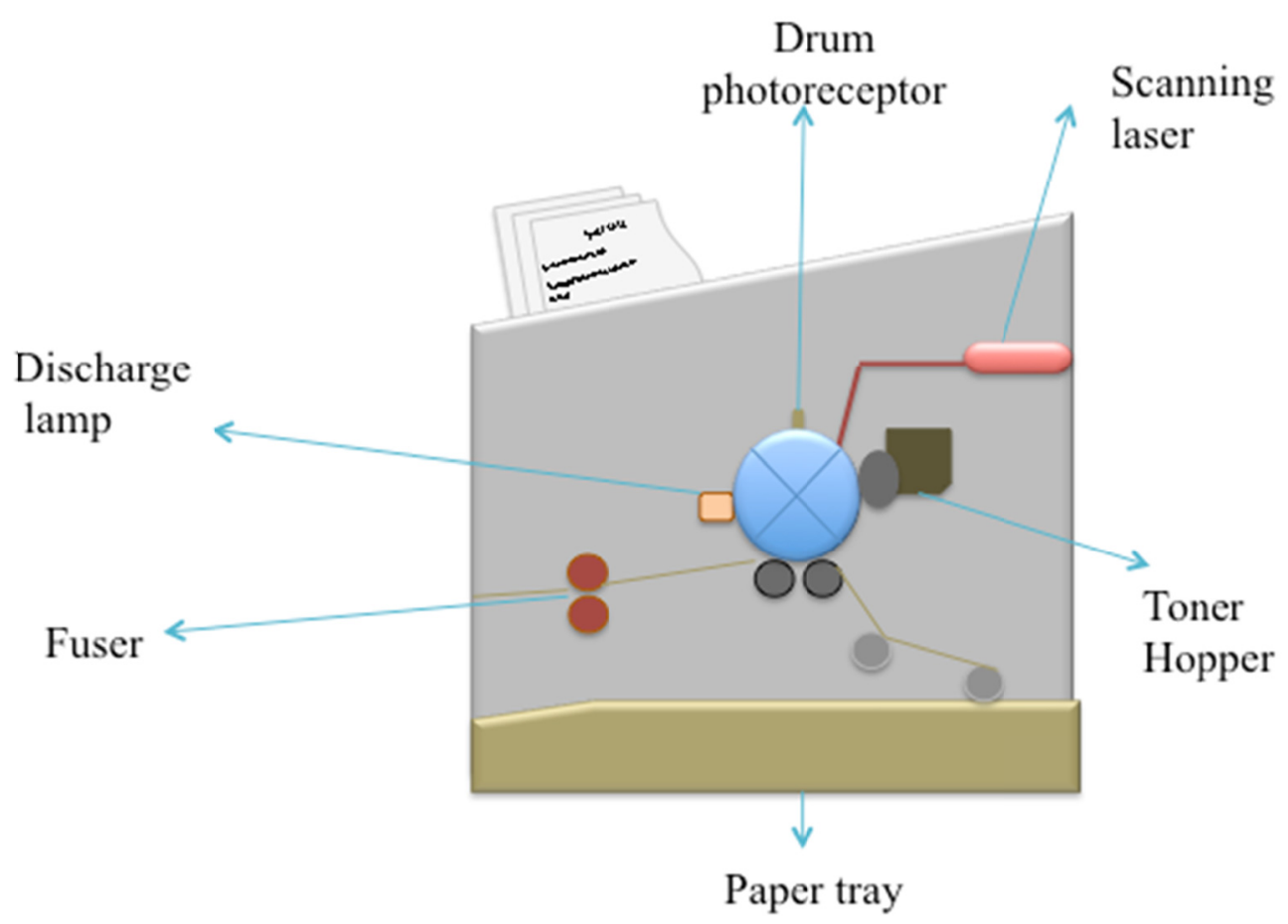

Figure 4. Diagram of main components of a laser printer

\subsubsection{Other laser printing processes}

Ion deposition works under the same principle that electrophotography with the exception that the drum is made of a dielectric material and the imaging is produced by an ion source array. The process is commonly used in printing plastic self-adhesive labels that otherwise could be damaged by heat [Hoffman 2004].

In electrostatic processes the dielectric medium is the substrate paper, which is charged by an electrode [Hoffman 2004].

Magnetographic printing uses a drum with a magnetic coating; the latent print is developed using magnetic toner particles. An advantage of this process is that the latent print is more permanent. Finally, in electrographic process an electroconductive material produces a latent print [Hoffman 2004]. 


\subsubsection{Raw materials and formulation of printing inks and writing inks}

\subsubsection{Pigments and extenders}

Pigments can be inorganic, organic or a combination of both. There are a large variety of pigments produced for the manufacture of ink, including materials from natural or synthetic sources. Some of the desired properties of an ink pigment are tinctorial strength, small particle size, low cost and some other characteristics that are specific to the end-use product [Brunelle et al., 2003; Hickman et al., 1993; Shaknovich et al., 2011]. For purposes of this study, only blue and black pigments will be discussed in detail, since they are the most commonly color found in forensic document examinations. Nevertheless, there are a large variety of coloring pigments that are used in both writing and printing inks.

\subsubsection{Dyes}

Dyes are mainly used for liquid inks although they can be used in some paste formulations. Some basic dyes can dissolve in fatty acids to be used as black inks in toners. The Color Index classifies the dyes in the following 18 categories: 1) acid dyes, 2) azoic dyes, 3) basic dyes, 4) developers, 5) direct dyes, 6) disperse dyes, 7) fluorescent brighteners, 8) food and drug dyes, 9) ingrain dyes, 10) leather dyes, 11) mordant dyes, 12) natural dyes, 13) oxidation bases, 14) reactive dyes, 15) solvent dyes, 16) sulfur dyes, 17) vat dyes and 18) pigments [Brunelle et al., 2003].

The Color Index is a database of manufactured dyes and pigments, maintained by the Society of Dyes and Colorists and the American Association of Textile Chemists and Colorists and now available online [Brunelle et al., 2003]. Some dyes can fit in more than 
one of the categories depending on their functional groups and characteristics. The colorant designations on their catalog are preceded by the abbreviation C.I followed by a serial number that simplifies the use of a standardized and universal language [Brunelle et al., 2003].

Within each category there are dozens to hundreds of formulations available in the market. Although any of this type of dyes can be found in printing and writing inks only the most prevalent ones will be discussed in more detail.

Amongst the most popular ones found in writing inks are: azoic dyes, solvent dyes, basic dyes, and some acid dyes [Brunelle et al., 2003]. Likewise, acid dyes, basic

dyes, solvent dyes and dispersive dyes are more often used in printing inks [Hickman et al., 1993].

\subsection{Acid dyes}

Acid dyes are anionic, soluble in water and mainly insoluble in organic solvents, with the exception of some that are soluble in alcohol, ketones and esters. They can be grouped according to their functional group as: azo, anthraquinone, triphenylamine, azine, xanthene, ketonimine, nitro and nitroso compounds [Hickman et al., 1993].

Within this category azo dyes are frequently found in writing documents. As the name implies these dyes contain the azo functional group $(\mathrm{N}=\mathrm{N})$ in their chemical structure. Examples of azo writing inks are: solvent black 3, direct black 168, reactive black 31, amido black 10B, solvent black 47, to mention some [Brunelle et al., 2003] 
Some of the common acid dyes found in printing inks are listed below on table 1.

Table 1. List of common acid inks used for printing

\begin{tabular}{|l|l|}
\hline \multicolumn{1}{|c|}{ Common name } & \multicolumn{1}{|c|}{ CI designation } \\
\hline Acid yellow & $3,5,17,23,36,54,73,121,157,194,204,236$ \\
\hline Acid black & $47,52,194$ \\
\hline Acid red & $18,52,87,88,143,221,289,357,3159$ \\
\hline Acid blue & $1,7,9,15,20,22,93,129,193,254,285$ \\
\hline
\end{tabular}

\subsection{Basic Dyes}

These cationic dyes are soluble in water and alcohol but insoluble in other organic solvents. They are popular in all types of printing inks, particularly on flexographic inks for its brilliant shades. They are often modified with tannic acid and dimethyl salicylic acid to improve their water resistant properties, and PMTA or copper ferrocyanide salts to improve their light stability [Hickman et al., 1993].

\subsection{Solvent Dyes}

As the name implies, these dyes are soluble in organic solvents and have good compatibility with a large variety of resins. They form metal complexes. Within this class there are acid dyes with azo chromium complex, xanthenes, and the base form of some basic dyes [Hickman et al., 1993; Hudd 2011].

Some of the most popular dyes in writing inks are the phtalocyanine dyes and the nigrosine. Phtalocyanine inks form complexes with transition metals, like copper and iron. They are commonly found in blue ballpoints as a result of its compatibility with 
glycols. Examples of phtalocyanine inks used in writing are copper phtalocyanine, solvent blue 64, solvent blue 38 and solvent blue 70 [Brunelle et al., 2003].

Nigrosines are used in blue to black writing inks. Although they do not form metallized complexes, they contain considerable amounts of metal contaminants [Brunelle et al., 2003].

\subsection{Dispersive dyes}

These dyes are amines insoluble in water and include amino azobenzene, amino antraquinones and nitroilaryl amines [Hickman et al., 1993]. They are adequate for printing with heat-transfer elements. Examples of dispersive dyes are: dispersive yellow 3, dispersive red 4, dispersive blue 3, and dispersive red 60 .

\subsubsection{Oils}

Oils are used as a medium to transfer the pigment and the resin to the substrate. They can be classified in three main categories as: drying, semi-drying and non-drying oils [Brunelle et al., 2003].

Drying oils such as Linseed oil, Tung oil, Oiticica oil and Castor oil are integral components of the resins and are recognized as fast drying agents. Unsaturated oils assist the drying process after ink application and also play and important role in the viscosity, resistance and durability of ink. Most of them are chemically modified, with the exception of linseed oil. Linseed oil however uses driers such as organic salts of Mn, Co and $\mathrm{Pb}$ to accelerate the drying process. Tung oil is the most resistant to water and alkali and is used in metallic inks. [Hickman et al., 1993] 
Semi-drying oils such as tobacco seed oil, sunflower seed oil and soya bean oil have a slower drying capability than drying oils. They are used in the formulation of synthetic resins, especially alkyds used in tin-printing inks. They impart good flexibility to the resin and are compatible with some pigments such as carbon blacks. [Ben-Mosche et al., 2011]

Non-drying oils such as mineral oils and castor oils are used as components of the ink vehicle, lubricants and plasticizers. They require higher temperatures to dry. It has average wetting pigment capability in comparison to semi-drying and drying oils [Brunelle et al., 2003].

\subsubsection{Resins}

Resins have many important roles in the properties of the ink including: hardness, gloss, lubrication, flexibility, viscosity and adhesion to the substrate. They serve as binder of the pigment; some of them can also impart color to the ink. Resins can be synthetic or natural and they can be used in the formulation alone or in a mixture of different type of resins [Brunelle et al., 2003, Hickman et al., 1993].

Among the natural resins used in ink industry are modified and unmodified rosin, shellac, manila copal, asphalts, starch and Arabic gum [Brunelle et al., 2003]. Advantages of these resins are that are ecologically friendly and relatively inexpensive.

There is a large variety of synthetic resins used in the manufacture of ink, including: a) pure phenolic resins, b) rosin modified resins, c) alkyd resins, d) hydrocarbon resins, e) polystyrene resins and copolymers, f) terpene resins, g) silicone resins, h) alkylated urea formaldehyde resins, i) alkylated melamine formaldehyde resins, 
j) polyamide resins, k) polyimide resins, 1) chlorinated rubber, m) vinyl resins, n) ketone resins, o) acrylic resins, p) epoxide resins, q) polyisocianates and polyurethanes and r) nitrocellulose [Hickman et al., 1993].

The choice of the type of resin depends on the chemical and physical features desired for the final formulation including: pigment-wetting quality, light resistance, solubility and compatibility with the other components of the formulation, reactivity, compatibility with the writing instruments or printing technology, compatibility with the end-use substrate, cost, and environmental and FDA requirements [Magdassi 2011].

\subsubsection{Solvents}

The most important properties of a solvent to consider for ink formulations are its polarity, rate of evaporation, residual odor, toxicity, purity and color. The main type of solvents used in ink industry are: a) hydrocarbon (kerosene, toluene, petroleum distillates, xylene); b) alcohols (ethanol, propanol, isopropanol, butanol, alicyclic alcohols), c) glycols, d) ketones (acetone, MEK, hexone, ciclohexanone), e) esters and f) water [Brunelle et al., 2003, Magdassi 2011].

\subsubsection{Driers}

Driers are used to accelerate the drying process by promoting oxidation of the oils. Most driers used in inks are inorganic salts and organometallic complexes. Typically 0.5 to $4 \% \mathrm{wt}$ of the drier is added to the formulation [Hickman et al., 1993]. 
Liquid driers are heavy metal salts of organic fatty acids. The metal content in the acid ranges from 3-18\%wt, with the exception of lead and zirconium, which may be present at higher levels [Hickman et al., 1993].

Cobalt is the most efficient drier. It is fairly soluble in acids but it tends to discolor some whites and tints. Manganese is less powerful than cobalt but has a smaller effect in the modification of the final colors. Cerium, zirconium and lithium are driers of medium efficiency; they have replaced lead because of environmental concerns and can be used in mixtures with either Co or Mn [Hickman et al 1993]. Calcium and Zinc are used in printing inks only for some white formulations due to poor efficiency. Iron is used in particular in tung oil varnishes [Hickman et al., 1993].

Paste driers are manufactured by mixing ground salts of $\mathrm{Pb}(\sim 40 \%)$ and $\mathrm{Mn}$ $(\sim 8 \%)$ in linseed oil. Nonetheless, in modern formulations lead has been replaced by less toxic elements such as $\mathrm{Zr}$ [Brunelle et al., 2003].

\subsubsection{Plasticizers and other additives}

The ink recipe may have many other additives that will provide the anticipated properties to the target market. Some of these additives include biocides, corrosion inhibitors, chelating agents, plasticizers, antioxidants and emulsifying agents [Magdassi 2011].

The main function of a plasticizer is to add flexibility to the dried ink; they can also impact other characteristics to the ink such as gloss, resistance to high temperatures and adhesion. Plasticizers are mainly of organic nature and include benzoates, citrates, 
phthalates, polyesters, polyol esters, stearates and sulfoamides [Brunelle et al 2003, Hickman et al., 1993].

Waxes are added to some ink recipes to provide water and scratch resistance. They are commonly used in printing inks that use heating elements. A variety of synthetic, natural and petroleum waxes are used for the manufacture of printing inks [Magdassi 2011].

Sequestrants or chelating agents are used to form stable ion complexes [Brunelle 2003]. They are used to improve color, stability and durability and favor cross-linking of polymers [Magdassi 2011]. Some examples of chelating agents are EDTA and its sodium salts, sodium salts of diethylenetriamine-acetic acid, dimethyl glyoxime and its sodium salts and alkanolamines [Hickman et al., 1993].

Surfactants improve the wetting and dispersion of pigments in the ink system [Magdassi 2011]. Anionic surfactants are especially used in aqueous solutions, usually added as alkali metal, ammonium or substituted ammonium salts of fatty acids. On the other hand, cationic agents are added to non-aqueous formulations, they include quaternary fatty ammonium halides, acetates or sulfates. Amphoteric surfactants can behave as anionic or cationic surfactants according to their media [Hickman et al., 1993].

Defoaming agents act as solvent to the surfactants and reduce undesirable foaming appearance in the recipe. Silicone defoaming agents such as polydimethyl siloxane are used in aqueous medias and emulsions, typically ranging from 10 to $30 \% \mathrm{wt}$ [Brunelle et al., 2003]. 


\subsubsection{Chemistry of writing inks}

There are hundreds of different ink formulations available for pen inks. The major components of ink are fairly similar to those encountered on inkjet systems. Although some dyes and pigments used for writing inks may be the same as the ones used in printing inks, the primary difference between them is that their grade and particle size is not as crucial for writing inks. [Brunelle et al., 2003]

Ballpoint inks can use either dyes and/or pigments. Popular dyes on these pens are cationic dyes, solid phtalocyanine bases (for blue), copper phtalocyanine and/or nigrosine for blacks. Most common pigments used in ballpoints are titanium dioxide, carbon black, metal powder and some organic ones such as azo, chelate-azo, phtalocyanine, antraquinone, and nitroso pigments. Organic solvents such as benzyl alcohol, phenoxyethanol, carbitols, glycols and cellosolves are often preferred in these systems. Resins such as ketone resins, aldehyde resins, phenolic resins and oil free alkyds and polyesters are often encountered in ballpoint pens [Brunelle et al., 2003].

Gel pens are water-based inks that gained popularity in the market since the late 80 's as a consequence of its cheap manufacture and positive acceptance by the customers. The first formulation made in by Sakura in 1984 was dye-based. A year later, most gel pen formulations were pigmented-based because they provide greater color availability. Modern black gels are now both pigmented and dye-based. [Wilson et al., 2004]. Some distinctive components used in gel inks are hexanol, hepthaethlyne glycol, penthaethylen glycol, 1-H benzotriazole, and triethanol amine [Wilson et al., 2004] Pseudoplasticizers such as xanthan gum, tamarind gum, gum rabic, guar gum, cellulose and water soluble acrylic synthetic polymers are used to provide the gel structure. The most common 
inorganic pigments found in gel pens are titanium oxide, iron oxide, carbon black and metal powder. Organic pigments such azo, chelate azo, anthraquinone and phtalocyanine are also popular. A typical gel formulation contains over $60 \%$ of water, although some modern gel pen inks may have as little as $4 \%$ of water if the dye/pigment ratio is increased [Brunelle et al., 2003].

The ink used for roller-ball pens is suitable for other types of ink such as fountain pens, felt-tip pens and inkjet printer inks. Food dyes and acid dyes are commonly observed in these systems. The solvent of choice for these formulations is ethylene glycol. [Wilson et al., 2004]

Table 2 shows examples of typical writing ink formulations. These recipes are provided as an illustrative example, however there are numerous possible combinations of modifications to the components in the market [Brunelle et al., 2003].

Table 2. Typical writing ink formulations

\begin{tabular}{|c|c|c|c|c|c|}
\hline \multicolumn{2}{|c|}{$\begin{array}{c}\text { Fountain pen (roller ball } \\
\text { pens, felt-tip pens, inkjet } \\
\text { ink) }\end{array}$} & \multicolumn{2}{|c|}{ Ballpoint inks } & \multicolumn{2}{c|}{ Gel pen inks } \\
\hline Water & $91-96 \%$ & $\begin{array}{c}\text { Organic } \\
\text { solvents }\end{array}$ & $50-95 \%$ & Water & $60-80 \%$ \\
\hline $\begin{array}{c}\text { Synthetic } \\
\text { dyes }\end{array}$ & $1-5 \%$ & Dyes & $5-35 \%$ & $\begin{array}{c}\text { Water- } \\
\text { soluble } \\
\text { organic } \\
\text { solvents }\end{array}$ & $1-40 \%$ \\
\hline Humectants & $<2 \%$ & Pigments & $0-2 \%$ & Pigments & $4-6 \%$ \\
\hline $\begin{array}{c}\text { Iron } \\
\text { components }\end{array}$ & $0-1 \%$ & Resins & $8 \%$ & Resins & $0.3-1 \%$ \\
\hline Tannic acid & $0-0.5 \%$ & Lubricants & $5 \%$ & Glycerin & $5 \%$ \\
\hline $\begin{array}{c}\text { Phenol } \\
\text { components }\end{array}$ & $<0.5 \%$ & Additives & $0.01-5 \%$ & $\begin{array}{c}\text { Pigment } \\
\text { dispersants }\end{array}$ & $1 \%$ \\
\hline
\end{tabular}




\subsubsection{Chemistry of printing inks}

\subsubsection{Chemistry of inkjet printers}

There are four main types of inkjet ink formulations: solvent-based, water-based, UV curable and phase-change. Combinations of the main types are also available (e.g., waterbased with some solvents) [Hudd 2011].

\subsection{Solvent-based inks}

Solvent-based inkjet inks are the most common as a result of its inherent advantages such as good printing quality, stability, durability, water-proof properties, low cost, fast drying time and high compatibility to several substrates, including flexible media [Samuel et al., 2011].

Solvent-based inks are typically used to print professional designs such as banners, vehicle graphics and adhesives. They can use dyes or pigments as colorants, although the later are most common due to durability [Samuel et al., 2011]. They can be classified according to the amount of solvent used in their formulation as hard solvent or “eco"-solvent.

The solvent is evaporated by heating of the substrate, which caused environmental concerns for the emission of VOCs. As a consequence, formulations using hard solvent

require the use of special ventilated areas. Another disadvantage of these inks are the relative high maintenance required to avoid clogging of the nozzle heads [Hickman et al., 1993]. 


\subsection{Water-based inks}

These inks are the inks of choice on desktop printers because they are relatively cheap and environmental friendly [Schmid 2011]. They are commonly used in printers with thermal inkjet heads. Their application in industrial settings is limited as a consequence of the requirement of porous substrates and incompatibility with piezotechnology.

Their formulations contain typically water as the primary solvent, glycol and other co-solvents to prevent nozzles from drying outs. Colorants in the form of dyes or pigments are used in concentrations ranging from 0.5 to $10 \% \mathrm{wt}$ [Schmid 2011].

\subsection{UV-curable inks}

Ultraviolet curable inks do not dry by evaporation, instead they are irradiated with UV light to initiate a chemical reaction that converts the liquid into a solid film. There is an increase use in thermal inkjet and piezoelectric DOD systems as a result of their consistent printing quality, adhesion to many types of substrates and reduced hazard air pollutants and VOCs. Their main components are acrylic monomers, such as acrylic acid and acrylate esters, and an initiator package [Hutchinson 2011] . The photoinitiators are used as a blend of more than one component to allow the efficient absorption of the UV light in short time intervals. They are typically present at $10-12 \% \mathrm{wt}$ of the formulation [Edison 2011]. Examples of photoinitiators are benzyl dimethyl ketal, Irgacure 651, hydroxycyclohexylphenylketone [Hutchinson 2011]. 


\subsection{Phase-change inks}

These inks are formulated in solid form and are melted before being printed. They dry very fast, are environmental friendly and provide good opacity. Drawbacks are lack of durability and poor abrasion resistance. They are used to print barcodes on non-porous materials [Hickman et al., 1993].

Regardless of the type of inkjet ink, one of the greatest effects to efficient formation of ink droplets relies on the viscosity of the formulation and therefore the selection of the proper binder is crucial.

One of the main differences in the formulation of inkjet inks in comparison to other inks (writing inks, toners) is that the dyes are predominantly preferred over pigments. Although, some pigments may be used for inkjets, they have to be especially designed for inkjet printing i.e. with a particle size $<1$ um [Magdassi 2011]. Dyes that are used for inkjet printing are usually customized with a) low impurity and low insoluble material $(<0.2 \%)$ and b) thermal stability to overcome temperatures above $60{ }^{\circ} \mathrm{C}$ for longer periods of time. In general, modern inkjet ink formulations are oriented towards non-metal complex dyes [Hickman et al 1993].

Additives are typically added to inkjets at levels lower than $0.1 \%$ wt. As a consequence of its inherent effect in the rheology of the recipe, it is not unusual to find more than ten different additives in a single formulation. The most important additive for inkjets is the conductive salt that facilitates the charging of the droplets. Conductive salts can be organic or inorganic; sometimes trace levels of metal salts in the formulation are enough to provide the conductive properties [Hickman et al., 1993]. Table 3 shows a typical formulation for CIJ ink, DOD inkjet ink and a DOD UV curable inkjet. 
Table 3. Typical formulations of inkjet inks

\begin{tabular}{|c|c|c|c|c|c|}
\hline \multicolumn{2}{|c|}{$\begin{array}{c}\text { CIJ inkjet [Hickman et al } \\
1993]\end{array}$} & \multicolumn{2}{|c|}{$\begin{array}{r}\text { DOD inkjet } \\
\text { [Schmid 2011] }\end{array}$} & \multicolumn{2}{|c|}{$\begin{array}{l}\text { DOD UV curable inkjet } \\
\text { [Edison 2011] }\end{array}$} \\
\hline Component & $\%$ weight & Component & $\begin{array}{l}\% \\
\text { weight }\end{array}$ & Component & \% weight \\
\hline $\begin{array}{l}\text { Methyl ethyl } \\
\text { ketone } \\
\text { (MEK) }\end{array}$ & $40-60$ & Water & $50-90$ & Pigment & $3 \%$ \\
\hline IMS & $20-30$ & Dye & $1-15$ & Wetting additive & 1 \\
\hline Water & 5 & Humectant & $2-20$ & $\begin{array}{l}\text { Low viscosity } \\
\text { oligomer }\end{array}$ & 10 \\
\hline $\begin{array}{l}\text { Ethylene } \\
\text { glycol }\end{array}$ & 5 & Penetrant & $0-10$ & $\begin{array}{l}\text { Triacrylate } \\
\text { monomer }\end{array}$ & 12 \\
\hline Black dye & $5-10$ & Surfactant & $0.1-6$ & & \\
\hline $\begin{array}{l}\text { Cellulose } \\
\text { derivative }\end{array}$ & $5-15$ & Resin & $0.2-10$ & $\begin{array}{l}\text { Diacrylate } \\
\text { monomer }\end{array}$ & 22 \\
\hline $\begin{array}{l}\text { Dibutyl } \\
\text { phthalate } \\
\text { plasticizer }\end{array}$ & $1-5$ & Biocide & $0.02-0.4$ & $\begin{array}{l}\text { Monoacrylate } \\
\text { monomer }\end{array}$ & 38 \\
\hline Defoamer & 1 & Fungicide & $0.05-1$ & Additives & 2 \\
\hline Antioxidant & 1 & Buffer & $0.05-1$ & $\begin{array}{l}\text { Photoinitiator } \\
\text { blend }\end{array}$ & 12 \\
\hline $\begin{array}{l}\text { Conductive } \\
\text { salt }\left(\mathrm{LiNO}_{3}\right)\end{array}$ & 2 & & & & \\
\hline
\end{tabular}

\subsubsection{Chemistry of toners}

The difference between inkjet ink and toner ink is not limited to the fact that one is mostly present in liquid form while the other is mostly powder. In fact, most of the differences lie in the chemical compositions of each. A toner is an electrostatic-charged fine powder. Toners can be formulated as dry powders or powders dispersed in a liquid.

The main components of a toner are the pigment and the resin. The pigment is responsible to provide color to the document to be printed, while the resin facilitates the melting of the toner when it is heated in the fuser. Typical formulations contain $\sim 50-90 \%$ of resin, depending on the presence or absence of magnetic additives. Common resins 
used in toner formulations are styrene-acrylic, polyesters, polystyrene n-butyl methacrylate, polystyrene n-butyl acrylate, epoxy polyethylene and polypropylene [Hickman et al., 1993]. Other components found in toners are charge control agents (CCA) and additives, such as surface additives, magnetic additives, and waxes. Surface additives such as silica can improve flow properties and transfer of the toner from the photoreceptor to the paper [Hickman et al., 1993].

Toner is used in monochrome printing (e.g., in black) or color printing. In order to achieve different color hue the printer repeats four times the printing process, passing each time for cyan, magenta, yellow and black. The combination of these four basic colors can generate the full range of colors.

Black toners are made predominantly of carbon black pigments $(5-15 \% \mathrm{wt})$ and magnetite $\left(\mathrm{Fe}_{3} \mathrm{O}_{4}\right)$. Carbon black consists of aggregates of spherical particles of elemental carbon with particle size ranging from 3 to $10 \mathrm{um}$. During the densification process, this aggregates form agglomerates. The surface area of this particles and the aggregates play an important role in the color properties, ease of dispersion and electrostatic properties of the toner [Kyrilis et al., 2008]

\subsection{Dry powder toners}

One important component of dry powders is the resin, which composition depends on the heating method applied. For example, polyester and epoxies are commonly used for radiant heat that can reach temperatures of $50-60{ }^{\circ} \mathrm{C}$; while styrene copolymers and polycarbonates are used for flash fusing that can reach higher temperatures up to $200^{\circ} \mathrm{C}$. Dry powder toners can be found as mono-component or two 
component formulations. The two component systems are highly used in high-speed laser printers and copiers, while the monocomponent are typically used by HP/Cannon LaserJet printers and by printers using the ion deposition system [Hickman et al., 1993].

\subsection{Two-component dry powder}

As the name implies, the two-component formulations consist of two main materials: the toner pigment and coarse beads. The coarse beads are coated with the toner pigments by having opposite charges. Particle size of these two-component formulations ranges from 5-32 um [Hickman et al., 1993]. They consist typically of large percent of polymer binder or resins ( $\sim 90 \% \mathrm{wt})$, a charge control agent and surface flow additives such as silicon oil or low molecular weight polyethylene.

\subsection{Mono-component powder}

There are two subcategories within the mono-component powder: the conductive and the resistive type. The later is the one commonly used in HP laserjet printers. In the conductive system the particles are magnetic and conductive, its particle size ranges from 5-45 um providing limited resolution [Hickman et al., 1993]. About 50 to $70 \%$ of the formulations consist of a magnetic powder; other components include the polymer binder, carbon black and a cleaning additive.

The resistive mono-component powders are similar to the conductive with the exception that uses lower percent of magnetic oxide (30-60\%) and smaller particle size 532um [Hickman et al., 1993]. 


\subsection{Liquid toners}

Liquid toners consist of a colloidal suspension of small particles (0.1-2um) in a highly insulating isoparafin [Hickman et al., 1993].

Historically toner particles have been prepared by mixing with polymers followed by pulverization process [Donnet et al., 1993]. Nevertheless, the manufacturing process has shifted in the last decades to chemical processes that are more cost-effective and improve the performance of the toner.

In general, pigments are dispersed first in a liquid phase such as water, solvent or a monomer, and then affixed to the polymer by agglomeration or direct polymerization. In order to improve the performance of the formulation pigments can be specially designed and modified. For example, the surface chemistry of the pigment can be modified by attaching chemically a variety of functional groups to the carbon black, such as aromatics, alkyl-aromatics, alkyl ester of aromatic or acid groups [Kyrilis et al., 2008]. The modified carbon black polymers usually have a better compatibility with the toner polymers.

Charge control agents are added for adequate charge level or rate of charging and account for about $1 \%$ of the formulation [Hickman et al., 1993].

\subsubsection{Ink Manufacturing}

The manufacture if ink is relatively simple, it requires the reproducible dispersion or solution of the colorant in the vehicle with appropriate mechanical tools. The key factor in the production of ink is the selection of raw materials in the right proportion to facilitate compatibility between ingredients and to assure stability of the final product. 
The ink industry can produce their own main components i.e., vehicle, additives and pigments or purchase them for a third party prior the manufacture of the ink recipe [Magdassi 2011].

\subsubsection{Manufacturing of inkjet printing ink and writing ink}

Ink batch productions are produced in lots ranging from 50 to $1500 \mathrm{~L}$. The manufacturing process can be executed in small batches, if flexibility for product's variety is required, or in large-scale batches of few similar products. [Hickman et al., 1993] Continuous production is also possible if the product capacity rather than diversity is the main focus of the plant [Grundeman et al., 2009].

In a typical batch production, the reactants such as the solvent, binders, pigments and additives are weighted and added to a stirred vessel where they are mixed. After mixing, the temperature can be raised to $50-160{ }^{\circ} \mathrm{C}$, depending on the ink type, to allow the reactions to take place [Grundeman et al., 2009]. The mixture is then cooled down to ambient temperature at a controlled rate. A conditioning/refining step occurs before filling the storage drums. The production cycle could take 3-7 hours, after which a rigorous cleaning step is required [Hickman et al., 1993].

Modern methods for writing inks may use micro-continuous processes that last about 48 hours, reducing the waste disposal from the unnecessary cleaning cycles. Microcontinuous method is more eco-friendly but requires a pre-mixing of powder-based reactants. As a consequence, this process is less flexible to variations in the quality of the ingredients than the traditional batch process and does not allow for adjustments within the manufacturing stages [Grundeman et al., 2009]. 
Although most ink manufacturing processes are similar, there are some significant differences encountered depending on the ink type. For instance, water-based and solvent-based inks have different production requirements as a result of the flammable nature of most organic solvents. Volatile solvents require enclosed and water-cooled stirrers [Hickman et al., 1993].

Printing liquid inks demand an additional filtration step after milling process and prior the pumping to the storage tanks or to the containers for delivery [Hickman et al 1993].

Liquid inks can be produced either by loading together the pigment, resin, solvent and other components in a ball mill or by premixing the solvent and the resin prior the addition of the colorant. Another production method is to use pigment "chips" which are a solid form produced by dispersing the pigments into a resin with plasticizer. The chips are later diluted and solubilized in the solvent [Hickman et al., 1993].

The manufacture of dye-based inks is more straightforward than formulations that contain pigments. The method of manufacture involves the solution of the dye into the solvent by constant stirring. Application of heat can improve solubility of the dye. Once the dye is dissolved in the media, the resin and other additives are added. The cooling rate is important to avoid undesirable suspensions or precipitation of the colorant.

The two main apparatus used at ink production plants are the milling and the mixing equipment. The main function of a mill instrument is to grind and reduce particle size and facilitate the homogeneity of the blended materials.

The storage of the inks is carefully controlled to avoid flocculation of the pigment and separation of the binders, amongst other problems. To avoid this, the ink industry 
usually produces tank sizes that will not be stored for more than 2 months [Hickman et al., 1993]. The capacity of storage of bulk inks range from 500 to 5000 L. Storage tanks usually have high levels of sophistication including manual or computer-controlled agitation, venting, temperature control, charging and discharging mechanisms.

Packaging then occurs in smaller containers ranging from 10kg polythene buckets to unit cartridges/pens. Many inkmaker plants have their own systems installed to fill ink for printers, which is more cost-effective [Hickman et al., 1993]. Some brands produced their own ink while others can purchase the ink from different suppliers.

On average, between 600,000 and 1.2 million pens can be filled with ink produced by a single batch [Cantu, personal communication]. Nonetheless, this numbers will vary from brand and from size of a plant within a single brand. For example, BIC produces most of its own ink and purchases approximately $5 \%$ from outside sources for specialty items. They use only one outside suppliers for products produced in BIC Plants. Bic reported that 5 million pens can be produced from a singe batch and a package of pens could have ink produced from different batches [Survey, information provided by BIC Consumer affairs team]

To place this numbers in perspective, in 2010 about 106 billion ballpoint pens were disposed in the USA. Worldwide, billions of disposable pens are sold annually. [http://agreenliving.net/save-the-planet-by-switching-pens]. These figures suggests that would be not possible to associate an ink composition to a specific pen, but still the large variety of types of pens and formulations of inks available in the market make ink a valuable type of evidence that can be used for evaluation of document forgery. 


\subsubsection{Manufacturing of toner}

Toner is produced by mixing the main components and raising the temperature to produce a hot melt or block, which is subsequently broken and ground into fine powder. The grinding is traditionally done by air jet mills to reduce the size of the particles, which are then sieved to an average size of $8-20 \mathrm{um}$. Particles produced by this method are typically of irregular shape. The fine particles are then blended with additive to adjust the electrostatic properties [Hickman et al., 1993].

Modern production methods are moving toward synthetic chemical toners by growing the particles from its reagents, at molecular levels. This method favors the production of smaller particle s of $<4 \mathrm{um}$, with uniform shapes and better printing resolution [Hickman et al., 1993].

Bulk toner is stored in barrels of approximately $10 \mathrm{~kg}$ and then distributed to the suppliers [Hickman et al., 1993].

\subsubsection{Forensic examinations of ink}

Inks are usually analyzed in document examinations with the purposes of a) comparing two or more ink entries to determine similarities or differences, b) identifying whether two or more entries were written with the same formula or/and batch of ink and/or c) dating ink entries to determine if documents have been backdated [Brunelle et al., 2003].

The ASTM Standard Guide for Test Methods for Forensic Writing Ink Comparison recommends conducting non-destructive optical examination first, such as light examination, infrared examination, reflected infrared or/and infrared luminescence. 
Further chemical examinations may be necessary to improve discrimination and identification of the samples, including spot testing and solubility tests, thin layer chromatography (TLC), FTIR, gas chromatography (GC, GC/MS), high pressure liquid chromatography (HPLC), microspectrophotometry, X-ray fluorescence (XRF) and capillary electrophoresis [ASTM E1422].

However, some inks such as gel inks are difficult to analyze by the recommended ASTM methods. Gel pen inks are pigment-based inks, and more recently (last decade) some of them are also dye-based. These inks have become prevalent in the market and represents a challenge to the document examiner because the pigment-based inks will not migrate on a TLC plate, which is one of the preferred methods for chemical analysis of inks. Moreover, some gel inks and particularly the black gel inks are inseparable with spectral techniques [Mazzela et al., 2003; Wilson et al., 2004; Zieba-Palus et al., 2008].

Wilson et al. [Wilson et al., 2004] proposed a scheme of analysis to separate some dye-based from pigment-base gel inks on the basis of spectral comparison, TLC, spot tests and GC/MS. The authors were able to separate 29 non-ballpoint inks into 19 groups. Raman spectroscopy has shown to offer added discrimination for the forensic analysis of inks. However, certain inks produce a strong fluorescence that masks the spectra. In general, these interferences are more critical in gel inks than in ballpoint inks. Zieba et al. reported that only about $50 \%$ of inks from a set of 80 multicolor inks originated from ballpoint pens and gel pens showed readable Raman spectra. The authors recognized that this method should be also complemented by elemental composition analysis such as XRF [Zieba-Palus et al., 2008]. 
The chemical characterization of document-related evidence, such as ink and paper, relies on the identification of their components. The majority of conventional methods are centered on the analysis of their organic components [Grim et al., 2001; Wilson et al., 2004, ASTM E2331, ASTM E1422, ASTM E1789].

Alternative mass spectrometric methods for the identification of organic components of inks have been recently reported, including Secondary Ionization Mass Spectrometry (SIMS) [Pachuta et al., 1994], Field Desorption Mass Spectrometry [Sakayanagi et al.,1999], Ambient Mass Spectrometry using DESI and EASI [Eberlin et al., 2010; Ifa et al., 2007; Lalli et al., 2010], Direct Analysis in Real Time (DART) [Jones et al., 2006] and Laser Desorption Ionization Mass Spectrometry (LDIMS) [Gallidabino et al., 2010; Weyerman et al., 2010; Weyerman et al 2012].

The inorganic analysis of ink has been also reported in the literature and has shown its potential to improve the discrimination value of the evidence [Polk 1977; Ferrero 1999; Rozic et al., 2005; Malzer et al.2004; Ouija et al. 2005; Morris 2002; Maind et al., 2006; Maind et al., 2008; Zieba-Palus et al., 2006; Grassi 2007; Zieba-Palus et al., 2008].

Although significant contributions and improvements have been reported in the last decade for the elemental analysis using different methodologies including SEMEDX, NAA, XRF, FTIR, ICP-OES, ICP-MS, PIXE, PIGE and LIBS, the majority of the applications were focused to historical and artistic prints rather than forensic analysis of contemporary documents [new-wave application note, Melessanaki et al., 2001; Ferrero 1999; Ouija 2005]. 
Moreover, some limitations remain on the existing methods; such as: a) the sensitivity does not allow the detection of elements present at trace elements, [Polk 1977, Zieba-Palus et al., 2008] b) the depth of the x-ray penetration its not easily controlled by the operator and may affect the results, [Zieba-Palus et al., 2006, Zieba-Palus et al., 2008] c) the contribution of the paper and the ink can not be easily isolated, [Malzer et al., 2004, Zieba-Palus et al., 2006], d) the technique is not readily available in forensic laboratories [Grassi 2007, Oujja 2005, Melessanaki et al., 2001], f) the technique consumes large amount of sample which may not be available or acceptable in a particular case [Spence et al., 2000; Rozic et al., 2005; Maind et al., 2006; Maind et al., 2008] or g) the technique is mainly qualitative [Polk 1977, Ferrero 1999, Ouija 2005, Zieba-Palus et al., 2008].

Although previous application notes and dissertation thesis have shown its potential, [Morris 2002, Naes 2009] this research generated the first forensic application of LA-ICP-MS on writing inks reported in a peer review paper. [Trejos et al, 2010]. To the best of my knowledge the forensic application of laser-microspectrometric methods on printing inks has not been published yet.

1.6 The composition, manufacture and forensic examination of glass

\subsubsection{Raw materials and chemistry of glass}

The ASTM defines glass "as an inorganic production of fusion that has been cooled to a rigid condition without crystallization" [ASTM C162-03]. One particular difference between glass and other matrices, such as ink and paper, is that glass is composed solely of a mixture of inorganic materials, there are no major organic 
compounds present in the glass formulation. The inorganic composition therefore becomes responsible for its final physical properties. From a forensic perspective, small variations in the chemical formulation can provide useful differentiation between glasses that have been manufactured in different manufacturing plants or even at the same manufacturing plant at different time intervals [Almirall et al., 2006].

Different raw materials are responsible for the formation of the glass structure, color, heat resistance, viscosity and other properties. For instance, $\mathrm{SiO}_{2}$ and $\mathrm{B}_{2} \mathrm{O}_{3}$ are used as network formers; $\mathrm{Na}_{2} \mathrm{O}, \mathrm{CaO}$ and $\mathrm{MgO}$ are used as modifiers; $\mathrm{Fe}_{2} \mathrm{O}_{3} ; \mathrm{As}_{2} \mathrm{O}_{3}$ and $\mathrm{CaSO}_{4}$ are used as refining agents; chromium and selenium can be used as colorants, while $\mathrm{As}_{2} \mathrm{O}_{3}, \mathrm{MnO}_{2}$ and $\mathrm{CoO}$ can be used as decolorants. The inorganic elements in the final composition may be present at different concentrations ranging from percent levels to low ppm levels [Koons et al., 2002].

Glass can be classified according to its composition as: a) as soda-lime glass, which is typically found in bottles, jars, drinking glass and window glass, b) lead glass, which is found in vases and decorative items and c) borosilicate glass that is commonly found in cooking wear, headlamp and decorative glasses.

One of the most common types of glasses found in forensic cases is soda-lime glass. There are three main raw materials often used in the formulation of soda lime glasses: a) sand $\left(\mathrm{SiO}_{2}\right)$, b) soda ash $\left(\mathrm{Na}_{2} \mathrm{CO}_{3}\right)$ and limestone $(\mathrm{CaO})$ [Koons et al., 2002].

As the names implies, lead glasses have a large composition of lead that provides particular sparkle to the end product $(\mathrm{PbO} \sim 13-15 \% \mathrm{wt}$ ) while borosilicate glass has $\mathrm{B}_{2} \mathrm{O}_{3}$ at levels ranging from $7-13 \% \mathrm{wt}$ providing heat resistance to the final product [Koons et al., 2002]. 
The main component of glass is the silica obtained from sand. Some natural impurities present in the sand are responsible to providing a differentiable "elemental fingerprint" to the end product, therefore glass manufactured at different plant locations would have different elemental profiles as a result in part to the different trace composition of the sand used in the formulation [Almirall et al., 2006].

The use of recycled glass or cullet is commonly employed in the manufacture of glass to reduce the cost of the manufacturing process by decreasing the melting temperature and recycling within the plant the broken glass. Some container plants use also recycled glass from consumers, which typically adds more variability and heterogeneity of the elemental composition between batches originating from the same plant.

Some elements can be found in glass as impurities introduced during the manufacturing process and may add additional discrimination. For instance, flat glass that is produced by the float process may have different levels of $\mathrm{Zr}$ as a product of leaching from the inner surfaces of the furnace into the molten glass [Koons et al., 2002].

The forensic examination of glass relies on the premise that despite technological standardization in the manufacture of glass, minor variations in the physical properties and chemical composition of the glass remain between and within batches because of the innate trace contaminations of raw materials [Almirall et al., 2006].

\subsubsection{Glass manufacturing}

Glass production ranges from simple glass containers to advanced microcomponents. The manufacturing of glass usually follows five steps: a) preparation of raw 
materials (storage, weighing and mixing), b) melting (refining and homogenizing), c) forming, d) annealing and e) secondary process and/or warehouse.

Nowadays, the melting process takes place at furnaces made of bricks that are resistant to high temperatures $\left(>1500{ }^{\circ} \mathrm{C}\right)$, where a flow of the melted glass is fed continuously [Copley, 2001]. A refining process is typically conducted to eliminate bubbles from the molten glass. Refining agents such as arsenic oxide or calcium sulfate can be added to facilitate the removal of the undesired bubbles. The refining process is accompanied by thermal and mechanical stirring to ensure homogenization of the glass. The melting step is critical to offer uniform refractive index in the product.

The forming procedure occurs then by changing gradually the viscosity of the molten glass to allow the formation of the glass structure [Copley, 2001]. Different forming materials will be added at this stage depending on the final product of interest (container, blowing, flat glass, glass fiber). After the forming step, the glass is allowed to solidify without crystallization at the annealing stage. The annealing stage requires the cooling of glass at strictly controlled rates.

Some glass products require a secondary processing such as tempering, coating and coloring or decolorizing. Tempered glass is ordinary glass that has followed a tempering process to provide additional strength and more safety breakage pattern. This process can be used for flat glass or some curved screens, however it cannot be applied for containers [Copley, 2001].

The coating method is typically used in the manufacture of containers to add protection, improved handling or strengthening of the glass. The coatings are applied twice as a spray or as vapor, first between the forming step and the annealing step (hot 
end) and then just after the annealing (cold end). Hot end coatings are mainly made of titanium or tin and the cold ends are organic waxes or fatty acids. Some flat glass products may be also coated [Coppley, 2001].

Some impurities from the raw materials, such as iron oxide, can produce a color in the glass. For some products, a clear appearance is desirable and therefore additional amounts of elements such as selenium and cobalt are added to decolor. On the other hand, some products are colored intentionally for decorative or technical reasons. Common colorants are iron (green, brown or blue), manganese (purple), cobalt (blue, green, pink), titanium (purple, brown), cerium (yellow) and gold (red) [Copley, 2001].

There are many different glass compositions, depending on the product end use. Since the manufacturing process differs from one product to the other, the following sections describe the main manufacturing processes of glass typically encountered in forensic examinations.

\subsubsection{Flat glass}

Within the flat glass manufacture there are two main glass-forming processes: the float process and the rolling process. The rolling process is used to produce pattern or texture glass for decorative purposes. In the rolling method a ribbon of glass is passed trough water-cooled metallic rollers, which transport the glass horizontally into an annealing oven and finally the glass is cut to size [Coppley, 2001]. The adjustment of the gap between the rollers controls the thickness of the glass piece. The rollers can also impress a final pattern into the glass, if required. 
The float glass method is the preferred manufacturing method for flat glass. In this process, the raw materials are introduced to one end of a glass tank and are melted in a big furnace. The glass emerges from the furnace into a float chamber that contains a pool of molten tin. The chamber is kept under controlled temperature and at atmosphere free of oxygen, in order to avoid oxidation of the tin. At the entrance of the chamber the tin is approximately at $1000{ }^{\circ} \mathrm{C}$ and at the exit the temperature is cooled at $600{ }^{\circ} \mathrm{C}$. There are rollers at the exit that pull the glass. The speed of the rollers will determine the thickness of the glass [Coppley, 2001].

\subsubsection{Containers}

Containers are produced mainly by the blowing or the flowing process. In the first method, the glass is placed in a mould and blown to the desired shape; then the container is reheated and annealed to prevent cracking of the product [Koons et al., 2002].

In the flowing method, the homogeneous molten glass flows and drops into the mould where it is shaped by pressing (wide neck jars) or blowing (bottles) before being transported to the blow mould. The flowing method is used in automatic production of containers. Most manufacturers of containers use recycled glass or "cullet" as raw materials, adding more heterogeneity to the glass [Koons et al., 2002]. 


\subsubsection{Fiber glass}

Fiber glass may be also encountered as trace evidence since it is widely used in composite materials, reinforcement of plastics, gypsum and as a thermal insulator. [Koons et al., 2002].

Fiber glass can be produced by the continuous glass filament process or by the glass wool process. The main difference between them is that in the first one filaments of molten glass are drawn mechanically downwards from the orifice of a specific diameter, while in the glass wool process the glass flows by gravity so the filaments are random in diameter [Koons et al., 2002].

\subsubsection{Forensic Examinations of glass}

The comparison of glass fragments recovered from crime scenes to glass sources of known origin has long been recognized as a key examination of physical evidence. The significance of any associations made as a result of these comparisons is improved when more discriminating analytical methods are used [Almirall et al., 2000]. The comparison of elemental composition between glass samples has proven to enhance the value of an association when one is found, and to reduce false associations between different sources that may result when less discriminating methods, such as refractive index are used [Reeve et al., 1976; Dudley et al., 1980; Howden et al., 1978; Koons et al., 1991; Hicks et al., 2003; Andrasko et al., 1978; Becker et al., 2001; Duckworth et al., 2002; Koons et al., 1988; Montero et al., 2003; Almirall et al., 2006; Suzuki et al., 2000; Hughes et al 1976; Coleman et al., 1973; Koons et al, 2001; Catterick et al., 1981; Buscaglia et al., 1994; Ryland et al., 2011]. As the number of forensic science 
laboratories performing elemental comparisons of glass fragments has increased, the need for consistency among laboratories concerning both analytical methodology and interpretive criteria has been recognized [NRC report 2009]. To address these issues, an Elemental Analysis Working Group (EAWG) consisting of 34 forensic glass examiners and research scientists from North America and Europe was formed under the direction of researchers at Florida International University with funding from the US National Institute of Justice. The goal of the EAWG was to develop analytical protocols and to assess the utility of glass source comparisons by way of several interlaboratory studies.

Part of this dissertation research consisted of coordinating the design and distribution of interlaboratory tests to the members of this working group, as well as gathering the data collected from all group members and conducting statistical analysis to evaluate the effect of match criteria on error rates. This dissertation describes the development of the analytical protocols for the elemental analysis of glass evidence fragments as well as the evaluation of match criteria for elemental analysis of glass.

Glass represents a model matrix for trace evidence examiners for several reasons: a) due to its fragile nature and wide use in society, it is one of the most common types of trace evidence found in case scenarios such as hit-and-run accidents, burglaries, kidnappings, homicides and shootings; b) it is easily transferred from the broken source to the scene, victims and others in the vicinity; c) it is easily recovered from a scene or object; d) it can persist after transfer; e) its chemical composition does not vary over time; f) the typical recovered fragment size is normally sufficient for analysis by a variety of analytical methods; g) there are sensitive methods and suitable reference standards routinely used in forensic laboratories to detect chemical and physical properties; h) the 
physical properties and elemental composition of glass fragments are relatively homogeneous within a single pane or sheet of glass; i) despite the standardization of manufacturing processes, detectable variations in the physical/optical properties and chemical composition permit the differentiation of glass samples from different manufacturing sources and from a single source over time; $\mathrm{j}$ ) when sensitive methods are used, excellent source discrimination can be achieved on the basis of the optical characteristics and elemental composition; and k) the framework proposed to construct opinions derived for glass comparisons can also be used by other types of trace evidence [Almirall et al., 2006].

For these reasons, glass was selected as a model material by the EAWG to work towards the standardization of analytical methods and the interpretation of evidence.

A number of analytical methods have been used to measure the elemental composition of glass for forensic purposes. These include multielemental determinations either by quantitative or qualitative methods. Currently, the methods most frequently used in forensic science laboratories are scanning electron microscopy-X-ray spectroscopy (SEMEDX), x-ray fluorescence spectroscopy (XRF) and inductively coupled plasma (ICP)based methods with either mass spectrometry (MS) or optical emission spectroscopy (OES) as a detection method. Effective sample introduction for ICP-MS and ICP-OES methods has been accomplished using either digestion of glass fragments followed by nebulization of the resulting solution or by laser ablation (LA) of the solid glass material.

Scanning electron microscopy-x-ray-spectroscopy is used both for the classification of the type of glass (soda-lime, borosilicate, alumino-silicate, lead-alkalisilicate, etc.) of recovered fragments and for the comparison of recovered glass fragments 
with potential sources [Andrasko et al., 1978]. The technique is nondestructive of the sample and allows the characterization of very small glass fragments such as glass debris on projectiles or pulverized and imbedded in tools and weapons. However, SEM-EDX has limited sensitivity and therefore can only be used to detect the presence of minor and major elements at concentrations greater than $0.1 \%$ [Bruzel-Mucha et al 1998; KuismaKursula et al., 200; Krusemann 2001]. In addition, the precision is generally poorer than other methods such as XRF and ICP-based methods. For these reasons, the interlaboratory exercises reported in this paper do not include SEM-EDX data but instead focused only on the more sensitive and discriminating methods.

In order to accommodate the small size of recovered glass fragments, $x$-ray fluorescence spectroscopy instruments with either highly collimated or capillary-focused x-ray beams are typically used for analysis. Collectively these instruments are referred to as micro-XRF instruments ( $\mu$-XRF). Emitted x-rays are detected with an energy dispersive detector in $\mu$-XRF instruments. The advantages of $\mu$-XRF are similar to those of SEM-EDX: it is nondestructive, relatively easy to operate, and provides simultaneous multielemental information. However, $\mu$-XRF is more sensitive than SEM-EDX especially for elements of energy higher than $3 \mathrm{keV}$ providing better discrimination between glasses of the same type [Roedel et al., 2003; Ryland et al., 1986]. Advantages of $\mu$-XRF over ICP-based methods are that it has a lower instrument cost and easier operation and maintenance; it does not require a pre-determined elemental menu prior to the analysis; it can be used at any point in the analytical scheme as a result of its totally non-destructive nature; and although data acquisition is more time-consuming, most instruments can operate unattended. 
The main drawback to $\mu-\mathrm{XRF}$ is that the analysis of very small and irregularly shaped samples can produce inaccurate quantitative results and less precise replicate measurements than ICP-methods,, both within a given fragment and between fragments from the same source [Almirall et al, 2006]. Also, $\mu$-XRF is not sensitive enough to measure several trace elements that have been shown to have good source discrimination capability [Almirall et al., 2006]. Accurate quantitation typically requires matrixmatched standards and use of a method such as embedding and polishing of the sample in order to present a flat surface to the x-ray beam [Roedel et al., 2003]. As a result, most forensic laboratories compare x-ray data taken from glass fragments by spectral overlay and/or semi-quantitative comparison of the ratios of the intensities of the x-ray emission peaks. However, the best comparisons can only be made between samples having relatively flat surfaces and similar shape morphologies [Ryland 2011; Naes et al 2008].

Several methods based upon inductively coupled argon plasmas (ICP) are gaining in popularity for the analysis of glass samples in forensic science laboratories. The inductively coupled plasmas are well-controlled, high- discharges that are used to excite and ionize elements that make up samples introduced into the plasma. Detection is made either by optical emission in ICP-OES instruments or mass spectrometry in ICP-MS instruments [Almirall et el., 2006]. ICP methods benefit from features such as nearly simultaneous multielemental capability, reduced matrix interference effects, wide linear dynamic ranges, and excellent precision and sensitivity. These attributes result in superior discrimination power compared to other methods of glass analysis [MoenkeBlankenburg et al., 1992; Koons et al., 1991, Wolnik et al., 1989, Zurhaar et al., 1990; Parouchais et al., 1996; Duckworth et al., 2000]. 
Initially, protocols using ICP-OES or ICP-MS for glass fragment analysis required dissolving the glass in a hydrofluoric acid-based mixture followed by evaporation to dryness to remove excess HF, and then reconstitution of the dissolved material in an acid matrix [Parouchais et al., 1996]. The resulting digest is aspirated into the plasma for analysis. The major drawbacks to these protocols are that they are rather time-consuming, require the use of hazardous reagents and can introduce contamination into the solution. ICP-MS instruments are normally 1-2 orders of magnitude more sensitive than ICP-OES, therefore allowing for the use of smaller glass fragments. A typical digestion of glass for ICP-OES analysis consumes 5 to $8 \mathrm{mg}$ per replicate, whereas ICP-MS requires only about 1 to $2 \mathrm{mg}$ per replicate measurement [Almirall et al., 2006].

To avoid the problems associated with dissolution, direct analysis of a solid glass sample can be accomplished by LA with introduction of the resulting aerosol directly into the ICP torch. Laser ablation can be coupled to either ICP-OES or ICP-MS instruments to simplify the analysis, significantly reducing not only the time and complexity of sample preparation but also the amount of sample consumption $(<0.3$ to $2 \mu \mathrm{g}$ per replicate) [Becker et al., 2003; Almirall et al., 2003; Trejos et al., 2005; Latkcoczy et al., 2005]. The main drawbacks to any ICP-based techniques are more expensive instrumentation, more challenging to operate, and currently available in only a few forensic science laboratories.

Although the aforementioned techniques are routinely used in forensic science laboratories worldwide, there is still a need for improved standardization of the methods within the forensic community. A preliminary effort towards this goal was reported by 
Becker et al. [Becker et al., 2011], where the discrimination potential of different techniques such as SEM-EDX, $\mu$-XRF, and ICP-MS was described. However, the work did not include comparisons to laser-based methods. The European Working Group (NITECRIME), using LA-ICP-MS only, conducted an analogous study on glass standards in the period 2001-2005 [Latkcoczy et al., 2005]. To the best of our knowledge, this is the first time that all three of these sensitive methods are directly compared to each other, not only based on their analytical performance but also based on their discrimination potential for glass evidence.

1.7 Fundamentals of laser-based spectrochemical methods for elemental analysis

Laser ablation spectrochemical methods, such as LA-ICP-MS and LIBS, are recognized as useful techniques for the elemental analysis of forensic evidence [Russo et al., 2011; Naes et al., 2008; Brends-Montero et al 2006; Bridge et al., 2006; RodriguezCelis et al., 2008; Cahoon et al., 2008; Trejos et al., 2005; Trejos et al., 2003; Almirall et al., 2003; Sarkar et al., 2010]

Both methods have in common the use of a short pulse laser beam to produce the ablation of the target material. In LA-ICP-MS, the removed particles are transported to an ICP-MS to be further atomized, ionized and detected by mass spectrometer. In LIBS, the optical emission from the laser-induced microplasma is collected, dispersed and sensed by a spectrograph detector [Russo et al., 1999; Russo et al., 2011]

Both of these processes of mass removal and formation of the microplasma occur during the laser ablation process, regardless of the selected collection/detection method. Nevertheless, in LA-ICP-MS the method parameters are optimized for an efficient 
production and transport of small submicron particles into the ICP-MS while in LIBS the method parameters are optimized for the formation of an efficient temporal micro-plasma and the collection of the emitted signal in the form of emission spectra.

Both laser ablation techniques can be used for quantitative and/or qualitative elemental analysis. In addition, LIBS can also be optimized for the analysis of molecular species as well as isotopic measurement [Russo et al., 20011; Mao et al., 2011]

The application of laser ablation methods to the elemental analysis of forensic matrices offers many advantages for solid sampling including a) the ability to perform direct, real-time and rapid micro-chemical analysis without need to conduct complex digestion protocols, b) minimal sample consumption and c) appropriate sensitivity and selectivity [Russo et al., 2011].

The following sections discuss in more detail the capabilities of each technique.

\subsubsection{Principles and capabilities of LA-ICP-MS}

Laser ablation is an alternative and versatile sample introduction technique for ICP mass spectrometry that enables the direct solid sampling without the use of chemical reagents for digestion of the samples. Laser ablation-ICP-MS can typically reach limits of detection in the order of low ppm to ppb, permiting trace and ultra-trace in-situ microanalysis.

Laser ablation-ICP-MS has many advantages over the solution ICP methods. When the analysis is carried out using laser ablation, the amount of sample consumed during the analysis is significantly reduced (i.e amount required per analysis can be reduced from milligrams to nanograms). The micro-destructive feature is particularly 
important in forensic sciences where the amount of evidence is often very limited and the preservation of the evidence after analysis is desirable for further testing or review at a later date [Almirall et al., 2006]. Moreover, the time of analysis is significantly reduced as well as the the potential for contamination from reagents and airborne particulate.

Laser ablation-ICP-MS is a mature technique whose fundamentals have been thoroughly studied and reported elsewhere [Koch et al., 2010; Almirall et al 2006; Evans et al., 2010; Russo et al., 2011]. A typical LA-ICP-MS setup consists of a laser, a CCD camera, an ablation cell and the ICP-MS, which is used as the secondary ionization source and analyzer. A solid material with little or no sample preparation can be placed directly inside the ablation cell, which is operated at ambient pressure. A CCD camera is typically used to observe the sample in a monitor and focus the laser beam into a specific area of interest. Once the laser is focused in or on the surface of the target material, the laser is fired. When the laser ablation energy threshold is reached, a cloud of fine particles or micro-droplets is removed from the sample. These particles are then transported by a carrier gas, usually argon or helium, and directed into the ICP plasma for atomization, ionization an analysis. The signal generated by the laser ablation process is called a "transient signal" where the intensity of the mass to charge ratio $(\mathrm{m} / \mathrm{z})$ of each analyte is monitored over time.

One of the most important parameters to select for a particular application is the laser wavelength. The wavelength depends on the type of material that emits the laser light, the lasers optical system and the way the laser is energized [Gonzalez et al 2002, Horn 2001; Koch et al., 2011]. 
Most forensic applications use ns-solid state lasers such as Nd:YAG lasers. The frequency of these lasers can be changed using a harmonic generator and therefore they could emit light at $1064 \mathrm{~nm}, 532,355,266 \mathrm{~nm}$ or $213 \mathrm{~nm}$ for different applications [Gonzalez et al., 2002].

Excimer lasers (excited-dimer) are also used in some applications. They use halogen glass-filled chambers rather than solid-state crystals. Their lasing wavelengths depend on the operating gas. For instance, rare-gas halides such as ArF can be operated at 193nm. These lasers are becoming more popular as a result of their ultraviolet wavelengths and short pulse duration.

The use of femtosecond lasers in LA-ICP-MS has many well-known advantages over nanosecond technology such as reduced fractionation, improved precision and improved measurement accuracy, although it is more expensive than ns lasers.

Once the laser wavelength has been selected, some of the parameters that are commonly adjusted to optimize a LA-ICP-MS method are the ablation mode, spot size, repetition rate, percentage of laser energy and respective irradiance and carrier gas used to transport the particles.

Although LA-ICP-MS is more sensitive than LIBS, the instrumentation and maintenance is more expensive. Other limitations of laser ablation include matrix dependence and the lack of solid calibration matrix-matched standards, which makes the quantification less straightforward than with solution analysis. 


\subsubsection{Principles and capabilities of LIBS}

The main components of a LIBS system is the pulsed laser, focusing mirrors/lenses, the ablation stage, the light collection system (lens, mirror or fiber optic) the detection system composed of the spectrometer that will filter or disperse the light and the detector and finally the computer that will process the data [Cremers et al., 2006].

A low energy pulsed laser is used in LIBS, typically in the order of 10 to 100 's $\mathrm{mJ} /$ pulse that is focused in or on the surface to generate a microplasma. That microplasma will produce the vaporization of small amounts of sample and the excitation of species present in the material. A portion of that plasma light is emitted by excited atoms and ions. The light is then collected and dispersed by a spectrometer. The detector records the signal of the emitted species, which is documented in the form of a spectrum of intensity versus wavelength. The generated spectra can be used as a fingerprint of the chemical composition of the emitting species [Cremers et al., 2006].

The generated microplasma is temporal and typically last few microseconds. The spectra changes as the plasma evolves and therefore the time for collection and detection of the species of interest is a fundamental factor that has to be optimized for each particular matrix [Russo et al., 2011].

In a typical $5-10 n s$ pulse laser, at early times the ionization of ions and atoms is very high. As the time evolves a recombination of electrons and ions occurs and neutrals and molecules form at this stage. During the plasma lifetime there will be also continuum background formed by photons emitted by electrons accelerated or decelerated by collisions. The continuum decays more quickly than the analytical spectral lines [Cremers et al., 2006]. 
As a result, the detector is typically gated to look at the signal once the continuum has decreased while the signals of interest become more relevant. The time between the initiation of the laser pulse and the opening of the detector window is called the gate delay. The detector will collect data for a specific time, usually 1-10 us. This is referred as the gate width [Cremers et al., 2006].

For a LIBS analytical signal to be efficient, the proper laser ablation threshold must be achieved. Typical irradiance for ns lasers ranges from $10^{8}$ to $10^{10} \mathrm{~W} / \mathrm{cm}^{2}$. In and on solid samples this threshold is sensitive to physical properties of the sample [Cremers et al., 2006].

There are different ways of improving the LIBS signal, all of which are well documented in the literature such as spectral resolution, gating, average of signals from many microplasmas, the use of double pulse lasers (either collinear or orthogonal), the ambient gas [Koch et al., 2011; Mogalaka 2006; Evans et al., 2010; Gornushkin et al., 2010; Wen et al., 2007; Lui et al., 2007; Gonzalez et al., 2002; Horn 2001]. As a result the appropriate selection of laser parameters is critical for getting good sensitivity and precision by LIBS.

Advantages of LIBS over LA-ICP-MS are extremely fast measurements, usually 30 seconds for multiple shot analysis (twice as fast as LA-ICP-MS); elemental analysis of elements that are difficult to analyze by ICP-MS such as $\mathrm{C}, \mathrm{N}, \mathrm{O}, \mathrm{Be}$ and $\mathrm{S}$ can be detected by LIBS; potential for portability, increase versatility and lower instrument cost and maintenance. Moreover, LIBS also allow the detection of molecular emission. Nevertheless, LIBS is not yet as sensitive, selective and mature as LA-ICP-MS. 


\subsection{Experimental}

\subsubsection{Instrumentation}

\subsubsection{Analysis of paper by LA-ICP-MS}

The LA-ICP-MS analyses were conducted on a quadrupole ELAN DRC II (Perkin Elmer LAS, Shelton CT USA), used in the standard operation mode. A $266 \mathrm{~nm}$ ns-Nd:YAG laser (LSX 500, CETAC, USA) was also used in this study. The analytical performance and discrimination capability of the following 39 isotopes was evaluated on paper matrices ${ }^{7} \mathrm{Li},{ }^{13} \mathrm{C},{ }^{23} \mathrm{Na},{ }^{24,25} \mathrm{Mg},{ }^{27} \mathrm{Al},{ }^{29} \mathrm{Si},{ }^{39} \mathrm{~K},{ }^{42} \mathrm{Ca},{ }^{45} \mathrm{Sc},{ }^{47,49} \mathrm{Ti},{ }^{52,53} \mathrm{Cr},{ }^{55} \mathrm{Mn}$, ${ }^{57} \mathrm{Fe},{ }^{59} \mathrm{Co},{ }^{60,62} \mathrm{Ni},{ }^{63,65} \mathrm{Cu},{ }^{64,66} \mathrm{Zn},{ }^{85} \mathrm{Rb},{ }^{88} \mathrm{Sr},{ }^{89} \mathrm{Y},{ }^{90} \mathrm{Zr},{ }^{103} \mathrm{Rh},{ }^{119,120} \mathrm{Sn},{ }^{137} \mathrm{Ba},{ }^{139} \mathrm{La}$, ${ }^{140} \mathrm{Ce},{ }^{142,143} \mathrm{Nd},{ }^{180} \mathrm{Hf},{ }^{206,207,208} \mathrm{~Pb}$.

\subsubsection{Analysis of paper by LIBS}

The LIBS analysis were conducted on a RT100HP system (Applied Spectra, Fremont, CA), equipped with a 1064nm ns-Nd:YAG laser and a Czerny Turner spectrograph (Princeton Instruments, NJ) with an ICCD detector (Gen II, Andor Technology , CT) and dual grating turret (operated at 2400 grooves/mm). The LIBS system has an automated X-Y-Z translational sample stage with a speed range of 1-20 $\mu \mathrm{m} / \mathrm{s}$. The analytical performance and discrimination capability of the following elements was evaluated for paper matrices for several emission lines of the elements $\mathrm{Na}, \mathrm{Mg}, \mathrm{Al}$, Si, Ca, Cr, Mn, Fe, Cu, Zn, Sr. 


\subsubsection{Reagents and standards}

For the optimization studies and the calibration curves, single element solutions of Sc, Ti, Cr, Mn, Fe, Co, Ni, Cu, Zn, Rb, Sr, Y, Zr, Rh, Sn, Ba, La, Ce, Nd, Hf, Pb at 1000 $\mu \mathrm{g} \mathrm{mL} \mathrm{m}^{-1}$ and $\mathrm{Na}, \mathrm{Mg}, \mathrm{Al}, \mathrm{Fe}, \mathrm{K}, \mathrm{Na}, \mathrm{Al}$ and $\mathrm{Ca}$ at $10000 \mu \mathrm{gmL}^{-1}$ (Peak performance, CPI International, USA) were used to prepare the stock solutions.

In-house matrix match standards were created to perform quantitative determinations. Whatman 42 filter paper was used as the support matrix for the preparation of the standards. External calibration and standard addition methods were used to characterize the paper standards. Calibration curves were then prepared by spiking the paper with $0.5 \mu \mathrm{L}$ of stock solutions ranging from $0.25 \mu \mathrm{g} / \mathrm{mL}$ to $2500 \mu \mathrm{g} / \mathrm{mL}$ for LA-ICP-MS and from $50 \mu \mathrm{g} / \mathrm{mL}$ to $2500 \mu \mathrm{g} / \mathrm{mL}$ for LIBS, depending on the element of interest.

The concentration units of the in-house standards and samples are reported in this document as $\mu \mathrm{g}$ of element by g of substrate (i.e paper). This estimation was conducted by weighing the amount of mass of standard spiked on the paper using an analytical microbalance (Cahn, USA). The mass was also corroborated with the theoretical value obtained by multiplying the concentration of the stock solution $(\mu \mathrm{g} / \mathrm{ml})$ by the volume of the micro-drop. The area of diffusion and distribution of the standard was then monitored by 3D microscopy (Keyence, USA) and SEM (Philips, the Netherlands) to determine the penetration depth and the surface area of deposition of the spiked mass. Finally, the mass of the substrate was estimated using the microbalance. At least 25 replicates were analyzed to estimate each standard concentration in $\mu \mathrm{g} / \mathrm{g}$. 


\subsubsection{Sample preparation}

Minimum sample preparation was required. The paper samples were cut into small squares $\left(\sim 2 \mathrm{~cm}^{2}\right)$, which were placed directly in the sample cell of the LA-ICP-MS and LIBS systems, respectively. All samples were stored in the dark in small paper envelopes, at room temperature.

\subsubsection{Sample collection}

The document paper selected for this study was common office paper $(8.5 \times 11$ inch, multipurpose/copy paper, white, 20lb). A total of 24 different sources of paper were purchased online as reams of 500 sheets, from which only 17 were used for the discrimination analysis because they did not present obvious visual/microscopic differences in color and texture. Three additional reams were provided from the manufacturer (International Paper, USA). The sample collection was composed of 20 different types of paper, from 7 different brands, manufactured at 10 different plants, all manufactured in the US. Table 4 summarizes the description of the paper sources. Some of the manufacturing information was provided to us confidentially. Therefore, for purposes of this document the sample identification number was assigned to leave the brand name and/or the name of the manufacturing plant anonymous.

The homogeneity and variation of the elemental composition in paper was studied within a single sheet, between pages that came from the same ream, between reams that came from the same production lot and between papers produced by the same plant at different time intervals. These studies were conducted on paper originating from four different brands. Within-sheet studies were conducted on five pieces of paper per sheet. 
Each of the five pieces of paper was cut into rectangles measuring $\sim 2 \mathrm{~cm}$ by $3 \mathrm{~cm}$. Five ablation replicates were conducted per sample, for a total of 25 replicates per sheet.

The within-ream studies were conducted by randomly selecting two sheets per ream and comparing 5 ablation replicates per sheet.

The within-production lots studies were conducted on three reams of paper provided directly by the manufacturing plant. These samples were chosen to be the same type and brand of paper produced in 2009 on July $30^{\text {th }}$, October $27^{\text {th }}$ and November $13^{\text {th }}$, respectively. Seven sheets were selected randomly from each ream and four replicates were conducted per sheet, for a total of 28 replicates per ream.

The discrimination and identification capabilities of each method were evaluated between papers from different brands. Five replicates per sheet were conducted on each of the samples.

2.1.5 Data reduction and statistical analysis

Data reduction and statistical analyses were performed by either the use of SYSTAT for windows (v.8.0, SPSS Science, Chicago, IL), JMP (v.5.0.1 SAS, NC), Excel 2003 (v9.0.2719, Microsoft Corp.,), Geopro (CETAC Technologies, v 1.0, NE), Plot for mac OSX (v.0.997, Berlin, Germany) or Mathematica (v. 5.2.0.0, IL) 
Table 4. Description of paper samples analyzed by LA-ICP-MS and LIBS

\begin{tabular}{|c|c|c|c|c|}
\hline $\begin{array}{c}\text { Sample } \\
\text { ID \# }\end{array}$ & $\begin{array}{c}\text { Brand } \\
\text { ID }\end{array}$ & $\begin{array}{c}\text { Paper type } \\
\text { (and recycled } \\
\text { content) }\end{array}$ & $\begin{array}{c}\text { Manufacturing } \\
\text { site }\end{array}$ & $\begin{array}{c}\text { Manufacturing } \\
\text { date }\end{array}$ \\
\hline 1 & A & $\begin{array}{l}\text { Multipurpose } \\
\text { Paper }(50 \%)\end{array}$ & Jackson, Alabama & Oct/16/2009 \\
\hline 2 & B & $\begin{array}{l}\text { Office Paper } \\
(0 \%)\end{array}$ & $\begin{array}{l}\text { Courtland, } \\
\text { Alabama }\end{array}$ & Oct/11/2009 \\
\hline 3 & B & $\begin{array}{l}\text { All-In-One Print } \\
\text { Paper }(0 \%)\end{array}$ & $\begin{array}{c}\text { Courtland, } \\
\text { Alabama }\end{array}$ & Aug/05/2009 \\
\hline 4 & A & $\begin{array}{c}\text { Recycled Paper } \\
(100 \%)\end{array}$ & Jackson, Alabama & Oct $/ 23 / 2009$ \\
\hline 7 & A & $\begin{array}{l}\text { Multipurpose } \\
\text { Paper }(0 \%)\end{array}$ & Jackson, Alabama & Oct/20/2009 \\
\hline 8 & $\mathrm{C}$ & $\begin{array}{l}\text { Multipurpose } \\
\text { Paper (100\%) }\end{array}$ & Boise, Idaho & unknown \\
\hline 9 & $\mathrm{C}$ & $\begin{array}{l}\text { Multipurpose } \\
\text { Paper }(30 \%)\end{array}$ & Jackson, Alabama & Nov/06/2009 \\
\hline 12 & $\mathrm{C}$ & Paper $(0 \%)$ & Boise, Idaho & unknown \\
\hline 13 & $\mathrm{D}$ & Copy Paper (0\%) & Wisconsin & Nov/29/2008 \\
\hline 15 & $\mathrm{E}$ & $\begin{array}{c}\text { Printing paper } \\
(0 \%)\end{array}$ & unknown & unknown \\
\hline 16 & $\mathrm{D}$ & $\begin{array}{l}\text { Multipurpose } \\
\text { Paper }(30 \%)\end{array}$ & Mississippi & Nov/22/06 \\
\hline 17 & $\mathrm{D}$ & $\begin{array}{c}\text { Printing paper } \\
(0 \%)\end{array}$ & New York & Nov/17/2009 \\
\hline 18 & B & $\begin{array}{c}\text { Laser Jet Paper } \\
(0 \%)\end{array}$ & Ticonderoga, NY & unknown \\
\hline 19 & $\mathrm{~B}$ & Laser Paper ( $0 \%)$ & Ticonderoga, NY & unknown \\
\hline 21 & $\mathrm{~A}$ & Laser Paper ( $0 \%)$ & Boise, Idaho & Jan/2011 \\
\hline 22 & $\mathrm{~F}$ & $\begin{array}{c}\text { Business paper } \\
(0 \%)\end{array}$ & Turner Falls, MA & unknown \\
\hline 23 & G & $\begin{array}{c}\text { Multipurpose } \\
\text { copy paper }(0 \%)\end{array}$ & Selma, Alabama & Oct $/ 27 / 2009$ \\
\hline 24 & $\mathrm{G}$ & $\begin{array}{l}\text { Multi-purpose } \\
\text { paper }(0 \%)\end{array}$ & Selma, Alabama & Nov/13/2009 \\
\hline 25 & G & $\begin{array}{l}\text { Multi-purpose } \\
\text { paper (0\%) }\end{array}$ & Selma, Alabama & July/30/2009 \\
\hline 26 & $\mathrm{C}$ & $\begin{array}{l}\text { Multi-purpose } \\
\text { paper }(100 \%)\end{array}$ & $\begin{array}{c}\text { Courtland, } \\
\text { Alabama }\end{array}$ & April/2009 \\
\hline
\end{tabular}




\subsection{Results and discussion}

2.2.1 Development and optimization of LA-ICP-MS method for the elemental analysis of paper

The optimal ablation parameters for LA-ICP-MS measurements depend first and foremost on the purpose of the analysis. The optimization has to be customized according to the type and characteristics of the matrix, the typical sample size consumption that could be afforded in real casework and the availability of reference standard materials.

In the case of forensic examinations of paper, the preservation of a document is fundamental and therefore the main challenge for the optimization of this method was to find the appropriate ablation parameters to produce the best analytical signal with a minimum damage to the material.

Multipurpose copy/printing paper is, in a macro-scale, a homogenous mixture of different raw materials, including pulp fiber, pigment particles, fillers and binders. Nonetheless, at the microscopic scale, the paper may become in some extent heterogeneous and as a consequence the understanding of how these raw materials interact with each other is essential in making decisions on sampling strategies and method optimization.

Common multipurpose paper such as the one of interest in this research has often a single coating layer above the base paper, which is applied to improve the surface quality. The thickness of this layer is not fully uniform and typically less than $10 \mu \mathrm{m}$. Higher quality printing papers and specialty papers may have more than one coating layer but they are out of the scope of this study. The ablation parameters were therefore 
optimized to sample enough material from both the coating layer and the base paper to obtain representative bulk chemical information.

Paper optimizations were conducted on standard Whatman 42 paper as well as on conventional multipurpose papers. Optimization of the laser parameters for the LA-ICPMS method included the study of different repetition rates $(2 \mathrm{~Hz}, 5 \mathrm{~Hz}, 10 \mathrm{~Hz})$, spot sizes $(100,200,250 \mu \mathrm{m})$, ablation rate $(10 \mu \mathrm{m} / \mathrm{s}, 15 \mu \mathrm{m} / \mathrm{s}, 25 \mu \mathrm{m} / \mathrm{s}, 35 \mu \mathrm{m} / \mathrm{s})$, flash lamp voltage $(20-40 \% \mathrm{E}$ in $5 \%$ increments) and length of the sampling area $(400-1200 \mu \mathrm{m})$. The optimum parameters are listed in table 5 , which provided good linearity $\left(\mathrm{r}^{2}>0.99\right)$, good sensitivity and good precision $(<10-15 \% \mathrm{RSD}$, depending on the concentration level).

Table 5. Optimized instrumental parameters for the analysis of paper by LA-ICP-MS

\begin{tabular}{|l|c|}
\hline Parameter & LAICPMS \\
\hline Laser & $266 \mathrm{~nm}, \mathrm{NdYAG}(9 \mathrm{~mJ}$ max $)$ \\
\hline Spot size & line \\
\hline Ablation mode & $25 \mu \mathrm{m} / \mathrm{s}$ \\
\hline Scan rate & 240 \\
\hline \# of shots & $200 \mu \mathrm{m} * 600 \mu \mathrm{m}$ \\
\hline Sampling area & $10 \mathrm{~Hz}$ \\
\hline Repetition rate & $35 \%$ \\
\hline Flash lamp voltage & $\mathrm{Na}, \mathrm{Al}, \mathrm{Zn}, \mathrm{Mg}, \mathrm{Sr}, \mathrm{Fe}, \mathrm{Mn}$, \\
& $\mathrm{Cu}, \mathrm{Ti}, \mathrm{Ba}, \mathrm{Zr}$ \\
\hline Element list & \\
\end{tabular}


The best ablation mode that removed enough paper material without ablating through the whole thickness of the document was the line mode. In this mode, the sample stage is moved at a constant rate while the laser interacts with the paper, limiting the penetration depth to less than $100 \mu \mathrm{m}$.

Figure 5 shows that the best precision was obtained using a frequency of $10 \mathrm{~Hz}$. Using frequency of $5 \mathrm{~Hz}$ and $2 \mathrm{~Hz}$ reduced too much the amount of ablated mass, affecting not only sensitivity but also precision of the measurements. This effect is shown in figure 6 , where the stability and intensity of the transient ablation signal for $\mathrm{Sr}$ on paper is improved at $10 \mathrm{~Hz}$ and scan rate of $25 \mu \mathrm{m} / \mathrm{s}$.

A low speed scan rate allows firing more shots per location and as a result the ablation line is shorter but the penetration into the paper is greater. For this reason, a balance between damage into the paper and length of the ablation mark must be found to minimize the overall damage of the paper. For example, it was found that lower speed rates such as $10 \mu \mathrm{m} / \mathrm{s}$ generated larger signals, however the damage on the paper was more pronounced as a result of the increased number of shots per substrate location. As a consequence this speed rate was eliminated from the optimization parameter options. A speed rate of $25 \mu \mathrm{m} / \mathrm{s}$ was found to be optimal in terms of precision and substrate microdestruction. 


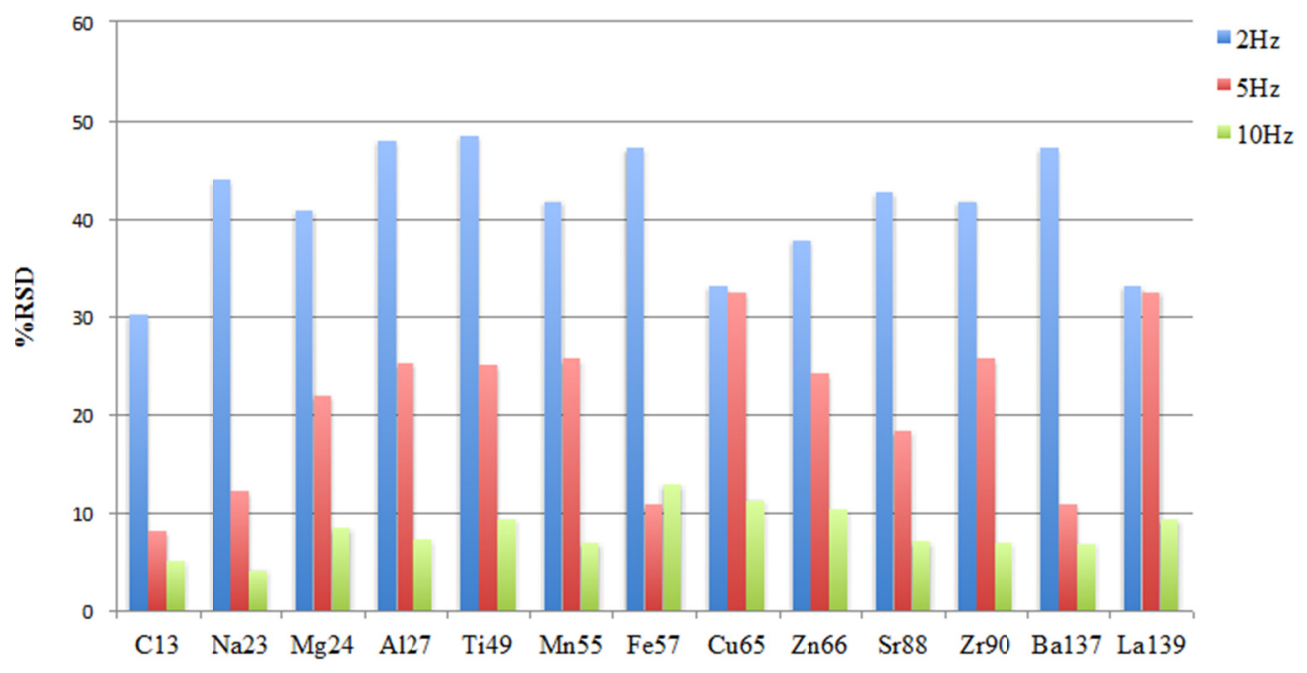

Isotope

Figure 5. Comparison of precision (\%RSD, $\mathrm{n}=7$ ) of multipurpose paper using LA-ICPMS at different frequency rates.

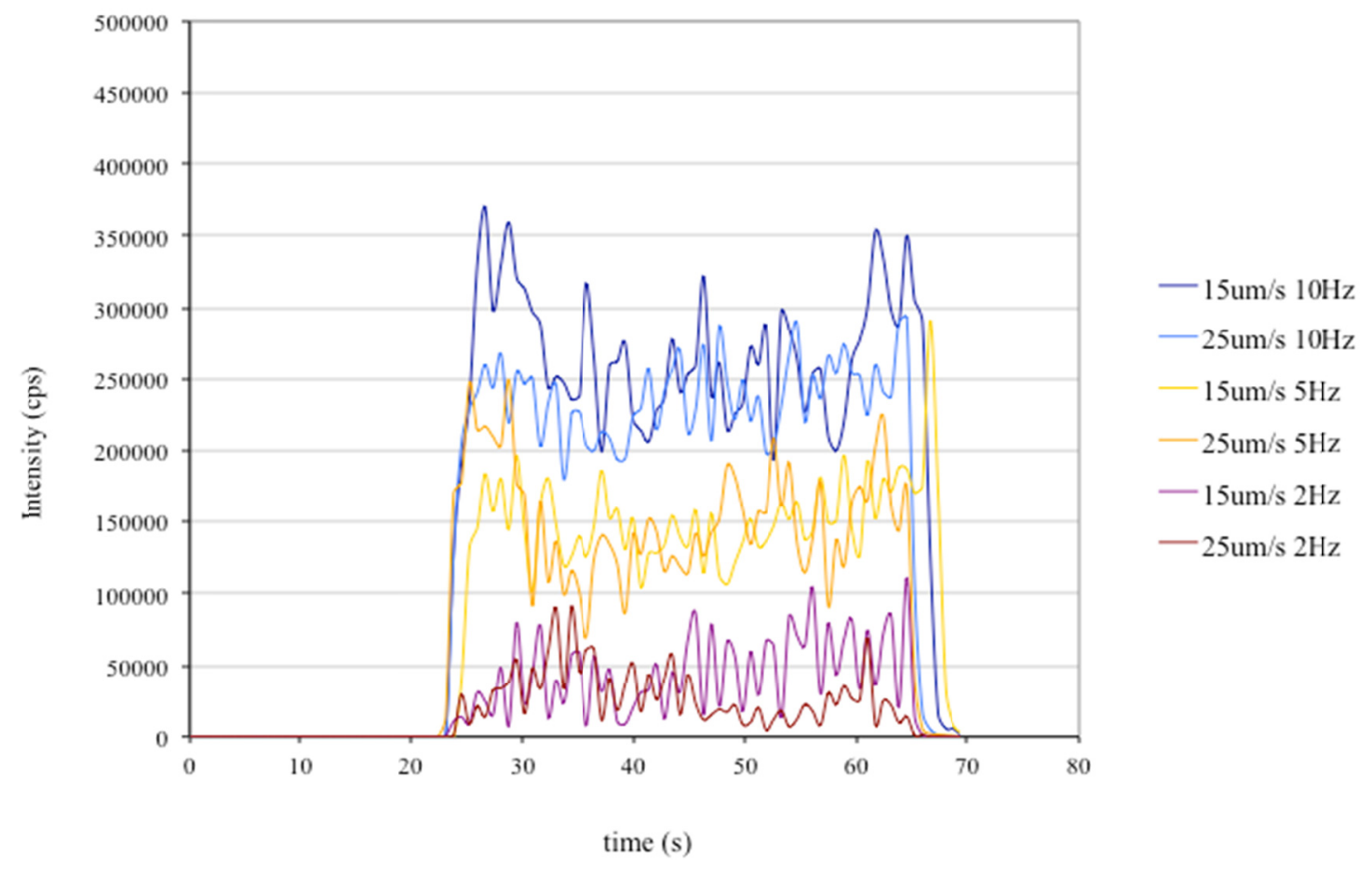

Figure 6. Comparison of signal intensity and signal stability of multipurpose paper using LA-ICP-MS at different frequency and ablation rates. 
The aim of the optimization of the spot size was to select the spot size that provided good sensitivity and representative composition of the bulk material with the smallest destruction of the sample.

The SEM images were obtained for different paper samples in order to estimate the chemical micro-heterogeneity. Figure 7 shows an example of typical size and distribution of chemical fillers (white spots) in the substrate. On the basis of these observations, spot sizes greater than $100 \mu \mathrm{m}$ were selected to account for possible heterogeneities at a microscopic scale. As a result, spot size of $100 \mu \mathrm{m}$ did not provided good sensitivity and/or reproducibility for some elements. Both, $200 \mu \mathrm{m}$ and $250 \mu \mathrm{m}$ spot sizes, produced signals with good intensity and precision below $15 \% \mathrm{RSD}$, therefore the smaller of this was selected to minimize the substrate damage.

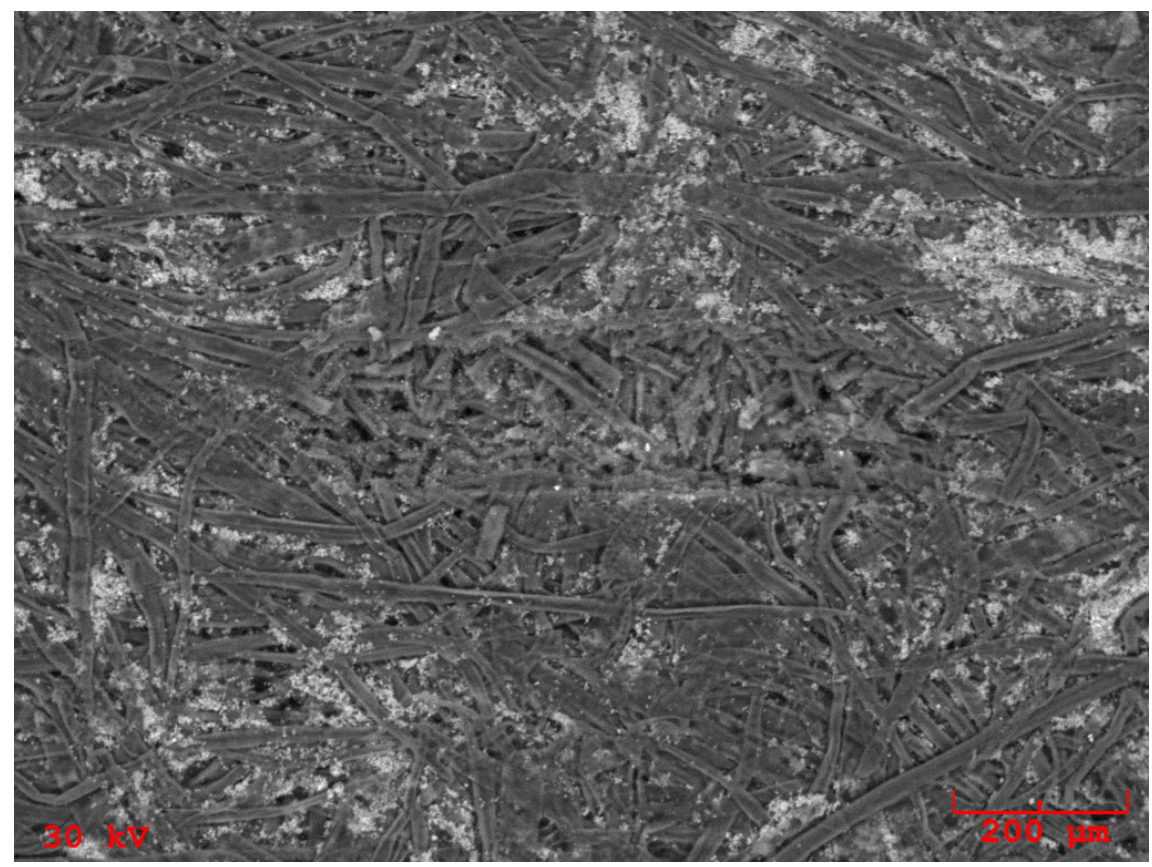

Figure 7. SEM image of paper surface at 100x magnification 
Another laser parameter of interest was the flash lamp voltage, which controls the amount of energy that the laser will deliver into the sample. For this purpose, different paper substrates were ablated at different energy levels (20-40\% energy in 5\% increments) and their respective laser ablation signals were monitored. It was found that below $25 \%(\sim 0.6 \mathrm{~mJ})$ there was not enough energy threshold to produce the ablation, while above $40 \%(\sim 1.9 \mathrm{~mJ})$ the laser ablated completely through the thickness of the paper. Therefore the optimization was focused in the range of $1.9 \mathrm{~mJ}$ to $0.6 \mathrm{~mJ}$. Laser energy of $35 \%(\sim 1.5 \mathrm{~mJ})$ was found to be optimal for the paper matrices under study. Figure 8 shows the SEM image of ablation marks left on the substrate using different energy levels.

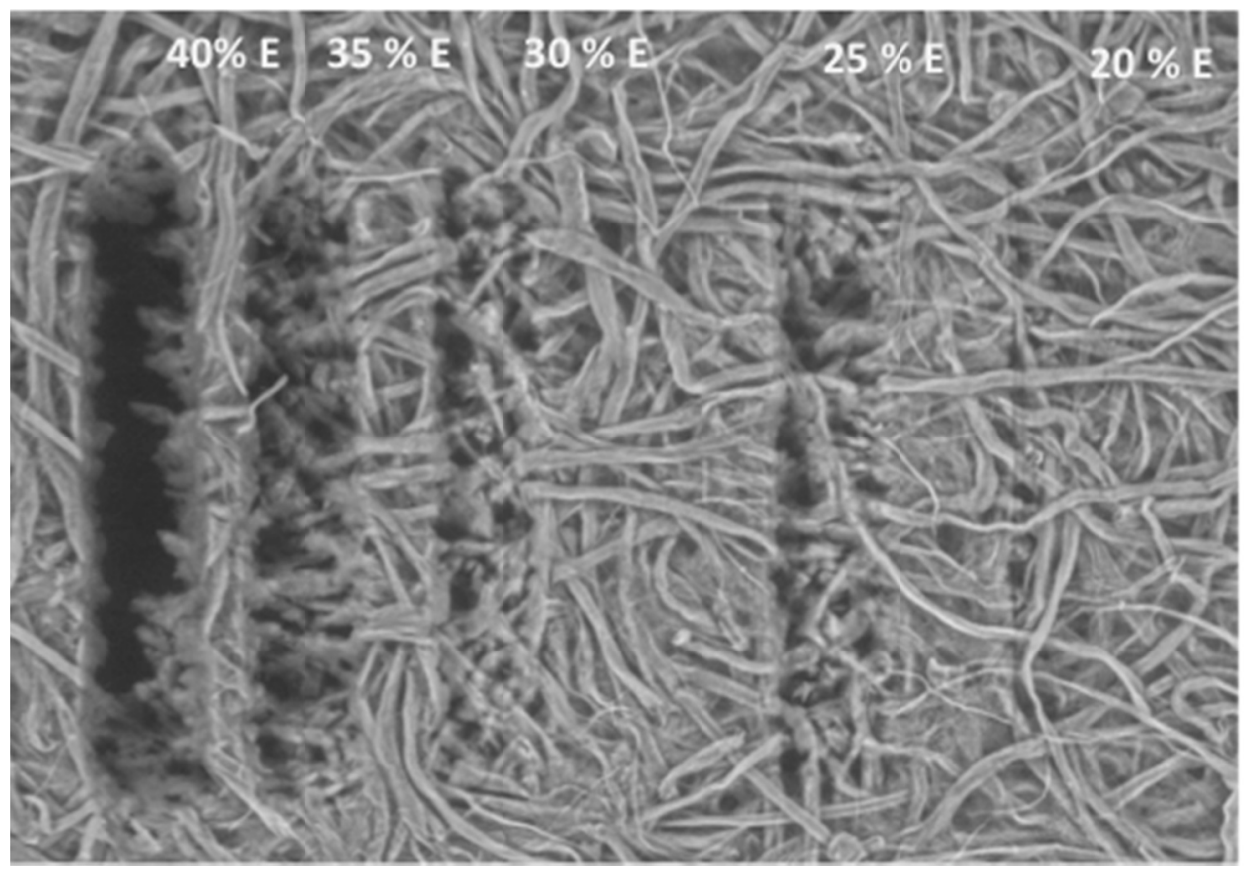

Figure 8. SEM image of ablation marks left on paper substrate after LA-ICP-MS at different energy levels. Image shown at 100x magnification 


\subsubsection{Calibration strategies}

Qualitative and quantitative analysis are possible by LA-ICP-MS. Both alternatives were explored for the analysis of paper, however it was found that most differences among elemental composition of paper where rather quantitative than qualitative.

Several calibration strategies for laser ablation analysis have been suggested for quantitative analysis of solid samples by the laser ablation method [Stix et al., 1995; Raith et al., 1996; Mokgalaka et al., 2006; Trejos et al., 2010].

One initial constraint for quantitative analysis was that there are no solid matrixmatched calibration standards available in the market for the elemental analysis of paper. Matched standards are indispensable for elemental analysis by laser ablation methods because the amount of mass ablated varies according to the sample matrix.

However, the physical and chemical properties of paper allowed the development of multiple home-made paper standards. As a result, external calibration with internal standardization using multiple point calibration curve was viable for laser ablation quantitative analysis (see figure 9).

A porous paper with low background of elemental composition (Whatman paper \#42) was used as the matrix-matched substrate. The paper was spiked with $0.5 \mathrm{uL}$ of stock solutions of increased concentrations and dried overnight. This generated standard areas of $\sim 0.5 \mathrm{~cm}$ of diameter per standard, which provided enough surface to conduct several ablation experiments. The solutions were initially spiked with ${ }^{103} \mathrm{Rh}$ as internal standard, which served also as a reddish-coloring agent to monitor the homogeneous distribution of the standard solutions into the paper. 
The paper and the in-house paper standards were acid-digested and analyzed by ICP-MS in order to corroborate accuracy and reproducibility among standards prepared at different days. The percent of recovery was estimated at different spike levels and found to be better than $96 \%$. The inter-day variation study demonstrated that the preparation method of the matrix-spike standards was reproducible $(<7 \% \mathrm{RSD})$. Good linearity was observed for the matrix-matched home-made standards.

Since the major component of document paper is cellulose $(\sim 80 \%)$, a low abundance carbon isotope was selected as an internal standard $\left({ }^{13} \mathrm{C}, 1.1 \%\right)$. The use of an internal standard is a common practice among laser ablation users to improve the analytical performance of the method by correcting for any difference of mass ablated between replicates. Other internal standards such as ${ }^{42} \mathrm{Ca}$ and ${ }^{103} \mathrm{Rh}$ were considered. Calcium is commonly present at high levels on document paper because it is used as filler $(\sim 15 \% \mathrm{wt})$, however it showed poor performance with poor signal repeatability ( $\sim$ RSD $>25 \%$ ) and poor reproducibility among different paper brands (\%RSD $15-40 \%)$. On the other hand ${ }^{103} \mathrm{Rh}$ worked as well as ${ }^{13} \mathrm{C}$ with the disadvantage that $\mathrm{Rh}$ has to be spiked into the sample prior the analysis while ${ }^{13} \mathrm{C}$ is already present at a fairly constant composition in the sample (see figure 9). 


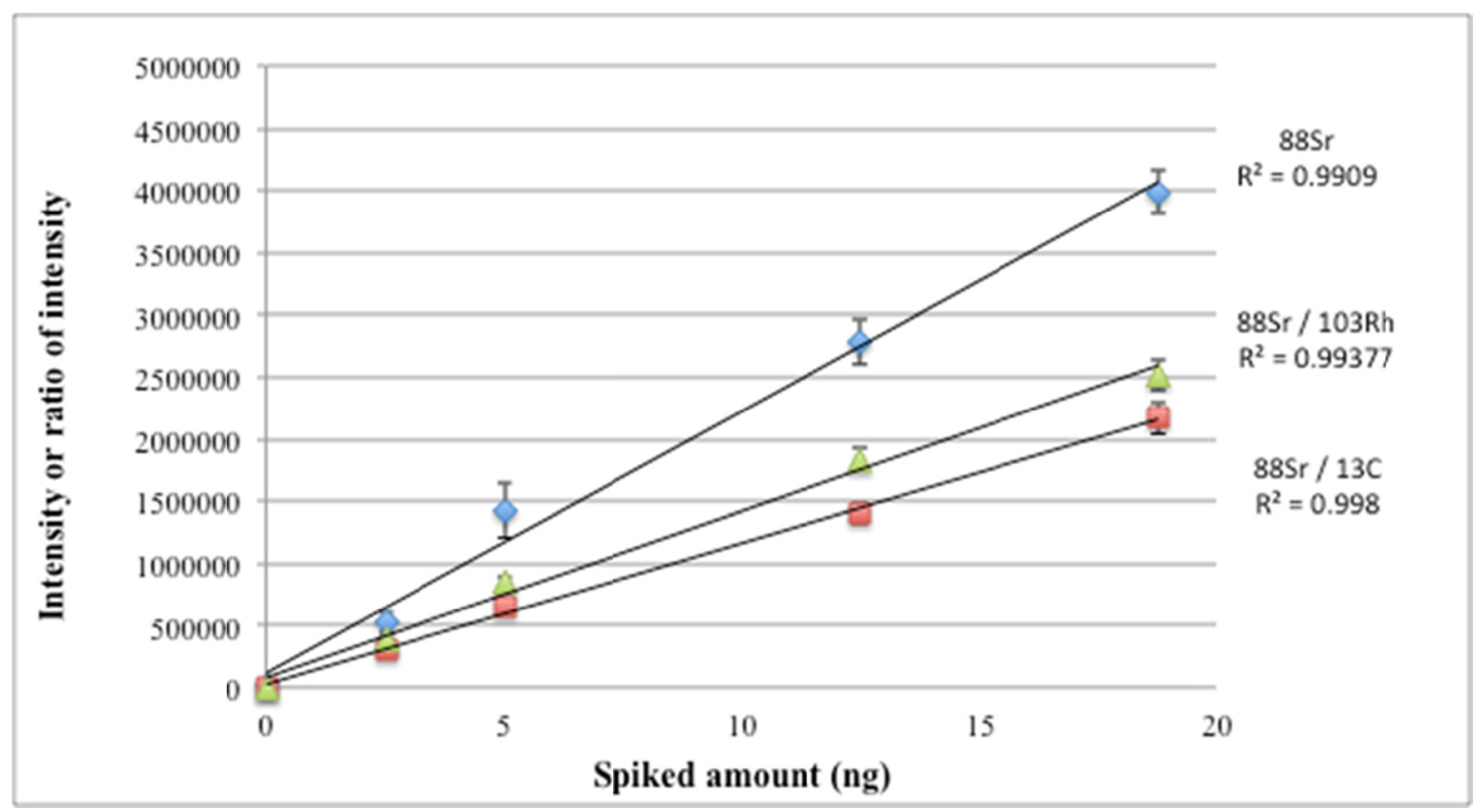

Figure 9. Calibration curves of spiked $\mathrm{Sr}$ in paper with and without internal standard

\subsubsection{Selection of the elemental list for LA-ICP-MS analysis of paper}

Once the ablation parameters were optimized, the most discriminating elements and isotopes were selected on the basis of the following criteria a) precision between replicates better than $15 \%$, b) homogeneous distribution within a source (sheet), c) presence above the limit of detection, d) linearity in the expected working range and e) good selectivity, f) low percentage of false exclusions and false inclusions and g) variability within a source (i.e. sheet/ream) significantly smaller than variability between sources (i.e different brands). The initial elemental menu for paper analysis by LA-ICPMS consisted of 39 isotopes from which ${ }^{7} \mathrm{Li},{ }^{45} \mathrm{Sc},{ }^{85} \mathrm{Rb},{ }^{89} \mathrm{Y},{ }^{103} \mathrm{Rh},{ }^{119,120} \mathrm{Sn},{ }^{139} \mathrm{La},{ }^{140} \mathrm{Ce}$, ${ }^{142,143} \mathrm{Nd},{ }^{180} \mathrm{Hf}$ and ${ }^{206,207,208} \mathrm{~Pb}$ were present below detection limit for the majority of the set of paper samples under study. The isotopes ${ }^{49} \mathrm{Ti},{ }^{59} \mathrm{Co}$ and ${ }^{60,62} \mathrm{Ni}$ had reproducibility 
between replicates greater that $20 \%$ and therefore were not selected as potential informing isotopes. The isotopes ${ }^{29} \mathrm{Si}$ and ${ }^{42} \mathrm{Ca}$ were monitored only qualitatively due to the large concentrations in samples, which complicated the preparation of matrixmatched standards $(>15 \% \mathrm{wt})$. The isotope ${ }^{39} \mathrm{~K}$ was rejected because of poor precision and non uniform distribution within the sheet. Chromium was present at large concentrations on the standard paper and therefore was not used for comparison purposes. The remaining eleven elements/isotopes met the criteria for good discriminators on paper by LA-ICP-MS analysis: ${ }^{23} \mathrm{Na},{ }^{24,25} \mathrm{Mg},{ }^{27} \mathrm{Al},{ }^{47} \mathrm{Ti},{ }^{55} \mathrm{Mn},{ }^{57} \mathrm{Fe}$, ${ }^{63,65} \mathrm{Cu},{ }^{64,66} \mathrm{Zn},{ }^{88} \mathrm{Sr},{ }^{90} \mathrm{Zr}$ and ${ }^{137} \mathrm{Ba}$.

As described in the introduction, these elements are likely originated from the raw materials and manufacturing process of the paper, such as fillers (Al, $\mathrm{Mg}, \mathrm{Ba}, \mathrm{Zn}$ ), pigments (Ti), detackifiers (Mg), sizing agents ( $\mathrm{Al}$ ), the chemical pulping liquor (Na) and other elements present in the pulp (i.e. $\mathrm{Mn}, \mathrm{Fe}, \mathrm{Cu}, \mathrm{Sr}$ and $\mathrm{Zr}$ ).

2.2.2 Development and optimization of LIBS method for the elemental analysis of paper Although the LIBS and LA-ICP-MS methods shared similar considerations in terms of the general purpose of analysis and nature of the sample, the laser and acquisition parameters for LIBS are focused in optimizing the optical emission of the laser-induced micro-plasma.

Optimization of the laser and detector parameters for the LIBS methods included the study of different laser shot repetition rates $(1 \mathrm{~Hz}, 2 \mathrm{~Hz}, 3 \mathrm{~Hz}, 4 \mathrm{~Hz}, 5 \mathrm{~Hz})$, line ablation mode moving the stage at different rates $(25 \mu \mathrm{m} / \mathrm{s}, 10 \mu \mathrm{m} / \mathrm{s})$, flash lamp energies $(25-40 \%$ 


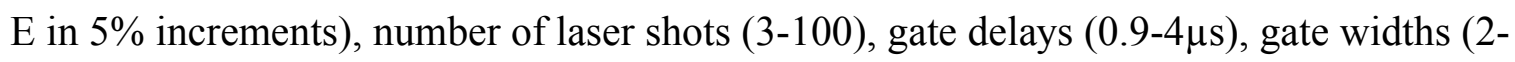
$10 \mu \mathrm{s})$ and detector gain (50-150).

The selection criteria for the optimized LIBS method parameters was determined by the following analytical factors: signal intensity (high signal to noise ratio), precision and reproducibility, maximum ink removal with minimum paper substrate removal, homogeneity, selectivity, informing power and linearity.

The optimum gate delay was selected based on the most intense signal possible with the highest signal to noise ratio and the lowest precision. A compromise between all these three criteria was found at 1.4 us for most of the elements of interest. Figure 10 shows an example of gate delay optimization for Sr II $(407.7 \mathrm{~nm})$ obtained from a standard paper spiked with $250 \mathrm{ng}$ of strontium.

Another critical parameter for the optimization of the LIBS method is the gate width or integration time. An optimized signal was observed at 4us gate width, where the precision was typically bellow $10 \%$ RSD while the signal to noise was the highest. Figure 11 shows an example of the gate width optimization for Sr spiked at $250 \mathrm{ng}$ in the paper standard.

In LIBS experiments, the signal from several laser shots fired into the sample can be accumulated in a spectra as a mean to increase the signal to noise ratio. Figure 12 shows an example of signal intensity obtained for $\mathrm{Sr}$ spiked at $35 \mathrm{ng}$, where it can be observed that at least 50 shots were necessary to achieve a good signal to noise ratio for Sr on paper at that concentration level. The best intensity and precision was achieved with the accumulation of 100 shots. Accumulation over 100 shots would probably raise the signal to noise ratio but would also be removing unnecessary amounts of material. 
Likewise, using similar decision criteria, the best analytical data was observed at laser frequencies of $3 \mathrm{~Hz}$ and speed rate of $10 \mathrm{um} / \mathrm{s}$. At $35 \%$ laser output $(\sim 6 \mathrm{~mJ})$ a compromise between signal intensity and paper damage was accomplished. The optimum performance metrics for LIBS measurements are listed in table 6.

Table 6. Optimized parameters for the analysis of paper by LA-ICP-MS and LIBS

\begin{tabular}{|l|c|}
\hline Parameter & LIBS \\
\hline Laser & line \\
\hline Spot size & $10 \mu \mathrm{mm} / \mathrm{s}$ \\
\hline Ablation mode & 100 \\
\hline Scan rate & $350 \mu \mathrm{m}$ \\
\hline \# of shots & $350 \mu \mathrm{m} * 1040 \mu \mathrm{m}$ \\
\hline Sampling area & $3 \mathrm{~Hz}$ \\
\hline Repetition rate & $35 \%$ \\
\hline Flash lamp voltage & $1.4 \mu \mathrm{s}$ \\
\hline Gate delay & $4 \mu \mathrm{s}$ \\
\hline Gate width & $\mathrm{Na}, \mathrm{Al}, \mathrm{Sr}, \mathrm{Ca}, \mathrm{Mg}$ \\
\hline Elemental list & \\
\hline
\end{tabular}



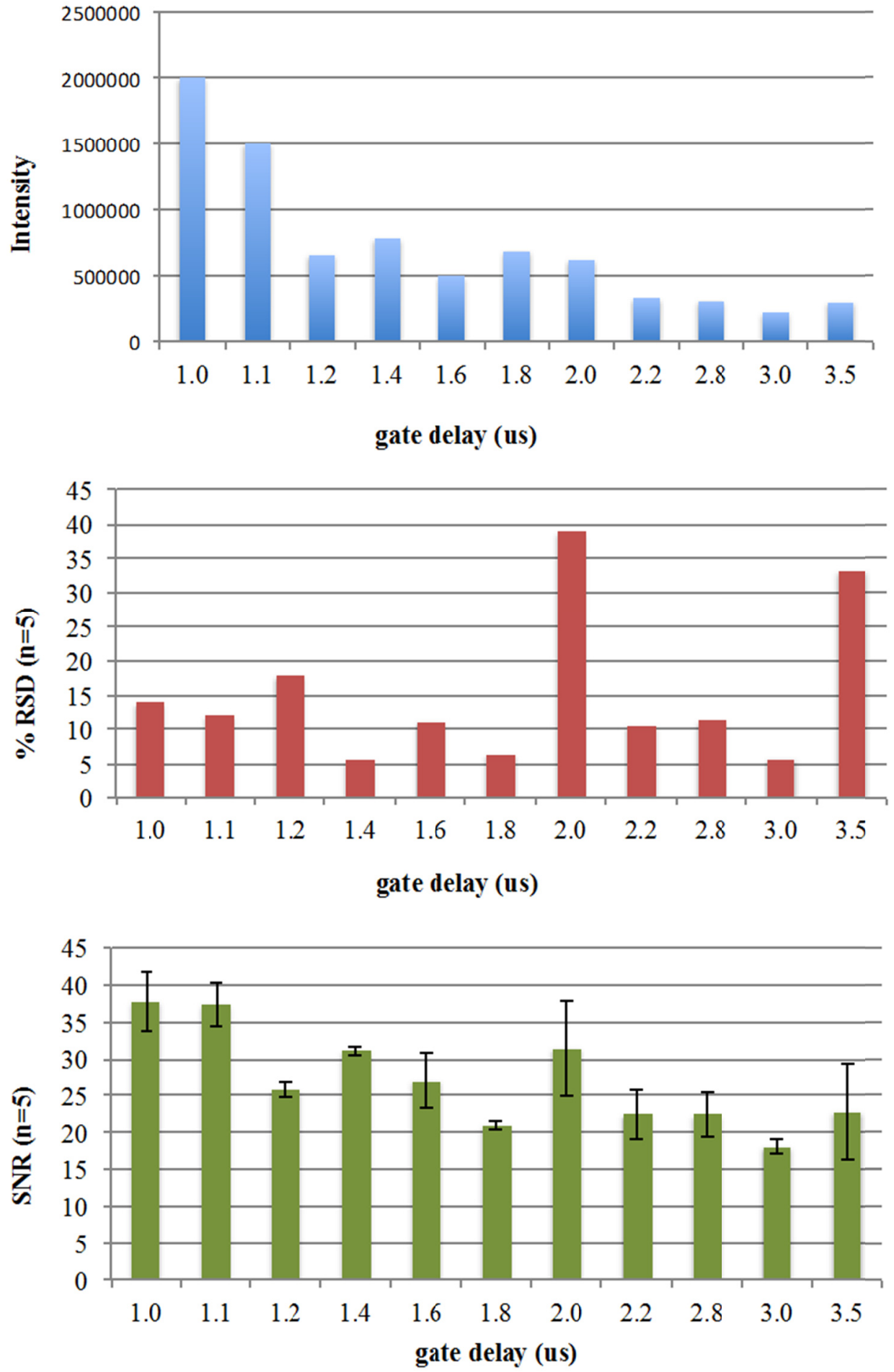

Figure 10. Optimization of gate delay for $\mathrm{Sr}$ spiked in paper ( $250 \mathrm{ng})$. Top to bottom: intensity response, precision (as \% RSD) and signal to noise ratio. 

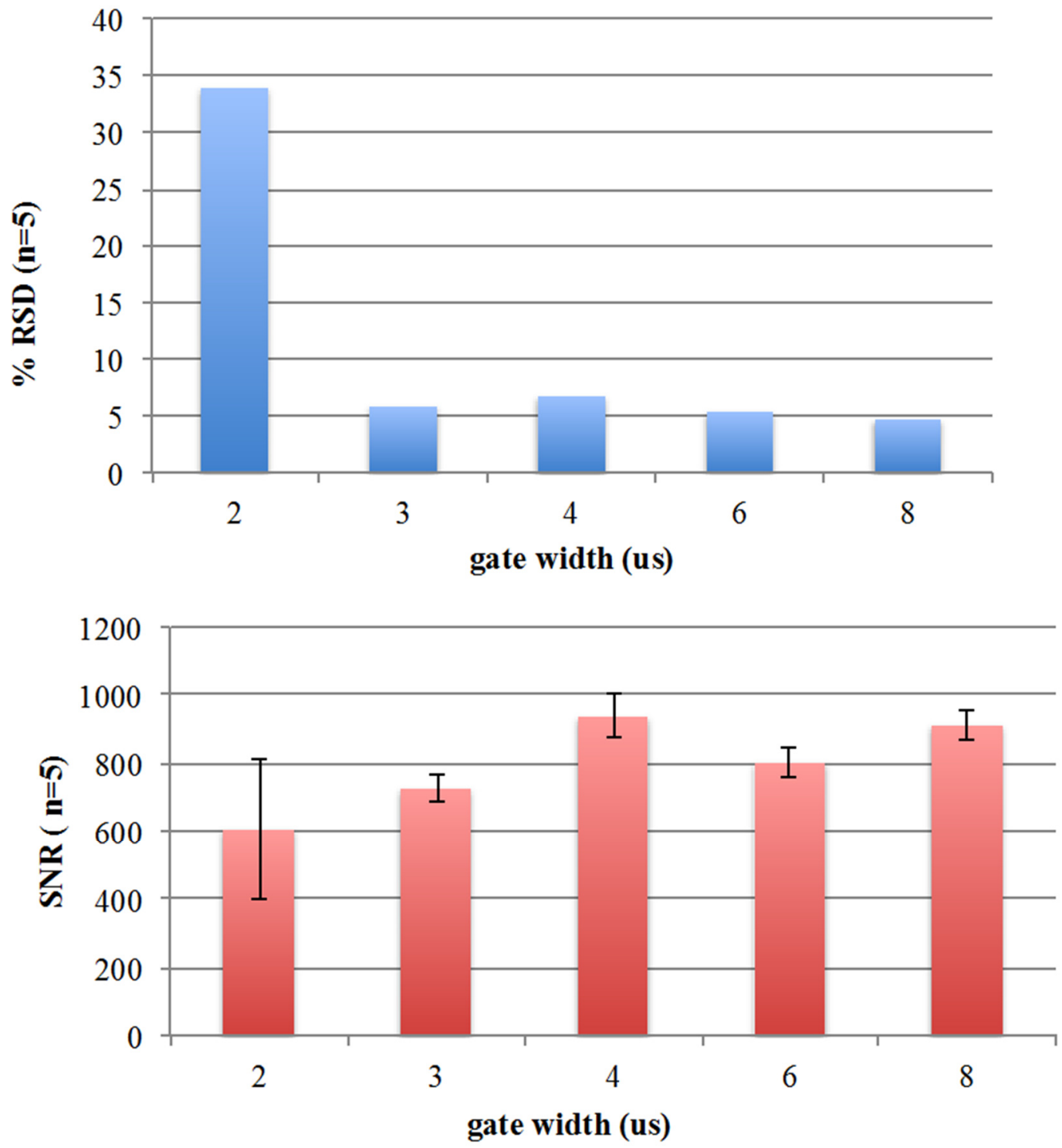

Figure 11. Optimization of gate width for Sr spiked in paper (250ng). Top to bottom: precision (as \% RSD) and signal to noise ratio. 

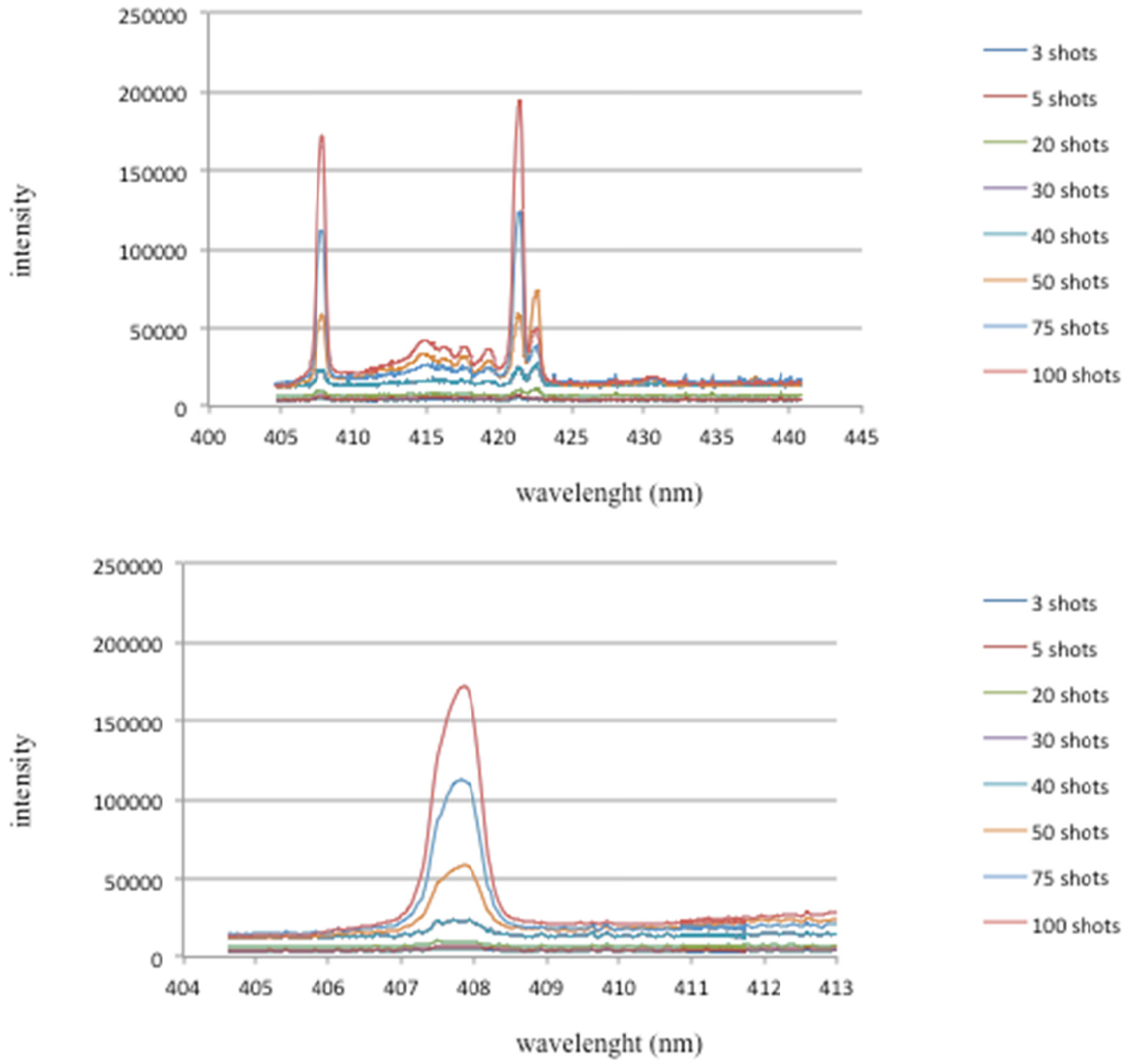

Figure 12. LIBS signal for $\mathrm{Sr} 421.5 \mathrm{~nm}$ (II) (top) and $\mathrm{Sr} 407.7 \mathrm{~nm}$ (II) (bottom) with different accumulation shots. 


\subsubsection{Calibration strategy and selection of the element list of LIBS}

The calibration strategy described for LA-ICP-MS was also applied to LIBS, where matrix-matched standards were created to do external calibration for quantitative analysis. Since LIBS is inherently less sensitive than LA-ICP-MS the concentration of the spiked solutions was adjusted according to its detection capabilities.

The elemental menu for paper analyzed by LIBS was initially based on the selected eleven elements that were found informative by LA-ICP-MS and in addition K, $\mathrm{Cr}$ and $\mathrm{Ca}$ were also monitored. Nine elements: $\mathrm{K}, \mathrm{Ti}, \mathrm{Zn}, \mathrm{Cu}, \mathrm{Cr}, \mathrm{Mn}, \mathrm{Zr}, \mathrm{Ba}$ and $\mathrm{Fe}$ were rejected from the elemental menu because of poor precision (>20\%RSD) or because these were masked by other emission lines and/or not detected at the typical concentration levels in the samples. The remaining five elements: $\mathrm{Na}, \mathrm{Mg}, \mathrm{Al}, \mathrm{Ca}$ and $\mathrm{Sr}$ were selected for comparison purposes.

The LIBS methods may suffer from spectral interferences and/or self-absorption and therefore the emission lines were carefully selected to avoid potential matrix interferences. The selected emission lines for quantitative analysis of paper were Na (I) 330.2nm, Mg (II) $280.2 \mathrm{~nm}, \mathrm{Al}$ (I) $308.2 \mathrm{~nm}, \mathrm{Sr}$ (II) $407.7 \mathrm{~nm}$ and $\mathrm{Ca}$ (I) $585.7 \mathrm{~nm}$. The resolution of the LIBS system used in this study is $\sim 0.1 \mathrm{~nm}$, therefore the emission lines are reported only with one decimal. One emission line per element was selected for discrimination between samples in order to avoid redundancy on multivariate comparisons. Nevertheless, at least 2 to 3 different emission lines were monitored qualitatively to confirm the presence of each element of interest. Sodium was also monitored at $330.2 \mathrm{~nm}(\mathrm{I}), 588.5 \mathrm{~nm}$ (I) and $589.5 \mathrm{~nm}$ (I). Good linearity was observed for all 3 emission lines, except for $588.5 \mathrm{~nm}$ (I) and $589.5 \mathrm{~nm}$ (I) on samples with 
concentrations above $3000 \mu \mathrm{g} / \mathrm{g}$ as a result of self absorption. The aluminum emission lines were monitored at $308.2 \mathrm{~nm}$ (I), 309.3nm (I), 394.6nm (I) and $396.2 \mathrm{~nm}$ (I). Good linearity was achieved for all lines from 0 to $5000 \mu \mathrm{g} / \mathrm{g}$ on the standard papers, however lines at $394.6 \mathrm{~nm}$ and $396.2 \mathrm{~nm}$ were rejected for quantitative comparison purposes as a result of poor resolution from the Ca peak when the calcium level was above $2 \%$ in the samples. Screening of $\mathrm{Sr}$ was conducted at $407.7 \mathrm{~nm}$ (II) and $421.5 \mathrm{~nm}$ (II), however only qualitative information was obtained from the $421.5 \mathrm{~nm}$ emission line because of the presence of an intense signal of calcium at $422.6 \mathrm{~nm}$ on real samples that prevented a baseline separation between the lines. Magnesium lines were monitored at 279.4nm (I), $280.2 \mathrm{~nm}$ (II), $517.3 \mathrm{~nm}$ (I) and 518.4nm (I). Calcium lines were screened at $585.7 \mathrm{~nm}$ (I), 315.1nm (I), 300.4nm (II) and 301.4nm (I). All emission lines for $\mathrm{Mg}$ and $\mathrm{Ca}$ were appropriate for quantitative analysis, but only one of them were used per element as explained above,

The LIBS system used for these studies used a Czerny Turner spectrograph and therefore it was limited to measure sequential channels of $\sim 50 \mathrm{~nm}$ each and consequently it was impractical to select an internal standard for each of the channels since the paper samples would have to be spiked with the mixture of internal standards. La, Y and Ce were also tested as potential internal standards but appropriate emission lines were not present at all five channels. Moreover, carbon the major component of paper is not a good emitter for LIBS. 
2.2.3. Comparison of figures of merit of laser ablation methods for paper analysis

A comparison of the figures of merit between the LA-ICP-MS and the LIBS methods is found in table 7. The selected elements/isotopes and emission lines were linear at the concentration range of the samples $\left(\mathrm{r}^{2} 0.999\right.$ to 0.989 for LA-ICP-MS, 0.997 to 0.984 for LIBS). Limits of detection were suitable for the typical concentration range found in the sets of real samples. Fewer elements were measured by LIBS mainly because of a) limitations in multi-elemental capability of the restricted spectral channel (Czerny Turner set up), b) concentration range of some elements were below detection limit.

The SEM imaging and microscopic photography was conducted to assess the crater morphology produced by the lasers. As a result of the instrumental configurations used at the time of this research, the LA-ICP-MS experiments were conducted with a 266nm laser while the LIBS experiments were collected using a 1064nm laser.

The craters produced by the $1064 \mathrm{~nm}$ LIBS laser are larger in diameter and less uniform than the ones produced by the $266 \mathrm{~nm}$ laser (LAICPMS). On the other hand, LA craters are deeper than LIBS and penetrate more into the substrate. Nonetheless, the total amount of paper removed per analysis is similar between both methods, in the order of $15 \mu \mathrm{g}$ per replicate (see table 7).

\subsubsection{Evaluation of the discrimination potential of LIBS and LA-ICP-MS}

For forensic purposes, a method should provide good analytical performance but most importantly, it has to be validated to demonstrate its relevance if used as a tool to generate potential evidence in court. 
In this context, an ideal method should provide sufficient discrimination capabilities in order to determine whether two sheets of paper originated from the same or different sources. The discrimination capability of a method depends on several factors such as: a) good precision of the measurements; b) good selectivity; c) uniform distribution of the elemental composition within the sample (i.e within the sheet); d) significantly large variation of the elemental composition between one paper source and another. For these reasons, the first step before evaluating the overall discrimination power of the methods was to understand the variability of the elemental composition within a source (within a sheet and within a ream).

Table 7. Figures of merit for the methods used for paper analysis.

\begin{tabular}{|c|c|c|c|c|c|}
\hline \multirow[b]{2}{*}{ Element } & \multirow[b]{2}{*}{$\begin{array}{l}\text { Sample set } \\
\text { concentration } \\
\text { range } \\
\mu \mathrm{g} \mathrm{g}^{-1}\end{array}$} & \multicolumn{2}{|c|}{ LA-ICP-MS - Paper } & \multicolumn{2}{|c|}{ LIBS -Paper } \\
\hline & & $\begin{array}{c}\text { LAICPMS } \\
\text { LOD } \\
\text { (ug/g) }\end{array}$ & $\begin{array}{c}\text { LAICPMS } \\
\text { precision } \\
(\% \mathrm{RSD})\end{array}$ & $\begin{array}{l}\text { LIBS } \\
\text { LOD } \\
(\mathrm{ug} / \mathrm{g})\end{array}$ & $\begin{array}{c}\text { LIBS } \\
\text { precision } \\
(\% \text { RSD })\end{array}$ \\
\hline $\mathrm{Na}$ & $500-4300$ & 1.0 & 6 & $\begin{array}{c}690(\mathrm{Na} I \\
330.2)\end{array}$ & 10 \\
\hline $\mathrm{Mg}$ & $\begin{array}{c}1000-500 \\
0\end{array}$ & 0.2 & 7 & $\begin{array}{c}47(\mathrm{Mg} \mathrm{II} \\
280.2)\end{array}$ & 10 \\
\hline $\mathrm{Al}$ & $112-2750$ & 0.3 & 4 & $\begin{array}{c}136(\mathrm{Al} \mathrm{I} \\
308.2)\end{array}$ & 9 \\
\hline $\mathrm{Ti}$ & nd- 300 & 5.1 & 3 & & \\
\hline $\mathrm{Mn}$ & nd-21 & 0.2 & 5 & & \\
\hline $\mathrm{Fe}$ & $50-500$ & 1.4 & 5 & & \\
\hline $\mathrm{Cu}$ & nd-4 & 0.1 & 5 & & \\
\hline $\mathrm{Zn}$ & nd-10 & 0.4 & 3 & & \\
\hline $\mathrm{Sr}$ & nd- 150 & 0.04 & 4 & $\begin{array}{c}14 \text { (Sr II } \\
407.7)\end{array}$ & 16 \\
\hline $\mathrm{Zr}$ & nd-5 & 0.07 & 10 & & \\
\hline $\mathrm{Ba}$ & nd-40 & 0.02 & 3 & & \\
\hline $\begin{array}{c}\text { Mass } \\
\text { removed }\end{array}$ & & $14 \pm 2 \mu \mathrm{g}$ & & $15 \pm 1 \mu \mathrm{g}$ & \\
\hline
\end{tabular}


2.2.4.1 Results for micro-homogeneity and within-source variation of elements on paper

Since the amount of mass being removed by the laser-methods is on the order of few micrograms, a homogeneity test was conducted to determine if the elements of interest were uniformly distributed throughout the paper sheet and to determine if the chemical composition of that micro-sample is representative from the bulk. These studies were conducted on paper originating from four different brands (described in Table 4 as ID \# 17, 22, 23 and 26). Five small pieces were randomly cut from different locations on each sheet of paper. Five ablation replicates were analyzed per piece, for a total of 25 replicates per sheet. Pairwise comparisons for all the 11 elements of interest were conducted between the five pieces of paper using analysis of variance with post-hoc Tukey's test at 95\% confidence. No significant differences were found in the elemental compositions of the five pieces of the four brands analyzed, supporting the hypothesis that the selected elements were uniformly distributed within a single sheet even at a micro-scale. Figure 2 shows the distribution of $\mathrm{Sr}$ within different areas on a sheet of paper as an example.

Studies of the variation within reams were conducted by randomly selecting two sheets per ream and comparing five ablation replicates per sheet. Statistical comparisons for all the 11 elements of interest were conducted between each pair of sheets that came from the same ream, using t-test with Bonferroni correction at 95\% confidence. No significant differences were found between the sheets in each ream of three of the four brands analyzed. Figure 13 shows the mean values and standard deviations of the concentration of strontium in two sheets from the same ream. Nevertheless, one of the paper types presented significant within-ream differences in the composition of $\mathrm{Ti}, \mathrm{Zn}$ 
and $\mathrm{Ba}$. The paper was the only one from this sub-set that was $100 \%$ recycled paper suggesting that this could be the source of larger variability.

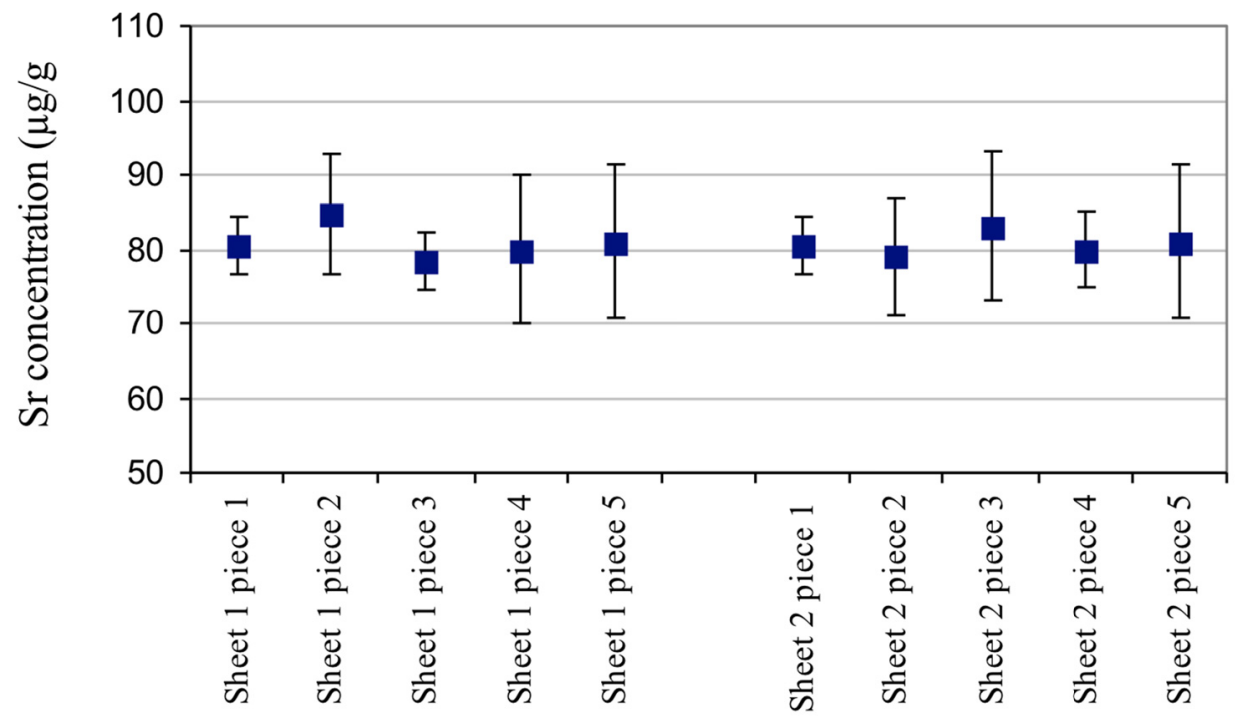

Figure 13. Variation of Strontium within a sheet of paper and between two sheets of paper from the same ream

Moreover, according to telephone survey conducted at FIU it is possible that a ream of paper may be made up of alternating sheets from different rolls and therefore the elemental composition may be distinguished by sensitive methods. Thus, in actual casework, it is recommended to characterize the variability within a ream by sampling, whenever possible, at least four sheets from the same ream or the known comparison sample. In multi-page documents, where a known ream is not available, it is recommended to sample different sheets from the known document as a way to characterize the variability. 
The study of the variability within-production batches was conducted on three subsets: a) three reams of paper provided directly by the manufacturing plant, they were the same type and brand and produced in the same paper plant and mill in 2009 on July $30^{\text {th }}$, October $27^{\text {th }}$ and November $13^{\text {th }}(25 \mathrm{G}, 23 \mathrm{G}$ and $\left.24 \mathrm{G}) ; \mathrm{b}\right)$ two reams of paper produced by the same manufacturing company as the first subset but processed in different mills and sold under different brand names (2B and 3B); c) three reams of paper sold under the same brand, manufactured by the same company, processed at the same mill, days to weeks apart, produced with different percentage of recycled paper $(1 \mathrm{~A}, 4 \mathrm{~A}$, $7 \mathrm{~A})$.

Seven sheets were selected randomly from each ream of the first set and four replicates were conducted per sheet, for a total of 28 replicates per ream. It was observed for this set that 4 sheets per ream provided sufficient description of the elemental composition within a ream. Therefore the rest of the study for the second and third set used only 4 sheets per ream.

Figure 14 shows that the elemental profile of the 3 batches produced in the same mill is similar but still significant differences were found between samples manufactured 3 months apart (25G July vs $23 \mathrm{G}$ Oct, $24 \mathrm{G}$ Nov). Moreover, significant differences in the overall elemental profile were observed between these 3-batch sets and a second sub-set of two additional samples, ID \#2 and \#3, which were manufactured by the same company, in the same month/year, using similar pulp and raw materials but processed at different mills. Finally, differences in the elemental profile were observed from samples that were manufactured in the same mill, produced just days apart. Samples described as 
1,4 and 7 have a content of recycled material of $50 \%, 100 \%$ and $0 \%$ respectively (see figure 14).

The results show that batches manufactured at short intervals (days to months) in the same mill can be differentiated using elemental analysis. The ability to detect those inter-batch differences depends on the control and standardization of the raw materials used in the mill, including the percent of recycled paper

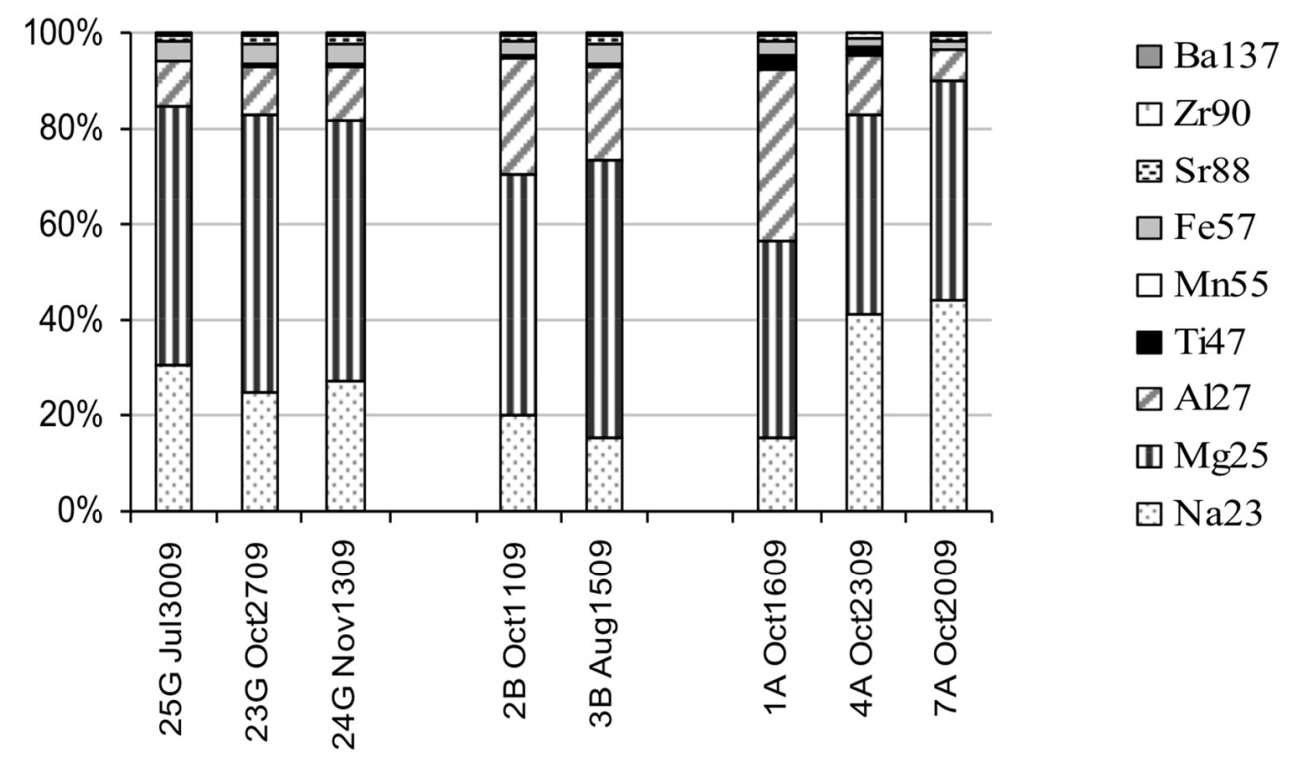

Figure 14. Normalized elemental profile from document paper collected from three different brands (brands G, B and A), processed in different mills and production batches.

A principal component analysis plot (PCA) for the same sub-set is shown in figure 15. Principal component analysis is used as a data reduction technique to aid in the visualization of grouping of multivariate data sets. Principal component analysis was 
applied to the multi-elemental composition of papers sources to determine whether or not there is grouping of the paper sources by manufacturing location and production time.

Several principal components were generated on JMP (v.5.0.1 SAS, NC) which are linear combinations of the original variables (elemental composition) and are calculated in such way that the first principal component (PC1) is the linear combination of the standardized original variables that accounts for most of the variance in the data set. Each subsequent principal component is the linear combination of the standardized original variables that has the next largest variance and is uncorrelated with all previously defined components (PC2, PC3 and so on)

This statistical test has the restriction that each new component should be uncorrelated with the previous ones, ensuring that each successive principal component will have a lower variance than its predecessor. For these reason, typically the first 2 or 3 principal components confine most of the sample variation. In the data set shown in figure 15 the first two components represent $\sim 78 \%$ of the variance of the data, which allowed a clear grouping of the data. Paper sheets from the same mill, produced about the same time can be statistically differentiated but still cluster together as a result of similar composition. An exception to this hypothesis is observed for samples manufactured in the same mill but with different recycled content, which is a consequence of the variability added by the origin and content of the recycled paper. 


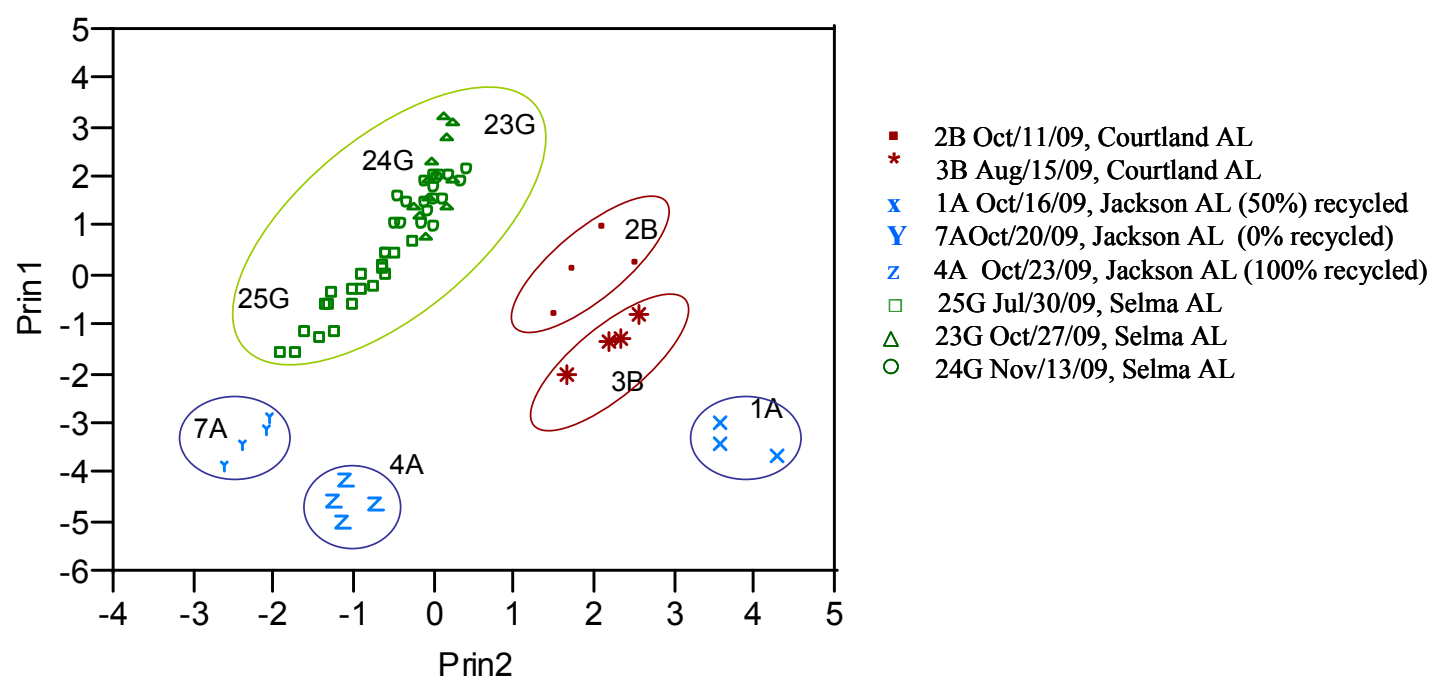

Figure 15. Results from principal component analysis of LA-ICP-MS data, showing differentiation and grouping of the paper samples produced in different mills/batches. Principal component 1 (Prin1) and principal component 2 (Prin2) describe 51.5\% and $26.1 \%$ of the total variance of the data, respectively.

\subsubsection{Results for differentiation and identification of paper}

In this research, the ability of a method to differentiate samples originated from different sources is evaluated by estimating the percent discrimination power (Dp) as:

$$
\% \mathrm{DP}=100 *[1-(\mathrm{Ip} / \mathrm{Cp})]
$$

Where Ip is the number of indistinguishable pairs and $\mathrm{Cp}$ is the total number of possible comparison pairs.

The total number of possible comparison pairs between samples it estimated as:

$$
\mathrm{Cp}=[\mathrm{n}(\mathrm{n}-1) / 2]
$$

Where $\mathrm{n}$ is the number of samples originated from different sources. Since a collection set could have certain number of duplicate samples originated from the same 
source, those pairs are subtracted from the total $\mathrm{Cp}$ value to avoid overestimating the discrimination capabilities.

The false inclusion rate is estimated as:

$$
\% \text { false inclusions }=100-\% \mathrm{DP}
$$

To evaluate the false exclusion rates, only those pairs known to belong to the same source (ss) are used to estimate the rate (i.e duplicate samples).

$$
\% \text { false exclusions }=100 *\left(\text { differentiated pairs }{ }_{\mathrm{ss}} / \mathrm{Cp}_{\mathrm{ss}}\right)
$$

For each collection set, the overall discrimination power is calculated as the sum of the individual discrimination power of each element. Two paper samples are considered different if at least one of the monitored elements is significantly different.

Using this method, a total of 17 different paper sources were used to test the discrimination or informing power of the methods. Samples described in Table 4 as \#1 to \#23 were used for this comparison study, representing 17 paper samples from 7 different brands, manufactured at 10 different plants in the US. In addition, duplicate control samples were also randomly selected and analyzed as "unknown" blind samples to determine whether or not they were correctly identified by their elemental composition. The combined discrimination power of the elements was found by pairwise comparison using analysis of variance (ANOVA) and Tukey's HSD test. A total of 171 possible comparison pairs can be generated when all seventeen samples are compared to each other. Table 6 shows that $99.4 \%$ of the seventeen sources were correctly differentiated by their elemental composition, when LA-ICP-MS is used as the method of analysis. The only pair of samples that was not differentiated (\#18 and \#19) belongs to the same paper brand manufactured in the same plant and mill, which is consistent with results 
previously discussed. Although the LIBS method is less sensitive than LA-ICP-MS, it still provided very good discrimination (97.7\%) because the concentration range of the target elements is still above the method detection limit. Only 2 out of 171 pairs were not differentiated by LIBS (\#18 and 19, \# 18 and 17), one of the pairs corresponds to the same pair indistinguishable by LA-ICP-MS and the other pair were samples manufactured in the same state, same paper plant and mill but sold under different brands. Moreover, the duplicate "unknown" samples were correctly identified by the elemental composition measured by both laser-based methods, providing no false exclusions for this set.

The results show that, different brands of papers can be clearly differentiated by elemental composition. Since the variability within replicates of a sheet/ream is smaller than the variation of the concentration between different samples, both methods are able to detect statistically significant differences in concentration from one paper source to another. Figure 5 shows an example of the variation within samples (represented by the error bars and by the reproducibility within control duplicates) and the overall variation between samples. Even samples from the same brand (grouped by similar column patterns) are significantly different from each other. 

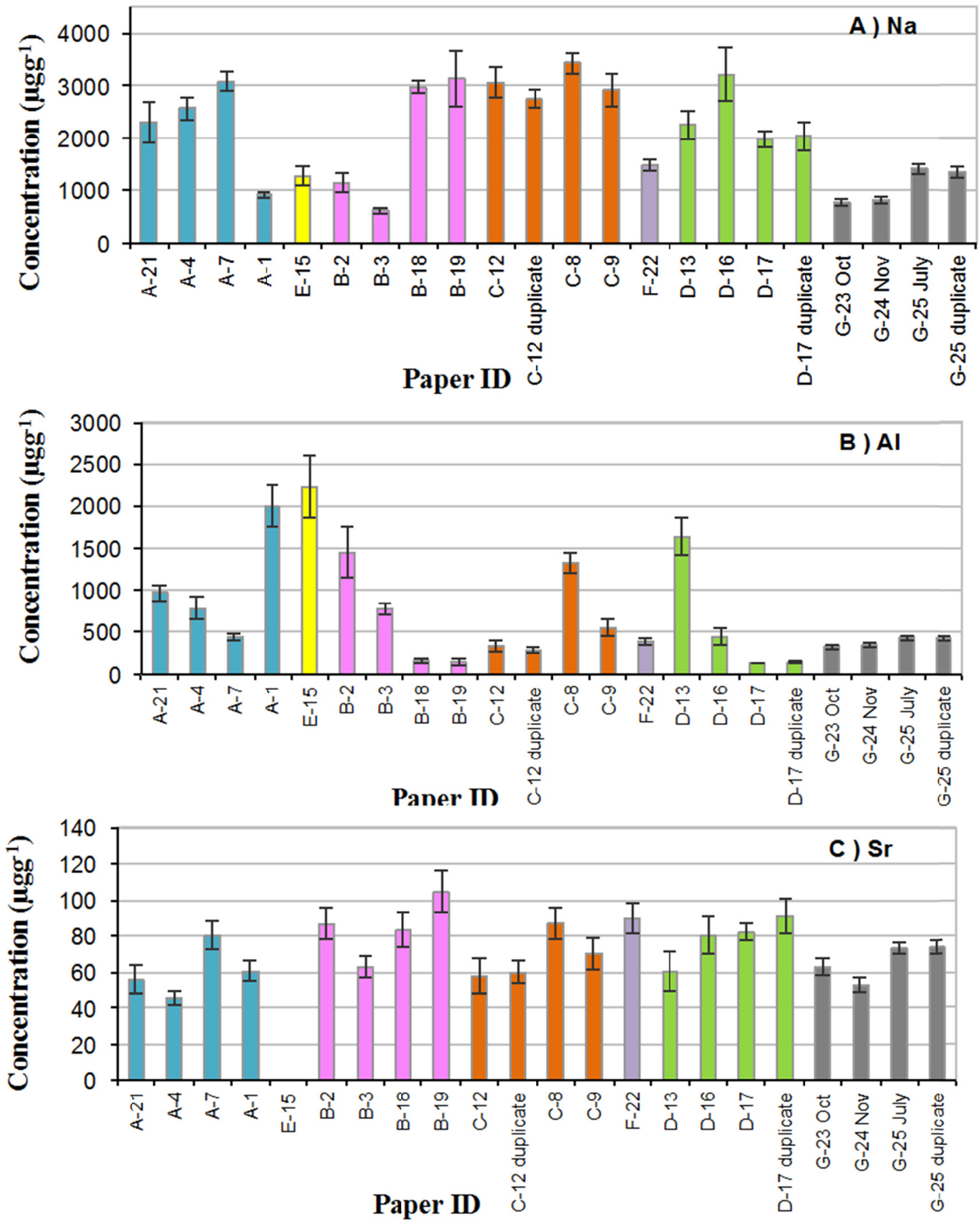

Figure 16. Comparison of the variation of the elemental composition within and between the paper sources. Letters in paper ID represent the brand and the number identify the sample as reported elsewhere. Each brand is also grouped by color or pattern. 
Table 8. Discrimination capabilities of elemental composition of paper by LA-ICP-MS and LIBS

\begin{tabular}{|c|c|c|c|c|c|}
\hline \multicolumn{3}{|c|}{ LA-ICP-MS } & \multicolumn{3}{|c|}{ LIBS } \\
\hline Element & $\begin{array}{c}\text { Number of } \\
\text { indistinguisha } \\
\text { ble pairs } \\
(p=0.05)\end{array}$ & $\begin{array}{c}\text { Percent of } \\
\text { discrimination }\end{array}$ & Element & $\begin{array}{c}\text { Number of } \\
\text { indistinguisha } \\
\text { ble pairs } \\
(p=0.05)\end{array}$ & $\begin{array}{c}\text { Percent of } \\
\text { discrimination }\end{array}$ \\
\hline $\mathrm{Na}$ & 69 & 59.6 & $\begin{array}{c}\mathrm{Na}(\mathrm{I}) \\
330.2 \mathrm{~nm}\end{array}$ & 30 & 82.5 \\
\hline $\mathrm{Al}$ & 71 & 58.5 & $\begin{array}{c}\mathrm{Al}(\mathrm{I}) \\
308.2 \mathrm{~nm}\end{array}$ & 31 & 81.9 \\
\hline $\mathrm{Zn}$ & 79 & 53.8 & $\begin{array}{c}\mathrm{Sr}(\mathrm{II}) \\
407.7 \mathrm{~nm}\end{array}$ & 53 & 69.0 \\
\hline $\mathrm{Mg}$ & 97 & 43.3 & $\begin{array}{c}\mathrm{Ca}(\mathrm{I}) \\
585.7 \mathrm{~nm}\end{array}$ & 53 & 69.0 \\
\hline $\mathrm{Sr}$ & 112 & 34.5 & $\begin{array}{c}\mathrm{Mg}(\mathrm{II}) \\
280.2 \mathrm{~nm}\end{array}$ & 95 & 44.4 \\
\hline $\mathrm{Fe}$ & 129 & 24.6 & & & \\
\hline $\mathrm{Mn}$ & 135 & 21.1 & & & \\
\hline $\mathrm{Cu}$ & 136 & 20.5 & & & \\
\hline $\mathrm{Ti}$ & 139 & 18.7 & & & \\
\hline $\mathrm{Ba}$ & 142 & 17.0 & & & \\
\hline $\mathrm{Zr}$ & 153 & 10.5 & & & \\
\hline $\begin{array}{l}\text { All } \\
\text { elements }\end{array}$ & $3(2 \mathrm{DC})$ & 99.4 & & $4(2 \mathrm{DC})$ & 97.7 \\
\hline $\begin{array}{l}\text { False } \\
\text { exclusion }\end{array}$ & 0 & 0 & & 0 & 0 \\
\hline $\begin{array}{l}\text { False } \\
\text { inclusion }\end{array}$ & 1 & 0.6 & & 2 & 1.2 \\
\hline
\end{tabular}


2.2.4.3 Evaluation of the significance of the elemental analysis of paper

The previous sections discussed two fundamental aspects for the evaluation of a novel forensic method: a) analytical performance and b) discrimination capability. The results showed that both laser ablation methods meet the analytical metrics required to fit for purpose. Moreover, the discrimination studies showed that the variation of the elemental composition within a sheet, ream and batches is appropriate to provide high discrimination between samples manufactured at different sites and/or at the same site at different time intervals.

The percent of false exclusions and false inclusions found in these paper sets suggest that elemental analysis of paper is a powerful tool to differentiate and/or to associate document paper.

However, when discriminating paper at a batch level or at a ream level another important question arise before the significance of an association or differentiation between papers can be addressed: How the production, storage, packaging and distribution of paper sheets could affect the significance of elemental analysis?

For this purpose, an effort was made to gather additional information about the manufacturing plants for our collection set, as well as information about stacking and cutting of papers for reams.

Table 9 summarizes the information provided during this telephone survey. Most of the companies provided additional information with confidentiality requests, therefore a letter/number code was assigned to each mill/plant/brand. 
Table 9. Information of manufacturing and distribution of paper reams for the paper collection set.

\begin{tabular}{|c|c|c|c|c|c|c|c|}
\hline $\begin{array}{c}\text { Sample } \\
\text { ID \# }\end{array}$ & $\begin{array}{c}\text { Brand } \\
\text { ID }\end{array}$ & $\begin{array}{c}\text { Mill } \\
\text { ID }\end{array}$ & $\begin{array}{l}\text { Parent } \\
\text { company }\end{array}$ & $\begin{array}{c}\text { Manufacturing } \\
\text { site }\end{array}$ & $\begin{array}{l}\text { Pulp and } \\
\text { paper } \\
\text { mill }\end{array}$ & $\begin{array}{c}\text { Annual } \\
\text { Capacity } \\
\text { (thousands } \\
\text { of short tons) }\end{array}$ & $\begin{array}{c}\text { Multiple } \\
\text { rolls per } \\
\text { ream }\end{array}$ \\
\hline 1 & A & M1 & $\mathrm{i}$ & $\begin{array}{l}\text { Jackson, } \\
\text { Alabama }\end{array}$ & Y & $\sim 491$ & $\mathrm{Y}$ \\
\hline 2 & $\mathrm{~B}$ & M2 & ii & $\begin{array}{l}\text { Courtland, } \\
\text { Alabama }\end{array}$ & $\mathrm{Y}$ & $\sim 7$ & $\begin{array}{l}\text { Y (up to } \\
6)\end{array}$ \\
\hline 3 & $\mathrm{~B}$ & M2 & ii & $\begin{array}{l}\text { Courtland, } \\
\text { Alabama }\end{array}$ & $\mathrm{Y}$ & $\sim 7$ & $\begin{array}{c}\text { Y (up to } \\
6 \text { ) }\end{array}$ \\
\hline 4 & A & M1 & $\mathrm{i}$ & $\begin{array}{l}\text { Jackson, } \\
\text { Alabama }\end{array}$ & $\mathrm{Y}$ & $\sim 491$ & $\mathrm{Y}$ \\
\hline 7 & A & M1 & $\mathrm{i}$ & $\begin{array}{l}\text { Jackson, } \\
\text { Alabama }\end{array}$ & $\mathrm{Y}$ & $\sim 491$ & $\mathrm{Y}$ \\
\hline 8 & $\mathrm{C}$ & M3 & $\mathrm{i}$ & Boise, Idaho & $\mathrm{U}$ & $\mathrm{U}$ & $\mathrm{U}$ \\
\hline 9 & $\mathrm{C}$ & M1 & $\mathrm{i}$ & $\begin{array}{l}\text { Jackson, } \\
\text { Alabama }\end{array}$ & $\mathrm{Y}$ & $\sim 491$ & $\mathrm{Y}$ \\
\hline 12 & $\mathrm{C}$ & M3 & $\mathrm{i}$ & Boise, Idaho & $\mathrm{U}$ & $\mathrm{U}$ & $\mathrm{U}$ \\
\hline 13 & $\mathrm{D}$ & $\mathrm{U}$ & iv & Wisconsin & $\mathrm{U}$ & $\mathrm{U}$ & $\mathrm{Y}$ \\
\hline 15 & $\mathrm{E}$ & $\mathrm{U}$ & $\mathrm{U}$ & $\mathrm{U}$ & $\mathrm{U}$ & $\mathrm{U}$ & $\mathrm{U}$ \\
\hline 16 & $\mathrm{D}$ & $\mathrm{U}$ & iv & Mississippi & $\mathrm{U}$ & $\mathrm{U}$ & $\mathrm{N}$ \\
\hline 17 & $\mathrm{D}$ & M4 & ii & New York & $\mathrm{Y}$ & $\sim 13$ & $\begin{array}{c}\text { Y (up to } \\
6)\end{array}$ \\
\hline 18 & $\mathrm{~B}$ & M4 & ii & $\begin{array}{c}\text { Ticonderoga, } \\
\text { NY }\end{array}$ & $\mathrm{Y}$ & $\sim 13$ & $\begin{array}{c}\text { Y (up to } \\
6 \text { ) }\end{array}$ \\
\hline 19 & $\mathrm{~B}$ & M4 & ii & $\begin{array}{c}\text { Ticonderoga, } \\
\text { NY }\end{array}$ & $\mathrm{Y}$ & $\sim 13$ & $\begin{array}{c}\text { Y (up to } \\
6 \text { ) }\end{array}$ \\
\hline 21 & A & $\mathrm{U}$ & $\mathrm{U}$ & Boise, Idaho & $\mathrm{U}$ & $\mathrm{U}$ & $\mathrm{U}$ \\
\hline 22 & $\mathrm{~F}$ & M5 & iii & $\begin{array}{c}\text { Turner Falls, } \\
\text { MA }\end{array}$ & $\mathrm{N}$ & $\mathrm{U}$ & $Y(5)$ \\
\hline 23 & $\mathrm{G}$ & M6 & ii & $\begin{array}{c}\text { Selma, } \\
\text { Alabama }\end{array}$ & $\mathrm{Y}$ & $\sim 6$ & $\begin{array}{c}\text { Y (up to } \\
6 \text { ) }\end{array}$ \\
\hline 24 & $\mathrm{G}$ & M6 & ii & $\begin{array}{c}\text { Selma, } \\
\text { Alabama }\end{array}$ & $\mathrm{Y}$ & $\sim 6$ & $\begin{array}{l}\text { Y (up to } \\
6 \text { ) }\end{array}$ \\
\hline 25 & $\mathrm{G}$ & M6 & ii & $\begin{array}{c}\text { Selma, } \\
\text { Alabama }\end{array}$ & $\mathrm{Y}$ & $\sim 6$ & $\begin{array}{c}\text { Y (up to } \\
6)\end{array}$ \\
\hline 26 & $\mathrm{C}$ & M2 & ii & $\begin{array}{l}\text { Courtland, } \\
\text { Alabama }\end{array}$ & $\mathrm{Y}$ & $\sim 7$ & $\begin{array}{c}\text { Y (up to } \\
6)\end{array}$ \\
\hline
\end{tabular}

U: unknown

Y: Yes 
This survey demonstrates that for this particular collection set, the following applies:

a) A paper ream can be sold under the same brand name but produced at different manufacturing plants or/and different paper mills.

b) Paper produced in the same plant, same mill and same parent company can be sold to different distribution companies and therefore labeled under different brand names.

c) A single plant can produce different quality paper, with differences in raw materials including different recycled paper content.

d) In my study, most of the paper plants that manufactured paper have the pulp plant and the mill plant in the same location, with one exception.

e) Most of the paper plants, with the exception of one, cut paper from different rolls to create a single ream of paper. The paper companies can use 2-6 different rolls to cut the individual paper sheets for further packaging into reams. Some of these rolls are often produced at different batches in the same day, or within several days. One of the parent companies reported that depending on the order size, some paper rolls could be produced within few days to weeks apart.

For this reason, it is possible that one ream could have alternating paper sheets with slight differences in their elemental composition every 2 to 6 sheets. If the rolls used were produced within small time intervals these differences may not be detected by these sensitive laser ablation methods, as shown in the results. 
Nonetheless, in casework if a batch or ream level of discrimination or association is required, it is recommended to sample from different sheets of a single ream whenever possible.

The significance of an association or discrimination between the elemental composition of document paper sheets has to be evaluate in a case-to-case basis, depending on the extent of characterization of the variability on the comparison sample.

The results show that it is feasible to differentiate samples produced at different plants/mills at different time intervals based on their elemental profile characterized by LA-ICP-MS or LIBS. The results obtained here may not apply to paper produced under different conditions and therefore this has to be address according to the policies of each manufacturing site/country. 


\subsection{Conclusions for elemental analysis of paper by LA-ICP-MS and LIBS}

Qualitative and quantitative LA-ICP-MS and LIBS methods have been developed and optimized for the elemental analysis of multiuse paper. Homogeneity studies show smaller variation of elemental compositions within a single source (i.e., sheet) than variations between different sources (i.e., brands, batches). Significant and detectable differences were observed between multipurpose white paper originated from different sources (discrimination of $\sim 97-99 \%$ depending on the sample set under investigation and the method applied). These differences of the elemental composition of paper were detected between a) papers of different brands; b) paper manufactured at different mills/plants, c) batches of paper manufactured at the same mill at times intervals ranging from few days to three months, depending on the variability of the raw materials and the recycled contents.

Sampling and characterization of the natural variability of the elemental composition of multiple sheets from a single ream or multiple pages from the comparison document is recommended before doing comparison to the questioned document. The number of sheets to be sampled should be according to the expected plant stacking policies, but it should be at least 4-6 sheets per ream.

Both laser-based methods are suitable for forensic comparison of multipurpose paper. These methods now present an attractive analysis alternative for forensic examiners to increase the informing power in comparisons and identification of these materials. Advantages of the laser-based methods include micro-bulk analysis with minimum sample destruction $(\sim 15 \mu \mathrm{g})$, multi-elemental capabilities, fast time of analysis and excellent discrimination power. 
In addition, the LIBS method has the advantage of being less complex to operate with an additional benefit of reduced instrument cost and maintenance. The paper analyses were conducted using a Czerny Turner spectrometer, which requires sequential analysis at different channels; however a broad-band spectrometer will be a more practical approach for this application because it will reduce the time of analysis and, most importantly, the amount of sample required. A broad-band spectrum also provides a better tool for the selection of an internal standard and/or elemental ratios of elements measured simultaneously.

Finally, laser ablation-ICP-MS could be the method of choice for those laboratories that have an ICP-MS or that already use the technique for forensic analysis of other evidence such as glass, paint and for the determination of provenance of materials. 


\section{MS AND LIBS}

\subsection{Experimental}

\subsubsection{Instrumentation}

\subsubsection{LA-ICP-MS analysis of writing and printing inks}

The LA-ICP-MS analyses were conducted on a quadrupole ELAN DRC II (Perkin Elmer LAS, Shelton CT USA), coupled to a $266 \mathrm{~nm}$ ns-Nd:YAG laser ablation system (LSX 500, CETAC, USA). The analytical performance and discrimination capability of the following isotopes was evaluated on ink matrices ${ }^{7} \mathrm{Li},{ }^{13} \mathrm{C},{ }^{23} \mathrm{Na},{ }^{24,25} \mathrm{Mg}$, ${ }^{27} \mathrm{Al},{ }^{29} \mathrm{Si},{ }^{39} \mathrm{~K},{ }^{42} \mathrm{Ca},{ }^{45} \mathrm{Sc},{ }^{47,49} \mathrm{Ti},{ }^{52,53} \mathrm{Cr},{ }^{55} \mathrm{Mn},{ }^{57} \mathrm{Fe},{ }^{59} \mathrm{Co},{ }^{60,62} \mathrm{Ni},{ }^{63,65} \mathrm{Cu},{ }^{64,66} \mathrm{Zn}$, ${ }^{85} \mathrm{Rb},{ }^{88} \mathrm{Sr},{ }^{89} \mathrm{Y},{ }^{90} \mathrm{Zr},{ }^{103} \mathrm{Rh},{ }^{119,120} \mathrm{Sn},{ }^{137} \mathrm{Ba},{ }^{139} \mathrm{La},{ }^{140} \mathrm{Ce},{ }^{142,143} \mathrm{Nd},{ }^{180} \mathrm{Hf},{ }^{206,207,208} \mathrm{~Pb}$.

\subsubsection{LIBS analysis of writing and printing inks}

The LIBS analyses were conducted on a RT100HP system (Applied Spectra, Fremont, CA), equipped with a 1064nm ns-Nd:YAG laser. The LIBS system has an automated X-Y-Z translational sample stage with a speed range of 1-20 $\mu \mathrm{m} / \mathrm{sec}$ For the writing ink experiments the LIBS instrument was configured with a Czerny Turner spectrograph (Princeton Instruments, NJ) with an ICCD detector (Gen II, Andor Technology, CT) and dual grating turret (operated at 2400 grooves $/ \mathrm{mm}$ ). For the analysis of printing inks, the system was equipped with a 6-channel broad band spectrograph (190nm to $1040 \mathrm{~nm}$ ), with a resolution of $<0.1 \mathrm{~nm}$ for UV to VIS and $<0.12$ for VIS to NIR. The software was also updated to include TruLIBS ${ }^{\mathrm{TM}}$ emission database and 
Aurora data analysis (Axiom 2.1, Applied Spectra, CA). The detector was replaced with a CCD linear array (Avantes, Broomfield, $\mathrm{CO}$ ) with possible gate delay adjustment from $50 \mathrm{~ns}$ to $1 \mathrm{~ms}$ with $25 \mathrm{~ns}$ step resolution and a fixed integration time of $1.1 \mathrm{~ms}$. The final element list was customized and optimized for each ink type.

An analytical microbalance (Cahn, USA) was used to determine the mass of the ablated particles from ink during LIBS and LA-ICP-MS experiments. A Scanning Electron Microscope XL 30 (Philips, The Netherlands) and a 3D digital microscope (Keyence NJ, USA) were used for the imaging of ink samples.

\subsubsection{Reagents and standards}

The calibration curve stock solutions were prepared from single element solutions of $\mathrm{Li}, \mathrm{Na}, \mathrm{Mg}, \mathrm{Al}$, , K, Ca, Sc, Ti, Cr, Mn, Fe, Co, Ni, Cu, Zn, Rb, Sr, Y, Zr, Rh, Sn, Ba, $\mathrm{La}, \mathrm{Ce}, \mathrm{Nd}, \mathrm{Hf}, \mathrm{Pb}, \mathrm{I}$ and $\mathrm{Br}$ at $1000 \mu \mathrm{g} \mathrm{mL}{ }^{-1}$ and/or $10000 \mu \mathrm{gmL}^{-1}$ (Peak performance, CPI International, USA).

Matrix-matched standards were created at the laboratory in order to perform quantitative determinations. Whatman 42 filter paper was used as the support matrix for the preparation of the standards. External calibration and standard addition methods were used to characterize the ink standards. A fountain-pen black ink (Montblanc, Germany) with low inorganic content was characterized by acid digestion-ICP-MS. High purity acids (optima grade) and ICP-MS grade standards were used for the digestion and characterization this ink.

About $0.5 \mu \mathrm{L}(0.035 \mathrm{mg})$ of that ink was deposited on $\mathrm{W} 42$ paper and dried overnight. Calibration curves were then prepared by spiking the ink drop at different 
concentration levels, depending on the element of interest and the technique used for analysis (final concentration from $2.5 \mu \mathrm{g} / \mathrm{mL}$ to $100 \mu \mathrm{g} / \mathrm{mL}$ for LA-ICP-MS, $25 \mu \mathrm{g} / \mathrm{mL}$ to $5000 \mu \mathrm{g} / \mathrm{mL}$ for LIBS).

The area of diffusion and distribution of the spiked standards were then monitored by 3D microscopy (Keyence, USA) and SEM (Philips, the Netherlands) to determine the penetration depth and the surface area of deposition of the spiked mass.

\subsubsection{Sample preparation}

Writing inks were collected by writing on Whatman 42 paper. Each ink collection consisted of 5 straight lines of $\sim 3 \mathrm{~cm}$ long and $5 \mathrm{~mm}$ wide, the name of the brand of the pen, the identification inventory number, the pen number, a signature and the words: "FIU, Florida International University and Trace Evidence Analysis Facility". A small portion of the paper $\left(\sim 1 \mathrm{~cm}^{2}\right)$ containing the ink writing patterns was placed directly in the respective ablation cells.

To prepare the printing ink samples, small strips of white paper $(2.54 \times 9.0 \mathrm{~cm}$, Whatman Grade 42, Whatman Ltd, NJ) were glued directly onto regular office paper (8.5 x 11 in., Boise Aspen 100). A small amount of glue was carefully placed only at a small area of each of the four corners on the strips of paper in order to avoid contamination of the sample with glue. Every strip was placed approximately 1.75 in. from the left side of the page and about 4 in. from the top of the page. Each sample was identified based on the name of the owner of the printer whom the sample was collected from, the location of the printer, the printer brand and model, the type of cartridge, the cartridge brand and model and any lot number associated with the cartridge. The percent of usage of the 
cartridge was also noted. For purposes of this study, new cartridges were said to have $100 \%$ usage and mostly used cartridges were given a $0 \%$. Figure 17 shows an example of the writing ink and the printing templates used to collect the ink samples.

All samples were stored in the dark, at room temperature in plastic bags and small envelopes. A small portion of the substrate paper and the printed ink was then cut for further analysis. Double-sided tape (3M, USA) was used to mount the samples in the ablation chambers.

3.1.3.1 Acid digestion methods for the characterization of fountain ink standard

All digestions were conducted in an open vessel hot block (Environmental Express, USA). The following digestion protocols were tested for the characterization of fountain ink, which was later used as the standard matrix for in-house ink standards:

a) Method 1: $0.1 \mathrm{~g}$ of ink were digested with $2 \mathrm{~mL}$ of $\mathrm{HNO}_{3} 16 \mathrm{M}$ optima grade. The sample was digested for 2 hours at $80^{\circ} \mathrm{C}$. The temperature was then raised to $120{ }^{\circ} \mathrm{C}$ until dryness of the digestate.

b) Method 2: $0.1 \mathrm{~g}$ of the ink was digested with $2 \mathrm{~mL}$ of $\mathrm{H}_{2} \mathrm{SO}_{4}$ optima grade. The sample was left at room temperature for 30 minutes until the exothermic reaction was completed. $2 \mathrm{~mL}$ of $\mathrm{HNO}_{3}(16 \mathrm{M}$, optima grade) were added and the mixture was allowed to react at $100{ }^{0} \mathrm{C}$ for about 7 hours.

c) Method 3: $0.1 \mathrm{~g}$ of the ink was mixed with $2 \mathrm{~mL}$ of $\mathrm{HNO}_{3}$ (16M, optima grade). The sample was placed in the hot block at $80{ }^{\circ} \mathrm{C}$. After one hour, the sample was cooled down at room temperature and $1 \mathrm{ml}$ of $\mathrm{H}_{2} \mathrm{O}_{2}(30 \%$, optima grade) was added to the tube. The mixture was then sonicated for 10 minutes and heated at $100{ }^{\circ} \mathrm{C}$ for about 8 hours. 
The digestates were reconstituted with nitric acid $0.8 \mathrm{M}$, sonicated, diluted and spiked with Rh and $\mathrm{Y}$ as internal standards. The quantitative analysis was conducted using ICP-MS with external calibration and standard addition methods.

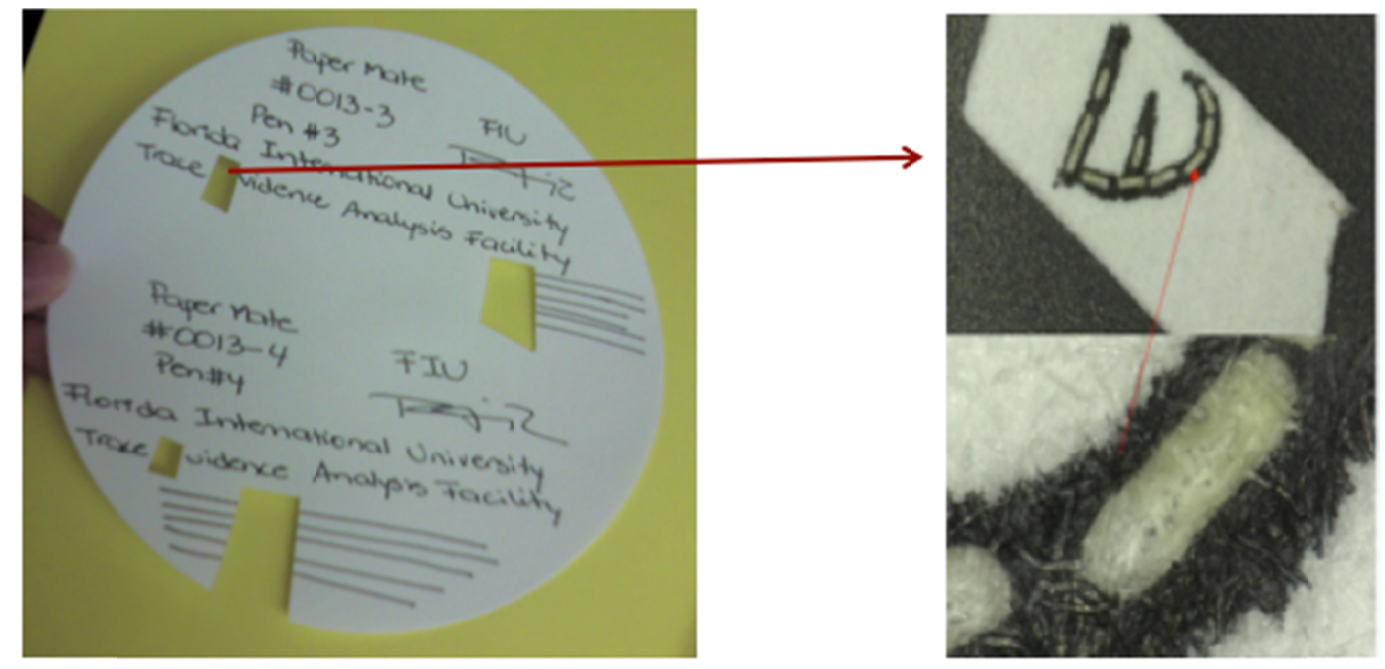

1

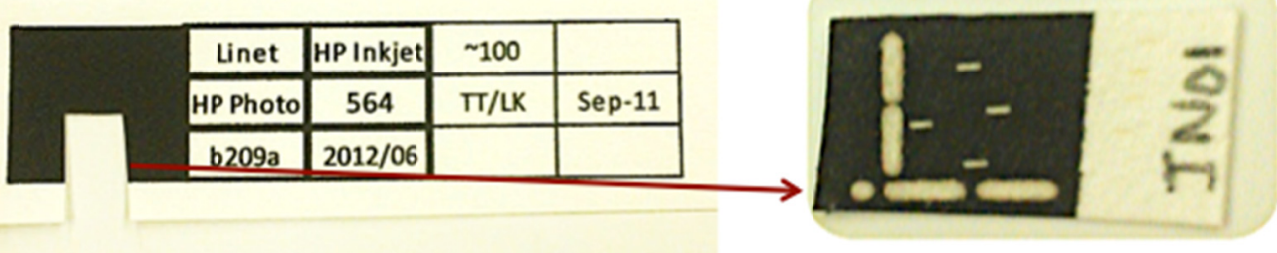

Figure 17. Examples of templates for the collection of writing inks (top left) and printing inks (bottom left) and their respective subsamples after ablation (right). 


\subsubsection{Sample collection}

\subsubsection{Collection of writing ink sources}

The ink from 323 pens was analyzed to determine the variation of the chemical composition of ink within a single pen, between pens from the same package and between brands of black gel inks, blue gel inks and black ballpoint inks. The set includes writing inks from 103 different sources (different brand, manufacturer, batch) and 220 entries from similar sources (i.e., duplicate controls, same pen at different percent use, different pens from the same package).

As part of the validation study, the discrimination and identification capabilities were tested on four independent sub-sets of ink. The first set consisted of 45 gel pen inks received as a blind test from the U.S. Secret Service. The brand and origin of these ink samples remain unknown because of proprietary information. The ink samples were received on a piece of Whatman paper 42. Samples were labeled with the numbers 1 to 45. A small piece of $\sim 1 \mathrm{~cm}^{2}$ was cut with plastic scissors to conduct laser ablation analyses. Each sample was analyzed in three replicates and quantified using in-house ink standards. Duplicate samples were included to test the type I error rate.

The second set consisted of black gel inks originating from 24 different brands/batches. All pens were purchased at retail stores in the US during a period of 2months. The third set consisted of black ballpoint refills from 20 different sources; all of them were purchased online on the same day from different brands. The fourth set consisted of 22 blue gel inks originating from 19 different brands/batches. Three additional blue gels from the same source were used as duplicate controls. A list the writing pens tested in this study for the $2^{\text {nd }}, 3^{\text {rd }}$ and $4^{\text {th }}$ set is found in tables 10 to 12 . The 
manufacturing information (i.e., made in) corresponds to the information found in the external package and therefore may refer to the country of pen assembly and not explicitly the country were the ink was manufactured.

Additional studies were performed to evaluate the variation of the elemental composition within pens and between pens from the same package. The within-pen variation study was conducted on three gel pens from different brands. The ink from each pen was analyzed at different percent of ink withdrawn. The ink-barrel had its own labeling for percentage of use of the ink and therefore the ink was collected on the paper substrate at $0 \%$ (mostly used), $10 \%, 25 \%, 50 \%, 75 \%$ and $100 \%$ (new). Between-package studies were conducted on four different brands of pens containing 4 to 12 pens per package. The brands selected for this study are identified as B002, B014, B009 and B018 on table 12. Four replicates were conducted on each of the pens. A total of 24 pens were used for this between-package study. 
Table 10. List of tested black gel pens.

\begin{tabular}{|c|c|c|c|c|c|}
\hline $\begin{array}{c}\text { Reference } \\
\text { Inventory } \\
\text { No. } \\
\end{array}$ & $\begin{array}{c}\text { Make } \\
\text { (Brand) }\end{array}$ & $\begin{array}{l}\text { Model } \\
\text { (type) }\end{array}$ & $\begin{array}{c}\text { \# pens } \\
\text { per } \\
\text { package }\end{array}$ & $\begin{array}{c}\text { Made } \\
\text { in }\end{array}$ & $\begin{array}{l}\text { Purchase } \\
\text { location }\end{array}$ \\
\hline B-001 & Gel writer & $\mathrm{Rx}$ & 5 & China & $\begin{array}{c}\text { Pompano beach, } \\
\text { FL }\end{array}$ \\
\hline B-002 & $\mathrm{Bic}$ & Velocity gel & 4 & France & Miami, FL \\
\hline B- 003 & Foray & $\begin{array}{c}\text { Retractable } \\
\text { gel }\end{array}$ & 6 & China & Miami, FL \\
\hline B-004 & Zebra & GR8 gel & 5 & China & Miami, FL \\
\hline B- 005 & Pilot & $\begin{array}{l}\text { Begreen G- } \\
\text { Knock }\end{array}$ & 3 & Japan & Miami, FL \\
\hline B-006 & Uni-Ball & Signo 207 & 2 & Japan & Miami, FL \\
\hline B-007 & Pilot & $\begin{array}{l}\text { Frixion } \\
\text { erasable }\end{array}$ & 2 & Japan & Miami, FL \\
\hline B-008 & Sharpie & Pen fine & 2 & Japan & Miami, FL \\
\hline B-009 & Staples & Gel stick & 12 & China & Margate, FL \\
\hline B-010 & Pilot & $\begin{array}{c}\text { Precise V7 } \\
\text { RT }\end{array}$ & 3 & China & Margate, FL \\
\hline B-011 & Uni-Ball & Signo 207 & 2 & Japan & Margate, FL \\
\hline B-012 & Zebra & Z-grip & 4 & China & Margate, FL \\
\hline B-013 & Papermate & Gel Click & 4 & China & Margate, FL \\
\hline B-014 & Pilot & G2 & 4 & Japan & Margate, FL \\
\hline B-015 & Staples & Sonix Gel & 4 & China & Margate, FL \\
\hline B-016 & Pilot & G2 & 4 & Japan & Margate, FL \\
\hline B-017 & Uni-Ball & $\begin{array}{c}\text { Signo Gel } \\
\text { RT } \\
\end{array}$ & 4 & Japan & Margate, FL \\
\hline B-018 & Bic & Velocity gel & 4 & France & St Louis, MO \\
\hline B-019 & Papermate & Gel Click & 4 & China & St Louis, MO \\
\hline B- 020 & Uni-Ball & $\begin{array}{c}\text { Signo Gel } \\
\text { RT }\end{array}$ & 4 & Japan & St Louis, MO \\
\hline B-021 & Pilot & G2 & 4 & Japan & Miami, FL \\
\hline B- 022 & Staples & Gel mini & 3 & China & Margate, FL \\
\hline B-023 & Staples & Opti flow & 1 & China & Miami, FL \\
\hline B-024 & Staples & Gel & 2 & China & Miami, FL \\
\hline
\end{tabular}


Table 11. List of tested black ballpoint refill inks

\begin{tabular}{|c|c|c|c|c|}
\hline $\begin{array}{c}\text { Reference } \\
\text { ID No. }\end{array}$ & Make (brand) & Model (type) & $\begin{array}{c}\text { \# refills } \\
\text { per } \\
\text { package }\end{array}$ & $\begin{array}{c}\text { Manufacture } \\
\text { Information }\end{array}$ \\
\hline BB-020 & Pentel & Ball point refill & 6 & $\begin{array}{c}\text { Assembled in } \\
\text { Mexico }\end{array}$ \\
\hline BB-021 & Sanford & Paper Mate Lubriglide & 2 & $\begin{array}{c}\text { Assembled in } \\
\text { Mexico }\end{array}$ \\
\hline BB-022 & Office Max & Chain pen refill & 3 & Made in China \\
\hline BB-023 & Pilot & TheBetter & 4 & Made in Japan \\
\hline BB-024 & Bic & 4Color & 8 & Made in France \\
\hline BB-025 & Waterman & Ball pen refill & 2 & $\begin{array}{c}\text { Made in } \\
\text { Germany }\end{array}$ \\
\hline BB-026 & Sanford & Paper Mate Lubriglide & 4 & $\begin{array}{c}\text { Assembled in } \\
\text { Mexico }\end{array}$ \\
\hline BB-027 & Uniball & Power Tank RT & 3 & Made in Japan \\
\hline BB-028 & StrideSchneider & Express 735 & 2 & $\begin{array}{c}\text { Made in } \\
\text { Germany }\end{array}$ \\
\hline BB-029 & Pilot & TheBetter & 2 & Made in Japan \\
\hline BB-030 & Bic & Stylo-Bille & 4 & $\begin{array}{c}\text { Made in } \\
\text { Mexico }\end{array}$ \\
\hline BB-031 & Zebra & F-Refill & 6 & $\begin{array}{c}\text { Made in } \\
\text { Indonesia }\end{array}$ \\
\hline BB-032 & AT Cross & Tech3 & 4 & Made in China \\
\hline BB-033 & AT Cross & ball pen refill & 2 & Made in China \\
\hline BB-034 & Pilot & Dr.Grip & 4 & Made in Japan \\
\hline BB-035 & Pentel & Client & 2 & Made in India \\
\hline BB-036 & Parker & Ball pen refill & 2 & Made in U.K \\
\hline BB-037 & Pentel & R.S.V.P. & 2 & $\begin{array}{c}\text { Assembled in } \\
\text { USA }\end{array}$ \\
\hline BB-038 & Penatia & Cross & 2 & Made in China \\
\hline BB-039 & Penatia & Size-it & 2 & Made in China \\
\hline
\end{tabular}


Table 12. List of tested blue gel pens and refill inks.

\begin{tabular}{|c|c|c|c|c|}
\hline $\begin{array}{l}\text { Reference } \\
\text { ID No. }\end{array}$ & $\begin{array}{c}\text { Make } \\
\text { (brand) }\end{array}$ & $\begin{array}{l}\text { Model } \\
\text { (type) }\end{array}$ & $\begin{array}{c}\text { \# pens / refills per } \\
\text { package }\end{array}$ & $\begin{array}{c}\text { Made } \\
\text { in }\end{array}$ \\
\hline BB-001 & $\begin{array}{c}\text { Sanford } \\
\text { (Rubbermaid } \\
\text { Company) }\end{array}$ & $\begin{array}{l}\text { Paper } \\
\text { Mate }\end{array}$ & 12 pens & Made in China \\
\hline BB-002 & $\mathrm{Bic}$ & ReAction $^{\mathrm{tm} / \mathrm{mc}}$ & 3 pens & Made in Japan \\
\hline BB-003 & Avery & $\begin{array}{c}\text { eGel } \\
\text { Retractable }\end{array}$ & 12 pens & Made in Korea \\
\hline BB-004 & $\begin{array}{c}\text { Stride- } \\
\text { Schneider }\end{array}$ & Gel IT & 12 pens & Made in Usa \\
\hline BB-005 & Office Max & $\begin{array}{c}\text { Gel } \\
\text { Retractable }\end{array}$ & 12 pens & Made in China \\
\hline BB-006 & Pentel & $\begin{array}{c}\text { EnerGel } \\
\text { Retractable } \\
\text { Liquid Gel. } \\
\text { Deluxe RTX }\end{array}$ & 2 pens & Made in Japan \\
\hline BB-007 & Pilot & G2 Bold & 12 pens & Made in Japan \\
\hline BB-008 & Uniball $^{1}$ & $\begin{array}{l}\text { Jet Stream } \\
\mathrm{tm} / \mathrm{mc}\end{array}$ & 2 pens & Made in Japan \\
\hline BB-009 & Zebra & Z.Grip Gel & 3 pens & Made in China \\
\hline BB-010 & Uniball $^{1}$ & Gel RT & 3 pens & Made in Japan \\
\hline BB-011 & $\mathrm{Bic}$ & $\operatorname{Pro}^{+t m / m c}$ & 4 pens & Made in China \\
\hline BB-012 & Pilot & P-700 & 12 pens & Made in Japan \\
\hline BB-013 & $\begin{array}{l}\text { Tul (distributed } \\
\text { by Office Max) }\end{array}$ & & 12 pens & $\begin{array}{l}\text { Designed in } \\
\text { US/Man. South } \\
\text { Korea }\end{array}$ \\
\hline BB-014 & $\mathrm{Bic}$ & ReAction $^{\mathrm{tm} / \mathrm{mc}}$ & 3 pens & Made in Japan \\
\hline BB-015 & Pentel & HyperG & 3 pens & Made in Japan \\
\hline BB-016 & Bic & $\mathrm{Pro}^{+\mathrm{tm} / \mathrm{mc}}$ & 4 pens & Made in China \\
\hline BB-017 & Pilot & G2 refill & 2 refills & Made in Japan \\
\hline BB-018 & AT Cross & refill & 2 refill & Made in China \\
\hline BB-019 & Uniball $^{1}$ & $\underset{\text { refill }}{\text { Impact }}$ & 2 refills & Made in Japan \\
\hline
\end{tabular}

${ }^{1}$ Uniball division of Newel Rubbermaid exclusively made for Sanford 


\subsubsection{Collection of printing ink sources}

The printing ink collection set consisted of ink collected from 47 different printers. This includes 21 inkjet ink samples from 11 different printers (different brand, model), 7 duplicate controls (printed from the same cartridge at different time intervals) and 3 blind samples. The toner subset consisted of 26 ink items printed from 13 different laser toner printers and 13 samples used as blind or duplicate controls. Tables 13 and 14 list the different types of printers and printer cartridges collected.

\subsubsection{Data reduction and statistical analysis}

Data reduction and statistical analyses were performed by either the use of SYSTAT for windows (v.8.0, SPSS Science, Chicago, IL), JMP (v.5.0.1 SAS, NC), Excel 2003 (v9.0.2719, Microsoft Corp.), Geopro (CETAC Technologies, v 1.0, NE), Plot for mac OSX (v.0.997, Berlin, Germany), Mathematica (v. 5.2.0.0, IL), Aurora LIBS data analysis software (v 2.1, Applied Spectra, CA). 
Table 13. List of tested inkjet printer inks.

\begin{tabular}{|c|c|c|c|c|c|c|}
\hline $\begin{array}{c}\text { ID } \\
\text { No. }\end{array}$ & $\begin{array}{c}\text { Printer } \\
\text { brand }\end{array}$ & $\begin{array}{c}\text { Printer } \\
\text { Model }\end{array}$ & $\begin{array}{c}\text { Cartridge } \\
\text { brand }\end{array}$ & $\begin{array}{c}\text { Cartridge } \\
\text { Model }\end{array}$ & $\begin{array}{c}\text { Cartridge } \\
\text { Lot \# }\end{array}$ & \% Usage \\
\hline IN01 & $\begin{array}{c}\text { HP } \\
\text { Photosmart }\end{array}$ & B209A & HP & 564 & 201206 & $\sim 100$ \\
\hline & $\begin{array}{c}\text { HP } \\
\text { OfficeJet } \\
\text { Pro }\end{array}$ & 8500 & HP & 940 & na & $\sim 100$ \\
\hline IN06 & $\begin{array}{c}\text { HP } \\
\text { Photosmart }\end{array}$ & D110 & HP & 60 & CC640W & $\sim 50$ \\
\hline IN07 & $\begin{array}{c}\text { HP } \\
\text { OfficeJet }\end{array}$ & J4580 & HP & $901 \times 1$ & na & $\sim 75$ \\
\hline IN08 & $\begin{array}{c}\text { HP } \\
\text { OfficeJet }\end{array}$ & J4581 & HP & $901 x 1$ & na & $\sim 75$ \\
\hline IN09 & $\begin{array}{c}\text { HP } \\
\text { Photosmart }\end{array}$ & C4400 & HP & 74 & na & $\sim 100$ \\
\hline IN10 & $\begin{array}{c}\text { HP } \\
\text { Photosmart }\end{array}$ & C4400 & HP & 74 & na & $\sim 100$ \\
\hline IN10-A & $\begin{array}{c}\text { HP } \\
\text { Photosmart }\end{array}$ & C4400 & HP & 74 & na & $\sim 100$ \\
\hline IN-10B & $\begin{array}{c}\text { HP } \\
\text { Photosmart }\end{array}$ & C4400 & HP & 74 & na & $\sim 100$ \\
\hline IN-10C & $\begin{array}{c}\text { HP } \\
\text { Photosmart }\end{array}$ & C4400 & HP & 74 & na & $\sim 100$ \\
\hline IN12 & Hp Deskjet & 3050 & HP & 61 & na & $\sim 75$ \\
\hline IN14 & Canon & MP490 & Canon & 210 & na & $\sim 100$ \\
\hline IN15 & LexMark & 2500 & LexMark & 28 & na & $\sim 33$ \\
\hline IN16 & $\begin{array}{c}\text { HP } \\
\text { OfficeJet }\end{array}$ & J4580 & HP & $901 X L$ & CC654A & $\sim 15$ \\
\hline IN17A & $\begin{array}{c}\text { HP } \\
\text { Photosmart }\end{array}$ & D110 & HP & 60 & CC640W & $\sim 50$ \\
\hline IN17B & $\begin{array}{c}\text { HP } \\
\text { Photosmart }\end{array}$ & D110 & HP & 60 & CC640W & $\sim 50$ \\
\hline IN17C & $\begin{array}{c}\text { HP } \\
\text { Photosmart }\end{array}$ & D110 & HP & 60 & CC640W & $\sim 100$ \\
\hline IN17- & $\begin{array}{c}\text { HP } \\
\text { Photosmart }\end{array}$ & D110 & HP & 60 & CC643W & $\sim 100$ \\
\hline IN17- \\
14 & $\begin{array}{c}\text { HP } \\
\text { Photosmart }\end{array}$ & D110 & HP & 60 & CC643W & $\sim 75$ \\
\hline IN17- & $\begin{array}{c}\text { HP } \\
\text { Photosmart }\end{array}$ & D110 & HP & 60 & CC643W & $\sim 50$ \\
\hline $\begin{array}{c}\text { IN-17- } \\
17 D\end{array}$ & $\begin{array}{c}\text { HP } \\
\text { Photosmart }\end{array}$ & D110 & HP & 60 & CC643W & $\sim 50$ \\
\hline
\end{tabular}


Table 14. List of tested laser toner inks

\begin{tabular}{|c|c|c|c|c|c|c|}
\hline $\begin{array}{c}\text { ID } \\
\text { No. }\end{array}$ & $\begin{array}{c}\text { Printer } \\
\text { brand }\end{array}$ & $\begin{array}{c}\text { Printer } \\
\text { Model }\end{array}$ & $\begin{array}{c}\text { Cartridg } \\
\text { e brand }\end{array}$ & $\begin{array}{c}\text { Cartridge } \\
\text { Model }\end{array}$ & $\begin{array}{c}\text { Cartridge } \\
\text { Lot \# }\end{array}$ & $\begin{array}{c}\% \\
\text { Usage }\end{array}$ \\
T01 & $\begin{array}{c}\text { HP Color } \\
\text { laserjet }\end{array}$ & CP2015 & HP & CC530A & MUI-854 & $\sim 10$ \\
0
\end{tabular}




\subsection{Results and discussion}

3.2.1 Development and optimization of a LA-ICP-MS method for the analysis of writing inks

In order to be realistic with regards to the amount of sample available in typical casework, all the optimization and validation studies were performed on the ink markings deposited directly by the pen on standard paper. As in the case of paper analysis, a minimum destruction of the substrate is also desirable for ink analysis. The analysis of ink on paper is however more challenging than the analysis of paper, because the ink is typically absorbed in some extent into the fibers of the paper and therefore the paper composition becomes part of the background or analytical noise.

Optimization was conducted on ink standards and on ink samples from the collection set. At least four different ink samples were selected from each ink subset. The optimization of the laser parameters for the LA-ICP-MS method for writing ink included the study of the ablation mode, different repetition rates $(2 \mathrm{~Hz}, 5 \mathrm{~Hz}, 10 \mathrm{~Hz})$, spot sizes $(100,200,250 \mu \mathrm{m})$, ablation rate $\left(10 \mu \mathrm{ms}^{-1}, 15 \mu \mathrm{ms}^{-1}, 25 \mu \mathrm{ms}^{-1}, 35 \mu \mathrm{ms}^{-1}\right)$ and flash lamp voltage $(20-50 \% \mathrm{E}$ in $5 \%$ increments). The best parameters are listed in table 15 , which provided good sensitivity and good precision $(<10 \%-15 \%$ RSD, depending on the concentration level).

The only ablation mode that was practical for ink analysis was the ablation line. Ablation line allows ink removal without ablating through the document. The rate at which the sample stage is moved while the laser interacts with the substrate was critical to determine how much ink is been removed and how much paper substrate is been 
removed with it. Another critical parameter that controls the percent of ink and paper removed from the laser micro-sampling is the percent energy of the laser beam. A percent energy of $35 \%(\sim 1.5 \mathrm{~mJ})$ was found to provide the best balance between ink removal and signal intensity and reproducibility.

The frequency, or number of shots per second, delivered by the laser was also optimized. Figure 18 shows that the best precision was obtained with ablation at $10 \mathrm{~Hz}$ $(\% \mathrm{RSD}<10 \%)$

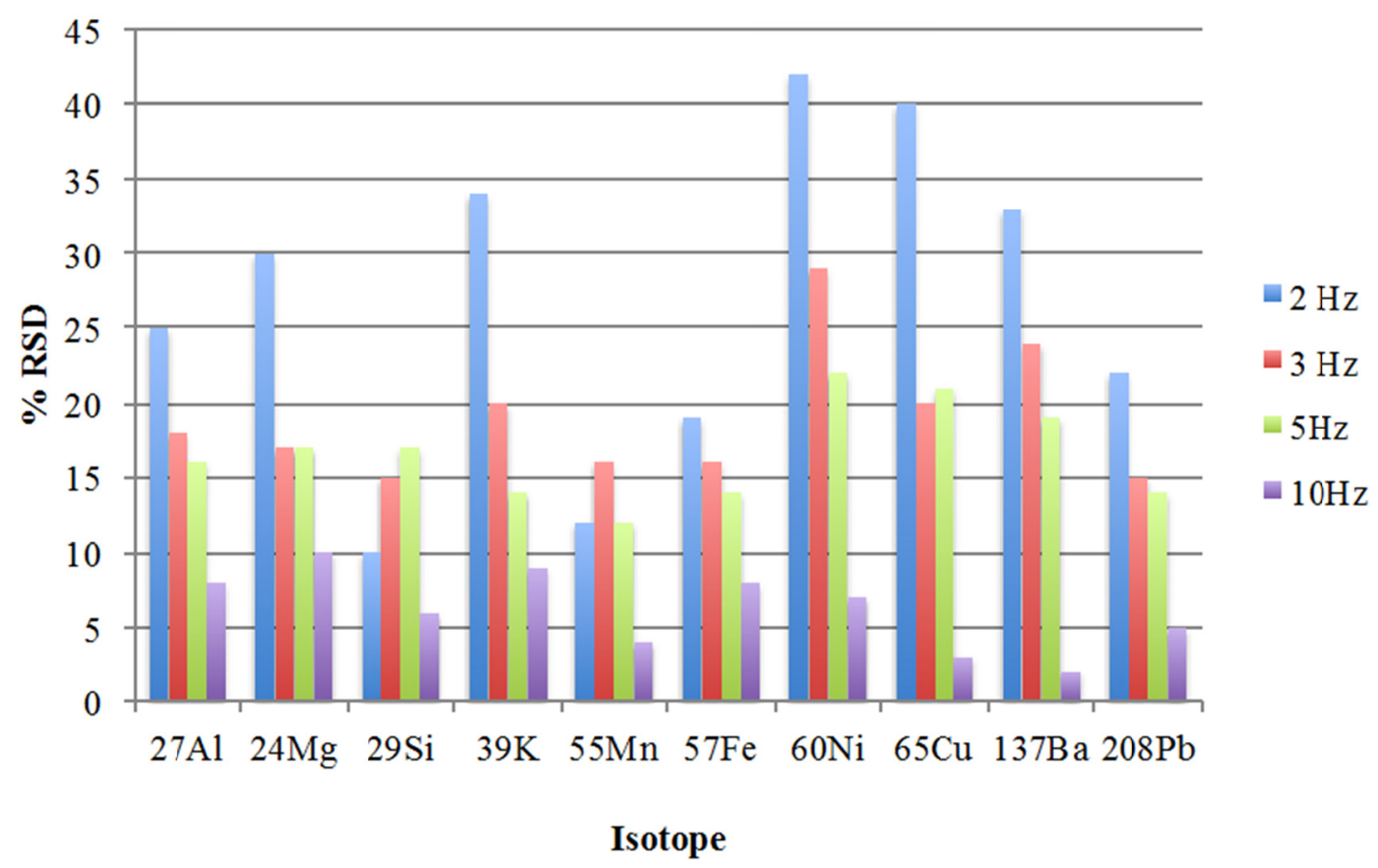

Figure 18. Effect of the laser frequency in the precision of the measurements (\%RSD, $n=5$ ) of the elemental composition of ink by LA-ICP-MS 
Table 15. Optimized instrumental parameters for the analysis of writing inks by LA-ICPMS.

\begin{tabular}{|c|c|}
\hline Parameter & LAICPMS \\
\hline Laser & $266 \mathrm{~nm}, \mathrm{NdYAG}(9 \mathrm{~mJ}$ max $)$ \\
\hline Spot size & $\sim 200 \mu \mathrm{m}$ \\
\hline Ablation mode & line \\
\hline Scan rate & $25 \mu \mathrm{m} / \mathrm{s}$ \\
\hline \# of shots & 240 \\
\hline Sampling area & $200 \mu \mathrm{m} * 600 \mu \mathrm{m}$ \\
\hline Repetition rate & $10 \mathrm{~Hz}$ \\
\hline Flash lamp voltage & $35 \%(1.5 \mathrm{~mJ})$ \\
\hline Elemental menu & Ink: (Al, Mg, Fe, Mn, Cu, \\
& $\mathrm{Ba}, \mathrm{Ni}, \mathrm{Pb}, \mathrm{Si}, \mathrm{K})$ \\
\hline
\end{tabular}

\subsubsection{Calibration strategies for writing ink analysis by LA-ICP-MS}

One of the greatest challenges for the analysis of writing inks was the development of matrix-matched standards. For this purpose, a water-based fountain ink was digested and characterized by ICP-MS to evaluate the viability to be used as the substrate ink for the preparation of ink-standards. A total of three different methods were initially selected for a preliminary study of the ink. The main objective at this time was to emerge with an efficient and reproducible digestion method that allows the removal of the organic components of the ink. The main differences between the methods were the 
temperature applied and the selection of the solvent(s). The third method described in the experimental section, which uses a mixture of nitric acid and hydrogen peroxide provided the most efficient and reproducible ink digestion.

Fountain ink was spiked at 6 different concentration levels in order to determine the elemental composition of the ink by the standard addition method. Percent of recovery for the acid digestions ranged from $95 \%$ to $115 \%$. Reproducibility of the digestion replicates was better than 13\% RSD for the majority of the monitored elements. Table 16 shows the elemental concentration levels found in the fountain ink. As expected this type of ink has very low concentration of inorganic components, with the majority of the monitored elements present at low ppb levels.

Table 16. Elemental composition of the tested fountain ink.

\begin{tabular}{|c|c|c|}
\hline $\begin{array}{c}\text { Element } \\
\text { monitored }\end{array}$ & $\begin{array}{c}\text { Mean concentration } \\
\text { n/g } \mathbf{g}(\mathbf{n}=\mathbf{5})\end{array}$ & $\begin{array}{c}\text { \% RSD } \\
(\mathbf{n}=\mathbf{5})\end{array}$ \\
\hline $\mathrm{Al}$ & 35 & 11 \\
\hline $\mathrm{Mg}$ & 40 & 10 \\
\hline $\mathrm{Ti}$ & 7.2 & 11 \\
\hline $\mathrm{Cr}$ & 5.9 & 6 \\
\hline $\mathrm{Mn}$ & 1.4 & 10 \\
\hline $\mathrm{Fe}$ & 68 & 13 \\
\hline $\mathrm{Co}$ & 0.6 & 4 \\
\hline $\mathrm{Ni}$ & 5.6 & 8 \\
\hline $\mathrm{Cu}$ & 3.8 & 10 \\
\hline $\mathrm{Sr}$ & 17.1 & 5 \\
\hline $\mathrm{Sn}$ & 4.6 & 12 \\
\hline $\mathrm{Ba}$ & 10.5 & 6 \\
\hline $\mathrm{Pb}$ & 6.4 & 23 \\
\hline
\end{tabular}

Once the background levels of the fountain ink were characterized, this ink was used as the matrix-matched substrate to create the in-house ink standards. Ink drops were 
deposited into Whatman 42 paper using $0.5 \mu \mathrm{L}, 1 \mu 1,2 \mu \mathrm{L}$ and $5 \mu \mathrm{L}$ volumes. The reproducibility of the deposited ink drops was studied in terms of shape, diameter and penetration into the paper. Volumes larger than $1 \mathrm{uL}$ generated uneven oval-like drops with more pronounced concentration of the ink towards the edges of the drop. A volume of $0.5 \mathrm{uL}$ was determined to generate more reproducible ink drops in the paper with a fairly even distribution of the elemental composition.

In order to verify the homogeneity of the elemental composition in the ink drop a laser ablation line was monitored from edge to edge of the drop. Figure 19 shows the transient LA-ICP-MS signal of one of the ink-spiked in-house standards. The stability of the signal across the drop shows that the distribution of elements in the drop was fairly homogeneous. An exception to this observation was detected for $\mathrm{K}$ and in less extent for $\mathrm{Al}$ and $\mathrm{Sn}$, which had a preference to migrate towards the edge of the drop. For this reason all the measurements were later conducted at least 300 um away from the edge of the standard ink drops.

Moreover, in order to test the reproducibility of the preparation of the ink standards and the repeatability of the measurements, the elemental composition was determined for 3 ink standards prepared in different days and by different analysts. Each of these ink standards was analyzed in 5 replicates. Experiments were conducted for ink drops spiked with $5 \mathrm{ng}$ and $12.5 \mathrm{ng}$ of the mix stock solution. Figure 20 shows the results for the ink standards spiked at the $12.5 \mathrm{ng}$. The repeatability of the measurements was better than $9 \%$ (represented by the error bars) while reproducibility between different ink drops was better than 5\%. Similar results were obtained for the lower spike level. 


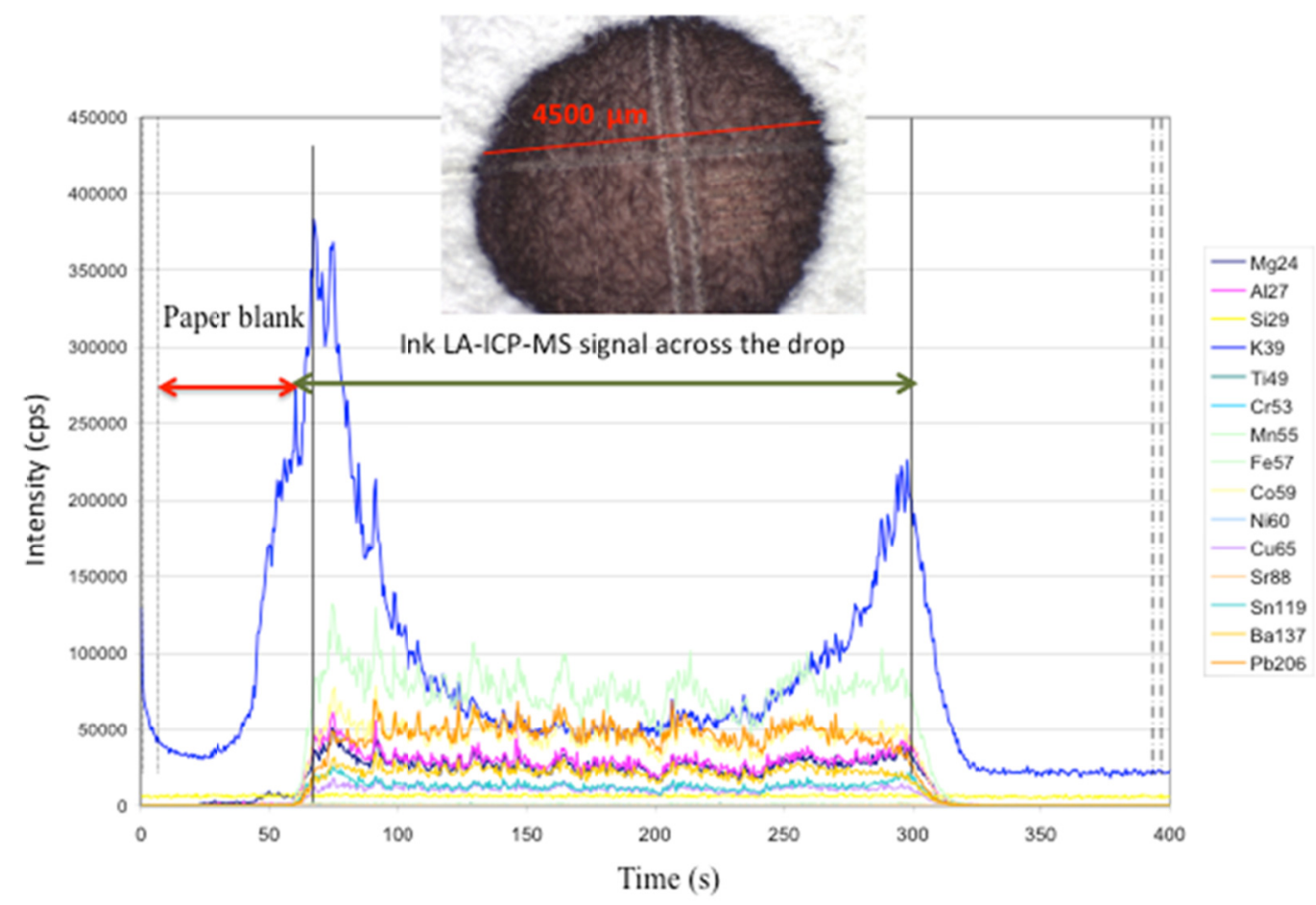

Figure 19. Photomicrograph of an ink standard drop (25x magnification) and transient LA-ICP-MS signal across an ink drop spiked with $5 \mathrm{ng}$ of a mixture of elements

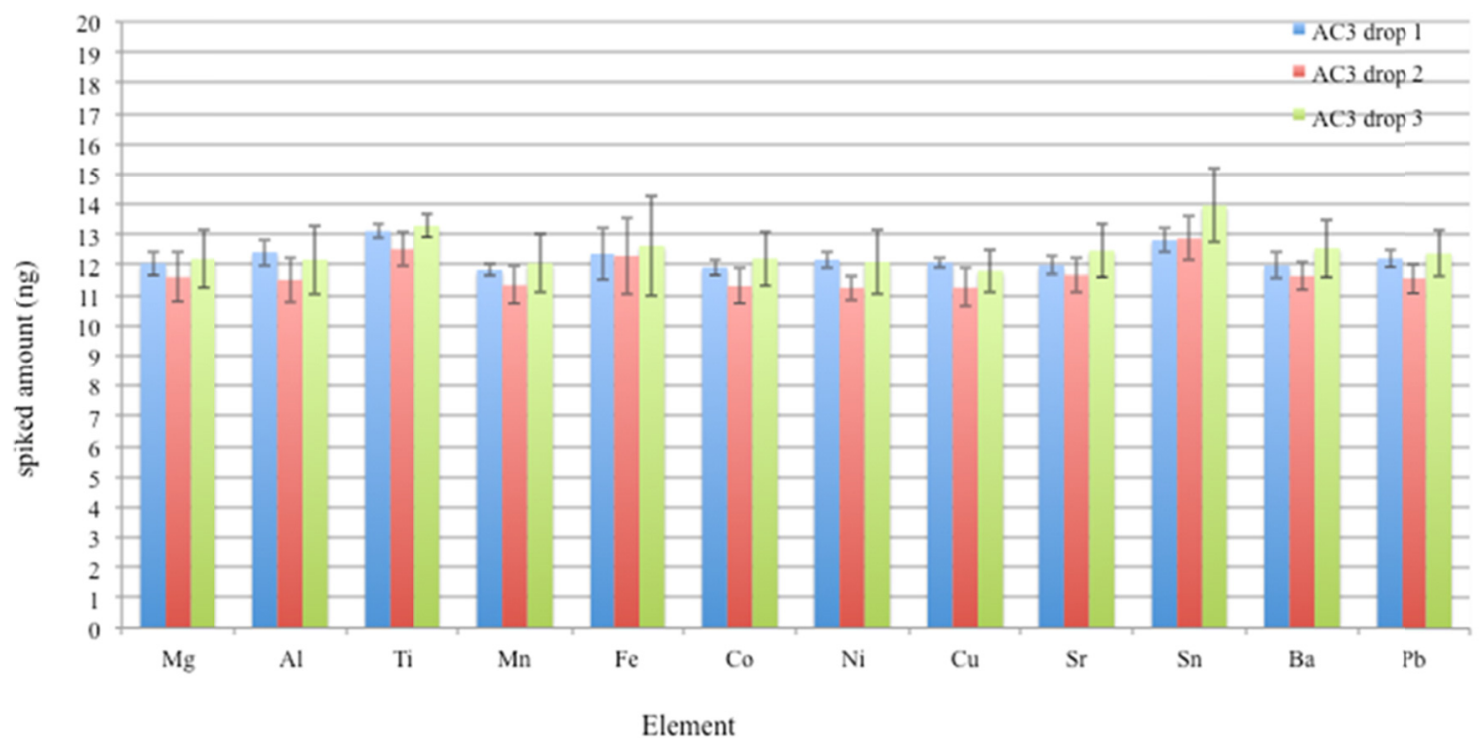

Figure 20. Reproducibility $(n=3)$ and repeatability $(n=5)$ obtained for ink standards spiked with $12.5 \mathrm{ng}$ of the elements of interest. 
The calibration curves were prepared spiking the dried ink drops with $0.5 \mathrm{uL}$ of stock solutions ranging from 5 to $37.5 \mu \mathrm{g} / \mathrm{mL}$, therefore the absolute spiked amounts in the total drop area ranged from 2.5 to $18.75 \mathrm{ng}$. Each ablation replicate removed ink from an area of about 7E4 $\mathrm{um}^{2}$. Since the total average drop area is about $6.4 \mathrm{E} 7 \mu \mathrm{m}^{2}$, assuming a homogeneous distribution of the spiked mass in the drop, the analytical signal detected by the instrument is coming from approximately 2.7 to $20 \mathrm{pg}$ of each spiked element. Good linear response was observed at these spike levels. For instance, figure 21 shows a calibration curve obtained by LA-ICP-MS analysis of an ink standard spiked with strontium.

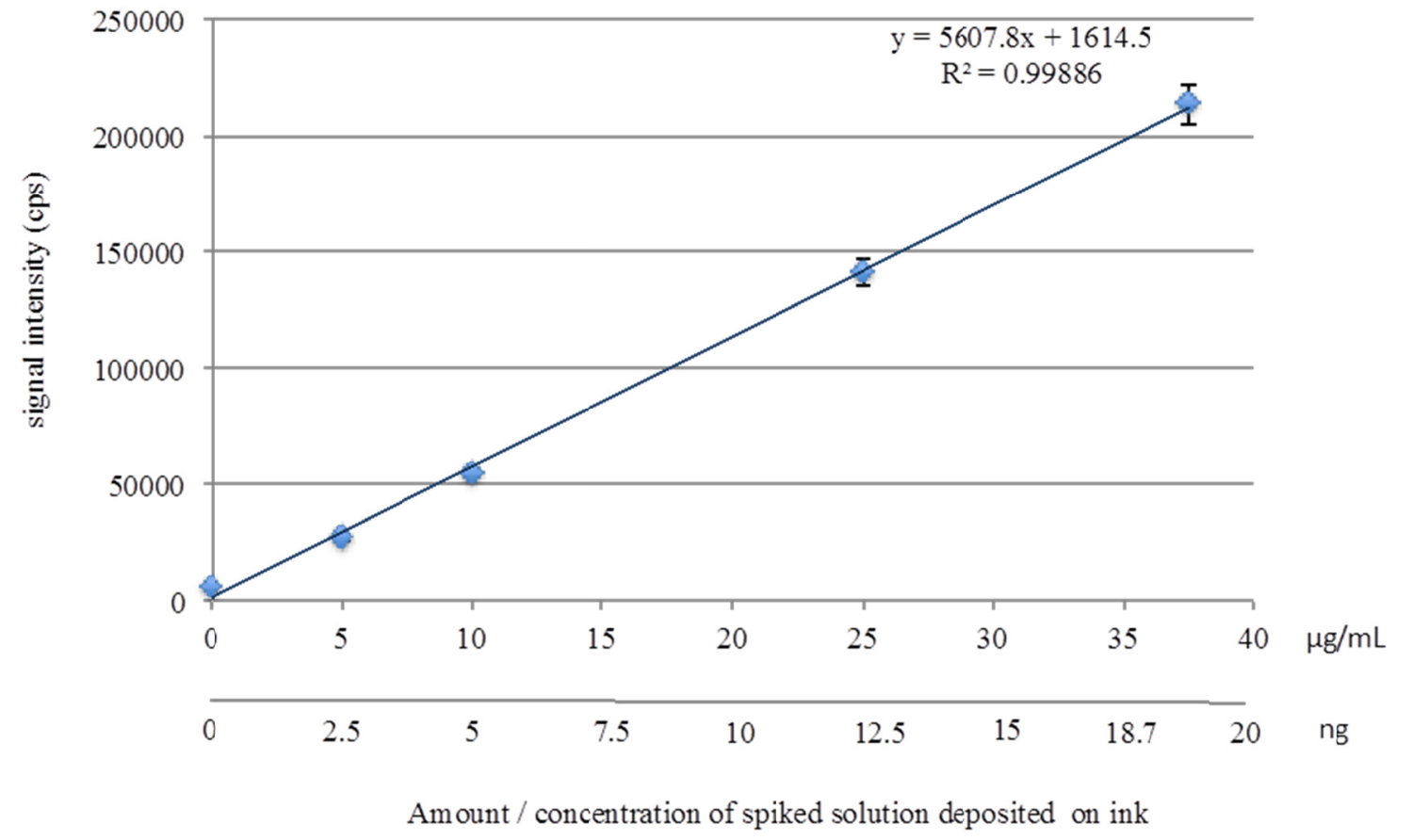

Figure 21. Calibration curve of matrix-matched spiked ink on paper for the analysis of $\mathrm{Sr}$ in writing inks by LA-ICP-MS. 
Finally, the use of internal standardization was also studied for ink analysis. Rhodium was evaluated as a potential internal standard that could be spiked at similar concentration levels in the in-house ink matrix-matched standards and in the ink samples. Although the calibration curve for the ink standards worked well with $\mathrm{Rh}$ as internal standard, a practical problem was identified with the spikes of the ink samples from our collection set. Depending on the ink type (i.e., ballpoint vs. gel), some ink surfaces affected the absorption and distribution of the internal standard into the writing strike. The lack of uniformity was easily observed with the Rh solution because of its inherent red-color. As a result the performance of $\mathrm{Rh}$ as an internal standard was diminished in real samples.

As an alternative, the use of ${ }^{13} \mathrm{C}$ was also explored for the analysis of ink. Since there is always a certain amount of paper substrate been removed along with the ink regardless of the mildest optimized ablation conditions- it is assumed that the ${ }^{13} \mathrm{C}$ signal comes primarily from the paper fibers and therefore it can be used as an internal standard.

It was previously demonstrated for the paper analysis that the ${ }^{13} \mathrm{C}$ level on paper does not vary considerably from papers of similar type (i.e., multipurpose) as a consequence of its relatively high composition of cellulose $(\sim 80 \%)$. As a result, the use of ${ }^{13} \mathrm{C}$ for ink analysis serves for two-fold purposes, to indicate and correct for any variation of the mass of ink removed between replicate analysis and also to monitor the amount of paper been removed with the ink.

Figure 22 shows the signal of ${ }^{13} \mathrm{C}$ as it is been monitored in the ICP-MS at different time intervals: a) prior laser ablation, just monitoring background levels of the gas blank (0-20 s); b) during the ablation of the paper substrate (20-60s); c) during the 
ablation of the ink standard deposited on the same paper substrate $(60-300 \mathrm{~s})$ and d) post ablation as the carrier gas cleans up the cell and gas lines $(300-400$ s). Figure 22 also shows the signal of 4 other analytes monitored during the same ablation stages; the graph highlights some important features of ${ }^{13} \mathrm{C}$ that make it a feasible internal standard for ink analysis. First, it can be assumed that the $\mathrm{C}$ content on paper is much greater than the $\mathrm{C}$ content on inks and therefore the major contribution of ${ }^{13} \mathrm{C}$ is coming from the paper substrate rather than the organic components on ink. The hypothesis is supported by the steady signal of ${ }^{13} \mathrm{C}$ at the "paper" ablation stage and the at the "ink signal" across the ink. No significant signal increase is observed while the laser is moved from the paper substrate to the ink substrate. In contrast, other signals coming primarily from the ink composition increased sharply once the laser beam starts interacting with the ink.

Second, the signal stability of the ${ }^{13} \mathrm{C}$ across the ink is appropriate for its use as internal standard. Third, the instrumental response for ${ }^{13} \mathrm{C}$ is within the same scale of the instrumental responses for other analytes of interest (i.e., $\mathrm{Mg}, \mathrm{Cu}, \mathrm{Ba}$ and $\mathrm{Sr}$ shown in the graph).

Finally, the variability of the ${ }^{13} \mathrm{C}$ within different samples and standards was determined to be less than $15 \%$ RSD. Calibration curves using ${ }^{13} \mathrm{C}$ had good linear response $\left(\mathrm{r}^{2}>0.992\right)$ and precision better than $10-15 \%$ RSD, depending on the element of interest and its concentration level. 


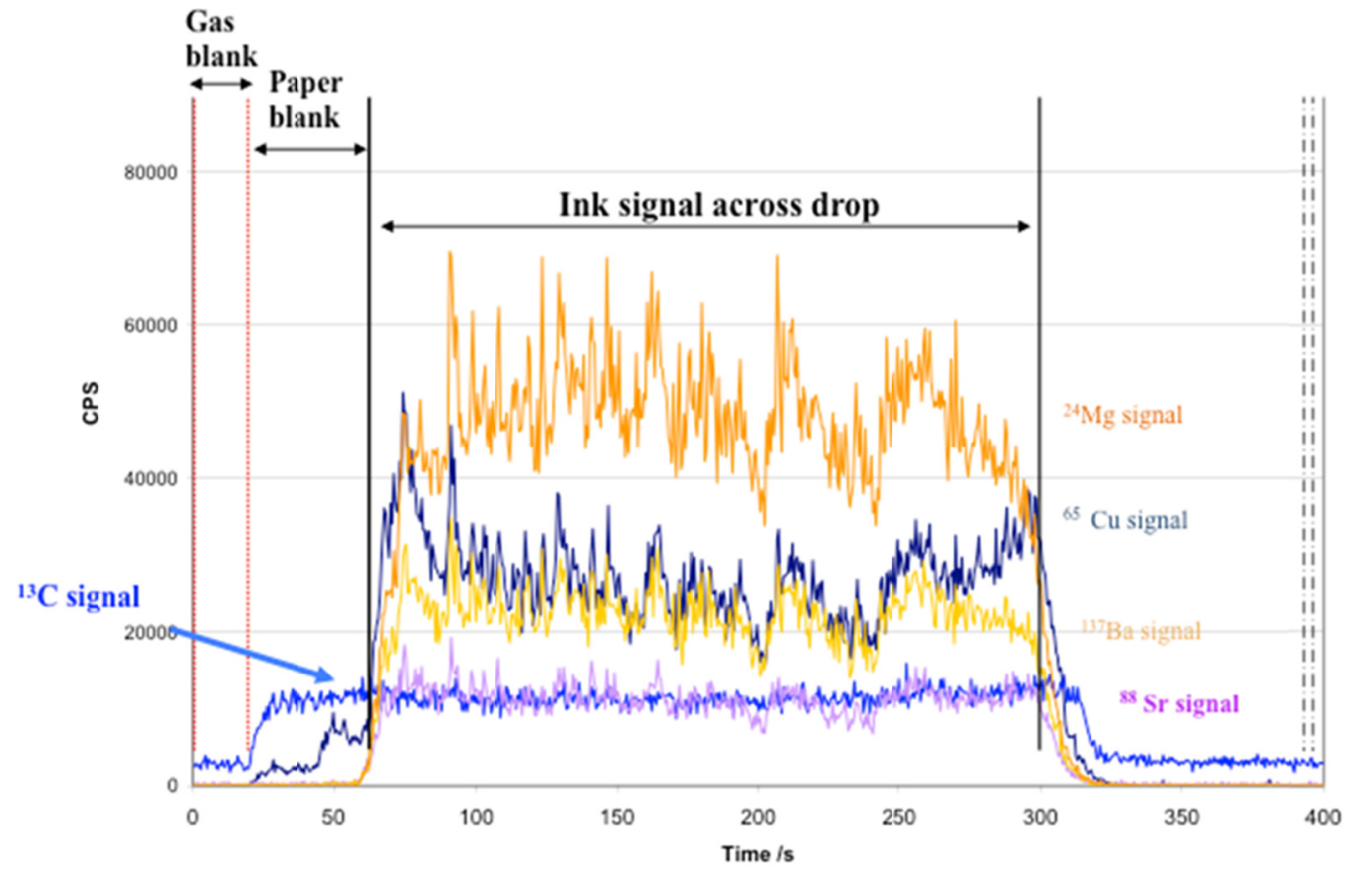

Figure 22. Signal of ${ }^{13} \mathrm{C}$ (light blue) for the gas blank, the ablation of paper and the ablation of ink on paper by LA-ICP-MS.

3.2.1.2 Selection of the elemental menu for the analysis of writing inks by LA-ICP-MS

The most discriminating elements were selected using the same selection criteria previously discussed for paper analysis, which are: a) precision between replicates better than $15 \%$ RSD, b) homogeneous distribution within a source (i.e., pen), c) presence above the limit of detection and above the paper background level d) low percentage of false exclusions and false inclusions, e) variability within a source (i.e., a pen or a package) significantly smaller than variability between sources (i.e., different brands).

One of the most significant differences found between paper and ink on paper matrices is that while the best discriminators found in paper were elements present at minor and major concentration levels, the best discriminators for ink were elements 
present at trace levels $(<1000 \mu \mathrm{g} / \mathrm{g})$. The element menu selected for LA-ICP-MS analysis of black ink samples is composed of eight elements ${ }^{24,25} \mathrm{Mg},{ }^{27} \mathrm{Al},{ }^{55} \mathrm{Mn},{ }^{57} \mathrm{Fe},{ }^{60} \mathrm{Ni},{ }^{65} \mathrm{Cu}$, ${ }^{137} \mathrm{Ba}$ and ${ }^{206,207,208} \mathrm{~Pb}$. In the blue gel formulations the following 13 elements were detected: ${ }^{24,25} \mathrm{Mg},{ }^{27} \mathrm{Al},{ }^{39} \mathrm{~K},{ }^{55} \mathrm{Mn},{ }^{57} \mathrm{Fe},{ }^{65} \mathrm{Cu},{ }^{66} \mathrm{Zn},{ }^{88} \mathrm{Sr},{ }^{91} \mathrm{Zr}$, ${ }^{120} \mathrm{Sn},{ }^{137} \mathrm{Ba},{ }^{178} \mathrm{Hf}$, and ${ }^{206,207,208} \mathrm{~Pb}$. Chromium was also found to be a potential good discriminator for inks but was not used for quantitative comparison purposes because of the high background contribution from the standard paper (Whatman 42). Nonetheless, after using semiquantitative comparison of the signal intensities, it was shown that $\mathrm{Cr}$ provides additional discrimination in some writing inks. The precision of sodium in the samples was greater than $15 \%$ RSD and therefore was monitored but not included in the discriminating menu for LA-ICP-MS.

The presence of Mg on inks can be attributed mainly to extenders used in some ink formulations (talc, china clay). Aluminum and barium are often used as extenders. In addition, Al can be also used as part of the pigments and thickeners composition (specially in ballpoint formulations). manganese, strontium and chromium salts are commonly employed as part of the composition of driers, particularly in resinates and long chain fatty acids. Iron and copper are commonly found as complexing agents on several pigment and dye formulations used for writing inks. For example, iron oxide and victoria blue ( $\mathrm{Cu}, \mathrm{Fe}$ complexes) are common pigments in gel inks, while $\mathrm{Cu}$ complexes are often used in phtalocyanine dyes in ballpoint inks. Nickel can be added as nickel acetate to resins to reduce hue shift and is also encountered in metallized nickel dyes. Although lead has been regulated in many modern formulations, it is still used as part of the pigment (i.e., $\mathrm{PbCrO}_{4}$ ) and the driers. Potassium is used in some blue complex dyes 
such as iron blue and Prussian blue. Tin can be derived from tin acetate used in some formulations as a reducing agent or from tin boxes that are used in the storage of ink tablets. Zinc can be added for many purposes such as pigment $(\mathrm{ZnO})$, extender $(\mathrm{ZnS})$, in resonates $(\mathrm{ZnO})$ and as a metallic drier.

3.2.2 Development and optimization of a LIBS method for the analysis of writing inks

The optimization protocol followed for the optimization of LIBS analysis of writing inks was very similar to the one previously discussed for paper analysis. The main differences found in terms of optimization were the frequency rate and the speed rate. In order to minimize the amount of paper been removed along with the ink, the frequency was reduced to $2 \mathrm{~Hz}$ and the speed rate was increased to $25 \mathrm{um} / \mathrm{s}$. As a result of the increase in speed rate, the length of the ablation line was increased to $2600 \mathrm{um}$ to be able to collect and accumulate 100 shots per spectra. Table 17 lists the optimum instrumental parameters for writing inks.

\subsubsection{Calibration strategies for writing ink analysis by LIBS}

Matrix-matched ink standards were prepared as previously discussed for LA-ICPMS analysis. However, as a result of the differences in sensitivities between the laser ablation techniques, the spike concentration levels were increased for LIBS analysis according to its limits of detection. Although linearity was tested from spiked levels from 0 to $3000 \mu \mathrm{g} / \mathrm{g}$ (amount deposited on ink from 0 to1500 $\mathrm{ng}$ ), it was later found that most of the elements were present at low concentration levels, therefore the calibration curve 
was only utilized at a range from 0 to $500 \mu \mathrm{g} / \mathrm{g}$ for most of the elements. Figure 23 shows an example of the linear response range for $\mathrm{Mg} 280.2 \mathrm{~nm}$ (II).

Carbon emission lines with enough sensitivity were not detected at the spectral ranges of interest. Since a Czerny Turner spectrometer was used for this set of samples, an useful internal standard was not found at the spectral regions of interest. Therefore quantitative analyses were conducted using the background-corrected integrated area for the peaks without internal standardization.

Table 17. Optimized instrumental parameters for the analysis of writing ink by LIBS

\begin{tabular}{|c|c|}
\hline Parameter & LIBS \\
\hline Laser & 1064nm (NdYAG, 50mJ max) \\
\hline Spot size & line \\
\hline Ablation mode & $25 \mu \mathrm{m} 2 \mathrm{~s}$ \\
\hline Scan rate & 100 \\
\hline \# of shots & $450 \mu \mathrm{m} * 2600 \mu \mathrm{m}$ \\
\hline Sampling area & $2 \mathrm{~Hz}$ \\
\hline Repetition rate & $35 \%$ \\
\hline Flash lamp voltage & $1.4 \mu \mathrm{s}$ \\
\hline Gate delay & $4 \mu \mathrm{s}$ \\
\hline Gate width & $\mathrm{Cu}, \mathrm{Na}, \mathrm{Mg}, \mathrm{Mn}$ \\
\hline Elemental menu & \\
\hline
\end{tabular}




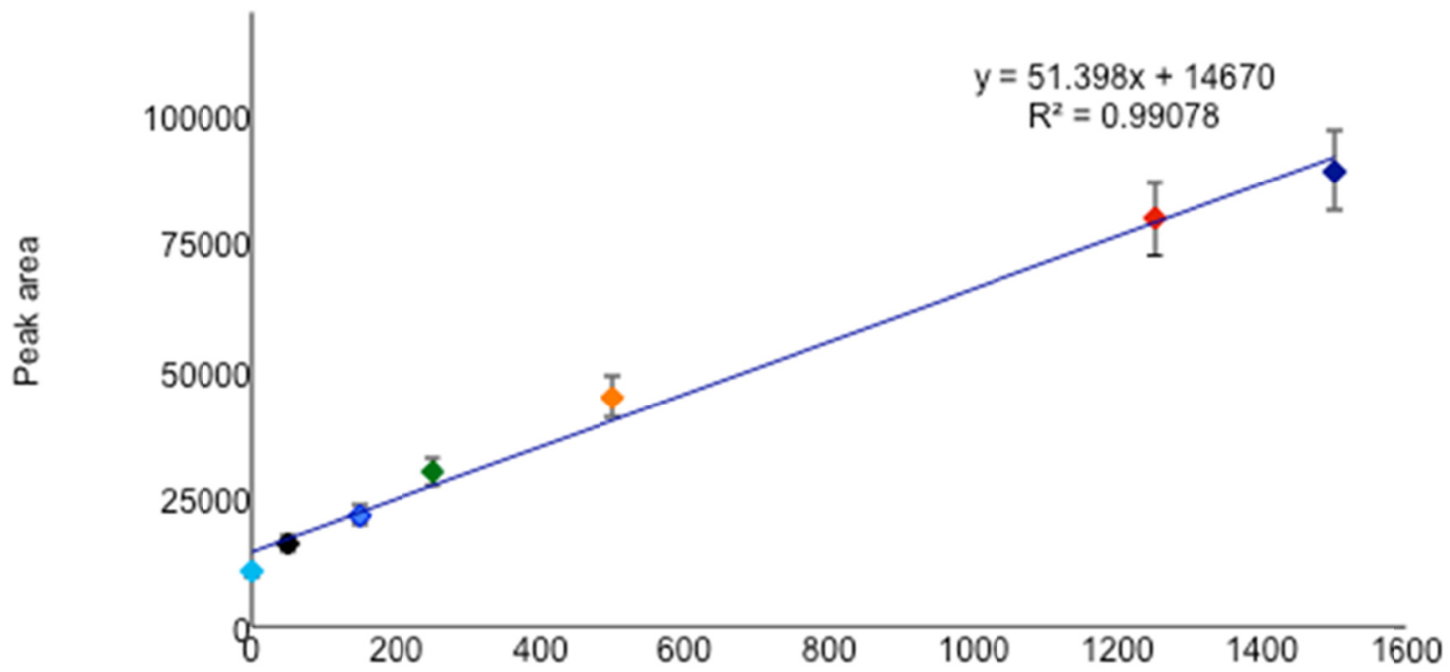

Deposited mass on ink (ng)

Figure 23. Calibration curve of Mg deposited on ink analyzed by LIBS (Mg II, $280.2 \mathrm{~nm}$ )

Although the quantitative analysis of inks by LIBS was viable, semi-quantitative comparison of the spectra was also explored as an alternative comparison method. One of the advantages of LIBS over LA-ICP-MS data is that the peak wavelength and peak height can be used to do semi-quantitative comparisons via spectral overlay. The LIBS system used in this research was equipped with software that allows easy comparison of spectra by the regions of interest. The performance of spectra overlay comparison was comparable to the quantitative results using external calibration, however spectra overlay was less time consuming.

Figure 24 shows some examples of qualitative and quantitative differences observed between black gel inks using the spectral overlay comparison. While some differences are qualitative, for example differences in Fe and Mn signals between spectra 
$\mathrm{A}$ and $\mathrm{C}$ or $\mathrm{Cu}$ in spectra $\mathrm{E}$, some differences are quantitative, for example the $\mathrm{Cu}$ content on spectra B and D.
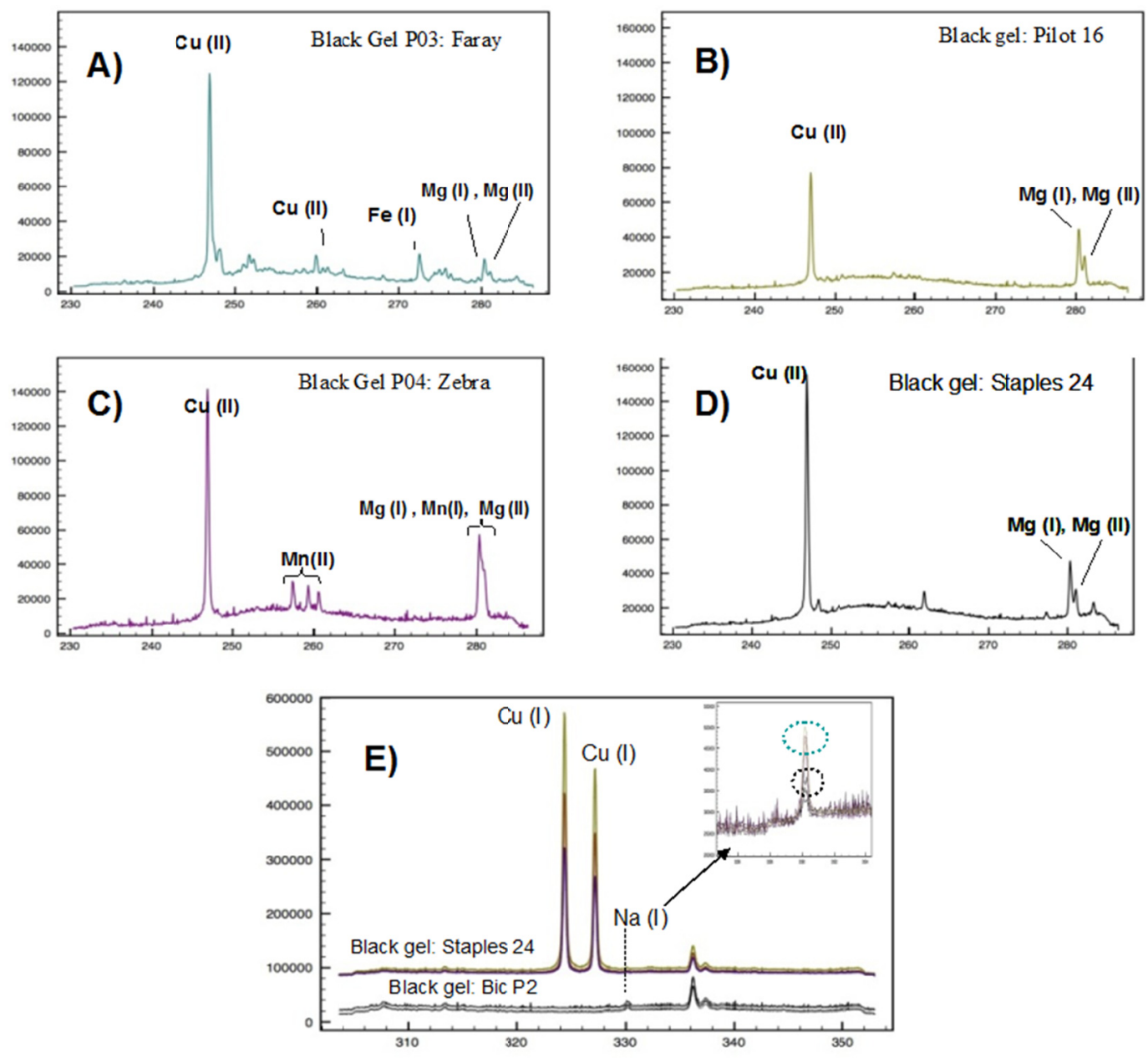

Figure 24. Part of the LIBS spectra of six different black gel inks at 232-284nm (A-D) and 304-354nm (E). 
3.2.2.2 Selection of the elemental menu for the analysis of writing inks by LIBS

For the analysis of inks by LIBS, the following emission lines were selected for quantitative and qualitative comparisons $\mathrm{Cu}$ (I) $324.3 \mathrm{~nm}, \mathrm{Na}$ (I) $330.2, \mathrm{Mg}$ (II) $280.2 \mathrm{~nm}$, Mn (II) $255.8 \mathrm{~nm}$. Additional qualifier lines were monitored qualitatively to corroborate the presence of each element, as follows: Copper (327.4nm (I), 329.3nm (I) and $261.8 \mathrm{~nm}$ (I)], Sodium [588.5nm (I) and 589.4nm (I)], Magnesium [279.4nm (I), 517.3nm (I), $518.4 \mathrm{~nm}(\mathrm{I})]$, Manganese [257.7nm (II), 259.3nm (II)].

3.2.3 Comparison of figures of merit for the analysis of writing inks by LA-ICP-MS and LIBS

A comparison of the figures of merit between the LA-ICP-MS and LIBS for the analysis of writing inks is found in table 18. The selected elements and emission lines were linear at the concentration range of the samples $\left(\mathrm{r}^{2} 0.999\right.$ to 0.989 for LA-ICP-MS, 0.997 to 0.984 for LIBS).

As reported here, LOD is the concentration at which the analyte signal is three times the system noise. The LODs were determined for several elements in in-house matrix match standards spiked at different levels close to the expected LOD.

The limits of detection of the methods were determined for each element by measuring procedure blanks. For LA-ICP-MS, blanks corresponded to the background signal prior the laser interaction with the ink material For LIBS, blanks corresponded to the background signal near the peak of interest.

The LODs were calculated by three times the standard deviation of twenty-one instrumental replicates from the matrix standards as follows: 


$$
L O D=\text { mean }_{\text {background }}+3 \text { stdev }_{\text {background }}(n=21)
$$

Limits of detection for LIBS were some orders of magnitude lower than LA-ICPMS, which affected the capability of detection of some elements that were found by LAICP-MS in the low ppm range.

Table 18. Figures of merit for laser-based methods for the analysis of writing ink.

\begin{tabular}{|c|c|c|c|c|c|}
\hline \multicolumn{2}{|c|}{ Elemental list } & \multicolumn{2}{|c|}{ LA-ICP-MS } & \multicolumn{2}{|c|}{ LIBS } \\
\hline Element & $\begin{array}{c}\text { Concentration } \\
\text { in sample sets } \\
\mu \mathrm{gg}^{-1}\end{array}$ & $\begin{array}{c}\mathrm{LOD} \\
\left(\mu \mathrm{gg}^{-1}\right)\end{array}$ & $\begin{array}{c}\text { Precision } \\
\text { (\%RSD) }\end{array}$ & $\begin{array}{c}\mathrm{LOD} \\
\left(\mu \mathrm{gg}^{-1}\right)\end{array}$ & $\begin{array}{l}\text { Precision } \\
(\% \text { RSD) }\end{array}$ \\
\hline $\mathrm{Na}$ & nd-5100 & 2.1 & 16 & $\begin{array}{c}720 \\
(\mathrm{Na} I 330.2)\end{array}$ & 9 \\
\hline $\mathrm{Mg}$ & nd-560 & 0.2 & 7 & $\begin{array}{c}50 \\
(\mathrm{Mg} \text { II } \\
280.2)\end{array}$ & 10 \\
\hline $\mathrm{Al}$ & nd-3841 & 0.9 & 5 & n.a & n.a \\
\hline $\mathrm{Mn}$ & nd-40 & 0.5 & 5 & $\begin{array}{c}15 \\
(\mathrm{Mn} \text { II } \\
255.8) \\
\end{array}$ & 7 \\
\hline $\mathrm{Fe}$ & nd-572 & 2.8 & 6 & n.a & n.a \\
\hline $\mathrm{Ni}$ & nd-12 & 0.6 & 4 & n.a & n.a \\
\hline $\mathrm{Cu}$ & nd-1000 & 0.3 & 4 & $\begin{array}{c}10(\mathrm{Cu} \mathrm{I} \\
324.3)\end{array}$ & 8 \\
\hline $\mathrm{Ba}$ & nd-21 & 0.6 & 6 & n.a & n.a \\
\hline $\mathrm{Pb}$ & nd-108 & 0.8 & 5 & n.a & n.a \\
\hline
\end{tabular}

nd: below method detection limit ; na: not measured ; LOD: limits of detection

3.2.4. Development and optimization of a LA-ICP-MS method for the analysis of printing inks

There are significant differences between writing inks, inkjet inks and laser toner inks in terms of their chemical composition as well as the physical interaction of the ink 
with the paper substrate. As a result each of these 3 ink types was treated as a different matrix and a independent optimization was conducted for each ink type to adjust the parameters to their specific requirements.

The major differences found between inkjet inks and toners were the elemental composition and the absorption/deposition interaction of the ink with the paper substrate. Table 19 summarizes the optimized parameters for these inks. The detail about how these parameters were chosen is discussed below.

One of the aims during the optimization of the energy, or flash lamp voltage, was to minimize the contribution of the paper signal to the ink signal. For this reason, it was necessary to select an energy that would allow for enough removal of ink without too much removal of paper. Samples of inkjet ink deposited on paper were ablated at different energy levels (20-35\% energy in 5\% increments). The respective laser ablation signals were monitored for 35 elements.

Regardless of the mild ablation conditions, there was always a percentage of paper removed along with the ink. In order to normalize any difference in the ratio of paper/ink removed between replicate samples, ${ }^{13} \mathrm{C}$ was used as internal standard. As explained before, the use of an isotope present in the matrix substrate, such as ${ }^{13} \mathrm{C}$, was convenient because it eliminates the need of spiking the samples with an exogenous internal standard.

During the optimization, the signal of ${ }^{13} \mathrm{C}$ was monitored along with the analytes of interest as an indication of how much paper is been removed with the ink. Figure 25 shows that at $20 \%$ energy the signal of the monitored analytes $(\mathrm{Mg}, \mathrm{K}, \mathrm{Cu})$ was not sensitive enough. At $25 \%$ and $30 \%$ however, the signal to noise ratio for the elements 
was significantly improved. At laser energy above $30 \%$, there was not a significant increase in the analyte's signal while the signal for ${ }^{13} \mathrm{C}$ increased, which means that more paper is being removed while the amount of ink available has been consumed.

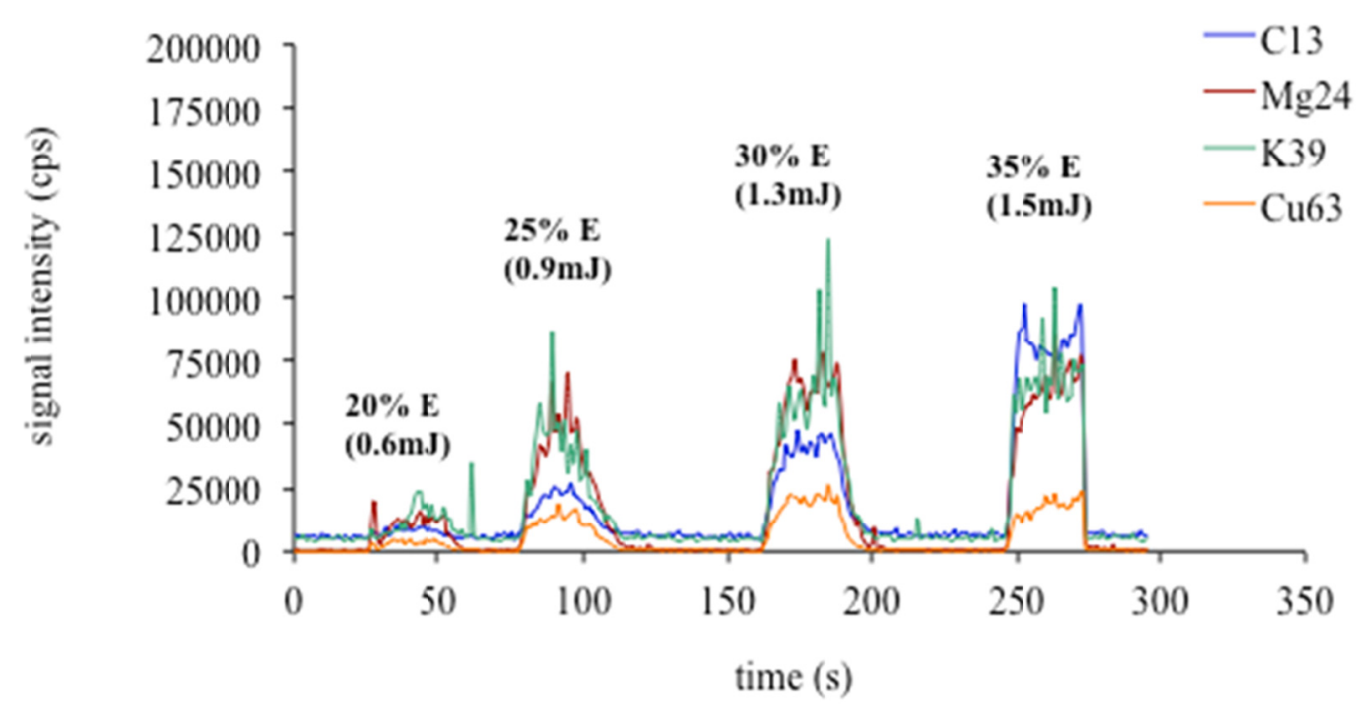

Figure 25. Laser ablation signals at different energy levels for $\mathrm{C}, \mathrm{Mg}, \mathrm{K}$ and $\mathrm{Cu}$.

In order to further investigate whether $25 \%$ or $30 \%$ energy was better, the signal to noise ratio (SNR) for a suite of elements of interest was estimated taken the average area of the signal from the paper as the noise and the average area of the signal from the ink on paper as the signal. Figure 26 shows the transient signal for some elements of interest for inkjets (top) and the zoomed signal for $\mathrm{Cu}$ only (bottom). Although a greater intensity was achieved for some elements at 30\% energy, the contribution of the paper in the signal was also larger, decreasing the overall SNR. For this reason, 25\% energy was selected as the optimum value. 


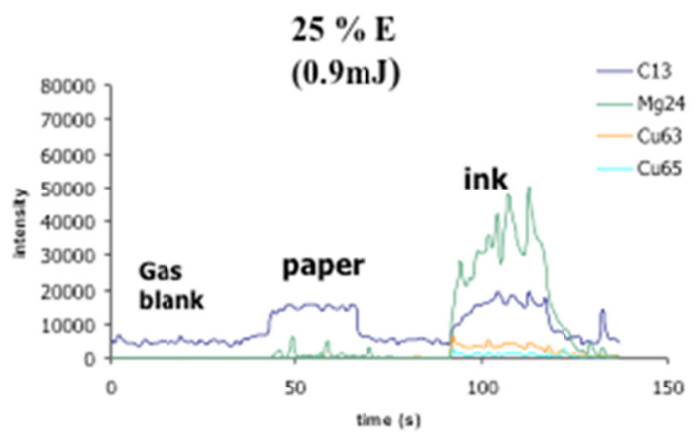

$\mathrm{Cu}$ SNR $=16$

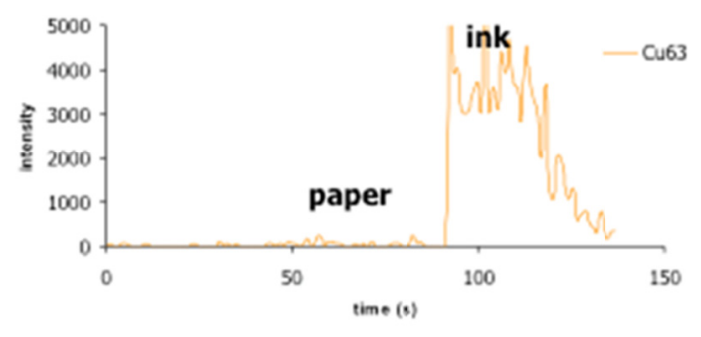

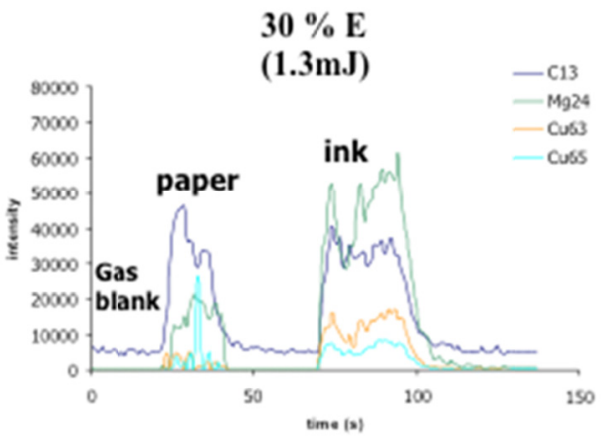

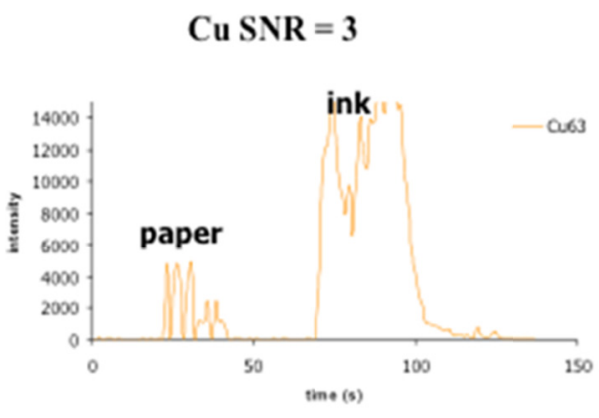

Figure 26. Top: LA-ICP-MS transient signal for gas blank, paper and ink on paper, respectively, for laser energy at $0.9 \mathrm{~mJ}$ (left) and $1.3 \mathrm{~mJ}$ (right). Bottom: respective signals for $\mathrm{Cu}$ only.

For further verification, a 3D microscope was used to observe the interaction between the inkjet ink and the paper at different energy levels. Figure 27 shows a 3D image of the ablation sites at different energy levels. At 30\% and 35\% energy a deeper crater is formed within the paper substrate. The deeper crater indicates that the laser has penetrated too deep and therefore has removed an unnecessary amount of paper. At $25 \%$ however, there is enough removal of ink with minimal paper destruction. A similar study was performed on a toner ink sample and the same energy parameter provided the best laser-ink interaction $(25 \% \mathrm{E})$. 
Table 19. Optimized instrumental parameters for the analysis of printing inks (inkjets and toners) by LA-ICP-MS.

\begin{tabular}{|c|c|c|}
\hline Parameter & Inkjet & Toner \\
\hline Laser & $\begin{array}{l}\mathrm{Nd}: Y A G \text { 266nm } \\
(\sim 9 \mathrm{~mJ} \text { max })\end{array}$ & $\begin{array}{l}\text { Nd:YAG 266nm } \\
\text { ( 9mJ max) }\end{array}$ \\
\hline Spot size & $200 \mathrm{um}$ & $250 \mathrm{um}$ \\
\hline Frequency & $10 \mathrm{~Hz}$ & $10 \mathrm{~Hz}$ \\
\hline Scan rate & $25 \mathrm{um} / \mathrm{s}$ & $25 \mathrm{um} / \mathrm{s}$ \\
\hline Line length & $600 \mathrm{um}$ & $800 \mathrm{um}$ \\
\hline \# shots & 240 & 320 \\
\hline \% Energy & $25 \%(\sim 0.9 \mathrm{~mJ})$ & $25 \%(\sim 0.9 \mathrm{~mJ})$ \\
\hline Elemental menu & $\mathrm{Mg}, \mathrm{K}, \mathrm{Cu}, \mathrm{Ni}, \mathrm{Zr}, \mathrm{Li}$ & $\begin{array}{c}\mathrm{Pb}, \mathrm{Ti}, \mathrm{Zn}, \mathrm{Ce}, \mathrm{V}, \mathrm{Ba}, \mathrm{La}, \\
\mathrm{Mg}, \mathrm{Co}, \mathrm{Al}, \mathrm{Fe}, \mathrm{Mn}, \mathrm{Si}, \mathrm{Sr}, \\
\mathrm{Cu}, \mathrm{Zr}, \mathrm{Ni} \text { and } \mathrm{Cr}\end{array}$ \\
\hline Calibration strategy & $\begin{array}{l}\text { Semi-quantitative ratio of } \\
\text { areas of intensity to }{ }^{13} \mathrm{C}\end{array}$ & $\begin{array}{c}\text { Semi-quantitative areas of } \\
\text { intensity }\end{array}$ \\
\hline
\end{tabular}



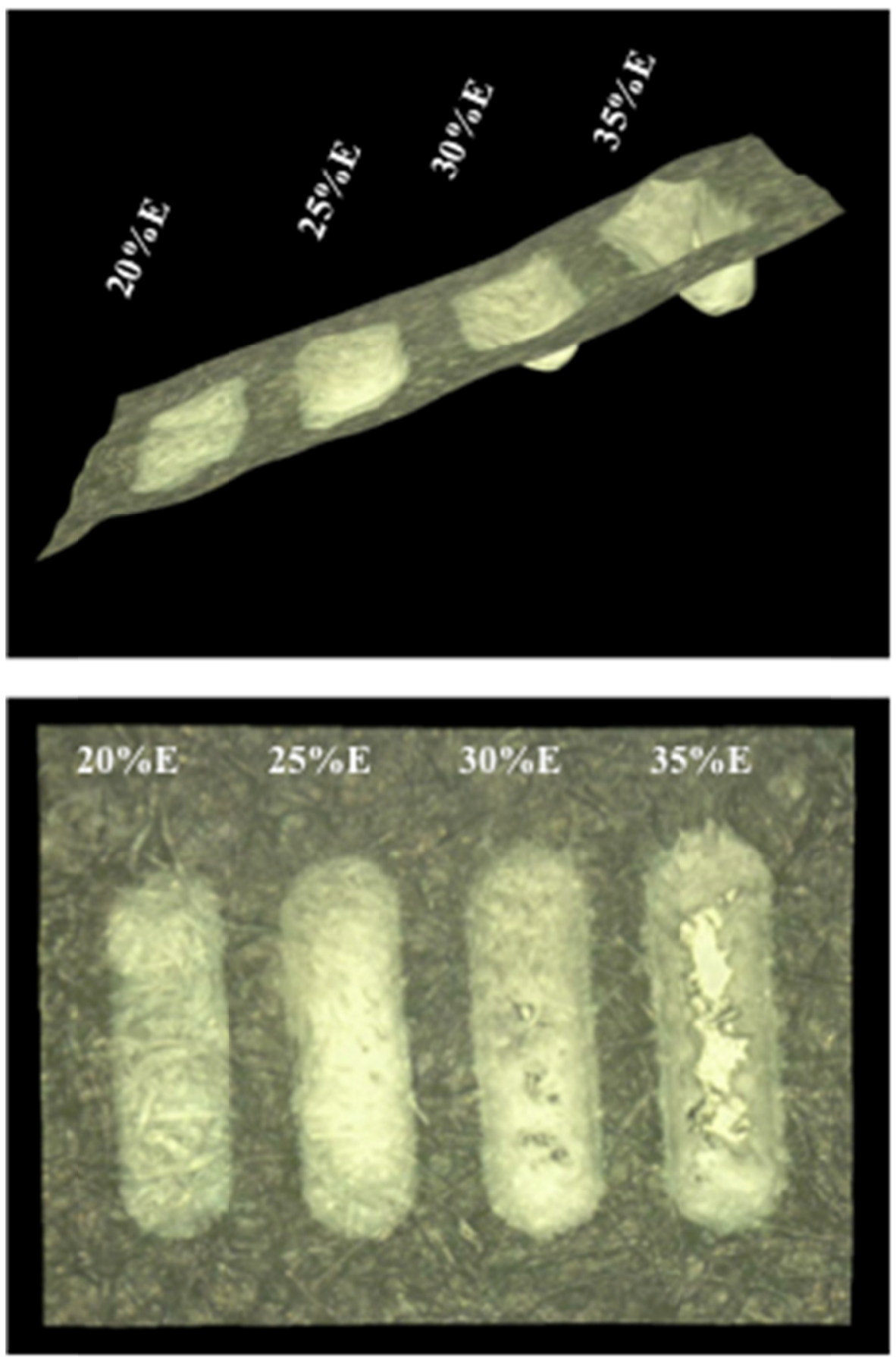

Figure 27. Imaging of the laser interaction with inkjet and paper at different laser energies. Top: 3D imaging, Bottom: 2D image. 
In order to optimize the spot size parameters, it was important to look at how the inks were absorbed and/or deposited onto the paper. Microscopic images were taken under a 3D microscope that revealed the absorption and deposition patterns. Figure 28 below shows the images obtained for both inkjets and toners.

The figure illustrates that toners and inkjets deposit and absorb differently onto the paper. As noted, toners deposit into small particles that appear to lie above the surface of the paper, thus creating a heterogeneous deposition pattern at a microscopic scale. On the other hand, inkjets appear to absorb into the fibers of the paper and thus creating a more homogenous mixture and embedding of ink on paper fibers.

Figure 29 and 30 shows the comparison of variability of deposition of inks between different types/brands on inkjets and toners respectively. Microphotographs were taken for the ink printed on letters. Inkjet samples had a fairly homogeneous absorption pattern of ink into the paper fibers, regardless of the brand or model of the printer (figure 29). On the other hand, large variations in the morphology of the deposited particles and the distribution of the particles is observed on toner samples printed from different brands/models (figure 30 and 31). Because of these differences, it was important to use a larger spot size for toners in order to account for the heterogeneity of the deposition. 

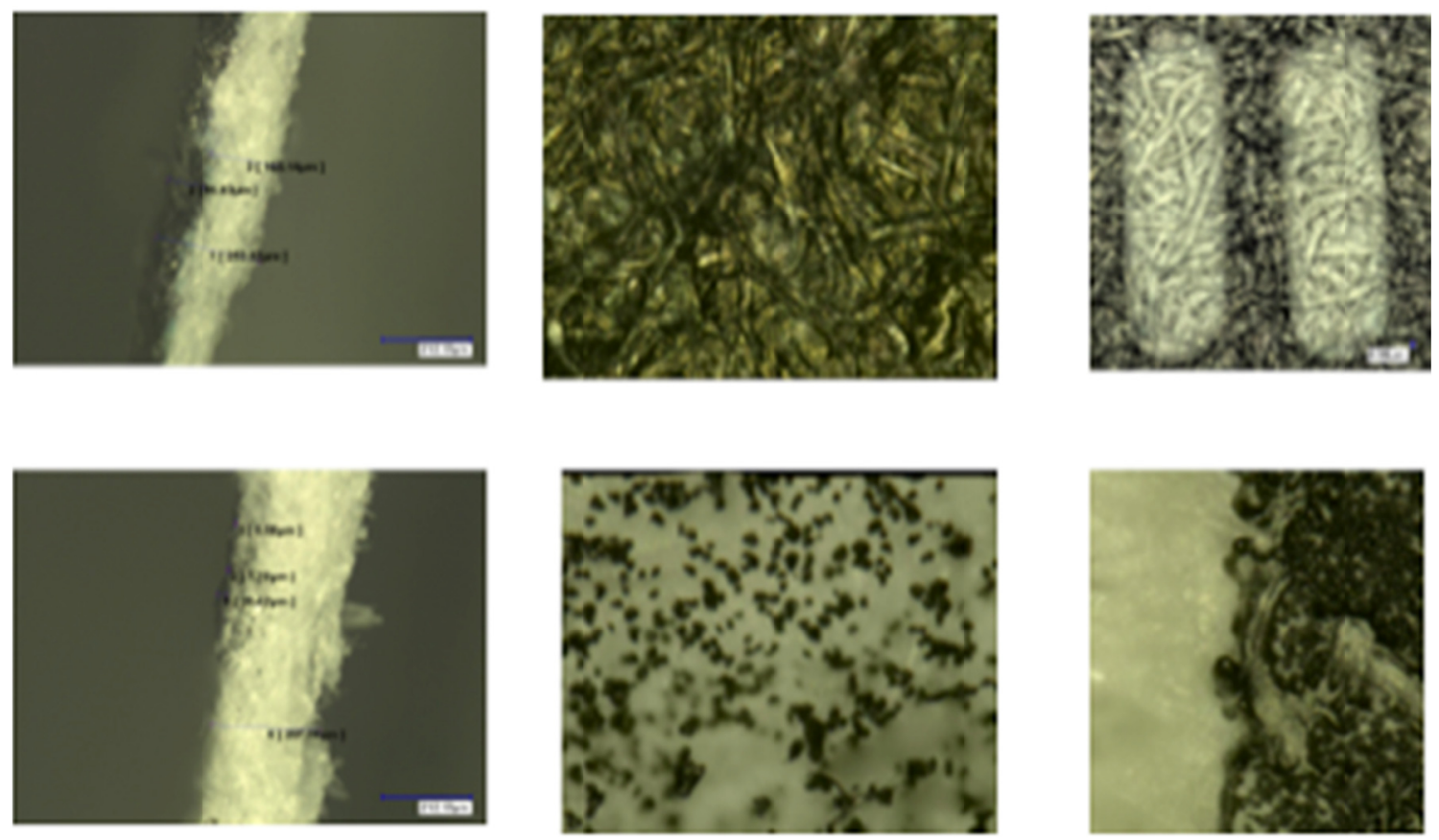

Figure 28. Microscopic images for ink on paper of inkjet (top images) and toner (bottom images). From left to right: cross section image of the deposition of ink on paper at 100x; top image of the ink deposited on the substrate at 500x; and image of the ablation patterns of ink of paper at 200x. 

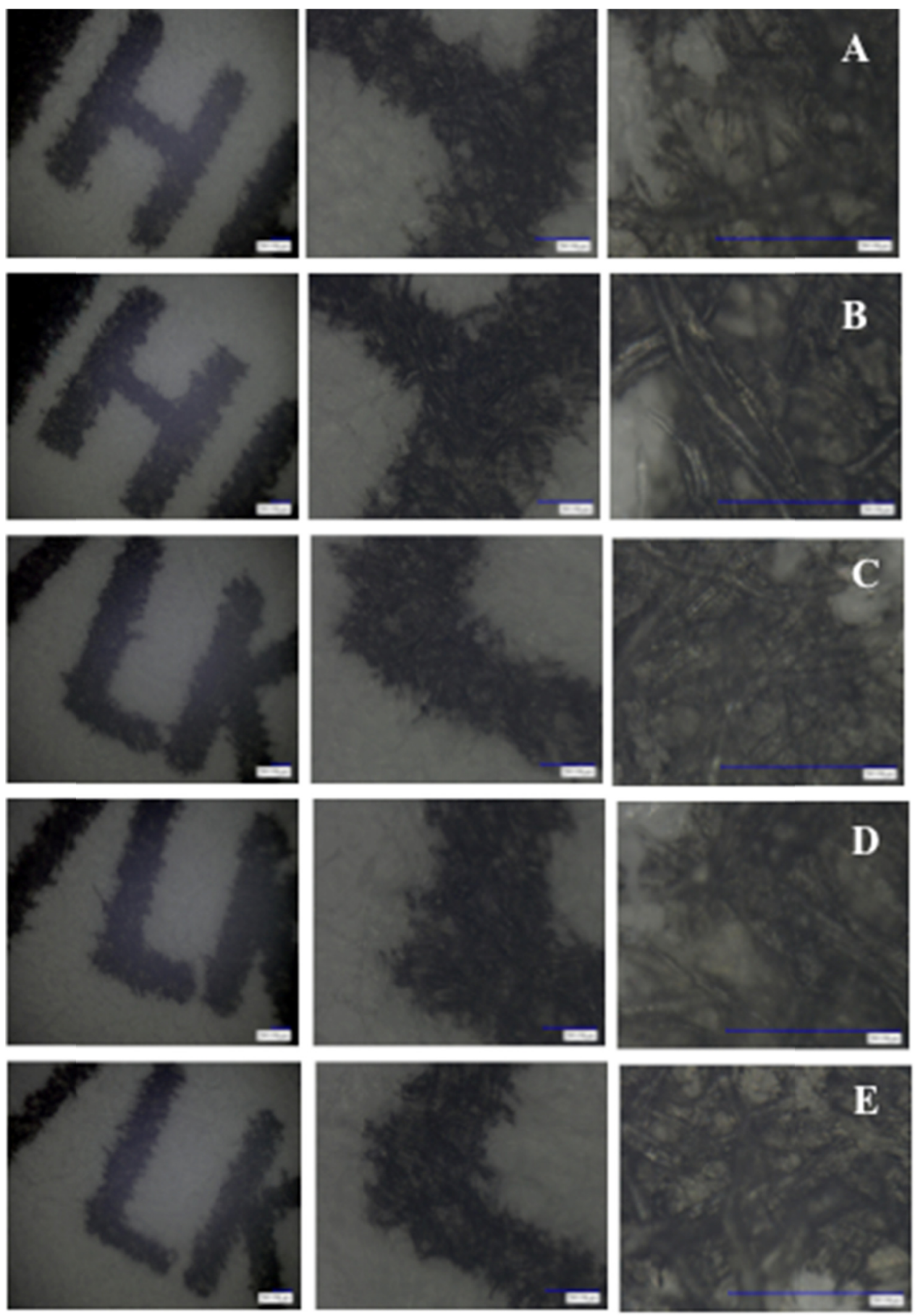

Figure 29. Comparison of absorption patterns of inkjet inks on paper. A) IN 01(Hewlett Packard), B) IN06 (Hewlett Packard), C) IN 14 (Canon), D) IN 15 (Lexmark) and E) IN 18 (Brother). From left to right: magnification at 100x, 300x and 1000x, respectively 

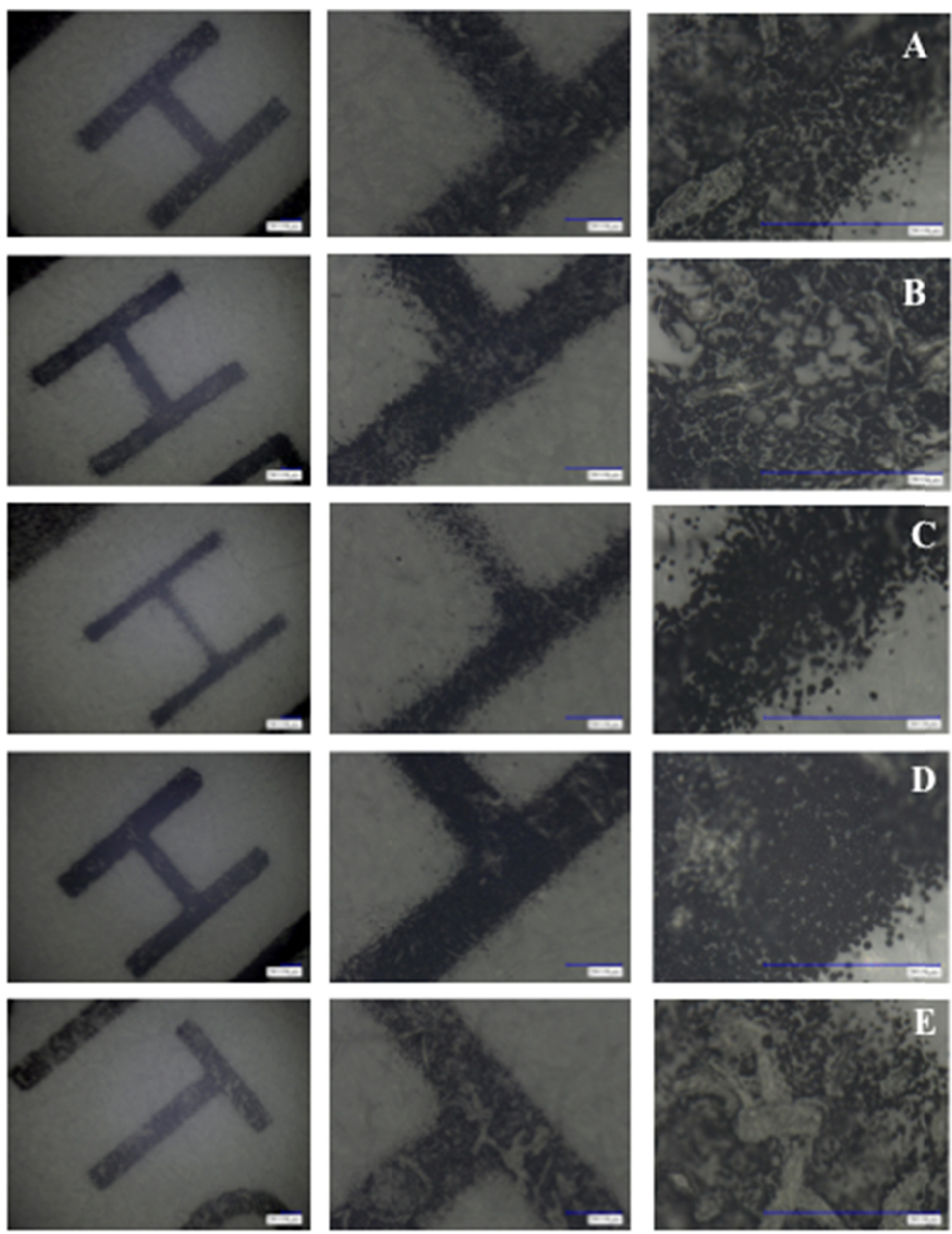

Figure 30. Comparison of deposition patterns of toners on paper. A) T01 (Hewlett

Packard), B) T05 (Hewlett Packard), C) T06 14 (Hewlett Packard), D) T03 (Brother) and

E) T02 (OKI). From left to right: magnification at 100x, 300x and 1000x, respectively. 

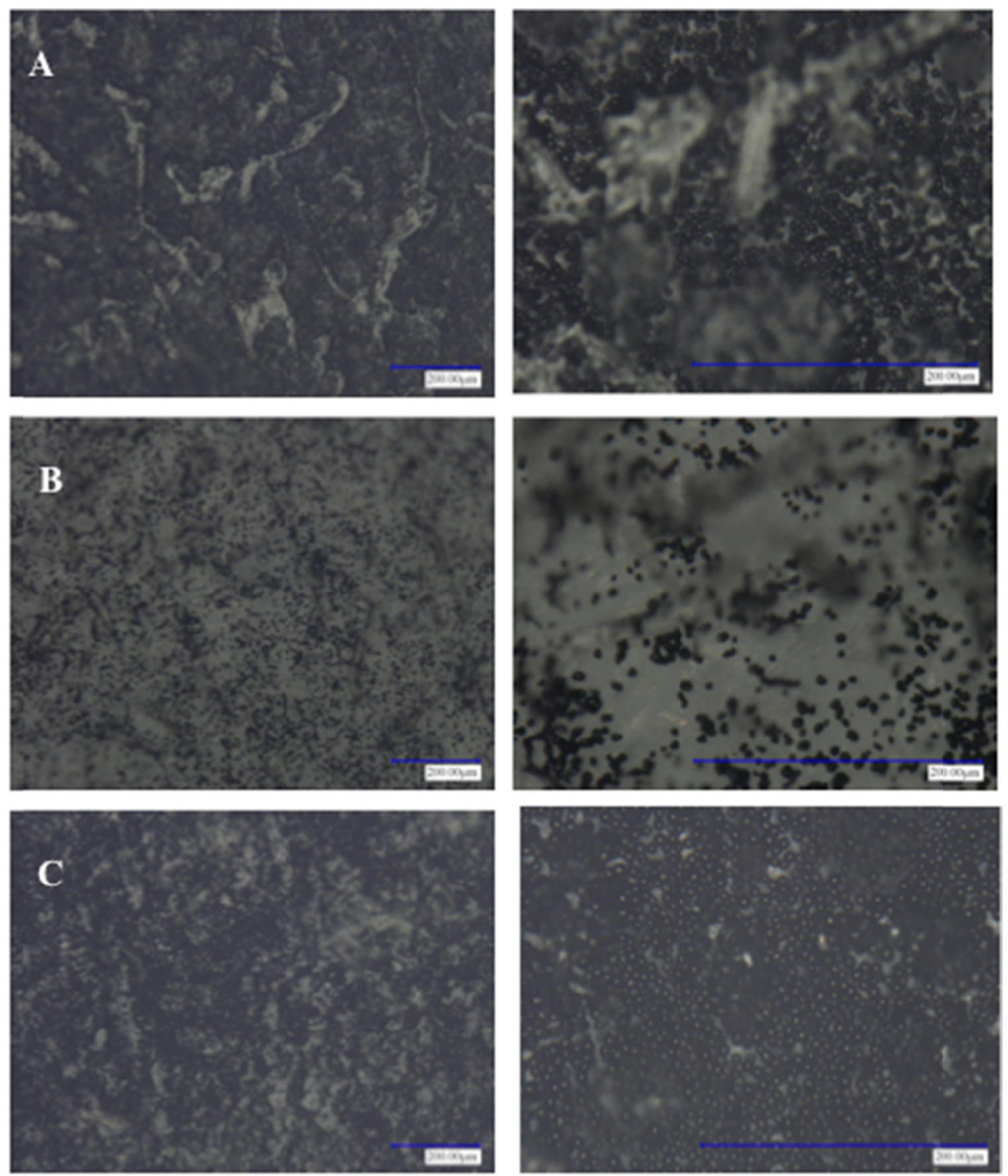

Figure 31. Examples of morphology of toners at 300x (left) and 1000x (right) for toners of the same brand (A and $\mathrm{B})$ and toners from different brand $(\mathrm{C})$. 


\subsubsection{Calibration strategies for the analysis of printing inks by LA-ICP-MS}

The ratio of ink and paper substrate removed during the laser ablation varied significantly between the printing inks and the in-house ink standard designed for writing inks. The amount of removal of paper substrate is consequence of inherent differences between the chemical composition of these inks and their deposition and/or absorption into the paper substrate.

Hence, the use of matrix-matched ink calibration standards was not feasible for printing inks. Instead, for inkjet inks, the area under the transient signal of the ablation was integrated using GeoPRO software. The blank signal and paper signal was used to do background subtraction and to determine which elements present in the ink were present at levels significantly higher than the paper substrate. The signal area was then ratio to

${ }^{13} \mathrm{C}$ as internal standard and used for the semi-quantitative comparison between samples.

On the other hand, the deposition of toner into the substrate was more superficial. For instance, the inkjet inks were fairly evenly absorbed by the ink substrate with penetration depths into the substrate ranging from 60-95 um, while the toners were deposited on top of the surface with layer thickness of less than 10um. Moreover, the density, distribution and shape of the toner particles was heterogeneous and as a consequence the ratio of paper removed with the ink was not as uniform. The elemental contribution of the paper signal to the ink signal was found to be less significant for toners than for other materials, in part to the fact that the elemental concentration on toners was significantly higher than the other types of ink under study.

As a summation of those observations, the use of ${ }^{13} \mathrm{C}$ as internal standard was not efficient for toners. Precision between replicates deteriorated instead of improved with 
internal standardization. The comparison of toners was then conducted on the basis of the semi-quantitative comparison of integrated intensities for the elements of interest.

3.2.4.2 Selection of the elemental menu for the analysis of printing inks by LA-ICP-MS

The process of selecting the elemental menu initially began by monitoring 38 different elements for the inkjet and toner set ( $\mathrm{Na}, \mathrm{Mg}, \mathrm{Al}, \mathrm{Si}, \mathrm{K}, \mathrm{Ca}, \mathrm{Sc}, \mathrm{Ti}, \mathrm{V}, \mathrm{Cr}, \mathrm{Mn}$, Fe, Co, Ni, Cu, Zn, Ga, Ge, As, Br, Rb, Sr, Y, Zr, Rh, Cd, Sn, I, Cs, Ba, Hf, Pb, Bi, La, $\mathrm{Ce}, \mathrm{Nd}$, Th and $\mathrm{U}$ ). Out of the 38 elements monitored for inkjets, only 5 of the elements were present in the samples above the limit of detection $(\mathrm{Mg}, \mathrm{K}, \mathrm{Cu}, \mathrm{Ni}$, and $\mathrm{Zr})$.

One of the advantages of doing LIBS is that the analytical signature of the emitting elements is observed without the need for pre-selecting an element menu. As a result, Li was found to be a good discriminating element for inkjets when analyzed by LIBS. Lithium was not originally included in the LA-ICP-MS initial list and therefore its valuable information was not detected. Lithium was later included in the element menu and confirmed its additional discrimination in this set of samples.

Lithium can be used on inkjets as a conductive element $\left(\mathrm{LiNO}_{3}\right)$ and in a lesser extent as a drier. Magnesium is mainly applied in inkjet formulations as extender. Potassium, copper and nickel are part of many dye compositions. On the other hand, zirconium was present in few inkjet samples. Zirconium can be used as drier and/or be a leaching element from the piezo-crystal component in some inkjet systems.

The small number of elements and the low concentration levels found in inkjet could be a result of the fact that inkjets use dyes rather than pigments in their formulation 
and most of the dyes are non-metallic and require particular low impurity levels to avoid clogging of the printing nozzles.

On the other hand, for the toner set 18 elements were present above the limit of detection (see table 19). Not only were more elements detected in the toner but also the concentration levels were generally higher than the observed on the inkjet samples. The improvement in detection is expected because of the higher amount of pigments, conductive and/or magnetic elements present in their formulation.

In addition to some of the elements already discussed for inkjet recipes. Elements such as $\mathrm{V}, \mathrm{Co}, \mathrm{Mn}, \mathrm{Ce}, \mathrm{Zr}, \mathrm{Sr}$ are used as drier agents in toners. Barium, titanium, zinc and aluminum are commonly employed as pigments and/or extenders. $\mathrm{Cr}$ and $\mathrm{Pb}$ can be found as part of the pigment composition. Silicon is highly used in toner silicon resins as well as anti-settling and bodying agent. $\mathrm{La}, \mathrm{Sr}, \mathrm{Ba}, \mathrm{Zn}$ and $\mathrm{Pb}$ can be used as part of the ferromagnetic composite carrier (i.e., lanthanum manganese hexaferrite, barium ferrite, etc.), particularly in can in two-component toners to aid the development of the electrostatic image. Iron can be part of the pigment composition, can be found as part of impurities from talc and mostly, can be used as magnetite in magnetic toners. When iron is used as magnetic oxide its concentration is typically at the percent levels. Some toner samples in these collection set were easily differentiated by their iron content ranging from percent level, low ppm levels and non-detects, which depends on the type of toner (two-component vs. mono-component, liquid vs powder, magnetographic vs. nonmagnetographic printing process). 
3.2.5 Development and optimization of a method for the analysis of printing inks by LIBS.

For the analysis of printing inks, the LIBS system was upgraded to a broad-band spectrograph from $190 \mathrm{~nm}$ to $1024 \mathrm{~nm}$, which facilitated in great extent the optimization of the parameters and reduced the number of replicate measurements previously required to cover separately every spectral region of interest. The optimization of the laser and detector parameters for the LIBS method included the study of different laser shot repetition rates $(1 \mathrm{~Hz}, 2 \mathrm{~Hz}, 3 \mathrm{~Hz})$. Software and hardware limitations prevented the test of laser frequencies greater than $3 \mathrm{~Hz}$ because the acquisition of the data was not properly managed by the current software settings. A frequency of $3 \mathrm{~Hz}$ was consistently optimal for both printing inks.

The line ablation mode was optimized at different scan rates $(15 \mu \mathrm{m} / \mathrm{s}$ to $50 \mu \mathrm{m} / \mathrm{s}$ in 5um/s increments), flash lamp energies (25-40\% E in 5\% increments), number of laser shots $(50-150)$ and gate delays $(0.9-4 \mu \mathrm{s})$. Table 20 shows the optimized instrumental parameters. The main differences in terms of optimization between these 2 types of printing inks were the gate delay and the elemental menu.

Table 20. Optimum instrumental parameters for the analysis of printing inks by LIBS.

\begin{tabular}{|c|c|c|}
\hline Parameter & Inkjet & Toner \\
\hline Spot size & $300 \mu \mathrm{m}$ & $300 \mu \mathrm{m}$ \\
\hline Line length & $1.875 \mathrm{~mm}$ & $1.875 \mathrm{~mm}$ \\
\hline Scan rate & $25 \mu \mathrm{m} / \mathrm{s}$ & $25 \mu \mathrm{m} / \mathrm{s}$ \\
\hline \# shots & 150 & 150 \\
\hline \% Energy & $35 \%$ & $35 \%$ \\
\hline Gate delay & $1.4 \mu \mathrm{s}$ & $1.2 \mu \mathrm{s}$ \\
\hline Gate width & Fixed $1 \mathrm{~ms}$ & Fixed $1 \mathrm{~ms}$ \\
\hline Elemental menu & $\mathrm{Mg}, \mathrm{K}, \mathrm{Cu}, \mathrm{Li}$ & $\mathrm{Mg}, \mathrm{Sr}, \mathrm{Zn}, \mathrm{Mn}, \mathrm{Al}$ and I \\
\hline
\end{tabular}


3.2.5.1 Calibration strategies and selection of the elemental menu for the analysis of printing inks by LIBS

For the same reason explained before in the LA-ICP-MS method development section, a complete quantitative method was not developed for the characterization of printing inks. Instead, the qualitative and semi-quantitative data from the peak intensities was found to be more useful for comparison of samples. Nonetheless, the linearity of the emission lines for detected elements was tested at different concentration levels to discard any emission line that could potentially produce errors in the comparison of spectra caused by presence of undesirable effects such as self-absorption or other matrix interferences.

Figure 32 shows an example of calibration curves obtained for printed inks spiked with $\mathrm{Li}$ and $\mathrm{Sr}$ at different concentration levels. Good linearity is observed for $\mathrm{Li}$ at the spiked range ( $\sim 2$ to $20 \mathrm{ng}$ of $\mathrm{Li}$ standard). In the case of the emission line of $\mathrm{Sr}$ at $460.7 \mathrm{~nm}$ good linearity was observed between $2 \mathrm{ng}$ at $16 \mathrm{ng}$ of spike level, but selfabsorption was observed above 16ng. 

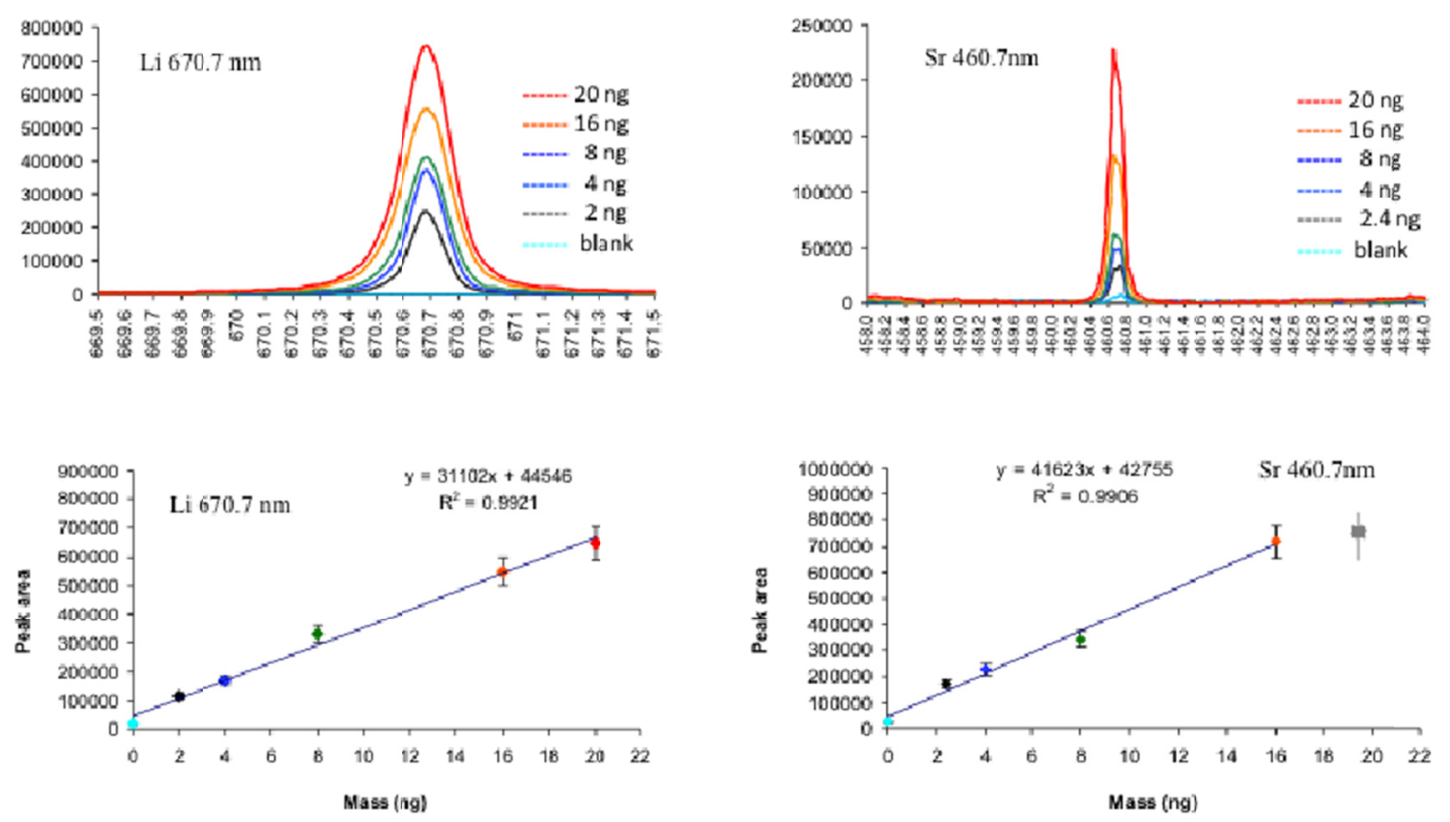

Figure 32. Signal increase at different spiked concentration levels (top) and its respective calibration curve (bottom) for the analysis of Li $670.7 \mathrm{~nm}$ (left) and $\mathrm{Sr} 460.7 \mathrm{~nm}$ (right) by LIBS.

After selection of the informing emission lines, the semi-quantitative method for the characterization of inks was compared to spectra overlay approach. A systematic peak identification and spectral comparison scheme was developed to search and compare only peaks that are relevant to the composition of the ink. As a result, the spectra overlay was conducted at different regions of interest instead of doing an overall comparison of the whole spectral range. Following this approach type I and type II errors cab be minimized by a) preventing comparison of spectral regions that do not have linear response, b) avoiding comparison of spectral regions that are below detection limit, c) limiting comparison of spectral regions that do not experience drastic spectral interferences. 
The spectral overlay approach consisted in the following steps: 1) split the spectra into smaller relevant regions of interest to do spectra overlay, 2) for each region, normalize the signal between replicates by applying background subtraction algorithm available in the LIBS data analysis software, 3) identify the elements of interest with a peak search tolerance equivalent to the spectra resolution $(0.1$ to $0.12 \mathrm{~nm}), 4)$ determine which elements are present above detection limit, 5) compare at least four replicates per sample to determine the within sample variation (range), 6) compare the spectra range of the "known" sample to the spectra range of the "questioned" sample, 7) select one spectra line per element for comparison purposes and at least one additional emission line for confirmation of the element.

The spectral overlay comparison is completed once all the recommended regions of interest are inspected. If a significant and reproducible difference is found between samples in terms of spectral shapes and relative peak heights between any of the monitored elements, then the compared samples are differentiated.

In the case that comparisons between multiple samples $(n>2)$ are required, pairwise comparisons can be conducted. A pairwise matrix of can be created per element of interest, where a total of $n(n-1) / 2$ pairs are compared per element. Where $n$ is the total number of samples compared to each other. The discrimination matrix of each element is then added together to evaluate if each pair of samples can be differentiated by at least one element.

Figure 33 shows the proposed spectral comparison scheme with the elements of interest. Emission lines that are underlined are the primary emission lines used for 
comparisons between samples, other element emissions not underlined are used as confirmatory lines.

Figure 34 shows an example of spectral overlay display from the LIBS software for region III. This example shows the reproducibility of replicate measurements for one of the samples (Toner 04) and the comparison of its profile in this region with two samples originated from different sources (T05 and T01, respectively). Sample T05 was not differentiated from $\mathrm{T} 04$ in this region while $\mathrm{T} 01$ shows a very distinctive spectrum from T04.

As a consequence of the differences in the signal collection and detection between LA-ICP-MS and LIBS, the element menu was slightly different for LIBS analysis. For the inkjet set, only 4 elements were present above the limit of detection for the inkjets. Three of those elements coincide with the element menu chosen for LA-ICP-MS, the rest were not detected by LIBS because of its lower sensitivity. However, one of the advantages of using LIBS is that a pre-set elemental menu is not required and therefore the scanning of the broadband allows for opportunities to detect unusual peaks in the samples that may have not previously preselected as potential discriminating elements. An example of this is that LIBS permitted the detection of Li in some of the ink samples, while the LA-ICP-MS analysis missed this element because it was not included in the preliminary scanning of the pre-set menu. The element was later included in the LAICP-MS method but required the re-analysis of the entire sample set. 


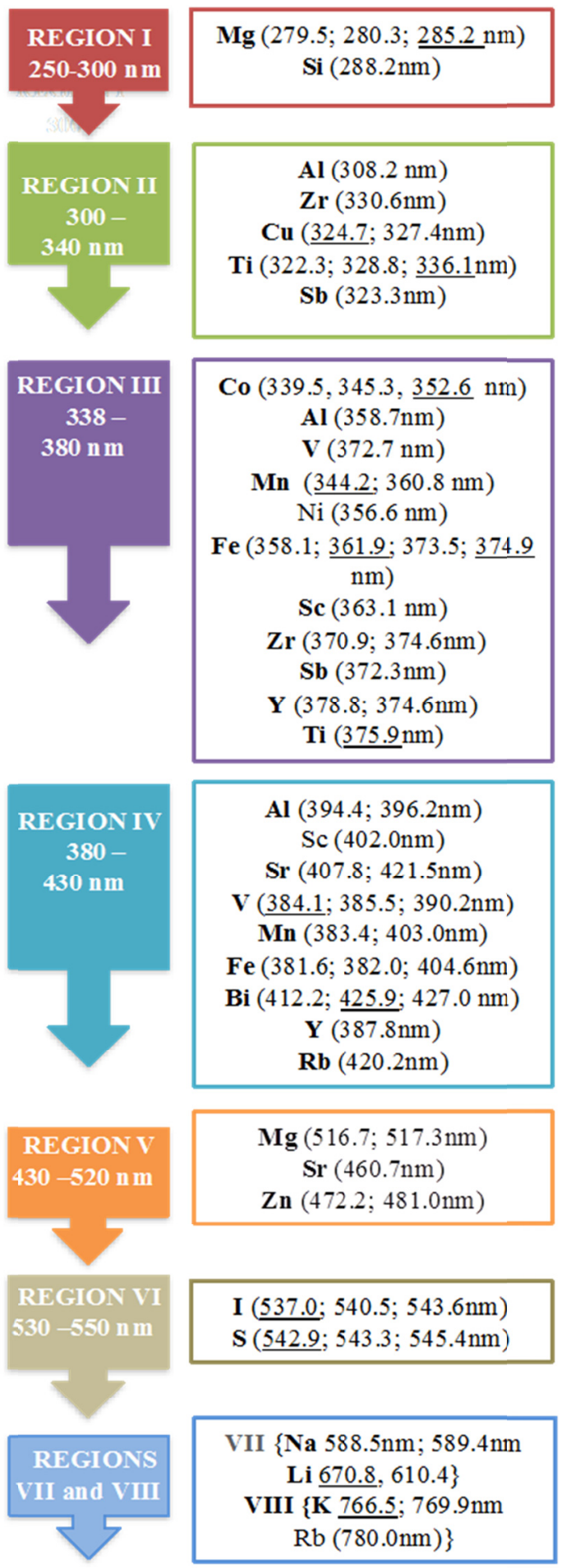

Figure 33. Scheme for the systematic identification of peaks and comparison of LIBS ink spectra by spectral overlay. 

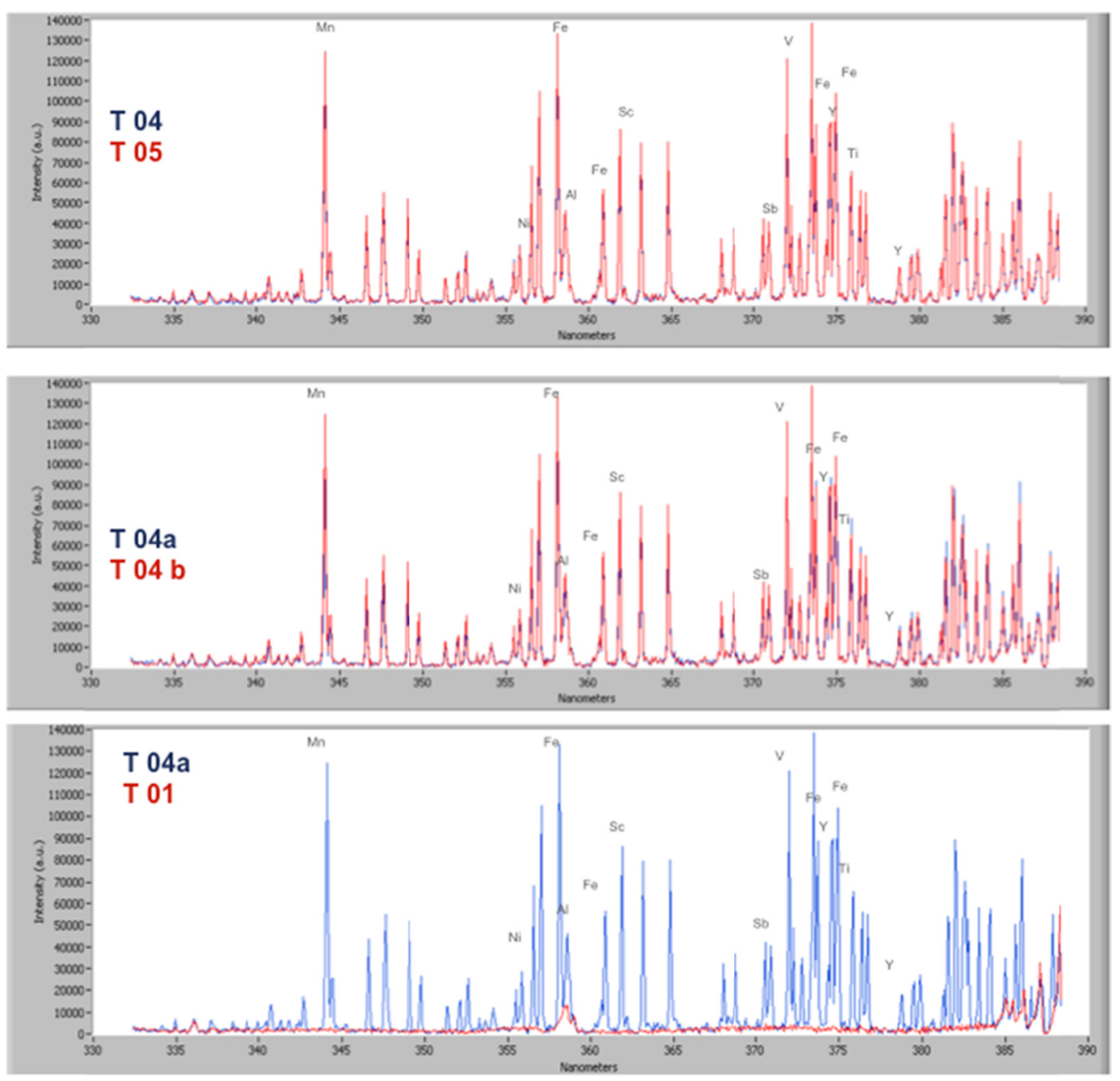

Figure 34. LIBS spectra of region III for toner inks. From top to bottom: Toner samples \#T04 and T05, replicate measurements from toner \#T04 and toner samples \#T04 and T01.

For the toner set, a total of 18 elements were detected by LIBS from which ten of them were also detected by the LA-ICP-MS method. The discrepancy is caused by the fact that the LIBS system has lower sensitivity than the LA-ICP-MS and therefore it did not detect all of the elements that were detected by the LA-ICP-MS. On the other hand, LIBS detected some elements that are problematic for ICP-MS detection such as I, Na and Sulphur. Regardless of the loaded LIBS spectrum of the toners, in comparison to the 
inkjets, only 6 out of the 18 elements detected were chosen for the final menu for the comparison of the samples because the remaining elements were highly correlated and did not offer additional discrimination capabilities.

The majority of the elemental data from toner was close to normal distribution and therefore a Pearson Correlation Coefficient was used to estimate the correlation between variables for the printing ink data sets. Correlation coefficients between 0.90 and 0.98 were found for the LIBS data between the following elements: $\mathrm{Ni}, \mathrm{Fe}, \mathrm{Sc}, \mathrm{Sb}$, $\mathrm{Ti}, \mathrm{Bi}, \mathrm{Na}, \mathrm{Y}, \mathrm{Rb}, \mathrm{Co}, \mathrm{S}, \mathrm{V}$ and $\mathrm{Mn}$. Indeed no additional discrimination was observed by adding these elements to the pairwise comparison of the toner samples. Although this elements were not included in the final discrimination study they were still monitored as they could eventually provide useful discrimination between samples originated from other sample set as the characterized here.

In contrast, for LA-ICP-MS data, V, Mn, Co and Fe showed some correlation (coefficients between 0.78 and 0.84 ), but they added additional discrimination when include as part of the element list for pairwise comparisons.

3.2.6 Comparison of the figures of merit of LA-ICP-MS and LIBS for the analysis of printing inks

The evaluation of the LODs played an important role in the optimization and standardization of the methods, helping on informed decisions of selection of an element menu and also as a mean to decide when a certain peak/signal should be used for comparison purposes. 
Table 22 shows the expected limits of detection (LOD) of the different laser ablation methods.

Table 21. Comparison of the elemental menu selected for the analysis of toners by LIBS and LA-ICP-MS

\begin{tabular}{|c|c|c|}
\hline & LA-ICP-MS & LIBS \\
\hline Detected elements & $\mathrm{Mg}, \mathrm{Al}, \mathrm{Mn}, \mathrm{Ti}, \mathrm{V}, \mathrm{Co}, \mathrm{Fe}$, & $\mathrm{Mg}, \mathrm{Al}, \mathrm{Mn}, \mathrm{Ti}, \mathrm{V}, \mathrm{Co}, \mathrm{Fe}$, \\
& $\mathrm{Ni}, \mathrm{Zn}, \mathrm{Sr}, \mathrm{Cu}, \mathrm{Si}, \mathrm{Cr}, \mathrm{Zr}$, & $\mathrm{Ni}, \mathrm{Zn}, \mathrm{Sr}, \mathrm{I}, \mathrm{Sc}, \mathrm{Sb}, \mathrm{Bi}, \mathrm{Na}$, \\
& $\mathrm{Ba}, \mathrm{La}, \mathrm{Ce}, \mathrm{Pb}$ & $\mathrm{Y}, \mathrm{Rb}, \mathrm{S}$ \\
\hline Monitored but below & $\mathrm{K}, \mathrm{Ca}, \mathrm{Sc}, \mathrm{Ga}, \mathrm{As}, \mathrm{Br}, \mathrm{Y}$, & $\mathrm{K}, \mathrm{Ca}, \mathrm{Ce}, \mathrm{Li}, \mathrm{Ba}, \mathrm{Pb}, \mathrm{La}$, \\
detection limit & $\mathrm{Rh}, \mathrm{Cd}, \mathrm{Sn}, \mathrm{I}, \mathrm{Cs}, \mathrm{Nd}, \mathrm{Hf}$, & $\mathrm{Cu}, \mathrm{Cr}, \mathrm{Si}, \mathrm{Zr}$ \\
\hline Elements correlated & $\mathrm{Bi}$ & \\
Pearson correlation & $\mathrm{Vn}, \mathrm{Fe}$ and Co but still & $\mathrm{Ni}, \mathrm{Fe}, \mathrm{Sc}, \mathrm{Sb}, \mathrm{Ti}, \mathrm{Bi}, \mathrm{Na}$, \\
coefficient $>0.80$ & provided added & $\mathrm{Y}, \mathrm{Rb}, \mathrm{Co}, \mathrm{S}, \mathrm{V}$ and Mn \\
& discrimination & didn’t provide additional \\
& & discrimination \\
\hline Element menu used for & $\mathrm{Mg}, \mathrm{Al}, \mathrm{Mn}, \mathrm{Ti}, \mathrm{V}, \mathrm{Co}, \mathrm{Fe}$, & $\mathrm{Mg}, \mathrm{Al}, \mathrm{Fe}, \mathrm{Sr}, \mathrm{Zn}$ and I \\
comparisons & $\mathrm{Ni}, \mathrm{Zn}, \mathrm{Sr}, \mathrm{Cu}, \mathrm{Si}, \mathrm{Cr}, \mathrm{Zr}$, & \\
\hline
\end{tabular}

The LA-ICP-MS methods showed superior limits of detection than LIBS (1-3 orders of magnitude) allowing the analysis of greater number of trace elements. However, 
the concentration range at which the elements are present in the inkjet and toners sets allowed the detection of several elements in both laser ablation methods. The detection limit for some elements that were detected by LIBS only (such as S, I) are not reported as a consequence of limitations on availability of standards.

For inkjet analysis, the precision figures for both laser ablation methods were comparable $(\% \mathrm{RSD}<15 \%)$ and dependent on the concentration level present on the sample. Toner samples however showed poorer precision between replicates (3-27 $\% \mathrm{RSD}$ ) as a result of its greater heterogeneity.

3.2.7 Evaluation of the discrimination capabilities of laser ablation methods for the analysis of writing and printing inks

The previous sections demonstrated that the analytical performance of both laser ablation methods was suitable for all the ink types tested. The following step was then to evaluate if these methods would provide valuable information within the forensic framework.

For this reason, the forensic applicability of the methods was evaluated in terms of a) assessment of the micro-homogeneity and within source variation of the elements on the ink and b) assessment of the variation of the elemental profile between samples originated from different sources (i.e., discrimination between batches, plants, manufacturers) and c) estimation of error rates (type I and type II errors). 
Table 22. Comparison of limits of detection of LA-ICP-MS and LIBS for the analysis of printing inks

\begin{tabular}{|c|c|c|c|c|}
\hline \multirow[b]{2}{*}{ Element } & \multicolumn{2}{|c|}{$\begin{array}{c}\text { Sample set concentration } \\
\text { range } \mu \mathrm{g} \mathrm{g}^{-1}\end{array}$} & \multirow{2}{*}{$\begin{array}{c}\text { LAICPMS } \\
\begin{array}{c}\text { LOD } \\
\left(\mu \mathrm{gg}^{-1}\right)\end{array}\end{array}$} & \multirow{2}{*}{$\begin{array}{c}\text { LIBS } \\
\begin{array}{c}\text { LOD } \\
\left(\mu g^{-1}\right)\end{array}\end{array}$} \\
\hline & Inkjet set & Toner set & & \\
\hline $\mathrm{Mg}$ & nd-1000 & nd - 2250 & 0.2 & $160(\mathrm{Mg} \mathrm{I}, 285.2)$ \\
\hline $\mathrm{Cu}$ & nd-500 & nd-400 & 0.3 & $135(\mathrm{Cu} \mathrm{I}, 324.3)$ \\
\hline $\mathrm{K}$ & $50-1000$ & nd-700 & 1.4 & $30(\mathrm{~K} \mathrm{I}, 766.5)$ \\
\hline $\mathrm{Li}$ & $60-200$ & nd & 1.0 & 18 (Li I, 670.7) \\
\hline $\mathrm{Ni}$ & nd-12 & nd-6 & 0.7 & na \\
\hline $\mathrm{Zr}$ & nd- 40 & nd-25 & 0.1 & na \\
\hline $\mathrm{Al}$ & nd & nd-1000 & 0.9 & 180 (Al II, 358.6) \\
\hline $\mathrm{Mn}$ & nd & nd-1000 & 0.5 & 70 (Mn II, 255.8) \\
\hline $\mathrm{Sr}$ & nd & nd-400 & 0.1 & $25(\mathrm{Sr} I, 460.7)$ \\
\hline $\mathrm{Zn}$ & nd & nd-900 & 0.5 & $350(\mathrm{Zn} \mathrm{I}, 481.0)$ \\
\hline $\mathrm{Fe}$ & nd & nd-8000 & 9.8 & $3500(\mathrm{Fe} \mathrm{I}, 361.9)$ \\
\hline $\mathrm{Ba}$ & nd & nd-30 & 0.3 & na \\
\hline $\mathrm{Pb}$ & nd & nd- 120 & 1.0 & na \\
\hline $\mathrm{Si}$ & nd & nd-100 & 3.1 & na \\
\hline $\mathrm{Ce}$ & nd & nd-25 & 0.1 & na \\
\hline $\mathrm{V}$ & nd & nd-250 & 0.2 & $50(\mathrm{~V} \mathrm{I}, 384.1)$ \\
\hline $\mathrm{La}$ & nd & nd-50 & 0.3 & na \\
\hline Co & nd & nd-500 & 0.2 & 40 (Co I, 352.6) \\
\hline $\mathrm{Cr}$ & nd & nd- 120 & 0.1 & na \\
\hline
\end{tabular}

3.2.7.1 Results for micro-homogeneity and within-source variation of elements on writing ink

Initial validation studies compared the elemental profile of lines vs. writing patterns such as numbers and letters. Since no significant difference was detected from different writing patterns, all comparison studies were conducted on writing lines.

Micro-homogeneity studies were conducted to evaluate the uniform distribution of the elements in the ink within a single pen and between pens that came from the same 
package. The within-pen variation was conducted on three gel pens from different brands. The ink of each pen was analyzed at different percent of ink withdrawn. As mentioned before, $0 \%$ refers to ink mostly used while $100 \%$ refers to a new pen. Significant variations were found only at the onset of the ink for two out of the three brands tested (see figure 35). For this reason, all ink samples were collected after $25 \%$ of use of the pen. These differences could be attributed to early contamination of the first ink withdrawal with the plug and ball of the pen or/and different amounts of ink deposited on the paper at the beginning of the pen use.

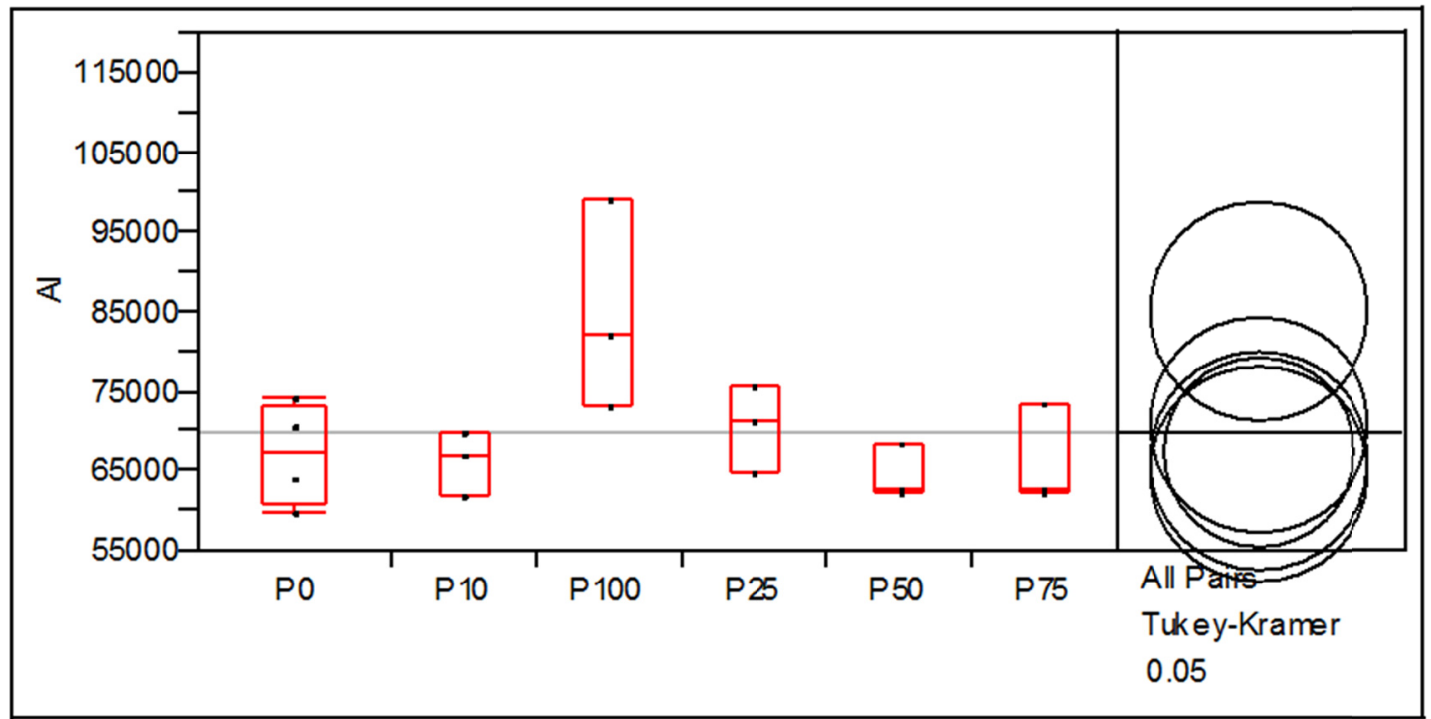

Figure 35. Representation of the variation of aluminum on black gel ink at different percent use of the pen.

Between-package studies were conducted on four brands of pens containing 4 to 12 pens per package. The brands selected for this study are identified in table 10 as B002, 
B014, B-009 and B-018. Four replicates were conducted on each of the pens. A total of 24 pens were used for this study. Two of the four packages presented uniform elemental profiles of the ink in their pens. The other two packages had some pens with significant differences ( $\mathrm{p}=0.05$ and 0.01$)$ in the elemental profile of pens that belong to the same pack.

\subsubsection{Results for differentiation and identification of writing inks}

Four independent sub-sets of ink were used to evaluate the discrimination capabilities of the methods. The discrimination power and error rates were estimated as reported in chapter two. The first set consisted of 45 gel pen inks received as a blind test provided by the U.S. Secret Service. The set was selected because the inks were difficult or impossible to discriminate by classical methods. The second, third and fourth sets were selected to represent the most common brands/types of pen found in retail stores in the US. A complete list of the writing inks is given on tables 10 to 12 .

Table 23 summarizes the LA-ICP-MS results for each of these ink sets. Significant and detectable differences were observed between black inks of different sources (discrimination of $\sim 97.4-99.1 \%$, depending on the sample set under investigation), with low rates of false inclusions (at most $<2.4 \%$ ). Low rates of false exclusions were also obtained, with the exception of the first blind set where details about sampling and specific source of origin were not available. 
Table 23. Discrimination capabilities of LA-ICP-MS for writing inks.

\begin{tabular}{|l|c|c|c|c|}
\hline Writing & USSS & Black & Black & Blue \\
\hline \# samples & blind set & gel inks & ballpoint & gel inks \\
\hline \# of different & 45 & 29 & 22 & 22 \\
sources & $\leq 40$ & 24 & 20 & 19 \\
\hline \# duplicate samples & 5 & 5 & 2 & 3 \\
\hline \# pairs & 990 & 406 & 231 & 231 \\
\hline$\%$ discrimination & $97.4 \%$ & $98.3 \%$ & $99.1 \%$ & $97.8 \%$ \\
\hline$\%$ false exclusions & $60 \%(3 / 5)$ & $0 \%$ & $0 \%$ & $0 \%$ \\
\hline$\%$ false inclusions & $\leq 2.4 \% *$ & $1.7 \%$ & $0.9 \%$ & $2.2 \%$ \\
\hline
\end{tabular}

As part of the validation study, the first subset was received as a blind test. Some of the ink samples were received as smears from the ink barrel on a piece of Whatman paper 42 and others as multi-directional superimposed lines produced by multiple writing patterns. Ink deposition on the paper was not uniform and some areas presented visible concentrated portions, which are difficult to sample (see figure 36). The samples were carefully inspected under a microscope to ablate from areas that presented similar ink deposition, nonetheless the different deposition conditions could have contributed to the observed error rates in this set. 


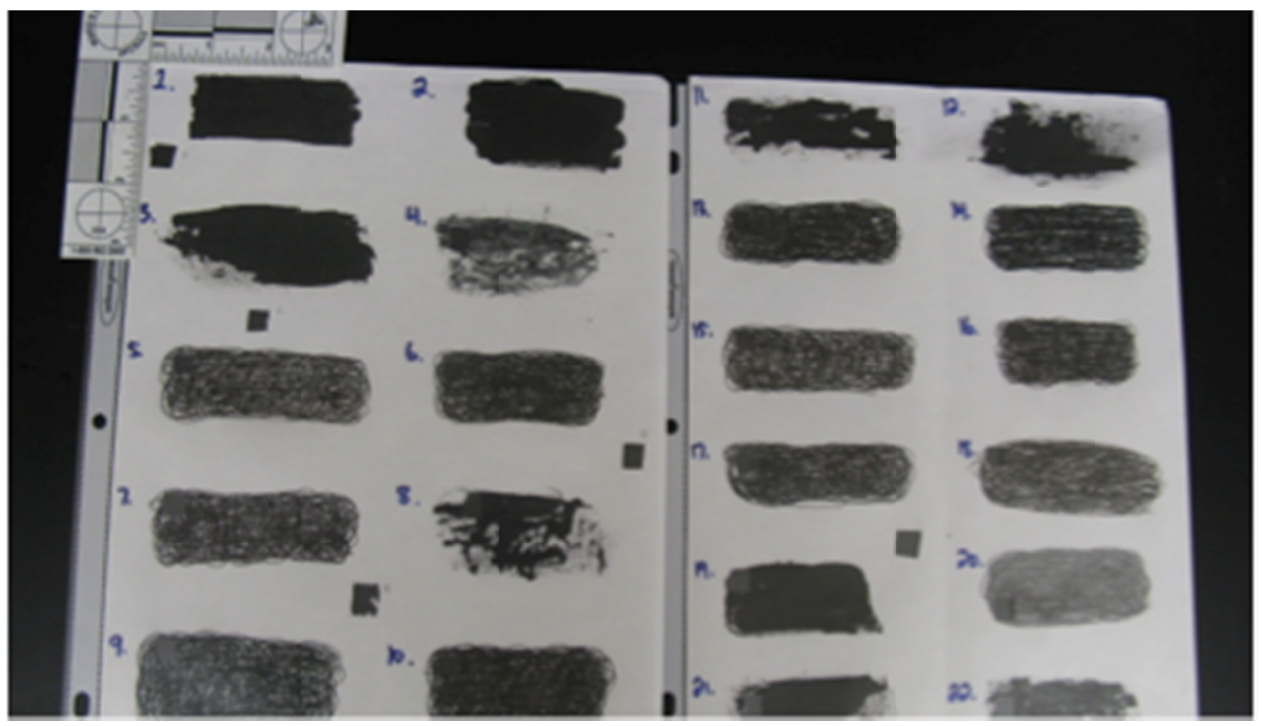

Figure 36. Photograph of $t$ different deposition patterns for the black gel blind sample set.

The comparison of each of the 45 samples subset to each other can generate a total of 990 comparison pairs. Analysis of Variance (ANOVA) was conducted at 95\% confidence level to identify the number of indistinguishable pairs. Table 23 shows that 26 out of 990 possible comparison pairs were not distinguished by LA-ICP-MS. The results show that LA-ICP-MS was able to differentiate $97.4 \%$ of the samples, that otherwise would not be discriminated by conventional methods. After submitting the results to the USSS, they disclosed that 5 of the 45 samples were pair samples from the same pen or pacakge. From this 5 pairs originated from the same pen/package, 2 were correctly identified to their source of origin or duplicate sample using the LA-ICP-MS method. The other 3 of the 5 pairs were differentiated by LA-ICP-MS (60\% false exclusion). The excluded pairs shared similar elemental profiles with small differences in just Mn and/or $\mathrm{Cu}$. This high rate of false exclusion is not surprising because a) the duplicate samples were not received on similar deposition methods (i.e., some were deposited on paper as 
direct smears from the barrel, others were deposited by multiple writing patterns), b) there is no certainty that the duplicate samples were generated from the same pen, it was revealed that some of them could have originated from pens from the same package and c) it is possible that some of these duplicate samples were taken at different percentages of use of the pen, which was previously demonstrated that could vary in the first $25 \%$ of use of the ink.

The brand and origin of those inks remained unknown to us because proprietary information as per the USSS. They noted that it is possible that some of the 26 pairs came from similar or the same sources. For this reason, the false "inclusion" rate for this set can not be estimated yet but it is clearly low (at most 24 of 990 or $2.4 \%$ ).

A subsequent study was conducted on a controlled set of black gel inks from 24 different brands/makes. All pens were purchased at retail stores in the United States in a short period of time (see table 10). Analysis was conducted on the ink lines written by the pens on Whatman paper \# 42. Five replicates per line were used for the comparison studies. In addition to the 24 different sources, 5 samples were randomly included in the sequence as unknown duplicates, for a total of 29 samples. Two of those duplicate samples were from the same pen (\#B007 and \#B008, respectively) and the other three belong to three different pens from the same package (\#B002). Table 23 shows that all these five unknowns were correctly identified to their duplicate sample $(0 \%$ false exclusion rate).

Only 7 out of 401 possible comparison pairs were indistinguishable by elemental analysis (97.5\% discrimination). Moreover, those 7 indistinguishable pairs had similar composition and originated from the same brand. One of the pairs came from two Pilot 
pens (\#B005-B014) and the remaining 6 pairs came from four different Uniball pens, which were characterized for low concentration levels of inorganic components and were not differentiated between each other (B006, B007, B011 and B020).

A third collection set of black non-gel inks (ballpoints) was also included in this study to evaluate if the method can be applied to different types of inks. Table 23 shows that excellent discrimination was also achieved for this set (99.1\%).

Finally, a set of blue gel inks consisting of inks originating from 19 different sources was included in the study. Three blind duplicate samples were also included in this set to evaluate false exclusion rates. All of the 3 blind samples were correctly associated to its source of origin. Out of the remaining 228 possible comparison pairs from samples coming from different sources, only five pairs remained indistinguishable based on its elemental composition. All of these 5 pairs had in common that their chemical composition had very low levels of the monitored elements.

The black gel and blue gel ink sets were further analyzed by LIBS. Table 24 summarizes the discrimination results.

Using only the emission lines of 4 elements, LIBS was able to discriminate 93 to $96.8 \%$ of the samples and to correctly associate the unknown duplicate samples to its source. Moreover the same pairs that were not discriminated by LA-ICP-MS were not differentiated by LIBS analysis. Comparisons were done qualitatively by spectral overlap of the regions of interest and quantitatively followed by pairwise comparisons as described before. The same conclusions were obtained using both comparison methods. 
Table 24. Discrimination capabilities of LIBS for the analysis of writing inks

\begin{tabular}{|c|c|c|}
\hline INK SET & black gel inks & blue gel inks \\
\hline \# samples & 29 & 22 \\
\hline \# of different sources & 24 & 19 \\
\hline \# duplicate samples & 5 & 3 \\
\hline \# pairs & 406 & 231 \\
\hline$\%$ discrimination & $96.8 \%$ & $93.0 \%$ \\
\hline$\%$ false exclusions & $0 \%$ & $0 \%$ \\
\hline$\%$ false inclusions & $3.2 \%$ & $7.0 \%$ \\
\hline
\end{tabular}

\subsubsection{Results for differentiation and identification of printing inks}

The printing ink collection set consisted of 47 ink samples printed from laser toner and inkjet printers. For purposes of this study only black ink was analyzed, since this color is commonly found in document examination and also it would be the most difficult to differentiate by physical and chemical properties than entries from other colors.

Samples were printed from printers of different brands, or from printers of the same brand but different toner/cartridge and/or similar cartridge at different percent use. 


\subsection{Evaluation of the variability of the elemental composition of inkjet inks}

The inkjet set consisted of a total of 21 samples representing ink from 11 different brands/cartridges. Ten samples consisted in duplicate controls and blind samples. A duplicate control is a sample collected from the same ink source and analyzed within the same analytical sequence. Duplicate controls are monitored as part of the quality control performance test to check for repeatability and false exclusion rates. On the other hand, blind samples are duplicate samples that are assigned a random ID number so the analyst wont know they are not part of the collection set until the analytical report is issued. Blind samples evaluate the capability of the methods to associate correctly a sample with its source of origin and are intended to eliminate any possible bias from the analyst in the interpretation of data.

The elements that were used for comparison of inkjets by LA-ICP-MS were Mg, $\mathrm{Cu}, \mathrm{K}, \mathrm{Ni}, \mathrm{Li}$ and $\mathrm{Zr}$. The elements monitored by the LIBS system were $\mathrm{Mg}, \mathrm{Cu}, \mathrm{K}$, and Li.

Table 25 summarizes the results obtained for the discrimination studies of inkjet inks by both LIBS and LA-ICP-MS. The results in Table 25 show that although there were a small number of elements detected on the inkjet set; there was sufficient variation to provide significant and detectable differences between inkjet inks of different sources (discrimination of $\sim 94.3-97.7 \%)$. Low rates of false exclusions $(0-0.4 \%)$ and false inclusions (2.3-5.7\%) were seen as well.

From the 88 possible comparison pairs from samples originated from different ink sources, only 2 pairs (sample IN 06 and IN07; IN 06 and IN08) were not differentiated by 
LA-ICP-MS. These two pair of samples originated from printers of the same brand but different model.

When the same sample set was analyzed by LIBS, only 5 out of the 88 possible comparison pairs were not differentiated. Two of these pairs were the same pairs not distinguished by LA-ICP-MS, the additional 3 pairs originated from inkjet printers from the same brand. These 3 pairs were differentiated by LA-ICP-MS by elements that were not detected by LIBS.

Moreover, all of the 24 possible comparison pairs from blind and/or the duplicate samples were correctly associated to their source of origin. An exception was found for blind samples IN 09 and IN10, which were printed with the same cartridge but still they were differentiated by LA-ICP-MS by its content of Mg only.

Sample number IN09 was the first printed page from a new cartridge installed in that printer, so there is a possibility that there may be a carry over from ink residues of the previous cartridge. To verify that, 3 additional samples were printed from the same cartridge to characterize their elemental profile. No significant differences were found between these additional samples and IN10, while the Mg difference between the first printed page, IN09, and the rest of the duplicate samples was confirmed.

Micro-homogeneity studies were conducted in order to evaluate the uniform distribution of the elements in the ink within a single cartridge. For the homogeneity studies of the inkjet set, 7 duplicate samples were analyzed. These 7 samples were all printed from the same cartridge (IN17) at different time intervals. The time intervals consisted of different hours within the same day and different days in consecutive order, with a variation of the percent use of the inkjet cartridge ranging approximately from 100 
to $50 \%$. Figure 37 summarizes the results obtained for the homogeneity studies of inkjet inks by LA-ICP-MS (orange bars). Figure 37 also shows the variation of the elemental composition of $\mathrm{Mg}, \mathrm{Cu}$, and $\mathrm{K}$ between ink cartridges from different sources.

Table 25. Discrimination capabilities and error rates for the elemental analysis of inkjet

\begin{tabular}{|c|c|c|}
\hline INKJET & LA-ICP-MS & LIBS \\
\hline \# inkjet samples & 21 & 21 \\
\hline \# samples from different & 11 sources and 3 blinds & 11 sources and 3 blinds (88 \\
sources & $(88$ comparison pairs) & comparison pairs) \\
\hline \# blind and duplicates & 3 blinds, 7 duplicates & 3 blinds, 7 duplicates \\
& $(24$ comparison pairs) & $(24$ comparison pairs $)$ \\
\hline \% discrimination & $97.7 \%$ (86 out of 88$)$ & $94.3 \%$ (83 out of 88$)$ \\
\hline \% false exclusions & $0.4 \%$ (1 out of 24$)$ & 0 \\
\hline & $2.3 \%$ false inclusions & \\
\hline
\end{tabular}

\subsection{Evaluation of the variability of the elemental composition of black toners}

For the discrimination studies on the toner set, a total of 26 samples were used for the analysis by LA-ICP-MS and LIBS. All samples were printed only from the black toners. Out of the 26 samples, 13 were from different sources and 13 were from blind samples and duplicates. Table 26 summarizes the results obtained for the discrimination studies of toner inks by both laser ablation methods. For this toner set, LA-ICP-MS had a significant better performance than LIBS, mainly as a consequence of the capability to 
detect a larger number of elements and detect small differences in the concentration of those formulations. The only pair that was falsely excluded by LA-ICP-MS was the samples identified as T10 and T15. They were different only by Mg. However, because of the precision of the measurements and the similarity of its $\mathrm{Mg}$ content, this difference was dependent on the match criteria employed. For instance, it was differentiated by ttest at $95 \%$ confidence but it was not differentiated by ANOVA at $95 \%$ confidence, PCA or by confidence interval ( $3 \mathrm{~s}, 4 \mathrm{~s})$.

Table 26. Discrimination capabilities and error rates for the analysis of black toners by LA-ICP-Ms and LIBS.

\begin{tabular}{|c|c|c|}
\hline Toner & LA-ICP-MS & LIBS \\
\hline \# samples & 26 (325 comparison pairs) & 26 (325 comparison pairs) \\
\hline \# samples from & 13 sources and 3 blinds (117 & 13 sources and 3 blinds (117 \\
different sources & comparison pairs) & comparisons pairs) \\
\hline \# blind and & 3 blinds, 10 duplicates (48 & 3 blinds, 10 duplicates (48 \\
duplicates & comparison pairs) & comparison pairs) \\
\hline$\%$ discrimination & $100 \%$ (117 out of 117$)$ & $87.2 \%$ (102 out of 117) \\
\hline$\%$ false exclusions & $2.1 \%$ (1 out of 48$)$ & $12.8 \%$ (15 out of 117$)$ \\
\hline$\%$ false inclusions & 0 & \\
\hline
\end{tabular}



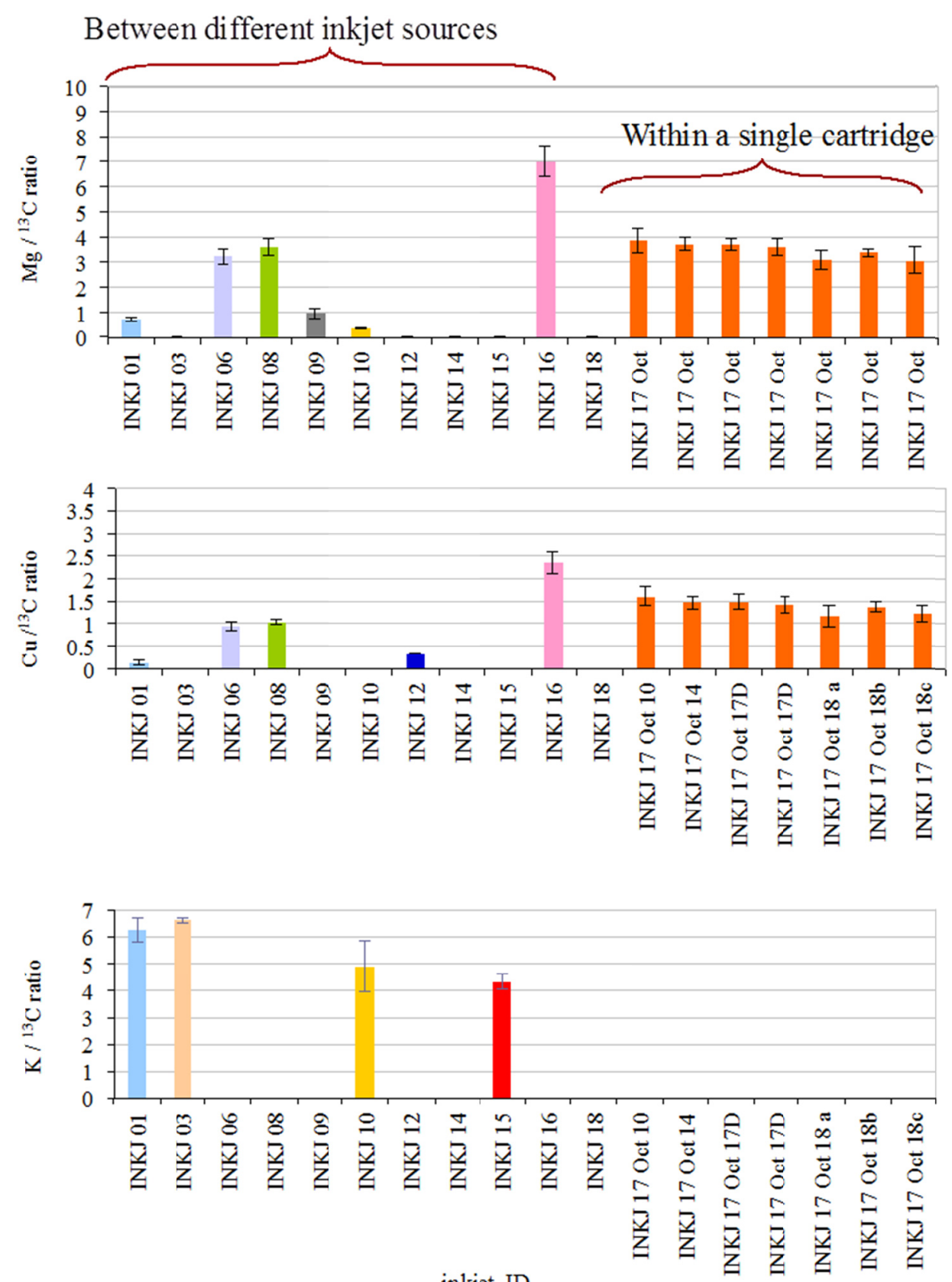

inkjet ID

Figure 37. Variation of elemental composition on inkjets by LA-ICP-MS. Top to bottom:

$$
\mathrm{Mg} /{ }^{13} \mathrm{C}, \mathrm{Cu} /{ }^{13} \mathrm{C} \text { and } \mathrm{K} /{ }^{13} \mathrm{C} \text {. }
$$

For the micro-homogeneity studies of the toner inks, a total of 10 toner samples were analyzed, samples were collected from a single toner at different time intervals. 
Figure 38 shows the variation of Sr within a single toner. Samples labeled as T02A were sampled from the same cartridge from 5 consecutive pages printed the same day, samples labeled T02B were 5 consecutive pages printed from the same cartridge a week later than T02A. No significant differences were observed between the toner samples by any of the laser ablation methods, suggesting that the variation within a cartridge is appropriate for this application. Nonetheless, the within sample repeatability observed from toners was greater than for other ink types, precision between replicates ranged from 3 to $27 \%$ RSD, depending on the element. The worse precision observed in toners, in comparison to writing inks and inkjets, may be the result of the heterogeneous distribution and deposition of toner particles, as discussed before.

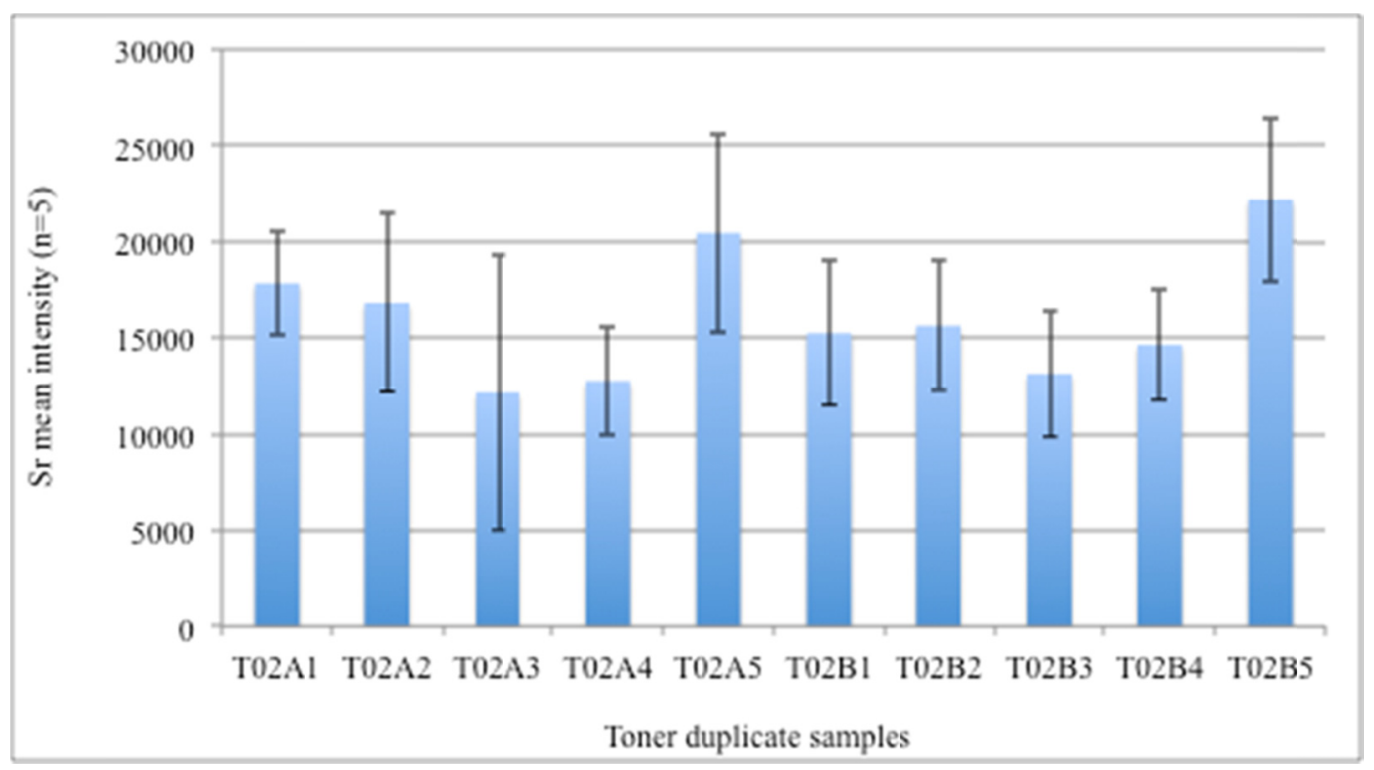

Figure 38. Variation of the elemental composition of Sr on toner samples collected from the same cartridge at different time intervals. 


\subsubsection{Principal component analysis of writing and printing inks}

Principal component analysis plot (PCA) were conducted as a way to reduce the large amount of information derived from the elemental analysis by laser-ablation methods to determine whether or not there is grouping of the ink sources by brand and/or manufacturing location.

The PCA analysis of black gel inks shows that detectable differences were observed between black gel inks of different brands (see figure 39). Sourcing by brand is possible, most of the brands were clearly grouped and separated with the exception of some overlapping of Uniball and Papermater gel inks, and some Staples and Pilot pens. Nonetheless, at this moment the grouping by brand and/or source of origin is not accurate as a result of the lack of information on the specific ink manufacturing plants and distribution/packaging of the pens. Some pens from different brands may contain ink that has been manufactured by a single parent ink company, therefore more information would be required to arrive to conclusions about sourcing.

Most of the participants that collaborated in the inkjet ink collection owned inkjet printers Hewlett Packard brand. Only 3 other brands were included in this collection set: Canon (IN14), LexMark (IN15) and Brother (IN18). For this reason, since the variety and distribution of brands is biased towards the brand HP, the PCA was not used to evaluate the capabilities of grouping by brand. Figure 40 shows however that most inks printed from different inkjet printers and/or different cartridge have a differentiable elemental profile. The only samples that were grouped together were either the duplicate control samples (IN17 and IN17D; IN7 and IN8) or samples that were not differentiated by LA-ICP-MS (IN 6 vs IN 7 and IN6 vs IN8). These results were in agreement with the 
results obtained from the discrimination studies using other criteria, such as ANOVA and Tukey $(p=0.05)$.

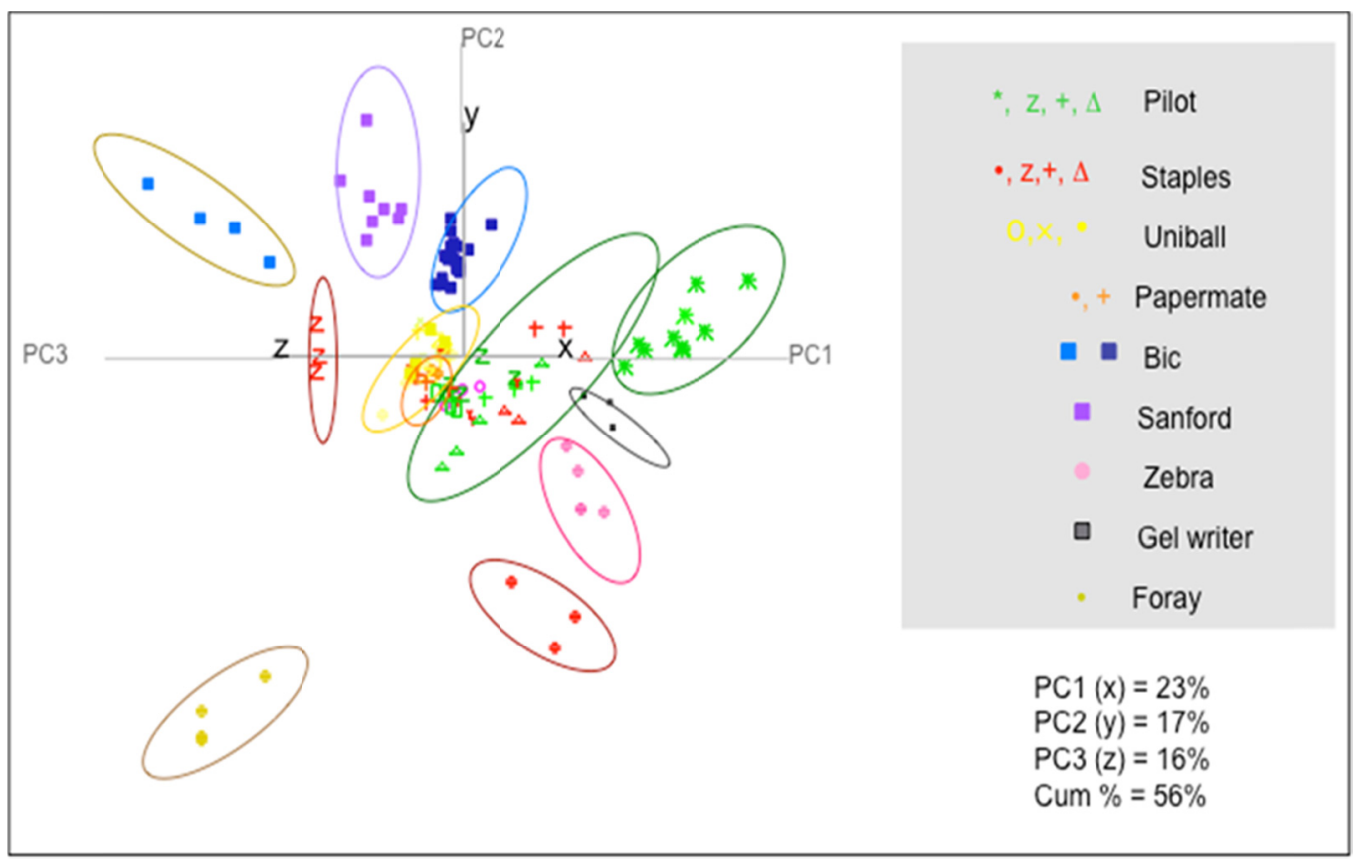

Figure 39 Results from principal component analysis of LA-ICP-MS data, showing differentiation and grouping of the ink samples from different brands The 3 first principal components describe $56 \%$ of the total variance in the data.

A similar situation was observed for the toner samples, were the big majority of the printer brand was Hewlett Packard, samples identified as T02 and T03 were OKI and Brother brand, respectively. Figure 41 shows that toner samples that were printed from printers of different brand and/or same brand but different model or different cartridge brand were clearly differentiated. Moreover, samples that belong to the same cartridge, such as the duplicate and blind samples T01 and TB, T13 and T14 and T15 and T10 were 
grouped in the PCA. It is also interesting to highlight that PCA permits the visualization of the similarities between the pair T10 and T15. This pair was the only one that was incorrectly excluded by elemental analysis when certain match criteria such as t-test was applied.

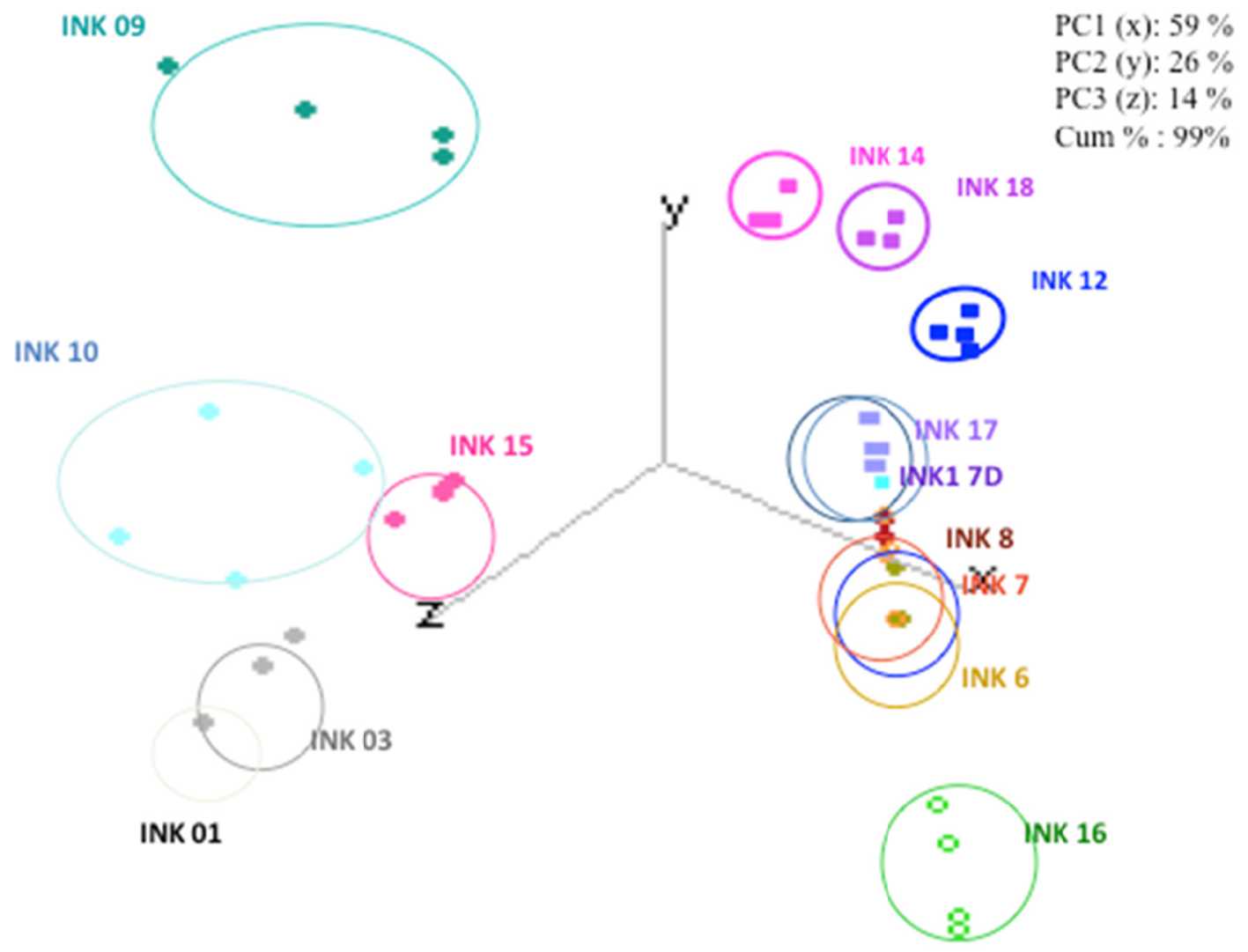

Figure 40 Results from principal component analysis of LA-ICP-MS data, showing differentiation and grouping of the inkjet samples from different brands and/or cartridges.

The 3 first principal components describe $99 \%$ of the total variance in the data. 
T02

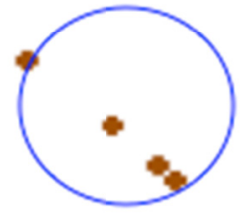

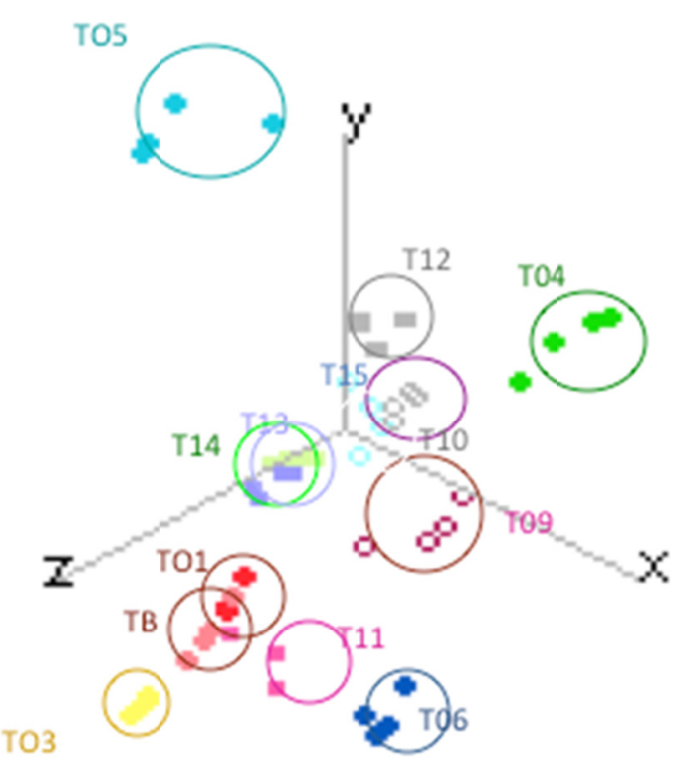

PCl (x): $93 \%$

PC2 (y): $5 \%$

PC2 (z): $1 \%$

Cum \%: 99\%

Figure 41. Results from principal component analysis of LA-ICP-MS data, showing differentiation and grouping of the toner samples from different brands and/or cartridges.

The 3 first principal components describe $99 \%$ of the total variance in the data. 
3.2.8 Evaluation of usefulness of molecular emissions in the discrimination of inks by LIBS

One of the advantages of LIBS over LA-ICP-MS methods is the potential to detect not only emission lines from atomic or ionic species but also emission bands from molecules and diatomic species. Since writing and printing inks are formulated with both inorganic and organic components, some emission bands observed at the LIBS spectra may provide information about their organic chemical composition.

Diatomic species such as $\mathrm{Ca}_{2}, \mathrm{CN}$ and $\mathrm{C}_{2}$ were observed in the LIBS spectra of both writing and printing inks. It has been reported that $\mathrm{CN}$ radicals can be formed in the plasma-induced plume by collisions between particles ejected from the target material and the nitrogen present in the air [Oujja et al., 2005].

Table 27 lists the main molecular bands detected on the LIBS spectra from writing inks and printing inks. From these emission species, only the $\mathrm{CN}$ bands and the unidentified bands around $674-676 \mathrm{~nm}$ provided additional discrimination to the atomic/ionic emission lines previously monitored.

Table 28 summarizes the additional discrimination gained in some ink sets after comparison of the molecular bands. All comparisons were done using spectral overlay after background normalization. In the blue gel set both the $\mathrm{CN}$ and the 674-676 bands provided additional discrimination between samples from different pens that otherwise were not differentiated based on their elemental profile. Figure 42 shows an example of the emission bands at the 674-676 range for two different blue gel inks and their respective duplicate controls. The shape and intensity of those emission peaks varied significantly between inks. It was observed that the paper substrate background also 
showed a peak at $674.7 \mathrm{~nm}$, nonetheless the intensity of this peak was significantly lower in the paper background than in the blue gel samples (see figure 43) and therefore it can be attributed to the ink composition. Moreover, the shape of the emission peaks was significantly different for the ink than the paper background for most of the samples.

On the other hand, the $\mathrm{CN}$ bands in the blue gel and toner samples were present at levels above the background paper. Additional discrimination was observed after comparison of the $\mathrm{CN}$ bands on blue gel samples (see figure 44). In the toner samples, although the $\mathrm{CN}$ bands discriminated 30 out of the possible 117 comparison pairs, those 30 pairs were already differentiated by their elemental profile thus no additional discrimination was gained.

$\mathrm{CN}$ bands were not detected above the paper substrate level on any of the inkjet samples. For instance, figure 45 compares $\mathrm{CN}$ signals for inkjet, toner and paper background.

Table 27. List of emission species detected in the LIBS spectra of inks

\begin{tabular}{|l|l|l|}
\hline Emission wavelength & Emitting specie & Transition \\
\hline $359 \mathrm{~nm}$ & $\mathrm{CN}$ & $\mathrm{B}^{2} \Sigma^{+}-\mathrm{X}^{2} \Sigma^{+}, \Delta v=+1$ \\
\hline $388 \mathrm{~nm}$ & $\mathrm{CN}$ & $\mathrm{B}^{2} \Sigma^{+}-\mathrm{X}^{2} \Sigma^{+}, \Delta v=0$ \\
\hline $421 \mathrm{~nm}$ & $\mathrm{CN}$ & $\mathrm{B}^{2} \Sigma^{+}-\mathrm{X}^{2} \Sigma^{+}, \Delta v=-1$ \\
\hline $554 \mathrm{~nm}$ & $\mathrm{Ca}_{2}$ & $\mathrm{~B}^{1} \Sigma_{\mathrm{v}}^{+}-\mathrm{X}^{1} \Sigma_{\mathrm{g}}^{+}$ \\
\hline $474 \mathrm{~nm}$ & $\mathrm{C}_{2}$ & $\mathrm{~d}^{3} \Pi_{\mathrm{g}}-\mathrm{a}^{3} \Pi_{\mathrm{v}} ; \Delta v=+1$ \\
\hline $516 \mathrm{~nm}$ & $\mathrm{C}_{2}$ & $\mathrm{~d}^{3} \Pi_{\mathrm{g}}-\mathrm{a}^{3} \Pi_{\mathrm{v}} ; \Delta v=0$ \\
\hline $674-676 \mathrm{~nm}$ (unresolved) & Not identified & Not identified \\
\hline
\end{tabular}


Table 28. Discrimination capabilities of the LIBS molecular bands on inks

\begin{tabular}{|c|c|c|c|}
\hline Ink set & $\begin{array}{c}\text { Discrimination } \\
\text { by elemental } \\
\text { profile }\end{array}$ & $\begin{array}{c}\text { Discrimination by elemental } \\
\text { and molecular bands }\end{array}$ & $\begin{array}{c}\text { Additional pairs } \\
\text { differentiated }\end{array}$ \\
\hline Blue gel & $93 \%$ & $94.3 \%(\mathrm{CN}$ bands $)$ & $2(\mathrm{CN}$ bands $)$ \\
inks & 94.3 & $96.5 \%(674-676$ bands $)$ & $7(674-676$ bands $)$ \\
\hline Inkjet inks & & $96.6 \%$ ( $674-676$ bands $)$ & $2(674-676$ bands $)$ \\
\hline Toners & $87.2 \%$ & $87.2 \%$ & $0(\mathrm{CN}$ bands $)$ \\
& & $95.7 \%(674-676$ bands $)$ & 10 (674-676 bands $)$ \\
\hline
\end{tabular}
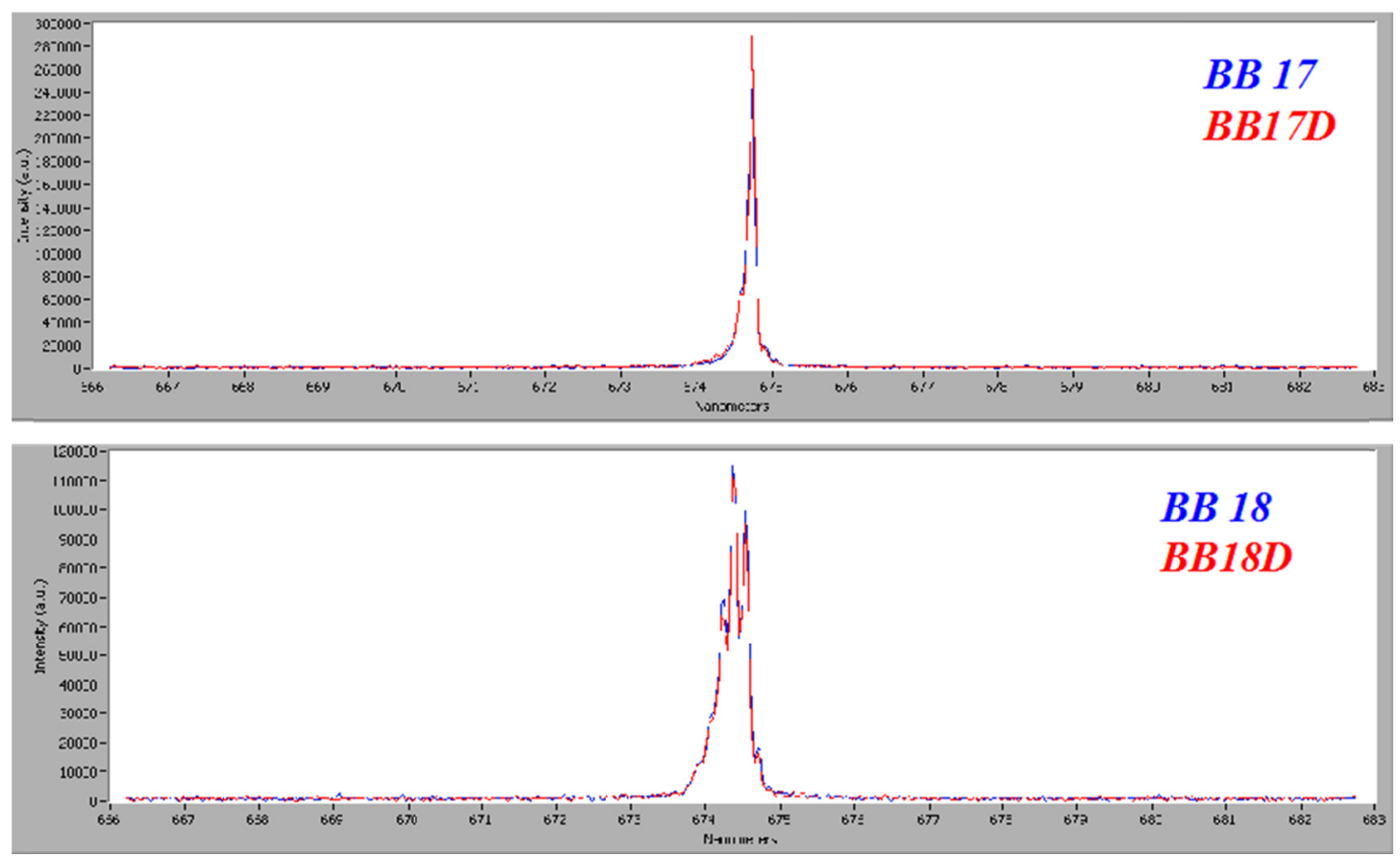

Figure 42. LIBS spectra for blue gels BB 17 (top) and BB18 (bottom) and their respective duplicate samples 

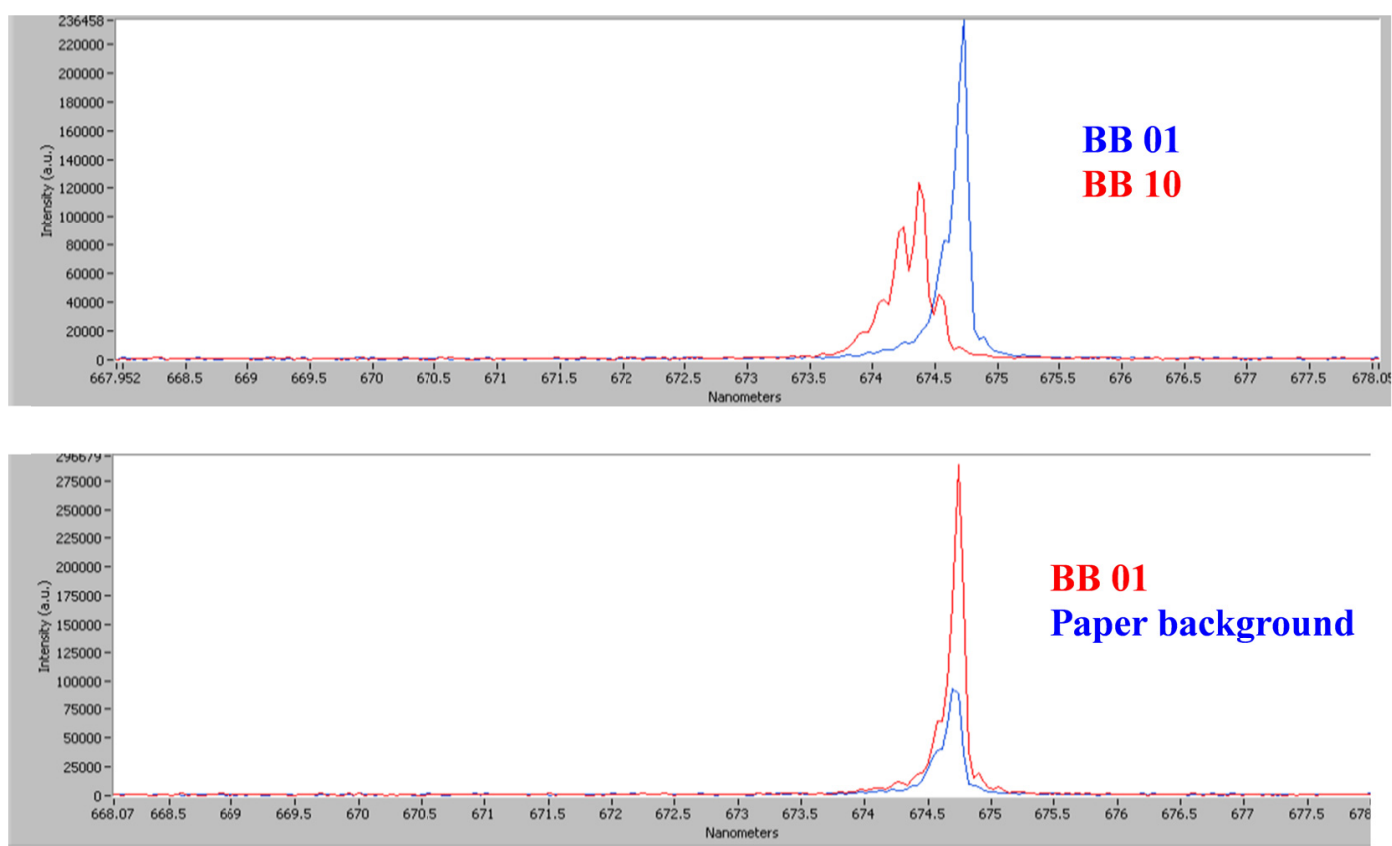

Figure 43. LIBS spectra of emission lines at the 674-676 nm range for blue gel samples $\mathrm{BB} 01, \mathrm{BB} 10$ and the paper background.

The most significant improvement in discrimination was observed for the toner set by comparing the unidentified $674-676$ bands. False inclusion rates decreased from $12.8 \%$ to $4.3 \%$. Nevertheless, one of the 3 duplicate pairs from the toner set was incorrectly excluded by spectral overlay of this region and therefore the usefulness of these bands should be more carefully studied with a larger number of duplicate or blind samples to better estimate false exclusion rates.

Furthermore, the LIBS method was optimized for identification of elemental emissions. It has been reported elsewhere that larger gate delays are needed to optimize the detection of molecular emission while minimizing atomic and continuum signals (Russo et al., 2011). 
For these reasons, this study was a preliminary evaluation of the usefulness of molecular emissions for the characterization and comparison of inks. Results have shown that molecular bands can be detected and could provide additional discrimination to other ionic/atomic emission from ink components. Yet, a more in depth study is recommended in the future.
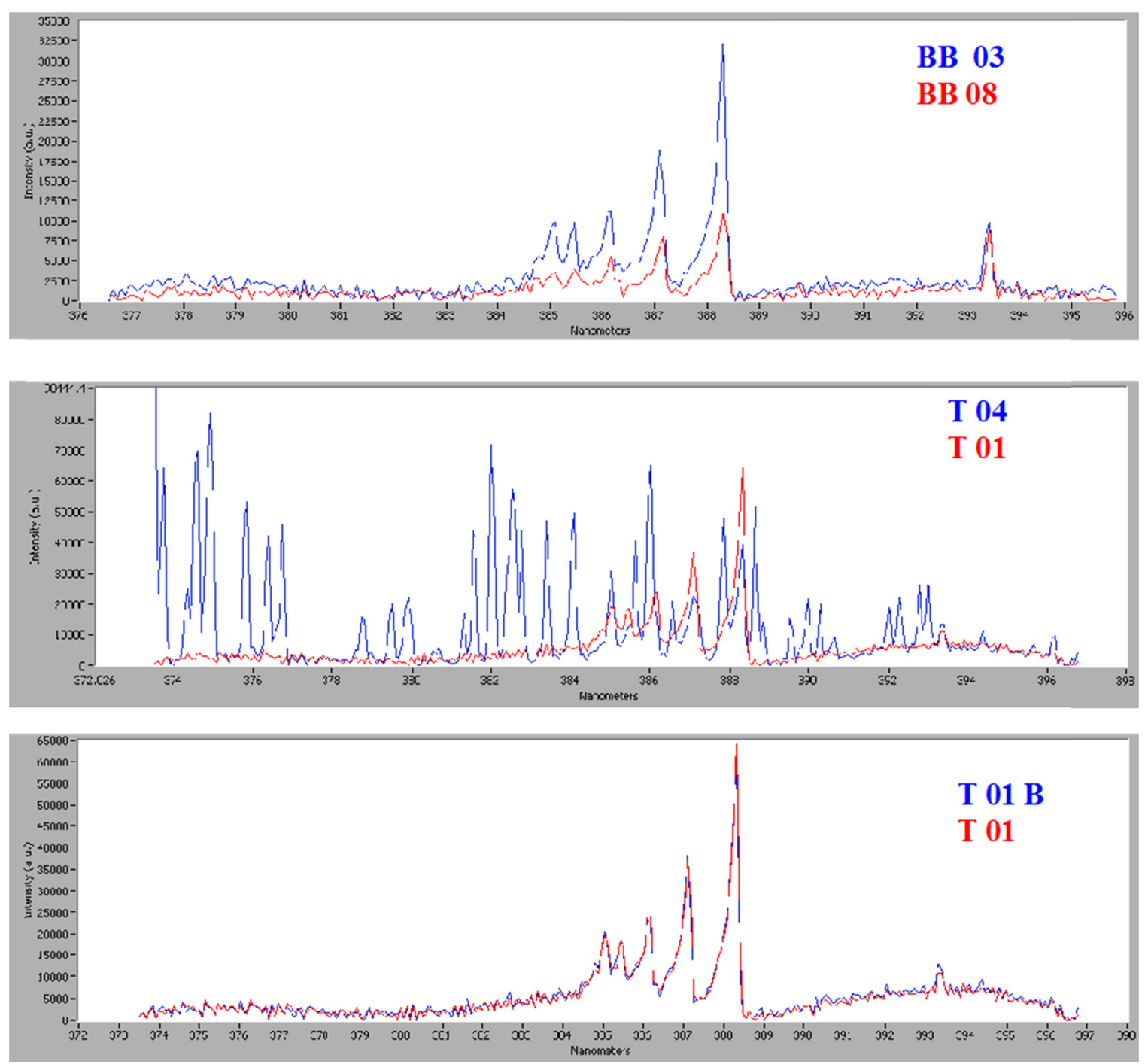

Figure 44. Examples of LIBS spectra for the CN bands on blue gel inks (top, BB03 and BB08), and toners (T04, T01 and T01 Blind, respectively) 

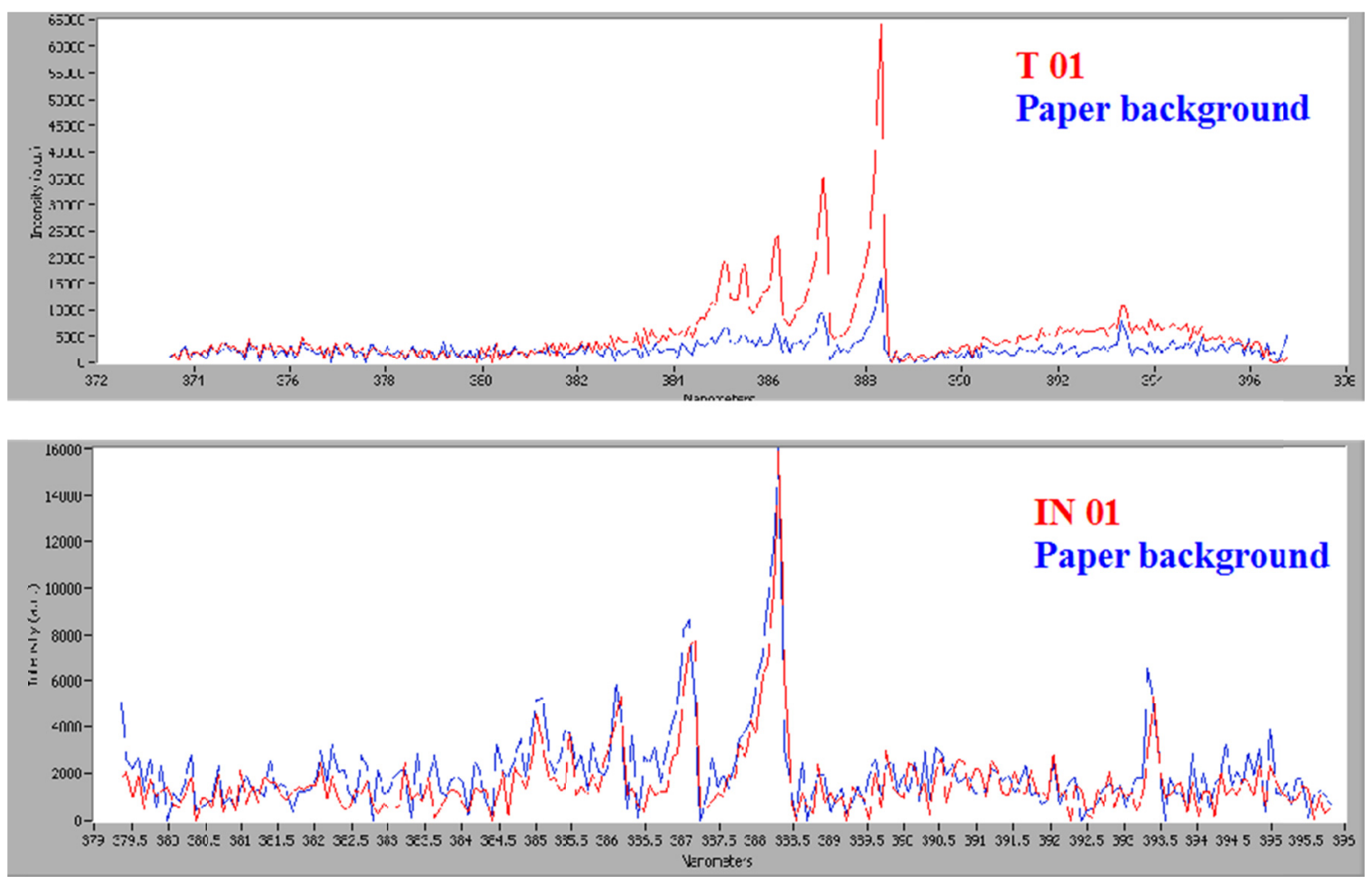

Figure 45. LIBS spectra for CN band in toner (top) and inkjet (bottom) and the respective background signal from paper substrate

\subsubsection{Determination of mass of ink removed by laser ablation methods}

Another important parameter evaluated in the validation of these laser-ablation methods was the amount of ink removed during the ablation process as well as the amount of paper substrate that is removed along with the ink analysis. To estimate the percent of ink and paper removed during laser ablation, a series of experiments were conducted for each ink type.

For writing ink analysis, the estimation of the percent of ink removed was conducted on standard in-house inks and on writing ink strikes. Background paper Whatman 42 was weighted in a microanalytical balance before deposition of the ink, after 
deposition of the ink, and after the ablation. Since the amount of mass removed per ablation replicate is not detectable in a micro-analytical balance, a total of 25 ablations were produced to estimate the mass removed per ablation. Five replicates (each one with 25 ablation measurements) were used to estimate the values.

The following parameters were measured with either a micro-analytical balance or a microscope (with length measurement capabilities):

a) Total area of the ink deposited on paper $\left(\mathrm{A}_{\text {ink }}\right)$.

b) Total mass of the ink deposited on paper ( $\left.\mathrm{md}_{\mathrm{ink}}\right)$.

c) Area of ink ablated per replicate ( $\left.\mathrm{A}_{\text {ablated }}\right)$.

d) Total mass of ink and paper per replicate removed during ablation ( $\mathrm{mr}_{\text {ablated ink }+}$ paper)

Once all those parameters were acquired, the mass of ink only $\left(\mathrm{mr}_{\mathrm{ink}}\right.$ only $)$ removed during the ablation was estimated using the following formula:

$$
\mathrm{mr}_{\text {ink only }}=\left(\mathrm{A}_{\text {ablated }} \mathrm{X} \mathrm{mr} \mathrm{ablated} \mathrm{ink}+\text { paper }\right) / \mathrm{A}_{\text {ink }}
$$

Then, the percent of ink and paper that is removed during each ablation can be estimated as:

$$
\% \text { ink removed during ablation }=100 \times \mathrm{mr}_{\text {ink only }} / \mathrm{mr}_{\text {ablated ink }+ \text { paper }}
$$

The total mass of ink and paper removed during the ablation was also measured using a piezoelectric balance and the values were in agreement with the mass determined by using the micro-analytical balance.

For printing inks, the calculation was more cumbersome because the small paper strips from the Whatman standard paper should be mounted first on regular document 
paper for printing. As a result, the addition of glue in the corners of the paper would inevitably alter the weight of the paper.

Therefore, several $1 \mathrm{~cm}^{2}$ squares were cut from the reference paper $(\mathrm{n}=25)$ to estimate the average weight of paper per $\mathrm{cm}^{2}$. The paper was stored under controlled humidity conditions to avoid bias.

The paper strips were glued into the regular paper for printing and then $1 \mathrm{~cm}^{2}$ squares were printed on the Whatman strips with each toner or inkjet ink. The printed ink squares were then carefully cut and weighted. The mass of ink deposited was then estimated as the difference between the $1 \mathrm{~cm}^{2}$ ink on paper (measured on micro-balance) and the average mass of paper previously recorded for blank $1 \mathrm{~cm}^{2}$ paper (Whatman).

Once the deposited ink mass was estimated, the same method and formulas previously described for writing ink was used for the printing inks.

Table 29 summarizes the mass removal estimates for each type of ink using both laser-based methods. From these results the following conclusions can be derived:

a) The percent of paper removed along with the ink is large regardless of the mild ablation conditions, particularly for writing and inkjet inks were the fibers are typically embedded with the ink.

b) Since the percent of paper removed during the ablation of the ink is significantly higher than the percent of only ink, this supports the assumption that ${ }^{13} \mathrm{C}$ signal is mainly originated from the paper. This assumption can be also done in part because the content of $\mathrm{C}$ in paper is greater than $80 \%$ while the $\mathrm{C}$ content in organic components on ink is only few percent. These results are in agreement 
with the efficiency of internal standardization by ${ }^{13} \mathrm{C}$ observed for writing inks and inkjets and not for toners.

c) Ablation on toners removes less paper than other inks, which support previous observations.

d) Since the percent of paper removed with ink is high, a paper substrate background correction is appropriate prior the characterization of the signal contribution from the ink.

e) Although the total mass of ink removed by LA-ICP-MS and LIBS remains nearly undetectable to the naked eye, the ablation conditions and the type of laser used during the LIBS and LA-ICP-MS experiments removes a larger amount of mass by the LIBS set up than by LA-ICP-MS.

The studies conducted on our sample collections support the hypothesis that elemental profiles of each individual matrix (ink and paper) can be identified after the proper background correction. Nonetheless, it is possible that some paper documents may contain a relatively large amount of certain elements that could mask the ink contribution. As a consequence, in real cases, the combined discrimination capability of the elemental profile of ink and paper together is a convenient approach to optimize the informative value of both matrices. 
Table 29. Comparison of mass removed during laser ablation experiments on inks. Mass is reported in $\mu \mathrm{g}$.

\begin{tabular}{|c|c|c|}
\hline INK type & LA-ICP-MS & LIBS \\
\hline WRITING INK & & $12 \pm 2$ \\
\hline removed & $6.9 \pm 0.2$ & \\
\hline Mass of only ink removed & $0.34 \pm 0.01$ & $3 \pm 0.02$ \\
\hline \% ink removed & $5.1 \pm 0.2$ & $24 \pm 1$ \\
\hline INKJET INK & & \\
\hline Total mass ink \& paper & $7 \pm 0.5$ & \\
\hline removed & & $3 \pm \pm 0.5$ \\
\hline Mass of only ink removed & $0.56 \pm 0.05$ & $28 \pm 6 \pm 17$ \\
\hline \% ink removed & $7 \pm 1$ & \\
\hline TONER & $25 \pm 8$ & \\
\hline Total mass ink \& paper & & \\
\hline removed & & \\
\hline Mass of only ink removed & & \\
\hline \% ink removed & & \\
\hline
\end{tabular}


3.3 Conclusions for the elemental analysis of ink by laser ablation methods

Qualitative and semi-quantitative LA-ICP-MS and LIBS methods have been developed and optimized for the elemental analysis of writing inks (gel and ballpoint) and printing inks (laser toner and inkjet).

Differences in the chemistry of the inks and ink-paper interaction required optimization of methods that were specific to the ink-type. Thus, the main differences in their analytical methods were in the sampling strategies, calibration methods and selection of the most informing elements.

Mass removal studies revealed that there is a considerable amount of paper substrate removed along with the ink during the ablation process and therefore the identification of the contribution of the paper has to be part of the analytical approach prior comparison of the elemental ink profile.

The study has demonstrated that both laser- based methods are suitable for comparison of writing and printing inks. Homogeneity studies show smaller variation of elemental compositions within a single source (i.e., pen or cartridge) than variations between different sources (i.e., brands, types).

Regardless of the small amount of ink removed during the analysis $(0.3-28 \mu \mathrm{g})$, significant and detectable differences were observed between each subset of black gel inks, blue gel inks, ballpoint inks, toners and inkjets from different sources (discrimination $(\sim 87-100 \%)$ and low error rates $(<0.4$ false exclusions; $1.2-12.8$ false inclusions) depending on the sample set under investigation and the method applied.

Differentiation of inks was possible at the brand, model, type and batch level for all the printing inks and writing inks studied here. 
Grouping of writing inks and printing inks by brand and/or source of origin is promising but still needs a larger sampling collection and more feedback from the ink industry regarding the origin of manufacture of ink specimens.

Advantages of the laser-based methods include micro-bulk analysis with minimum sample destruction, multi-elemental capabilities, fast time of analysis and excellent discrimination power. In addition, the LIBS method has the advantage of less complexity of operation and reduced instrument cost and maintenance. Moreover, the results indicate that laser-induced molecular emissions could provide additional discrimination to the ionic/atomic emissions of ink.

Broad-band spectrum provided a better tool for the comparison of ink samples reducing time of analysis and amount of mass removed. Nonetheless, ICCD detectors are recommended over CCD detectors because of its increased sensitivity.

These methods now present an attractive analysis alternative for forensic examiners to increase the informing power in comparisons and identification of these materials. 


\section{PERFORMANCE OF STANDARDIZED METHODS FOR THE FORENSIC ELEMENTAL ANALYSIS OF GLASS BY $\mu$-XRF, ICP-MS, LA-ICP-MS AND LIBS.}

\subsection{Experimental}

\subsubsection{Instrumentation}

Several different instruments were used within the interlaboratory studies. The ICP, $\mu-X R F$ and LIBS instruments and analytical parameters used in this study are summarized in Tables 30, 31 and 32, respectively.

Participants using ICP-based methods reported between 10 and 18 element concentrations from the following list: $\mathrm{Li}, \mathrm{Mg}, \mathrm{Al}, \mathrm{K}, \mathrm{Ca}, \mathrm{Fe}, \mathrm{Ti}, \mathrm{Mn}, \mathrm{Rb}, \mathrm{Sr}, \mathrm{Zr}, \mathrm{Sn}, \mathrm{Ba}$, $\mathrm{La}, \mathrm{Ce}, \mathrm{Nd}, \mathrm{Hf}$, and $\mathrm{Pb}$. The digestion and ICP-MS method followed the ASTM method E2330 [ASTM E2330-04].

As a result of the nature of the technique, the $\mu$-XRF participants did not have a pre-determined element list but were asked to report data for any detected elements with atomic number greater than ten, including at least $\mathrm{Na}, \mathrm{Mg}, \mathrm{Al}, \mathrm{Si}, \mathrm{K}, \mathrm{Ca}, \mathrm{Ti}, \mathrm{Fe}, \mathrm{Sr}$, and Zr. Participants were asked to report peak area intensity data for the following ratios: $\mathrm{Ca} / \mathrm{Mg}, \mathrm{Ca} / \mathrm{Ti}, \mathrm{Ca} / \mathrm{Fe}, \mathrm{Sr} / \mathrm{Zr}, \mathrm{Fe} / \mathrm{Zr}$, and $\mathrm{Ca} / \mathrm{K}$.

LIBS participants did not have a predetermined element list either but were asked in the instructions to report data for $\mathrm{Ca}, \mathrm{Fe}, \mathrm{Al}, \mathrm{Na}, \mathrm{Sr}, \mathrm{K}, \mathrm{Ti}, \mathrm{Ba}, \mathrm{Mg}$ and the following peak area/intensity ratios were suggested: A1394.4/Na330.0; K766.5/Ca643.9; Al394.4/Fe371.9; Fe438.4/K766.5; Al394.4/Sr460.7; Sr460.7/K766.5; Na818.3/K766.5; and $\mathrm{Ca} 643.9 / \mathrm{Mg} 279.5$ 
Table 30. Instrumental parameters used for the LA-ICP-MS or ICP-MS laboratories that participated on tests 1 to 4.

\begin{tabular}{|c|c|c|c|c|c|c|c|}
\hline Lab ID & $\begin{array}{l}\text { B- } \\
\text { ICP }\end{array}$ & $\begin{array}{l}\text { C- } \\
\text { ICP }\end{array}$ & $\begin{array}{l}\text { D- } \\
\text { ICP }\end{array}$ & $\begin{array}{l}\text { F- } \\
\text { ICP }\end{array}$ & $\begin{array}{l}\text { G- } \\
\text { ICP }\end{array}$ & \begin{tabular}{|l|} 
H- \\
ICP
\end{tabular} & $\begin{array}{l}\text { I- } \\
\text { ICP }\end{array}$ \\
\hline Method & LA-ICP-MS & LA-ICP-MS & LA-ICP-MS & $\begin{array}{l}\text { Digestion- } \\
\text { ICP-MS }\end{array}$ & LA-ICP-MS & LA-ICP-MS & $\begin{array}{l}\text { LA-ICP- } \\
\text { MS }\end{array}$ \\
\hline $\begin{array}{l}\text { ICPMS } \\
\text { instrument }\end{array}$ & $\begin{array}{l}\text { Perkin Elmer } \\
\text { Elan DRC II }\end{array}$ & $\begin{array}{l}\text { Thermo } \mathrm{X} \\
\text { series II }\end{array}$ & $\begin{array}{l}\text { Perkin Elmer } \\
\text { Elan DRC II }\end{array}$ & $\begin{array}{l}\text { Agilent } \\
\text { Technologies } \\
7500\end{array}$ & $\begin{array}{l}\text { Agilent } \\
\text { Technologies } \\
3500\end{array}$ & $\begin{array}{l}\text { Agilent } \\
\text { Technologies } \\
7500\end{array}$ & $\begin{array}{l}\text { Perkin } \\
\text { Elmer- } \\
\text { Elan DRC } \\
\text { II }\end{array}$ \\
\hline $\begin{array}{l}\text { RF power } \\
\text { (W) }\end{array}$ & 1500 & 1450 & 1500 & 1600 & 1350 & 1390 & 1300 \\
\hline $\begin{array}{l}\text { Ar gas flow } \\
\left(\mathrm{Lmin}^{-1}\right)\end{array}$ & 1.0 & 1.0 & 0.90 & 0.50 & 0.9 & 0.9 & 0.95 \\
\hline $\begin{array}{l}\text { Laser ablation } \\
\text { instrument }\end{array}$ & $\begin{array}{l}\text { New Wave } \\
\text { UP213 }\end{array}$ & $\begin{array}{l}\text { New Wave } \\
\text { UP213 }\end{array}$ & $\begin{array}{l}\text { New Wave } \\
\text { UP213 }\end{array}$ & n.a. & $\begin{array}{l}\text { New Wave } \\
\text { UP213 }\end{array}$ & $\begin{array}{l}\text { New Wave } \\
\text { UP213 }\end{array}$ & $\begin{array}{l}\text { CETAC } \\
\text { LSX500 }\end{array}$ \\
\hline $\begin{array}{ll}\begin{array}{l}\text { Carrier } \\
\left(\mathrm{Lmin}^{-1}\right)\end{array} & \text { gas }\end{array}$ & $\mathrm{He}, 1.0$ & $\mathrm{He}, 1.0$ & $\mathrm{He}, 0.90$ & n.a. & $\mathrm{He}, 0.70$ & $\mathrm{He}, 0.93$ & $\mathrm{He}, 0.95$ \\
\hline $\begin{array}{l}\text { Wavelength } \\
(\mathrm{nm})\end{array}$ & 213 & 213 & 213 & n.a. & 213 & 213 & 266 \\
\hline $\begin{array}{l}\text { Spot size } \\
(\mu \mathrm{m})\end{array}$ & 60 & 55 & 55 & n.a. & 60 & 55 & 50 \\
\hline $\begin{array}{l}\text { Fluence } \\
\left(\mathrm{Jcm}^{-2}\right)\end{array}$ & 17.5 & 19 & 30 & n.a. & 22 & 12 & $\mathrm{nr}$ \\
\hline $\begin{array}{l}\text { Tube length } \\
(\mathrm{m})\end{array}$ & 0.91 & 1.8 & 1.2 & n.a. & 1.2 & 1.2 & 0.75 \\
\hline $\begin{array}{l}\text { Ablation cell } \\
\text { volume }\left(\mathrm{cm}^{3}\right)\end{array}$ & 80 & 25 & 25 & n.a. & 25 & 25 & 50 \\
\hline
\end{tabular}

$*^{\mathrm{a}}$ Data reported only for interlaboratory test \# 2. 
Table 31. Instrumental parameters used for the additional ICP participants in inter-laboratory tests 3 and 4 ..

\begin{tabular}{|c|c|c|c|c|c|}
\hline Lab ID & ICP-A & ICP-E & ICP-J* & ICP-K* & ICP-L* \\
\hline Method & LA-ICP-MS & LA-ICP-MS & LA-ICP-OES & LA-ICP-MS & LA-ICP-MS \\
\hline ICPMS instrument & $\begin{array}{l}\text { Perkin Elmer } \\
\text { Elan DRC II }\end{array}$ & $\begin{array}{c}\text { Thermo } \\
\text { Element } 2\end{array}$ & $\begin{array}{c}\text { Perkin Elmer } \\
\text { Optima } \\
\text { 7300DV }\end{array}$ & $\begin{array}{l}\text { Perkin Elmer } \\
\text { Elan DRC II }\end{array}$ & $\begin{array}{c}\text { Thermo } \\
\text { Element } 2 \text { XR }\end{array}$ \\
\hline $\begin{array}{c}\text { RF power } \\
\text { (W) }\end{array}$ & 1325 & 1250 & 1500 & 1400 & 1260 \\
\hline Ar gas flow $\left(\mathrm{Lmin}^{-1}\right)$ & 1.0 & 1.0 & 0.7 & 0.9 & 0.8 \\
\hline Laser ablation instrument & $\begin{array}{c}\text { New Wave } \\
\text { UP213 }\end{array}$ & $\begin{array}{l}\text { New Wave } \\
\text { UP213SS }\end{array}$ & $\begin{array}{c}\text { New Wave } \\
\text { UP213 }\end{array}$ & $\begin{array}{l}\text { CETAC } \\
\text { LSX 500 }\end{array}$ & New Wave UP-193fx \\
\hline Carrier gas $\left(\mathrm{Lmin}^{-1}\right)$ & $\mathrm{He}, 0.75$ & $\mathrm{He}, 0.7$ & He, 0.6 & $\mathrm{He}, 0.92$ & $\mathrm{He}, 0.415$ \\
\hline Wavelengh (nm) & 213 & 213 & 213 & 266 & 193 \\
\hline $\begin{array}{c}\text { Spot size } \\
(\mu \mathrm{m})\end{array}$ & 80 & 50 & 100 & 50 & 50 \\
\hline $\begin{array}{l}\text { Fluence } \\
\left(\mathrm{Jcm}^{-2}\right)\end{array}$ & 8 & 9.5 & 25 & 3.5 & 6.1 \\
\hline Tube length (m) & 1.0 & 1.0 & 1.2 & 1.0 & 1.1 \\
\hline Ablation cell volume $\left(\mathrm{cm}^{3}\right)$ & 33 & 40 & 25 & 33 & 50 \\
\hline
\end{tabular}

* Data reported for test 4 only 
Table 32. Instrumental parameters used for the elemental analysis of glass fragments by $\mu-\mathrm{XRF}$

\begin{tabular}{|c|c|c|c|c|c|c|c|c|c|}
\hline Lab ID & A-XRF & B-XRF & C-XRF & D-XRF & E-XRF & F-XRF & G-XRF & H-XRF ${ }^{* a}$ & I-XRF $^{* a}$ \\
\hline Instrument Model & $\begin{array}{l}\text { EDAX Eagle } \\
\text { III }\end{array}$ & $\begin{array}{l}\text { EDAX } \\
\text { Eagle II }\end{array}$ & $\begin{array}{l}\text { EDAX } \\
\text { Eagle III }\end{array}$ & $\begin{array}{l}\text { IXRF } \\
\text { coupled } \\
\text { to } \\
\text { Phillips } \\
\text { XL30 }\end{array}$ & $\begin{array}{l}\text { EDAX } \\
\text { Eagle } \\
\text { III }\end{array}$ & $\begin{array}{l}\text { EDAX } \\
\text { Eagle III }\end{array}$ & $\begin{array}{l}\text { EDAX } \\
\text { Eagle II }\end{array}$ & $\begin{array}{l}\text { EDAX } \\
\text { Orbis }\end{array}$ & $\begin{array}{l}\text { EDAX } \\
\text { Eagle } \\
\text { III }\end{array}$ \\
\hline Dead time (\%) & 35 & 40 & 35 & $35-40$ & $35-40$ & $18-22$ & Avg. & 40 & 25 \\
\hline Beam size $(\mu \mathrm{m})$ & 114 & 300 & 100 & 100 & 210 & 100 & 50 & 30 & 100 \\
\hline Beam energy (kV) & 40 & 40 & 50 & 45 & 45 & 50 & 38 & 50 & 50 \\
\hline $\begin{array}{l}\text { Time } \\
(\mu s)\end{array}$ & 17 & 17 & 35 & 2 & 17 & 35 & 17 & 12.8 & 35 \\
\hline $\begin{array}{l}\text { Acquisition time } \\
\text { (Live seconds) }\end{array}$ & $1200-1500$ & 1200 & 1200 & 1200 & 1200 & $\begin{array}{l}1200- \\
1800\end{array}$ & 1200 & 1200 & 1200 \\
\hline Resolution (eV) & 138.4 & 161.9 & 145.5 & 146.0 & 147.2 & 148.3 & 164.3 & 177.5 & 148.0 \\
\hline $\begin{array}{l}\text { Collimation of } \\
\text { capillary beam }\end{array}$ & $\begin{array}{l}\text { Poly- } \\
\text { capillary }\end{array}$ & $\begin{array}{l}\text { Mono- } \\
\text { capillary }\end{array}$ & $\begin{array}{l}\text { Mono- } \\
\text { capillary }\end{array}$ & $\begin{array}{l}\text { Poly- } \\
\text { capillary }\end{array}$ & $\begin{array}{l}\text { Poly- } \\
\text { capillary }\end{array}$ & $\begin{array}{l}\text { Mono- } \\
\text { capillary }\end{array}$ & $\begin{array}{l}\text { Poly- } \\
\text { capillary }\end{array}$ & $\begin{array}{l}\text { Poly- } \\
\text { capillary }\end{array}$ & $\begin{array}{l}\text { Mono- } \\
\text { capillary }\end{array}$ \\
\hline Tube material & $\mathrm{Rh}$ & $\mathrm{Rh}$ & $\mathrm{Rh}$ & Mo & $\mathrm{Rh}$ & $\mathrm{Rh}$ & $\mathrm{Rh}$ & $\mathrm{Rh}$ & $\mathrm{Rh}$ \\
\hline
\end{tabular}

${ }^{* a}$ Data reported only for interlaboratory test \# 2. 
Table 33. Instrumental parameters used for the elemental analysis of glass fragments by LIBS.

\begin{tabular}{|c|c|c|c|c|}
\hline Lab ID/ & H-LIBS & I-LIBS $^{\mathbf{a}}$ & J-LIBS $^{\text {b }}$ & K-LIBS $^{\text {b }}$ \\
\hline Instrument & In-house set up & $\begin{array}{c}\text { RT100-HP } \\
\text { Applied spectra }\end{array}$ & Insight-266 & $\begin{array}{l}\text { Continuum } \\
\text { Surelight II }\end{array}$ \\
\hline $\begin{array}{c}\text { Laser } \\
\text { wavelength }\end{array}$ & $266 \mathrm{~nm}$ & $266 \mathrm{~nm}$ & $266 \mathrm{~nm}$ & $266 \mathrm{~nm}$ \\
\hline $\begin{array}{l}\text { Energy } \\
\text { density }\end{array}$ & $27 \mathrm{~mJ}$ & $1.16 \mathrm{~mJ}$ & $12 \mathrm{~mJ}$ & $32 \mathrm{~mJ}$ \\
\hline LTSD & $\begin{array}{c}1.5 \mathrm{~mm} \text { into the } \\
\text { sample }\end{array}$ & n.a & n.a & n.a \\
\hline $\begin{array}{l}\text { Number of } \\
\text { shots per } \\
\text { replicate }\end{array}$ & $\begin{array}{l}100 \text { (only last } 50 \\
\text { used for analysis) }\end{array}$ & 15 & 50 & 50 \\
\hline Spectrometer & $\begin{array}{l}\text { Mechelle (Andor } \\
\text { Technologies) }\end{array}$ & $\begin{array}{c}\text { Princeton } \\
\text { Instruments }\end{array}$ & Echelle & $\begin{array}{c}\text { Echelle } \\
\text { (Aryelle } \\
\text { Butterfly } \\
\text { LTB) }\end{array}$ \\
\hline Detector & ICCD & $\mathrm{CCD}$ & ICCD & ICCD \\
\hline Gate delay & $1 \mu \mathrm{s}$ & $0.5 \mu \mathrm{s}$ & $1.4 \mu \mathrm{s}$ & $1.2 \mu \mathrm{s}$ \\
\hline Gate width & $3.5 \mu \mathrm{s}$ & $7 \mu \mathrm{s}$ & $10 \mu \mathrm{s}$ & $3.5 \mu \mathrm{s}$ \\
\hline
\end{tabular}

${ }^{*}$ Data reported only for round robin 3 and 4.

${ }^{*}$ Data reported only for round robin 4 . 


\subsubsection{Reagents, Standards and Samples}

The standard reference materials NIST SRM 612, NIST SRM 1831 (National Institute of Standards and Technology, Gaithersburg, MD) and the matrix-matched float glass standard (FGS) glasses FGS 1 and FGS 2 (Bundeskriminalamt, Wiesbaden, Germany) were provided to each participant for the interlaboratory studies. The glass DGG 1 (Deutsche Glastechnische Gesellschaft, Offenbach, Germany) was also used as a control check in an extended study. In addition, glass samples were submitted as mock casework comparisons. Those samples were selected from a set of different sources collected and analyzed at Florida International University between 1998 and 2010.

\subsubsection{Analytical protocols and descriptions of interlaboratory tests}

The project consisted of four interlaboratory tests conducted by the EAWG members. The first and second tests were designed to develop and characterize the $\mu$ XRF, LA-ICP-MS and LIBS analytical protocols. The second, third, and fourth tests contained sample fragments that each participant analyzed and compared to determine which ones could be distinguished as having come from different sources. In every case, participants made three measurements on each of three fragments provided for each sample. Previous analytical results obtained at FIU for the samples included in test 2, 3 and 4 are shown in Table 33. The information is given to show the general differences between the samples and show which elements are most likely to be distinguishable among samples by the various techniques. All concentration values were obtained by acid digestion ICP-MS analysis and are reported in $\operatorname{ppm}\left(\mu \mathrm{gg}^{-1}\right)$. 
Each interlaboratory test contained the instructions for analysis and reporting according to the analytical method. The protocol of analysis was standardized for each analytical method as much as possible to facilitate interlaboratory comparisons. However, each laboratory was allowed some latitude in setting instrumental parameters according to their own optimized method. The participants were not told of the sources of the samples for these blind interlaboratory tests.

\subsubsection{First interlaboratory test}

The first glass interlaboratory test was designed to conduct analyses on glass standard materials NIST 612 and NIST 1831 and also to conduct analyses on glass fragments that simulate glass transfer evidence in order to answer the question "Does the glass from the known sample (K1) and the questioned sample (Q1) share the same elemental composition?"

Items were packaged individually in weighing paper and placed in pill boxes properly identified with labels. Glass samples that were packaged and labeled as item 1 $(\mathrm{K} 1)$ and item $2(\mathrm{Q} 1)$ originated from the same source. The fragments were obtained from a windshield glass from the FIU glass collection. The windshield was manufactured by PPG industries, Pittsburgh USA in August 2002 and displays the logo: TOYOTA. Participants in the study were not informed as to the source of the samples or that they originated from the same source in this blind study.

Pieces of $\sim 2-3 \mathrm{~cm}^{2}$ were collected from an area of about $30 \mathrm{~cm}^{2}$ of the inside panel of the windshield. The glass samples were then washed with methanol, nitric acid $(0.8 \mathrm{M})$ and DI water. Once the samples were dry, they were broken into small fragments. 
Sample size was selected to be representative of typical fragments received in casework. About $\sim 3-5$ fragments of 3 to $7 \mathrm{~mm}$ length were placed in pillboxes and labeled as $\mathrm{K} 1$. About 7-10 small fragments of 1 to $5 \mathrm{~mm}$ in length were placed in pillboxes and labeled as Q1. One pair of pillboxes along with the test instructions was provided to each participant, for each analytical method used.

\subsubsection{Second interlaboratory test}

The second glass interlaboratory test was designed to conduct elemental analyses on glass standard materials NIST 1831, FGS 1 and FGS 2 to study both the intralaboratory and interlaboratory variation in the measurements. Glass fragments of NIST 1831 were submitted as full thickness fragments (ranging from 5 to $12 \mathrm{~mm}$ in length) and small fragments (ranging from 1 to $3 \mathrm{~mm}$ in length) to evaluate the effects of fragment size and shape.

An expanded study was conducted to evaluate the homogeneity of the elemental composition of glass standard SRM 1831 at bulk and surface fragments by LA-ICP-MS. A sample fragment taken from SRM NIST 1831 was broken into four full-thickness fragments that were then used for the full thickness measurements (surface and bulk). The full-thickness fragments were analyzed in different orientations (surface 1 up focused to the laser beam, surface 2 up focused to the laser beam and bulk material tilted (cross section) focused to the laser beam). Four small fragments were also sampled from the bulk area. All fragments were analyzed in 6 replicates. Reference standard materials SRM NIST 612 and/or FGS 2 were used as calibrators. The glass DGG 1 was used for quality control verification. 
In addition, a set of glass fragments was submitted for comparison in order to permit further evaluation of different match criteria and to address the interpretation. Items were packaged individually in weighing paper and then in envelopes properly identified with labels. Glass samples that were packaged and labeled as item 1 (K1), item $2(\mathrm{Q} 1)$ and item $3(\mathrm{Q} 2)$ were architectural float glass manufactured at the same manufacturing plant (Cardinal Glass Industries, Portage, WI, USA). Glass samples labeled K1 and Q1 shared a common origin. They were sampled from a 4 x $4 \mathrm{~cm}$ glass fragment collected from a glass pane sampled at the Cardinal manufacturing plant on April 1, 2001. Glass samples labeled Q2 originated from a different glass sheet of glass from those labeled sample K1, however they were compositionally similar. Although they were manufactured at the same manufacturing plant, the glass Q2 was manufactured 2 years and 8 months before glasses K1 an Q1 (August 12, 1998).

A total of three fragments, all of them full thickness ranging from 2 to $7 \mathrm{~mm}$ across, were submitted as known samples (K1). Three fragments were submitted for each of the questioned samples; at least two of them were full thickness fragments ranging from 1 to $4 \mathrm{~mm}$. The glass samples were washed with methanol, nitric acid $(0.8 \mathrm{M})$ and deionized water and examined microscopically to assure full thickness and/or original surfaces were present when required. Once the samples were dry, they were carefully broken and measured with a caliper to group them by size and make sure all participants had series of fragments of similar size and shape. Each sample was prepared in a separate clean area to avoid cross contamination. The participants were informed that preliminary tests (color, microscopic examination and refractive index) showed no significant differences between K1 and items Q1 and Q2. 
Table 34. Description of manufacturing dates of float glasses and the composition of the inter-laboratory test samples

\begin{tabular}{|c|c|c|c|c|c|c|c|c|c|}
\hline $\begin{array}{c}\text { Test } \\
\text { Sample }\end{array}$ & $\begin{array}{c}\text { TEST } 2 \\
\text { Q2 }\end{array}$ & $\begin{array}{l}\text { TEST } 2 \\
\text { K1, Q1 }\end{array}$ & $\begin{array}{c}\text { TEST } 3 \\
\text { K1 }\end{array}$ & $\begin{array}{c}\text { TEST } 3 \\
\text { K2 }\end{array}$ & $\begin{array}{c}\text { TEST } 3 \\
\text { Q1 }\end{array}$ & $\begin{array}{c}\text { TEST } 3 \\
\text { Q2 }\end{array}$ & $\begin{array}{c}\text { TEST } 3 \\
\text { Q3 }\end{array}$ & $\begin{array}{c}\text { TEST } 4 \\
\text { Q1 }\end{array}$ & $\begin{array}{c}\text { TEST } 4 \\
\text { K1, K2, } \\
\text { Q2, Q3 }\end{array}$ \\
\hline Plant & Cardinal & Cardinal & Cardinal & Cardinal & Cardinal & Cardinal & Cardinal & Pilkington & Pilkington \\
\hline $\begin{array}{c}\text { Manufacture } \\
\text { date }\end{array}$ & $08 / 12 / 98$ & $04 / 01 / 01$ & $08 / 17 / 01$ & $04 / 15 / 98$ & $08 / 31 / 01$ & $05 / 17 / 98$ & $07 / 17 / 98$ & $02 / 18 / 10$ & $03 / 03 / 10$ \\
\hline $\mathbf{L i}$ & - & - & - & - & - & - & - & 6.79 & 6.14 \\
\hline Mg & 22139 & 22021 & 11499 & 21704 & 13365 & 19887 & 21069 & 29287 & 30487 \\
\hline Al & - & - & - & - & - & - & - & 847 & 906 \\
\hline $\mathbf{K}$ & - & - & - & - & - & - & - & 146 & 191 \\
\hline $\mathrm{Ca}$ & - & - & - & - & - & - & - & 61236 & 62326 \\
\hline $\mathbf{T i}$ & 123 & 62.9 & 58.9 & 118 & 57.51 & 155 & 125 & 504 & 315 \\
\hline Mn & 101 & 20.0 & 17.3 & 92.3 & 17.1 & 158 & 100 & 18.75 & 12.08 \\
\hline $\mathbf{F e}$ & 150 & 530 & 391 & 147 & 420 & 137 & 156 & 4279 & 3086 \\
\hline $\mathbf{R b}$ & 0.73 & 1.66 & 1.64 & 0.63 & 1.62 & 0.92 & 0.72 & 0.68 & 0.76 \\
\hline $\mathrm{Sr}$ & 38.4 & 31.6 & 31.7 & 37.3 & 29.3 & 41.9 & 37.6 & 47.8 & 47.7 \\
\hline $\mathbf{Z r}$ & 34.0 & 34.3 & 28.9 & 32.7 & 31.2 & 36.4 & 34.2 & 24.9 & 21.3 \\
\hline Sn & - & - & - & - & - & - & - & 21.3 & 12.8 \\
\hline Ba & 19.7 & 10.2 & 9.34 & 15.9 & 11.9 & 23.0 & 17.6 & 8.31 & 6.90 \\
\hline $\mathbf{L a}$ & 3.49 & 2.89 & 2.77 & 3.48 & 2.70 & 4.04 & 3.51 & 1.47 & 1.48 \\
\hline $\mathrm{Ce}$ & 6.28 & 3.79 & 4.54 & 6.08 & 4.49 & 7.42 & 6.27 & 2.30 & 2.17 \\
\hline Sm & 0.51 & 0.43 & 0.35 & 0.46 & 0.34 & 0.62 & 0.51 & - & - \\
\hline Nd & - & - & - & - & - & - & - & 1.25 & 1.12 \\
\hline Hf & 0.82 & 1.06 & 0.70 & 0.78 & 0.77 & 0.87 & 0.74 & 0.67 & 0.60 \\
\hline $\mathbf{P b}$ & 0.75 & 1.36 & 1.66 & 0.93 & 1.02 & 0.86 & 0.71 & 0.67 & 0.65 \\
\hline
\end{tabular}




\subsubsection{Third interlaboratory test}

The glass samples for this test were selected to study the capabilities of the techniques to

discriminate glass produced in the same manufacturing plant at different time intervals (i.e. manufactured years apart, months apart and weeks apart).

The samples, labeled K1, K2, Q1, Q2, and Q3 were architectural float glass manufactured between April 15, 1998 and August 31, 2001 at the same Cardinal Glass Industries plant as used in the second test (see Table 33). They were sampled from a $2 \mathrm{x}$ $2.5 \mathrm{~cm}$ glass fragment originally sampled from a glass ribbon at the manufacturing plant.

Samples labeled as K1 and $\mathrm{K} 2$ consisted of fragments that were 2 to $7 \mathrm{~mm}$ in size and those labeled as Q1, Q2, and Q3 consisted of fragments that were approximately 1 to $4 \mathrm{~mm}$ in size. Each sample contained three fragments.

Each participant was asked to conduct elemental analysis in order to compare K1 and K2 with each of the questioned items. The participants were informed that preliminary screening analysis (color and refractive index) showed no significant differences between K1 and K2 and any of the questioned items, Q1, Q2 and Q3.

Participants received no other information concerning the sources of the samples. Participants were instructed to make three measurements on each of the fragments. As in test 2, participants were again told to group the data from the three fragments together for each of the samples when making interpretations.

Sixteen participants reported analytical results for this test. One participant performed acid digestion followed by ICP-MS, six conducted the analysis using LA-ICPMS, two used LIBS and seven used $\mu-X R F$. 


\subsubsection{Fourth interlaboratory test}

The set of glass samples for this test was selected primarily to study the capabilities of the techniques to associate glass that originated from the same source and also to discriminate glass produced in the same manufacturing plant at different time intervals.

This set of glass fragments, consisted of 2 known samples and 3 questioned samples. Samples K1, K2, Q2 and Q3 originated from the same source. The glass fragments originated from two pieces, one $4.0 \times 4.3 \mathrm{~cm}$ and the other $5.0 \times 4.5 \mathrm{~cm}$, which were once part of a single piece of glass. The glass was manufactured at a Pilkington plant (CA, USA) on 03/03/10.

The glass items labeled as Q1 originated from glass manufactured in the same plant approximately two weeks before the other samples $(02 / 18 / 10)$.

Known samples, $\mathrm{K} 1$ and $\mathrm{K} 2$ consisted of three full thickness fragments. Questioned samples Q1, Q2, and Q3 were each three small irregular fragments of approximately 0.5 to $1 \mathrm{~mm}$ in size, smaller than the fragments used in the prior tests.

Participants were told that preliminary analysis (color and refractive index) showed no significant differences between $\mathrm{K} 1$ and $\mathrm{K} 2$ and all of the questioned items (Q1, Q2 and Q3) and were given no other information about the sources of the samples.

Each participant was instructed to conduct elemental analysis in order to compare each of the questioned items with K1and $\mathrm{K} 2$ to determine if any of the questioned items could have originated from either $\mathrm{K} 1$ or $\mathrm{K} 2$. 
For this test, each Q fragment was to be considered separately, rather than grouping the three fragments as in the previous tests. Additionally, the Q fragments in this test were smaller than in previous tests, making this test more difficult.

Seventeen participants submitted results for this test. One laboratory performed acid digestion followed by ICP-MS, eight conducted the analysis using LA-ICP-MS, one used LA-ICP-OES, and seven used $\mu$-XRF.

\subsubsection{Data analysis}

Five ICP-participant laboratories processed their TRA signal from laser ablation with GLITTER ${ }^{\mathrm{TM}}$ software (GEMOC, Macquarie University, Sidney, Australia), which allows reduction of transient signal to quantitative data. One of the participants used Plasmalab (Thermo Fisher XSeriesII, Bremen, Germany) and Microsoft Excel (Microsoft Corp, WA, USA), and one used in-house software for the data reduction.

The XRF data was processed using manufacturer's software (EDAX, NJ, USA) for spectral overlay and Microsoft Excel (Microsoft Corp, WA, USA).

LIBS data was processed using plot for mac OSX (v.0.997, Berlin, Germany) or Mathematica (v. 5.2.0.0, IL, USA).

Statistical analyses were performed by either the use of SYSTAT for windows (v.8.0, SPSS Science, IL, USA), JMP (v.5.0.1 SAS, NC, USA), Excel 2003 (v9.0.2719, Microsoft Corp., WA, USA). 


\subsection{Results and Discussions}

4.2.1 Results from the first and second interlaboratory test: method standardization

The interlaboratory tests were intended to assist participating forensic laboratories in improving elemental analysis of glass comparisons by cross-validating their methods and evaluating their analytical protocols. The main objective of these studies was to conduct elemental analysis of glass with different analytical techniques in order to provide standardized methods and a basis for discussion of the utility of elemental analysis comparison methods, the effectiveness of different methods of statistical analysis and the interpretation of results.

Both interlaboratory studies consisted of two main tasks: a) analysis of reference standard materials to evaluate the analytical performance within and among methods and b) analysis of glass fragments submitted as "blind" tests to evaluate the capabilities of the techniques to correctly associate glass that originated from the same source and/or discriminate glasses that originated from different sources.

The glass standard reference materials NIST 612, NIST 1831, and the glass standards FGS 1 and FGS 2 were used to evaluate the accuracy and precision of individual laboratory measurements. Glass fragments were submitted with a simulated casework scenario to assist the selection of match criteria and the reporting of comparison results between questioned and known fragments.

\subsubsection{Evaluation of the analytical performance}

The results for the elemental analysis of glass standards were separated into two sub-groups based on the techniques used by the participants: (1) the "ICP Group" 
consisted of 6-7 laboratories that performed elemental analysis by ICP-MS or LA-ICPMS and (2) the "XRF Group" consisted of 7-9 laboratories that conducted elemental analysis by $\mu$-XRF. Only one participant conducted LIBS analysis for the first 2 tests and therefore it was not possible to conduct a complete comparison of the analytical performance of the method.

As a result of the nature of the techniques used for the analysis of the standards and samples, the ICP Group reported quantitative data, whereas the XRF and LIBS Group reported semi-quantitative data; therefore, different statistical methods were used to evaluate the results for each group.

\subsection{Analytical performance of ICP-MS methods}

The bias and precision obtained by each laboratory were compared to the interlaboratory results as well as to the certified or reference values for the glass standards.

All LA-ICP-MS laboratories were asked to use the standard SRM NIST 612 as a single calibrator for the analysis of verification control standards and samples. Concentration values for SRM NIST 612 were used as reported by Pearce et al. [Pearce et al., 1996]. The participant that conducted acid digestion followed the dissolution and calibration methods described in ASTM E2330 [ASTM E2330-04].

The glass reference materials NIST 1831, FGS 1 and FGS 2 were used to monitor the analytical performance of the methods. These reference materials were selected due to the similarity of their compositions to the typical soda-lime glass found in forensic casework. The interlaboratory test results for precision and bias obtained for the three 
reference standard materials are shown in Tables 3 to 5. Each of the ICP laboratories made seven replicate sample measurements each on SRM NIST 1831, FGS 1 and FGS 2. The repeatability and reproducibility are calculated as specified in ASTM Practice E 177 [ASTM E177-04].

The majority of the 18 isotopes monitored showed study bias and interlaboratory reproducibility better than $10 \%$, demonstrating that ICP-MS methods (solution and laserablation-based) can provide accurate and precise quantitative information that can be used for forensic comparison of glass samples.

Although accuracy is important in the decision to include data in glass databases or data collections, for purposes of typical forensic comparisons between known and questioned fragments, precision is more critical. As shown in Tables 35 to 37, repeatability within replicates measured by a single laboratory is typically better than $5 \%$. Reproducibility better than $10 \%$ was achieved between participants in different laboratories that used different instruments, operating parameters, and operators.

An exception was observed for iron. Even though good repeatability was achieved by individual laboratories for replicate measurements, poor interlaboratory reproducibility was observed between participants. The inferior performance for iron, in terms of bias and reproducibility, was not surprising because standard quadrupole ICPMS instruments suffer from polyatomic interferences including oxides and hydroxides such as ${ }^{40} \mathrm{Ar}^{16} \mathrm{O}^{1} \mathrm{H}^{+},{ }^{40} \mathrm{Ca}^{16} \mathrm{O}^{1} \mathrm{H}^{+},{ }^{41} \mathrm{~K}^{16} \mathrm{O},{ }^{40} \mathrm{Ar}^{16} \mathrm{O}^{+},{ }^{40} \mathrm{Ca}^{16} \mathrm{O}^{1+}$ that compromise the analytical determination of ${ }^{56} \mathrm{Fe}^{+}$and ${ }^{57} \mathrm{Fe}^{+}$. As a consequence of the nature and abundance of these interferences, standard unit resolution ICP-MS instruments cannot measure the most abundant iron isotope ${ }^{56} \mathrm{Fe}^{+}(91.72 \%$ abundant $)$; therefore, limits of 
detection for the lower abundant isotope ${ }^{57} \mathrm{Fe}^{+}(2.2 \%$ abundant $)$ are typically high $(>10$ $\mu \mathrm{gg}^{-1}$ ) [Castro et al., 2008]. Moreover, the concentration of iron in the standard SRM NIST 612 used as calibrator for LA-ICP-MS is close to the limit of quantitation for some of the instrument configurations, introducing a source of error and inconsistency.

Table 35. Bias and precision obtained by ICP-methods for SRM NIST 1831 from the second interlaboratory study.

\begin{tabular}{|c|c|c|c|c|c|}
\hline Element & $\begin{array}{l}\text { Reported } \\
\text { value, } \\
\boldsymbol{\mu g ~ g ~ g}^{-1}\end{array}$ & $\begin{array}{c}\text { Study } \\
\text { Average, } \\
\mu \mathrm{g} \mathrm{g}^{-1 \mathrm{~d}}\end{array}$ & $\begin{array}{c}\text { Study } \\
\text { Bias } \\
\%\end{array}$ & $\begin{array}{l}\text { Repeatability- } \\
\text { within } s_{r}(\%)\end{array}$ & $\begin{array}{l}\text { Reproducibility- } \\
\text { between } s_{R}(\%)\end{array}$ \\
\hline $\mathrm{Li}$ & $5.00^{\mathrm{a}}$ & 5.3 & 6 & 5.1 & 5.6 \\
\hline $\mathrm{Mg}$ & $21200^{b}$ & 23200 & 9.4 & 1.1 & 10.8 \\
\hline $\mathrm{Al}$ & $6380^{b}$ & 6400 & 0.3 & 1.1 & 8.7 \\
\hline $\mathrm{K}$ & $2740^{b}$ & 2680 & -2.2 & 2.3 & 6.7 \\
\hline $\mathrm{Ca}$ & $58600^{b}$ & 58000 & -1.0 & 2.6 & 3.6 \\
\hline $\mathrm{Fe}$ & $608^{b}$ & 540 & -11 & 2.7 & 24.9 \\
\hline $\mathrm{Ti}$ & $114^{b}$ & 130 & 14 & 2.6 & 6.5 \\
\hline $\mathrm{Mn}$ & $15.0^{\mathrm{c}}$ & 13.3 & -11 & 1.8 & 2.5 \\
\hline $\mathrm{Rb}$ & $6.11^{\mathrm{c}}$ & 6.0 & -1.8 & 2.4 & 3.5 \\
\hline $\mathrm{Sr}$ & $89.1^{\mathrm{c}}$ & 86 & -3.5 & 2.0 & 5.6 \\
\hline $\mathrm{Zr}$ & $43.4^{\mathrm{c}}$ & 37 & -15 & 2.2 & 6.8 \\
\hline $\mathrm{Ba}$ & $31.5^{\mathrm{c}}$ & 30 & -4.8 & 2.6 & 7.9 \\
\hline $\mathrm{La}$ & $2.12^{\mathrm{a}}$ & 2.2 & 3.8 & 2.6 & 6.7 \\
\hline $\mathrm{Ce}$ & $4.54^{\mathrm{c}}$ & 4.4 & -3.1 & 2.6 & 3.8 \\
\hline $\mathrm{Nd}$ & $1.69^{\mathrm{a}}$ & 1.8 & 6.5 & 2.3 & 7.1 \\
\hline $\mathrm{Hf}$ & $1.10^{\mathrm{c}}$ & 1.0 & -9.1 & 3.7 & 8.5 \\
\hline $\mathrm{Pb}$ & $1.99^{\mathrm{c}}$ & 1.8 & -9.5 & 5.0 & 4 \\
\hline
\end{tabular}

${ }^{\mathrm{a}}$ Historical data from a single lab over one year period ( $\mathrm{n}=42$ days).

${ }^{\mathrm{b}}$ Certified by NIST

${ }^{\mathrm{c}}$ Reported in ASTM E2330, values obtained by acid digestion ICP-MS interlaboratory test.

${ }^{\mathrm{d}}$ Average value obtained from 7 participant laboratories using different manufacturer LA and ICP-MS instruments. 
Table 36. Bias and precision obtained by ICP methods in FGS 1 from the second interlaboratory study.

\begin{tabular}{|c|c|c|c|c|c|}
\hline Element & $\begin{array}{c}\text { Reported } \\
\text { value }{ }^{\mathrm{a}}, \\
\mu_{\mathrm{g} \mathrm{g}} \mathrm{g}^{-1}\end{array}$ & $\begin{array}{c}\text { Study } \\
\text { Average, } \\
\mu \mathrm{g} \mathrm{g}^{-1 \mathrm{~b}}\end{array}$ & $\begin{array}{c}\text { Study } \\
\text { Bias } \\
\%\end{array}$ & $\begin{array}{c}\text { Repeatability } \\
\text {-within } s_{r} \\
\text { (\%) }\end{array}$ & $\begin{array}{l}\text { Reproducibility- } \\
\text { between } s_{R}(\%)\end{array}$ \\
\hline $\mathrm{Li}$ & 6.0 & 5.9 & -1.8 & 4.5 & 8.2 \\
\hline $\mathrm{Mg}$ & 23900 & 26100 & 9.2 & 1.6 & 9.0 \\
\hline $\mathrm{Al}$ & 1500 & 1560 & 4.0 & 2.2 & 3.5 \\
\hline $\mathrm{K}$ & 920 & 1000 & 8.7 & 4.1 & 4.7 \\
\hline $\mathrm{Ca}$ & 60600 & 59200 & -2.3 & 1.0 & 5.5 \\
\hline $\mathrm{Fe}$ & 580 & 530 & -8.6 & 1.6 & 26 \\
\hline $\mathrm{Ti}$ & 69 & 80 & 16 & 4.5 & 8.8 \\
\hline $\mathrm{Mn}$ & 43 & 45 & 3.5 & 0.8 & 2.8 \\
\hline $\mathrm{Rb}$ & 8.6 & 7.8 & -8.8 & 2.8 & 3.1 \\
\hline $\mathrm{Sr}$ & 57 & 56 & -1.6 & 2.3 & 6.7 \\
\hline $\mathrm{Zr}$ & 49 & 46 & -5.9 & 2.4 & 8.9 \\
\hline $\mathrm{Sn}$ & 19 & 20 & 4.7 & 1.9 & 1.9 \\
\hline $\mathrm{Ba}$ & 40 & 41 & 2.3 & 2.8 & 8.0 \\
\hline $\mathrm{La}$ & 4.3 & 4.2 & $\begin{array}{l}-2.1 \\
\end{array}$ & 4.2 & 6.7 \\
\hline $\mathrm{Ce}$ & 5.2 & 5.0 & -4.6 & 0.9 & 7.8 \\
\hline $\mathrm{Nd}$ & 5.1 & 5.0 & $\begin{array}{l}-2.4 \\
\end{array}$ & 3.8 & 7.7 \\
\hline $\mathrm{Hf}$ & 3.20 & 3.0 & -6.6 & 2.4 & 10 \\
\hline $\mathrm{Pb}$ & 5.8 & 5.2 & -10 & 1.6 & 2.9 \\
\hline
\end{tabular}

${ }^{a}$ Consensus values reported in ASTM E2330 ( $\left.\mathrm{n}=5-10\right)$.

${ }^{\mathrm{b}}$ Average value obtained from 7 participant laboratories using different manufacturer LA and ICP-MS instruments. 
Table 37. Bias and precision obtained by ICP methods in FGS 2 from the second interlaboratory study

\begin{tabular}{|c|c|c|c|c|c|}
\hline Element & $\begin{array}{c}\text { Reported } \\
\text { value }^{\mathrm{a}}, \\
\mu \mathrm{g} \mathrm{\textrm {g } ^ { - 1 }}\end{array}$ & $\begin{array}{c}\text { Study } \\
\text { Average, } \\
\mu \mathrm{g} \mathrm{g}^{-1 \mathrm{~b}}\end{array}$ & $\begin{array}{c}\text { Study } \\
\text { Bias \% }\end{array}$ & $\begin{array}{c}\text { Repeatability } \\
\text {-within } s_{r} \\
(\%)\end{array}$ & $\begin{array}{l}\text { Reproducibility } \\
\text {-between } s_{R}(\%)\end{array}$ \\
\hline $\mathrm{Li}$ & 29 & 26 & -10.3 & 1.7 & 4 \\
\hline $\mathrm{Mg}$ & 23400 & 25600 & 9.4 & 1.1 & 10 \\
\hline $\mathrm{Al}$ & 7400 & 7600 & 2.7 & 1.1 & 7.2 \\
\hline $\mathrm{K}$ & 4600 & 4900 & 6.5 & 0.8 & 6.5 \\
\hline $\mathrm{Ca}$ & 59300 & 59000 & -0.5 & 1.3 & 6.5 \\
\hline $\mathrm{Fe}$ & 2600 & 2600 & 0.8 & 1.5 & 15.3 \\
\hline $\mathrm{Ti}$ & 326 & 370 & 13.5 & 1.3 & 10.6 \\
\hline $\mathrm{Mn}$ & 221 & 222 & 0.5 & 2.3 & 2.1 \\
\hline $\mathrm{Rb}$ & 35 & 38 & 7.7 & 1.5 & 3.8 \\
\hline $\mathrm{Sr}$ & 253 & 256 & 1.2 & 0.7 & 6.1 \\
\hline $\mathrm{Zr}$ & 223 & 221 & -0.9 & 1.8 & 9.7 \\
\hline $\mathrm{Sn}$ & 94 & 97 & 3.4 & 1.4 & 2.3 \\
\hline $\mathrm{Ba}$ & 199 & 198 & -0.5 & 1.3 & 8.3 \\
\hline $\mathrm{La}$ & 18 & 19 & 5.0 & 1.5 & 8.2 \\
\hline $\mathrm{Ce}$ & 23 & 24 & 3.5 & 3.5 & 6.4 \\
\hline $\mathrm{Nd}$ & 25 & 25 & 1.6 & 4.1 & 8.6 \\
\hline $\mathrm{Hf}$ & 15 & 14 & $\begin{array}{l}-5.3 \\
\end{array}$ & 2.3 & 7 \\
\hline $\mathrm{Pb}$ & 24 & 24 & 1.7 & 1.8 & 4.4 \\
\hline
\end{tabular}

${ }^{a}$ Consensus values [Latkoczy et al., 2005].

${ }^{\mathrm{b}}$ Average value obtained from 7 participant laboratories using different manufacturer LA and ICPMS instruments. 
In addition to the interlaboratory measures of precision and bias reported, each laboratory was later provided with detailed information of a) the individual mean values and standard deviations reported by each laboratory for each element, b) certified values, c) acceptance study range, d) interlaboratory variation of the measurements, and e) zscores. This information allowed an effective way for each participant to evaluate their own protocol and detect outliers or systematic bias, if any.

The z-score corresponds to how far the reported value from each laboratory was from the study mean, divided by the standard deviation of the study [Miller et al., 2000]. The acceptance range for the purposes of this interlaboratory study was defined as the study mean \pm three times the study standard deviation [Miller et al., 2000].

Strontium results for FGS 1 are shown in Figure 46 as an example of the interlaboratory statistics. In general, all laboratories had excellent of accuracy and precision for most elements. All laboratories were within the control criteria for the interlaboratory comparison (reported as z-score), with few exceptions for few elements. For instance, one participant laboratory presented a systematic bias for $\mathrm{Zr}$ (for the three reference standard materials), which led to improvement of their method of analysis.

One of the participants experienced inconsistencies of the results of the concentrations of $\mathrm{Ce}$ and $\mathrm{La}$ for the glass reference FGS 1, which led to an interesting finding for the forensic laser ablation community.

It was made clear by the participant that these values derived from measurements that were taken from a fragment that had originated from the frosted rim of the FGS 1 glass disk. The TRA signal of these ablations exhibits a large peak in the beginning, followed by tailing, suggesting surface contamination. 
Triggered by these observations, several experiments were carried out by the issuer of the FGS glasses (BKA/Germany). All eight FGS 1 and FGS 2 glasses that were examined exhibited a pre-peak-like signal for $\mathrm{Ce}$ and to a smaller extent also for La, combined with spiking of the TRA signal. Based on communication with SCHOTT AG/Germany, the producer of the glass, this is most certainly caused by a partial removal of cerium oxide that was used during the polishing stages of the FGS 1 and FGS 2 disks. Moreover, several sets of analyses have been carried out by BKA, ablating on the polished surface very close to the rim of FGS 1 and FGS 2. When ablating on the rim or very close to the rim (up to $250 \mu \mathrm{m}$ ) in several cases spikes can be detected for Ce and $\mathrm{La}$, inspecting the TRA signal. These spikes led to incorrect high concentrations for cerium and lanthanum. After removal of these peaks using the time-resolved analysis software GLITTER ${ }^{\mathrm{TM}}$, the concentrations for Ce and La were correct.

It can be concluded that measurements/ablations on the rim and very close to the rim of the FGS standards (FGS 1 and FGS 2) should be avoided. The interlaboratory exercises showed that the analytical methods used by ICP participants are fairly standardized and provide consistent results between laboratories regardless of the instrument configuration. The analytical performance of the method proved to be fit for purpose. 


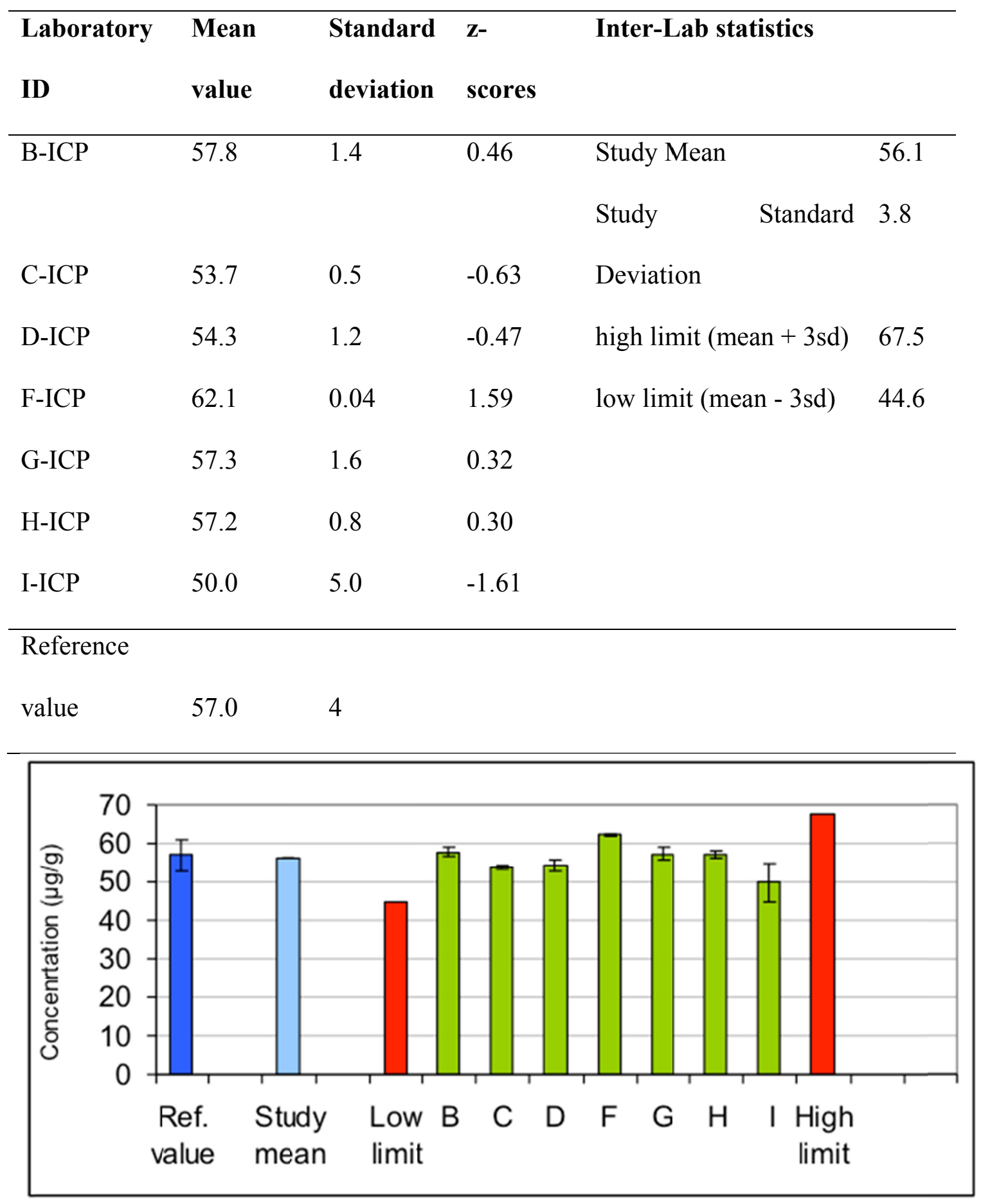

Figure 46. Example of interlaboratory statistics of ICP-MS participants for strontium in FGS 1 


\subsection{Analytical performance of $\mu$-XRF methods}

The $\mu$-XRF group reported results based on semi-quantitative analysis (i.e., intensities or ratios of intensities for the analytes). Although some calibration strategies can be used to conduct quantitative analysis of glass by $\mu-X R F$, this is not typically performed in forensic laboratories as part of their glass examinations. Quantitative accuracy and precision are dependent on algorithm ZAF corrections that can vary significantly for uneven surfaces and varying sample thicknesses. Instead, comparisons of spectra and/or of ratios of intensities, the latter intended to mitigate the effects of varying take-off angles, are common practice among forensic examiners.

All the individual laboratories were asked to report intensities for a predetermined list of elements. A large variation in the analytical signal was observed amongst participant laboratories as a result of the differences of instrument configurations and acquisition parameters, making the evaluation of the interlaboratory performance particularly challenging.

Although these interlaboratory differences do not affect the interpretation of the individual comparison results, a direct comparison between labs was unattainable at this stage. For this reason, a standardization of the data was conducted versus the standard reference material 1831 measured by each participant as a way to attempt to standardize the responses from different laboratories. In order to conduct the standardization for each laboratory, measurements of the glass samples and the SRM 1831 were conducted on the same day. The mean intensity of an element measured on the glass standard was divided by the mean intensity of the same element measured on the SRM 1831: 


$$
E_{\text {normalized }}=\frac{\left[\frac{1}{n} \sum_{i=1}^{n} E_{i}\right]_{\text {sample }}}{\left[\frac{1}{n} \sum_{i=1}^{n} E_{i}\right] \text { SRM } 1831}
$$

where $\mathrm{E}$ is the peak area intensity of the analyte of interest and $\mathrm{n}$ is the number or replicate measurements.

This approach relies on the premise that if a certain instrument configuration produces a lower intensity for a specific element, the response will be lower for both the sample and the 1831 reference standard SRM, and vice versa. Therefore, by using the ratios, these relative interlaboratory differences can be minimized.

Figure 47 illustrates this effect, where significant differences between laboratories were observed, before standardization, in the response of calcium and magnesium on FGS 1. After standardization with SRM NIST 1831, the responses between participants were comparable. Standard deviations of the ratios were estimated as a random propagation of errors.

This approach allowed a comparison of the response between laboratories for the following ratios on standards FGS 1 and FGS 2: $\mathrm{Ca} / \mathrm{Mg}, \mathrm{Ca} / \mathrm{Ti}, \mathrm{Ca} / \mathrm{Fe}, \mathrm{Sr} / \mathrm{Zr}, \mathrm{Fe} / \mathrm{Zr}$ and $\mathrm{Ca} / \mathrm{K}$. The semi-quantitative normalized data expressed as ratio of the peak area intensities were used to estimate z-score values and to detect systematic errors within laboratories. Table 38 illustrates that data obtained by different participants were very consistent after standardization, with variation between laboratories within the acceptance criteria (absolute z-score value equal to or less than 3). The standardization not only 
facilitated interlaboratory comparisons but also opened an opportunity to share XRF databases in the future.
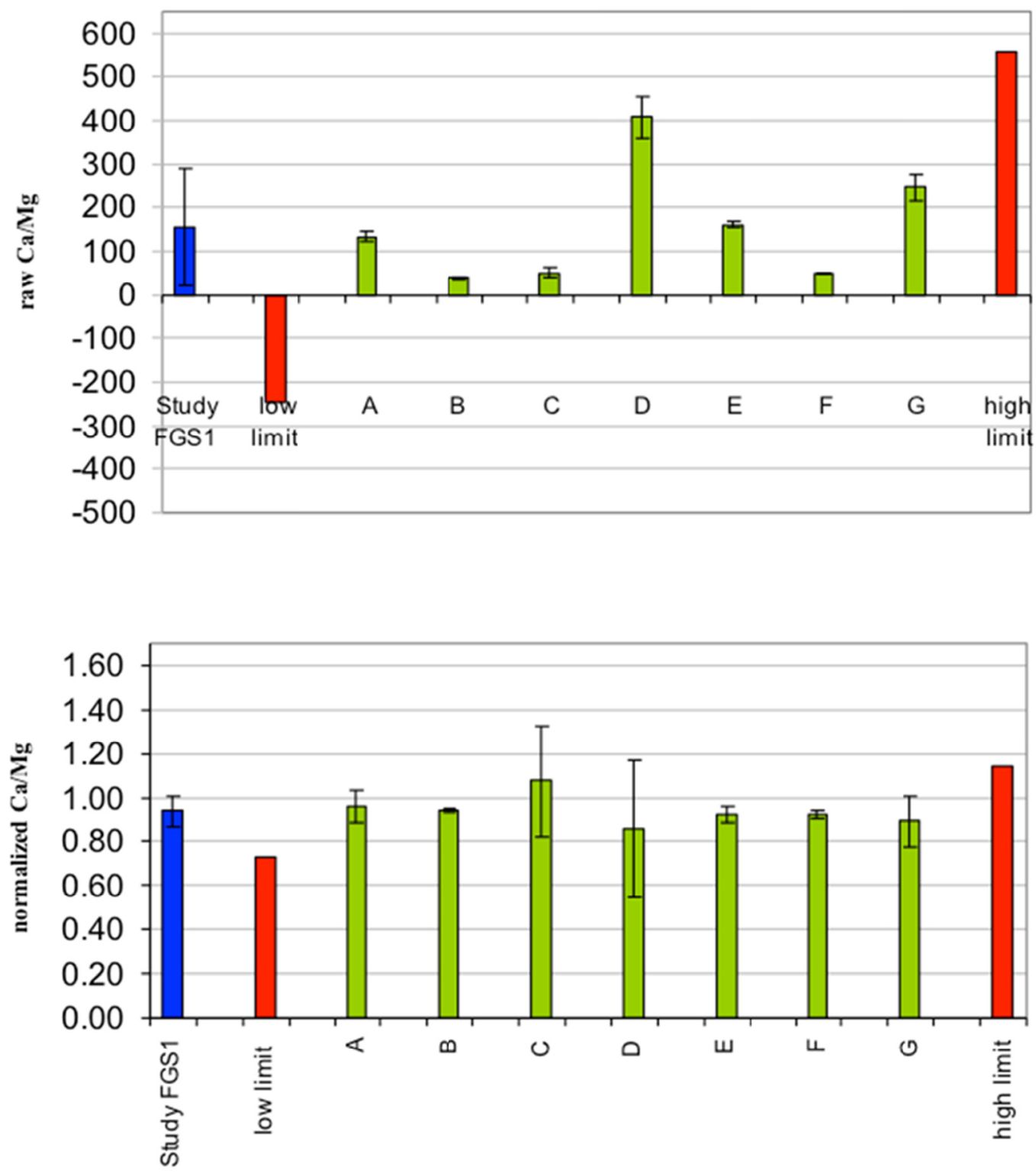

Figure 47. Interlaboratory comparison of the $\mathrm{Ca} / \mathrm{Mg}$ ratio measured by $\mu$-XRF, for FGS1 without standardization (top) and after standardization (bottom) with SRM NIST 1831 
Table 38. Values of z-score obtained from the interlaboratory comparison of elemental ratios by $\mu$-XRF for FGS 1 and FGS 2 .

\begin{tabular}{|c|c|c|c|c|c|c|}
\hline \multicolumn{7}{|c|}{ z-scores for FGS 1} \\
\hline Lab ID & $\mathrm{Ca} / \mathrm{Mg}$ & $\mathrm{Ca} / \mathrm{K}$ & $\mathrm{Ca} / \mathrm{Fe}$ & $\mathrm{Sr} / \mathrm{Zr}$ & $\mathrm{Fe} / \mathrm{Zr}$ & $\mathrm{Ca} / \mathrm{K}$ \\
\hline A-XRF & 0.36 & 0.04 & 0.98 & 1.20 & 0.94 & 0.09 \\
\hline B-XRF & 0.39 & 0.26 & 0.16 & 0.72 & 1.23 & 1.61 \\
\hline C-XRF & 1.41 & 1.89 & 0.81 & 1.05 & 0.19 & 0.42 \\
\hline D-XRF & 1.64 & 0.91 & 2.09 & na & na & 1.51 \\
\hline E-XRF & 0.24 & 0.32 & 0.05 & 1.18 & 0.49 & 0.83 \\
\hline F-XRF & 0.16 & 0.16 & 0.25 & 0.31 & 0.15 & 0.08 \\
\hline G-XRF & 0.95 & 0.18 & 0.18 & 0.63 & 0.86 & 0.51 \\
\hline \multicolumn{7}{|c|}{ z-scores for FGS 2} \\
\hline Lab ID & $\mathrm{Ca} / \mathrm{Mg}$ & $\mathrm{Ca} / \mathrm{K}$ & $\mathrm{Ca} / \mathrm{Fe}$ & $\mathrm{Sr} / \mathrm{Zr}$ & $\mathrm{Fe} / \mathrm{Zr}$ & $\mathrm{Ca} / \mathrm{K}$ \\
\hline A-XRF & 0.33 & 0.88 & 1.17 & 0.17 & 0.04 & 0.46 \\
\hline B-XRF & 0.05 & 0.66 & 0.38 & 0.77 & 1.34 & 1.09 \\
\hline C-XRF & 1.97 & 1.67 & 0.98 & 1.84 & 1.51 & 1.10 \\
\hline D-XRF & 1.21 & 0.36 & 1.33 & na & na & 1.75 \\
\hline E-XRF & 0.23 & 0.66 & 0.45 & 0.45 & 0.06 & 0.62 \\
\hline F-XRF & 0.23 & 1.00 & 0.21 & 0.07 & 0.43 & 0.37 \\
\hline G-XRF & 0.68 & 0.64 & 1.42 & 0.87 & 0.26 & 0.02 \\
\hline
\end{tabular}


The efficiency of the standardization approach is also reflected in Table 39 where the reproducibility is presented for the FGS standards. With the exception of $\mathrm{Fe} / \mathrm{Zr}$, reproducibility among laboratories was better than $12 \%$. The poorer precision of $\mathrm{Fe} / \mathrm{Zr}$ could be a result of the $\mathrm{x}$-ray energies for $\mathrm{Fe}$ and $\mathrm{Zr}$ that are widely divergent and much more prone to take-off angle variations.

Table 39. Precision data obtained by $\mu$-XRF methods for FGS 1 and FGS 2.

\begin{tabular}{|c|c|c|c|}
\hline \multicolumn{4}{|c|}{ FGS 1 Precision } \\
\hline Element Ratio & Average $^{A}$ & $\begin{array}{l}\text { Repeatability-within } \\
\operatorname{sr}(\%)^{\mathrm{A}}\end{array}$ & $\begin{array}{l}\text { Reproducibility- } \\
\text { between } S_{R}(\%)^{B}\end{array}$ \\
\hline $\mathrm{Ca} / \mathrm{Mg}$ & 0.89 & 5 & 11 \\
\hline $\mathrm{Ca} / \mathrm{Ti}$ & 1.44 & 9 & 8 \\
\hline $\mathrm{Ca} / \mathrm{Fe}$ & 1.07 & 1 & 3 \\
\hline $\mathrm{Sr} / \mathrm{Zr}$ & 0.60 & 9 & 12 \\
\hline $\mathrm{Fe} / \mathrm{Zr}$ & 0.81 & 11 & 16 \\
\hline $\mathrm{Ca} / \mathrm{K}$ & 2.61 & 3 & 7 \\
\hline \multicolumn{4}{|c|}{ FGS 2 Precision } \\
\hline Element Ratio & Average $^{A}$ & $\begin{array}{l}\text { Repeatability-within } \\
\operatorname{sr}(\%)^{\mathrm{A}}\end{array}$ & $\begin{array}{c}\text { Reproducibility- } \\
\text { between } \\
\mathrm{S}_{\mathrm{R}}(\%)^{\mathrm{B}}\end{array}$ \\
\hline $\mathrm{Ca} / \mathrm{Mg}$ & 0.93 & 4 & 9 \\
\hline $\mathrm{Ca} / \mathrm{Ti}$ & 0.36 & 3 & 6 \\
\hline $\mathrm{Ca} / \mathrm{Fe}$ & 0.23 & 1 & 3 \\
\hline $\mathrm{Sr} / \mathrm{Zr}$ & 0.55 & 2 & 8 \\
\hline $\mathrm{Fe} / \mathrm{Zr}$ & 0.86 & 5 & 15 \\
\hline $\mathrm{Ca} / \mathrm{K}$ & 0.55 & 2 & 4 \\
\hline
\end{tabular}

${ }^{\mathrm{A}}$ Average value obtained from 9 different $\mu$-XRF instrument configurations, 7 replicates per configuration for a total of 63 replicates.

${ }^{\mathrm{C}}$ Variation estimated as \%RSD from mean values for 9 different $\mu$-XRF instrument configurations. Mean values were estimated from ratios normalized to SRM NIST 1831. 


\subsection{Comparison of figures of merit of $\mu$-XRF, ICP-based methods and LIBS.}

Figures of merit such as repeatability, reproducibility, bias and limits of detection were evaluated in these interlaboratory tests. Precision and bias figures obtained by ICP and $\mu$-XRF methods were suitable for purposes of glass comparisons in the forensic context.

The precision in terms of repeatability and reproducibility is reported for ICP-MS (Tables 35-37) and $\mu$-XRF methods (Table 39). For LIBS analysis only repeatability between samples was calculated because only one participant laboratory conducted LIBS analysis. Precision between replicate measurements for the glass standards was better than $11 \%$ RSD for LIBS data. Although good precision is observed by all the studied methods, better repeatability between replicate measurements is attainable by the ICPbased methods.

Reproducibility and repeatability in the measurements by $\mu$-XRF methods are more affected than ICP-MS measurements by changes in the instrument configurations, acquisition parameters, limits of detection and sample fragment size and orientation. The concentrations of some elements in the standards analyzed in this study were close to the limits of detection (LOD) and/or quantitation limits for some XRF systems, which affected the overall precision. However, most monitored elements in $\mu$-XRF are typically observed at higher concentrations than present in the standard reference materials and, therefore, better precision $(<10 \%)$ was observed on the K/Q comparisons.

The LOD have been used consistently in the area of analytical chemistry as an objective way of evaluating and reporting the performance of the methods. For this reason, the LODs were reported for ICP, LIBS and $\mu$-XRF data as a means to monitor 
and compare the methods and techniques used in these interlaboratory tests. The evaluation of the LODs played an important role in the optimization and standardization of the methods, helping participants to 1) evaluate the performance of their instrumentation and optimize their parameters to achieve expected threshold values, 2) make informed decisions about the selection of elements for the comparison of glass samples, and 3) validate the methodology through interlaboratory comparison of the sensitivity for a suite of relevant elements.

Table 40 shows the expected LODs of the different methods. The LODs were determined for several elements in NIST SRM 1831, FGS 1, and FGS 2 [ACS 1980; IUPAC 1976].

The background count level in $\mu$-XRF is affected by the sample and uses counting statistics, therefore to estimate the signal-to-noise ratio (SNR), the noise in a $\mu$-XRF spectrum is calculated as the square root of the background counts under the peak of interest. Limits of detection were estimated as the concentration of each analyte corresponding to three times the noise. More detail in data treatment was recently reported by Ernst et al. [Ernst et al., 2012 submitted].

The limits of detection of the method for LA-ICP-MS data were determined for each element by measuring procedure blanks. Blanks corresponded to the background signal prior to the laser interaction with the glass. For LIBS the background correspond to the signal at the baseline close to each emission peak. The LODs were calculated by three times the standard deviation of twenty-one instrumental replicates from the standards NIST 1831, FGS 1 and FGS 2. 
The performance of the methods in terms of limits of detection were ICP $>$ LIBS >> XRF. It is worth stressing that limits of detection on LIBS are particularly affected by the instrument configuration and acquisition method. For instance, detection limits can be improved by doing multiple pulse ablations, using Argon as the ambient gas, using fslasers, to mention some. These LIBS limits of detection are reported for a ns-laser, run at ambient air with the instrument parameters described on table 32 (Lab H-LIBS).

As expected, the LODs for $\mu$-XRF improved with increasing atomic number as a consequence of the increase in critical escape depth and excitation efficiency of the generated x-rays from these elements in thicker samples [Ryland, 2011].

Regardless of the differences in sensitivity, most elements monitored by each method are above the typical concentration range observed in soda-lime glass (Table 39). Therefore, it is anticipated that all methods will provide information about the elemental composition that is sensitive to variations in the composition of glass manufactured in different plants or at the same plant at different time intervals.

To evaluate whether or not the differences in figures of merit among techniques affect the discrimination capabilities, a set of glass samples were analyzed in both interlaboratory studies as described in the following section. 
Table 40. Expected Limits of Detection (LOD) for glass analysis by ICP-MS, LA-ICP-

MS, $\mu-X R F$ and LIBS methods, respectively.

\begin{tabular}{|c|c|c|c|c|c|}
\hline $\begin{array}{l}\text { Method/ } \\
\text { Element }\end{array}$ & $\begin{array}{c}\text { LA-ICP- } \\
\text { MS }^{\text {a }}\end{array}$ & $\begin{array}{l}\text { digestion- } \\
\text { ICP-MS }^{b}\end{array}$ & $\mu-\mathrm{XRF}^{\mathrm{c}}$ & LIBS & $\begin{array}{c}\text { Range of } \\
\text { sample } \\
\text { concentrations } \\
\left(\mu \mathrm{gg}^{-1}\right) \\
\end{array}$ \\
\hline $\mathrm{Li}$ & 0.75 & n.a & n.a & na & $0.8-7^{d}$ \\
\hline $\mathrm{Na}$ & n.a & n.a & 7400 & 11 & n.a \\
\hline $\mathrm{Mg}$ & 0.52 & 7.5 & 1300 & 2.9 & $6273-51076^{e}$ \\
\hline $\mathrm{Al}$ & 1.85 & 5.0 & 890 & 1.3 & $298-11940^{e}$ \\
\hline $\mathrm{K}$ & 2.22 & n.a & 100 & 6.0 & $45-6328^{e}$ \\
\hline $\mathrm{Ca}$ & 145 & n.a & 49 & 42 & $46086-69767^{e}$ \\
\hline $\mathrm{Ti}$ & 3.15 & 0.18 & 20 & 3.0 & $39-3226^{e}$ \\
\hline $\mathrm{Fe}$ & 9.21 & n.a & 11 & 7.5 & $461-6063^{d}$ \\
\hline $\mathrm{Mn}$ & 0.77 & 0.17 & 14 & n.a & $9-468^{e}$ \\
\hline $\mathrm{Rb}$ & 0.19 & 0.04 & 6.4 & 1.4 & $0.3-33^{\mathrm{e}}$ \\
\hline $\mathrm{Sr}$ & 0.07 & 0.06 & 7.8 & 3.1 & $19-576^{\mathrm{e}}$ \\
\hline $\mathrm{Zr}$ & 0.13 & 0.91 & 5.8 & n.a & $19-269^{e}$ \\
\hline $\mathrm{Sn}$ & 0.52 & n.a. & n.a & n.a & $11-2180^{d}$ \\
\hline $\mathrm{Ba}$ & 0.30 & 0.04 & n.a & 2.3 & $3-384^{e}$ \\
\hline $\mathrm{La}$ & 0.05 & 0.02 & n.a & n.a & $1-19^{e}$ \\
\hline $\mathrm{Ce}$ & 0.03 & 0.05 & n.a & n.a & $2-1896^{\mathrm{e}}$ \\
\hline $\mathrm{Nd}$ & 0.17 & n.a & n.a & n.a & $0.8-8^{d}$ \\
\hline $\mathrm{Hf}$ & 0.09 & 0.15 & n.a & n.a & $0.5-7^{\mathrm{e}}$ \\
\hline $\mathrm{Pb}$ & 0.16 & 0.05 & n.a & n.a & $0.3-251^{\mathrm{e}}$ \\
\hline
\end{tabular}

${ }^{\mathrm{a}}$ Average limits of detection for measurements of glass standards FGS 1, FGS 2 and SRM NIST 1831, values expressed as $\mathrm{ugg}^{-1}$ of the elemental concentration in the solid glass.

${ }^{\mathrm{b}}$ Values reported for a set of 50 soda-lime glass samples all expressed as $\mathrm{ngg}^{-1}$ of the elemental concentration in the final solution [ASTM E2330-04].

${ }^{\mathrm{c}}$ Average limits of detection for instrument configurations A-I, for data collected for glass standards FGS 1, FGS 2 and SRM NIST 1831 expressed as ugg $^{-1}$ of the elemental concentration in the solid glass.

${ }^{\mathrm{d}}$ From actual measurement of a set of 127 soda-lime glass samples from vehicle and architectural windows by LA-ICP-MS.

${ }^{\mathrm{e}}$ From actual measurement of a set of 286 soda-lime glass samples from vehicle and architectural windows by digestion-ICP-MS. 


\subsection{Evaluation of association and/or discrimination capabilities of the methods}

Another aim of these studies was to evaluate and compare the discrimination capabilities of the different techniques and methods in traditional glass samples. Blind test samples were submitted to each participant along with a simulated casework scenario and preliminary analysis results (color, microscopic examination and refractive index) to assist their selection of match criteria and reporting.

As detailed in the experimental section, samples submitted as known and questioned items (K1 and Q1) for the first interlaboratory tests originated from the same source, so it was expected that respondents associate those fragments based on their elemental composition and their selected match criteria.

The glass from K1 and Q1 was analyzed prior its distribution and found to be indistinguishable by refractive index and elemental analysis. Pre-distribution elemental analysis conducted by LA-ICP-MS revealed no significant differences, using the t-test at $95 \%$ confidence, in the content of the following elements: $\mathrm{Al}, \mathrm{K}, \mathrm{Ti}, \mathrm{Mn}, \mathrm{Fe}, \mathrm{Rb}, \mathrm{Sr}, \mathrm{Zr}$, $\mathrm{Ba}, \mathrm{La}, \mathrm{Ce}, \mathrm{Nd}, \mathrm{Hf}$ and $\mathrm{Pb}$.

All fourteen respondents of this first tests correctly reported that item 1 (K1) was found to be indistinguishable from item 2 (Q1) based on LA-ICP-MS, $\mu$-XRF or LIBS. Each participant was asked to use the match criteria commonly used in their casework. Although there was agreement in the reporting of results, a lack of standardization in the match criteria was observed for this first interlaboratory test. The participants reported a variety of match criteria, including t-test, $\pm 2 \mathrm{~s}, \pm 3 \mathrm{~s}, \pm 4 \mathrm{~s}$, modified $\pm 4 \mathrm{~s}$, range overlap and spectral overlay. 
For the second interlaboratory trial, glass samples that were submitted as item 1 (K1), item $2(\mathrm{Q} 1)$ and item $3(\mathrm{Q} 2)$ were architectural float glass manufactured at the same manufacturing plant. Glass samples sent as $\mathrm{K} 1$ and Q1 shared a common origin; they were sampled from a glass pane manufactured in 2001. Glass samples sent as Q2 originated from a different source than sample K1. Although they were manufactured at the same manufacturing plant, the glass Q2 was manufactured 2 years and 8 months before.

The glass samples were analyzed prior to their distribution and found to be indistinguishable by RI. These particular glass sources were selected specifically because they had similar refractive indices but different elemental composition of some of their trace elements. Concentration of the trace discriminating elements in these glass sources ranged from 0.5 to $125 \mu \mathrm{gg}^{-1}$, with exception of iron that was present at $\sim 600 \mu \mathrm{gg}^{-1}$. Major elements such as $\mathrm{Al}, \mathrm{K}, \mathrm{Mg}$ and $\mathrm{Ca}$ were present at concentrations above $1 \%$.

All the participating laboratories correctly reported that item 1 (K1) was indistinguishable from item $2(\mathrm{Q} 1)$, and all the labs correctly reported that item 1 (K1) was distinguishable from item 3 (Q2). For this second trial, there was a consensus amongst the $\mu$-XRF participants towards using spectral overlay and $\pm 3 \mathrm{~s}$ as match criteria. The ICP participants still reported a large variety of match criteria for this test.

In this test, the basis for discrimination (differences) between the elemental compositions of glasses manufactured at different times depends on the LODs of the methods. Significant differences were found by ICP-MS on a large number of elements ( 7 to 15 out of the 16 to 18 elements analyzed were found to be distinguishable based on their selected match criteria). The XRF participants detected differences primarily on 
major elements $(\mathrm{K}, \mathrm{Ca})$ and trace elements that were present in these samples above 70 $\mu g^{-1}(\mathrm{Ti}, \mathrm{Mn}$ and Fe). The LIBS participant reported differences for 3 out of the 7 evaluated ratios $(\mathrm{Fe} / \mathrm{Sr}, \mathrm{Al} / \mathrm{Ca}, \mathrm{Ca} / \mathrm{Sr})$.

The results of these two studies demonstrate that each of the evaluated methods (ICP-MS, LA-ICP-MS and $\mu$-XRF) can be successfully applied to determine the elemental composition of glass fragments as a tool to improve discrimination capabilities of preliminary screening tests, such as RI. Despite the use of a variety of analytical methods and match criteria, all laboratories were able to correctly associate samples that originated from a single source and discriminate between glasses manufactured in the same plant at different periods of time.

The lack of standardization of the match criteria used by the participants motivated the design of additional interlaboratory exercises that permitted a thorough evaluation of the effect of match criteria on the incidence of type 1 and type 2 errors. Those results are described later in this text.

4.2.1.1.5 Comparison of composition data from SRM 1831 full thickness versus small fragments

The effects of size of glass fragments on the analytical measurements by LA-ICPMS and its performance in forensic comparisons were also studied as part of the second inter-laboratory test.

Data reported in the literature have shown that fragment size and shape do not affect the performance of the quantitative data on glass fragments by LA-ICP-MS. These studies have been reported on standard reference materials NIST 612, NIST 610 and 
several flat glass samples but, to the best of our knowledge, have not been reported on SRM NIST 1831 [Trejos et al., 2005] .

In this interlaboratory exercise, quantitative data obtained from fragments of SRM NIST 1831 having different thicknesses and sizes showed good precision and accuracy (repeatability $<1-5 \%$, bias $<10 \%$ ). Nevertheless, significant differences were detected between full thickness and small fragments using the most common match criteria reported by the participants (ANOVA $(p=0.05)$, t-test comparison $(p=0.05)$ and \pm 3 SD) (see Table 40).

Significant differences were also found between small and full thickness data collected by $\mu$-XRF. These differences were expected as a result of the well-known effects of the take-off angle and critical depth on XRF measurements [Howden et al., 1978]. For this reason, the study was then focused on ICP-MS data only.

For the purposes of forensic glass comparisons, if the two fragments being compared are significantly different by at least one element (or ratio), these can be excluded as having come from the same source. In this exercise, full thickness fragments were used for the known source and the small fragments were used for questioned samples. The results presented here indicate that the application of multiple t-tests for multivariate datasets obtained by LA-ICP-MS measurements might be problematic (Table 41). The possible reasons for these type 1 errors (false exclusions) might be dayto-day variations of measurement conditions, sample orientation or position in the ablation cell, sample heterogeneity, and small variations between replicate measurements.

In an effort to identify the sources of type 1 errors in this set, an additional experiment was conducted to evaluate whether the differences in elemental composition 
were due to: a) fragment size, b) surface versus bulk heterogeneity, and/or c) match criteria used for comparisons.

Analyses were conducted on full thickness fragments at both original surfaces $(\mathrm{S} 1, \mathrm{~S} 2)$, at the bulk area of full thickness fragments (B1 and B2), and on 4 small fragments taken from the bulk of a SRM NIST 1831 fragment. Six replicate measurements were acquired from each fragment.

Pairwise comparisons by ANOVA $(\mathrm{p}=0.05)$ show significant differences between the small fragments, bulk areas and surface areas.

A recent study published by the Bundeskriminalamt/Federal Criminal Police Office, Forensic Science Institute [Weis et al., 2011] reported that wider match criteria are recommended for LA-ICP-MS measurements of glass due to the excellent precision between replicates. The authors conducted an extensive study on the elemental variability of 34 glass fragments that originated from the same glass sheets and found that tight match criteria, such as the t-test, produced high rates of false exclusions. The best results for glass casework were achieved using a broader match criterion, such as a modified $\pm 4 \mathrm{~s}$ approach, based on fixed relative standard deviations. 
Table 41. Detail of elements with differences in elemental composition for full thickness vs small fragment of SRM NIST 1831 measured by LA-ICP-MS

\begin{tabular}{|c|c|c|c|c|c|c|c|}
\hline $\begin{array}{l}\text { Lab } \\
\text { ID }\end{array}$ & $\begin{array}{l}\text { Elements } \\
\text { distinguished by } \\
\text { t-test }(p=0.05)\end{array}$ & $\begin{array}{l}\text { Elements } \\
\text { distinguished } \\
\text { by } \\
\text { t-test with } \\
\text { Bonferroni } \\
\text { correction } \\
(p=0.05\end{array}$ & $\begin{array}{l}\text { Elements } \\
\text { distinguished } \\
\text { by } \pm \mathbf{3 s}\end{array}$ & $\begin{array}{l}\text { Elements } \\
\text { distinguished } \\
\text { by } \\
\pm 4 \mathrm{~s}\end{array}$ & $\begin{array}{l}\text { Elements } \\
\text { distinguished } \\
\text { by } \\
\pm 4 \mathrm{~s} \text { with } \\
3 \% \text { min RSD }\end{array}$ & $\begin{array}{l}\text { Elements } \\
\text { distinguished } \\
\text { by } \\
\pm 4 \mathrm{~s} \text { with } \\
4 \% \text { min RSD }\end{array}$ & $\begin{array}{l}\text { Elements } \\
\text { distinguished by } \\
\pm 4 \mathrm{~s} \text { with } 5 \% \\
\text { min RSD }\end{array}$ \\
\hline B & $\begin{array}{l}\mathrm{Mg}, \mathrm{Al}, \mathrm{Sr}, \mathrm{Zr}, \\
\mathrm{Sn}, \mathrm{Nd}, \mathrm{Hf}, \mathrm{K}, \mathrm{Ca}, \\
\mathrm{Ti}, \mathrm{Mn}, \mathrm{La}, \mathrm{Pb}\end{array}$ & $\begin{array}{l}\mathrm{Mg}, \mathrm{Al}, \mathrm{Sr}, \mathrm{Zr} \\
\mathrm{Hf}, \mathrm{Ca}, \mathrm{Ti}, \mathrm{Pb}\end{array}$ & $\begin{array}{l}\mathrm{Mg}, \quad \mathrm{Al}, \quad \mathrm{Sr} \\
\mathrm{Zr}, \mathrm{Sn}, \mathrm{Hf}\end{array}$ & $\mathrm{Hf}, \mathrm{Zr}, \mathrm{Sn}$ & $\mathrm{Hf}, \mathrm{Zr}, \mathrm{Sn}$ & $\mathrm{Sn}$ & $\mathrm{Sn}$ \\
\hline $\mathbf{C}$ & $\begin{array}{l}\text { Mg, K, Fe, Li, Al, } \\
\text { Ti, Mn, Rb, Sr, } \\
\mathrm{Zr}, \mathrm{Sn}, \mathrm{La}, \mathrm{Nd}, \\
\mathrm{Hf}, \mathrm{Pb}\end{array}$ & $\mathrm{Mg}, \mathrm{K}, \mathrm{Fe}, \mathrm{Mn}$ & $\begin{array}{l}\mathrm{Mg}, \mathrm{K}, \mathrm{Fe}, \mathrm{Zr}, \\
\mathrm{Sn}, \mathrm{Nd}\end{array}$ & $\begin{array}{l}\mathrm{K}, \mathrm{Fe}, \mathrm{Zr}, \mathrm{Sn}, \\
\mathrm{Nd}\end{array}$ & $\mathrm{Fe}, \mathrm{Zr}, \mathrm{Sn}$ & $\mathrm{Fe}, \mathrm{Sn}$ & none \\
\hline D & $\begin{array}{l}\mathrm{Mg} . \mathrm{Sr}, \mathrm{Zr}, \mathrm{Al}, \mathrm{K}, \\
\mathrm{Ca}, \mathrm{Ti}, \mathrm{Fe}, \mathrm{Rb}, \\
\mathrm{Ba}, \mathrm{La}\end{array}$ & $\mathrm{Mg}, \mathrm{Sr}, \mathrm{Zr}, \mathrm{Ti}$ & $\mathrm{Al}, \mathrm{Mg}, \mathrm{Sr}, \mathrm{Zr}$ & $\begin{array}{l}\mathrm{Al}, \mathrm{Mg}, \mathrm{Sr}, \\
\mathrm{Zr}\end{array}$ & $\mathrm{Sr}, \mathrm{Zr}$ & $\mathrm{Sr}, \mathrm{Zr}$ & none \\
\hline $\mathbf{G}$ & $\begin{array}{l}\mathrm{Sr}, \mathrm{Zr}, \mathrm{Sn}, \mathrm{Nd}, \mathrm{Hf} \text {, } \\
\mathrm{Li}, \mathrm{Mg}, \mathrm{Al}, \mathrm{K}, \mathrm{Ca} \text {, } \\
\mathrm{Ti}, \mathrm{Mn}, \mathrm{Fe}, \mathrm{Ba} \text {, } \\
\mathrm{La}, \mathrm{Ce}, \mathrm{Pb}\end{array}$ & $\begin{array}{l}\mathrm{Sr}, \mathrm{Zr}, \mathrm{Sn}, \mathrm{Nd}, \\
\mathrm{Hf}, \mathrm{Al}, \mathrm{Ti}, \mathrm{Mn}, \\
\mathrm{Ba}, \mathrm{La}, \mathrm{Ce}, \mathrm{Pb}\end{array}$ & $\begin{array}{l}\text { Ti, Sr, Zr, Sn, } \\
\text { Nd, Hf }\end{array}$ & $\begin{array}{l}\text { Ti, Sr, Zr, Sn, } \\
\text { Nd, Hf }\end{array}$ & $\begin{array}{l}\mathrm{Sr}, \mathrm{Zr}, \mathrm{Sn}, \\
\mathrm{Pb}, \mathrm{Hf}\end{array}$ & $\begin{array}{l}\text { Sr, Zr, Sn, } \\
\text { Hf }\end{array}$ & $\mathrm{Sr}, \mathrm{Zr}, \mathrm{Sn}$, \\
\hline $\mathbf{H}$ & $\begin{array}{l}\mathrm{Mg}, \mathrm{Al}, \mathrm{Zr}, \mathrm{K}, \mathrm{Ca}, \\
\mathrm{Mn}, \mathrm{Fe}, \mathrm{Sr}, \mathrm{Nd}, \\
\mathrm{Hf}\end{array}$ & $\begin{array}{l}\mathrm{Mg}, \mathrm{Al}, \mathrm{Zr}, \mathrm{Mn}, \\
\mathrm{Fe}, \mathrm{Hf}\end{array}$ & $\begin{array}{l}\mathrm{Mg}, \mathrm{Al}, \quad \mathrm{Zr}, \\
\mathrm{Hf}\end{array}$ & $\begin{array}{l}\mathrm{Mg}, \mathrm{Al}, \mathrm{Zr}, \\
\mathrm{Hf}\end{array}$ & $\mathrm{Zr}, \mathrm{Hf}$ & none & none \\
\hline I & $\begin{array}{l}\text { Mg. Sr, Zr, Al, } \\
\mathrm{Ca}, \mathrm{Ti}, \mathrm{Fe}, \mathrm{Rb}, \\
\mathrm{Ba}, \mathrm{La}, \mathrm{Sn}\end{array}$ & none & $\begin{array}{l}\mathrm{Mg}, \mathrm{Al}, \quad \mathrm{Sr}, \\
\mathrm{Zr}, \mathrm{Pb}\end{array}$ & $\begin{array}{l}\mathrm{Mg}, \mathrm{Al}, \mathrm{Sr}, \\
\mathrm{Zr},\end{array}$ & $\mathrm{Sr}, \mathrm{Zr}, \mathrm{Sn}$ & $\mathrm{Sr}, \mathrm{Zr}, \mathrm{Sn}$ & $\mathrm{Sn}$ \\
\hline
\end{tabular}


As a result of the close precision obtained and reported by most of the ICP-based participants ( $\leq 1-5 \% \mathrm{RSD})$, it was observed that match criteria, such as the t-test, may be too sensitive to false exclusions, depending on the data set under evaluation. For this reason, a modified $\pm 4 \mathrm{~s}$ criterion was applied to these samples. Table 42 shows that, for most participants, the number of elements distinguished is reduced by using a 4-s criterion with a minimum of 3-5\% RSD. Further discussion of this recommendation is included later in this document.

Some ICP laboratories still detected differences on the tin content, even after applying wider match criteria. Although SRM NIST 1831was not produced by the float glass process, ICP methods detected a slightly different composition on the original surfaces versus the cross section of the glass. Original surfaces were only present on the full thickness fragments. Nevertheless, in casework, tin is typically monitored to detect the float versus the non-float side of a glass and is not typically included as part of the elements used for comparison between samples.

The results in Table 42 demonstrate that the differences detected between the SRM NIST 1831 fragments submitted for the interlaboratory tests were the result of a combination of the heterogeneity between surface and bulk composition on SRM NIST 1831 and the selection of match criteria used for comparisons.

First, the use of wider match criteria, such as $\pm 4 \mathrm{~s}$ with minimum $3 \% \mathrm{RSD}$, reduced the number of false exclusions. Using ANOVA, 18 out of 28 possible comparison pairs were excluded ( $64 \%$ ); using $\pm 4 \mathrm{~s}$ criterion, the number of exclusions was reduced to 13 out of 28 possible comparison pairs (46\%), whereas using the wider match criteria the number of exclusions were limited to 7 out of 28 possible pairs ( $25 \%)$. 
Second, when using wider criteria (i.e. \pm 4 s criteria with a minimum of $3 \% \mathrm{RSD}$ ) significant differences are still detected between one of the original surfaces (S2) and the rest of the fragments, while no significant differences are detected between the rest of the fragments regardless of their size.

The results revealed that one of the original surfaces of the SRM NIST 1831 is depleted in $\mathrm{Sr}, \mathrm{Zr}$, $\mathrm{Hf}$ and $\mathrm{Pb}$ which causes a significant heterogeneity for microsampling techniques like LA-ICP-MS.

Although this study implies that fragment size does not affect comparison of the elemental composition of glass by LA-ICP-MS, caution should be taken when using full thickness fragments to avoid possible differences in the composition of original flat surfaces. The effects of expanding the match criteria on type 1and type 2 errors was further studied and is reported later in this chapter. 
Table 42. Pairwise comparison of SRM NIST 1831 glass fragments using ANOVA ( $\mathrm{p}=0.05)$ and 4s interval, respectively.

Elements listed were significantly different using the specified match criteria.

\begin{tabular}{|c|c|c|c|c|c|c|c|c|}
\hline $\begin{array}{l}\text { ANOVA } \\
p=0.05\end{array}$ & B1 & B2 & F5 & F6 & F7 & F8 & S1 & S2 \\
\hline \multicolumn{9}{|l|}{ B1 } \\
\hline B2 & $\mathrm{Fe}$ & & & & & & & \\
\hline F5 & & $\mathrm{Fe}$ & & & & & & \\
\hline F6 & $\mathrm{Li}$ & $\mathrm{Li}, \mathrm{Fe}$ & & & & & & \\
\hline F7 & $\mathrm{Li}, \mathrm{Fe}$ & & $\mathrm{Fe}$ & & & & & \\
\hline F8 & & & $\mathrm{Fe}$ & & & & & \\
\hline S1 & & $\mathrm{Na}, \mathrm{Fe}$ & & $\mathrm{Li}, \mathrm{Na}$ & $\mathrm{Na}, \mathrm{Fe}$ & $\mathrm{Ti}, \mathrm{Fe}$ & & \\
\hline S2 & $\mathrm{Fe}, \mathrm{Sr}, \mathrm{Pb}, \mathrm{Zr}$ & $\mathrm{Sr}, \mathrm{Pb}, \mathrm{Zr}$ & $\begin{array}{l}\mathrm{Fe}, \mathrm{Sr}, \mathrm{Hf}, \mathrm{Pb}, \\
\mathrm{Zr}\end{array}$ & $\begin{array}{l}\mathrm{Fe}, \mathrm{Sr}, \mathrm{La}, \mathrm{Hf}, \\
\mathrm{Pb}, \mathrm{Zr}\end{array}$ & $\begin{array}{l}\text { Sr, Hf, Pb, } \\
\mathrm{Zr}\end{array}$ & $\begin{array}{l}\mathrm{Sr}, \mathrm{Hf}, \mathrm{Pb}, \\
\mathrm{Zr}\end{array}$ & $\begin{array}{l}\mathrm{Na}, \mathrm{Fe}, \mathrm{Sr}, \mathrm{Pb}, \\
\mathrm{Zr}\end{array}$ & \\
\hline
\end{tabular}

\begin{tabular}{|l|l|l|l|l|l|l|l|l|}
\hline $\mathbf{1}$ 4s & B1 & B2 & F5 & F6 & F7 & F8 & S1 \\
\hline B1 & & & & & & & \\
\hline B2 & & & & & & & \\
\hline F5 & & $\mathrm{Fi}$ & & & & & \\
\hline F6 & & & & & & & \\
\hline F7 & & $\mathrm{Fe}$ & & $\mathrm{Li}, \mathrm{Na}$ & $\mathrm{Li}, \mathrm{Fe}, \mathrm{Zr}$ & $\mathrm{Li}, \mathrm{Na}$ & \\
\hline F8 & & & & & \\
\hline S1 & $\mathrm{Sr}, \mathrm{Pb}, \mathrm{Zr}$, & $\mathrm{Sr}, \mathrm{Pb}, \mathrm{Zr}$ & $\mathrm{Fe}, \mathrm{Sr}, \mathrm{Pb}, \mathrm{Zr}$ & $\mathrm{Fe}, \mathrm{Sr}, \mathrm{Pb}, \mathrm{Zr}$ & $\mathrm{Sr}, \mathrm{Pb}, \mathrm{Zr}$ & $\mathrm{Sr}, \mathrm{Zr}$ & $\mathrm{Fe}, \mathrm{Sr}, \mathrm{Pb}, \mathrm{Zr}$ & \\
\hline S2 & $\mathrm{Fe}$ & & & & \\
\hline
\end{tabular}


Table 42B. Pairwise comparison of SRM NIST 1831 glass fragments using 4s minimum 3\% RSD. Elements listed were significantly different using the specified match criteria.

\begin{tabular}{|c|c|c|c|c|c|c|c|c|}
\hline $\begin{array}{l}\begin{array}{l} \pm \mathrm{s} \\
(\mathrm{min}\end{array} \\
\text { 3\%RSD) }\end{array}$ & B1 & B2 & F5 & F6 & F7 & F8 & S1 & S2 \\
\hline B1 & & & & & & & & \\
\hline B2 & & & & & & & & \\
\hline F5 & & & & & & & & \\
\hline F6 & & & & & & & & \\
\hline F7 & & & & & & & & \\
\hline F8 & & & & & & & & \\
\hline S1 & & & & & & & & \\
\hline S2 & $\begin{array}{l}\mathrm{Sr}, \mathrm{Pb}, \mathrm{Zr} \text {, } \\
\mathrm{Hf}\end{array}$ & $\begin{array}{l}\mathrm{Sr}, \mathrm{Pb}, \mathrm{Zr}, \\
\mathrm{Hf}\end{array}$ & $\begin{array}{l}\mathrm{Sr}, \mathrm{Pb}, \mathrm{Zr}, \\
\mathrm{Hf}\end{array}$ & $\begin{array}{ll}\mathrm{Sr}, & \mathrm{Pb}, \mathrm{Zr} . \\
\mathrm{Hf}\end{array}$ & $\begin{array}{l}\mathrm{Sr}, \quad \mathrm{Pb}, \\
\mathrm{Zr}, \mathrm{Hf}\end{array}$ & $\begin{array}{l}\mathrm{Sr}, \mathrm{Pb}, \mathrm{Zr} \text {, } \\
\mathrm{Hf}\end{array}$ & $\mathrm{Sr}, \mathrm{Pb}, \mathrm{Zr}$ & \\
\hline
\end{tabular}


4.2.2 Results and discussion for interlaboratory tests 2, 3 and 4: Evaluation of the performance of different criteria for comparing elemental composition

It has been well established that major, minor, and trace element profiles can provide excellent discrimination among glass sources [Koons et al., 1991; Becker et al., 2001; Hicks et al., 2003; Almirall et al., 2011; Ryland, 2011]. In order to assess the extent to which this discrimination can be made, participants in three interlaboratory tests provided elemental data measured in their laboratories using several analytical instrumental methods. The $\mu$-XRF users provided fluorescence peak intensity ratios, typically reporting between six and eight ratios for each sample. The ICP-MS and ICPOES users reported the measured concentrations of up to 18 elements. The LIBS participants provided emission lines intensity, peak area and/or peak intensity ratios for six to eight ratios.

Analytical data were received from 24 participants in 22 laboratories. The pool of participants used a suite of different instruments, brands, configurations and analytical parameters that represent instrumental techniques currently used by the forensic community. An exception to this observation is for the LIBS participants, which none of them are currently forensic glass practitioners. One of the laboratories though has validated their LIBS method for the particular application of forensic glass analysis (lab H-LIBS).

The data were utilized to assess the ability of the participants to correctly associate glass fragments from the same source and to distinguish between fragments from different sources. Throughout this study, a K and Q pair of samples was considered to be indistinguishable when every measured parameter, either element concentration or 
intensity ratio, for the two samples could not be distinguished using the pertinent match criterion. For the purposes of error rate analysis, the "correct" result was that two samples were considered indistinguishable only when they came from the same small panel of glass in the FIU collection. Two samples produced on the same float line at different times were considered as different sources in assessing the accuracy of conclusions. This approach was taken because in most cases, the question of forensic interest is whether or not two fragments can be associated with the same window, rather than made in the same manufacturing plant.

4.2.2.1 Results are reported by each participant laboratory using their selected match criteria

\subsection{Results reported for the second interlaboratory test}

This test was organized like a traditional proficiency test with one $\mathrm{K}$ sample and two Q samples. All 16 of the responding participants correctly reported that samples K1 and Q1 were indistinguishable and K1 and Q2 were distinguishable. Results for each analyst with corresponding match criteria and the number of element concentrations or intensity ratios measured are shown in Table 43.

As indicated, the participants used several different match criteria to reach their conclusions. However, it is noteworthy that all methods gave correct results in this rather simple test. This result was anticipated, since, as shown in Table 34, the concentrations of $\mathrm{Ti}, \mathrm{Mn}, \mathrm{Fe}$, and $\mathrm{Rb}$ are quite different between $\mathrm{K} 1$ and $\mathrm{Q} 2$. 
With these results, the protocols for both $\mu$-XRF and LA-ICP-MS were considered robust and further, more difficult tests were designed. In order to evaluate the LIBS capabilities more LIBS participants were invited for the third and fourth tests.

Table 43. Results for the inter-laboratory test 2 sample comparisons as reported by each participant using their match criteria.

\begin{tabular}{|c|c|c|c|c|}
\hline Lab ID & $\begin{array}{l}\text { K1 vs } \\
\text { Q1 }\end{array}$ & $\begin{array}{l}\text { K1 vs } \\
\text { Q2 }\end{array}$ & Reported match criteria & $\begin{array}{l}\text { No. of } \\
\text { elements or } \\
\text { ratios }\end{array}$ \\
\hline XRF-A & $\mathrm{I}$ & $\mathrm{D}$ & Spectral overlay & 6 \\
\hline XRF-B & $\mathrm{I}$ & $\mathrm{D}$ & $\begin{array}{l}\text { Spectral overlay, } \pm 3 \mathrm{~s} \text { of ratio } \\
\text { intensities }\end{array}$ & 8 \\
\hline XRF-C & I & $\mathrm{D}$ & $\begin{array}{l}\text { Spectral overlay, range overlap } \\
\text { of ratio intensities }\end{array}$ & 6 \\
\hline XRF-D & $\mathrm{I}$ & $\mathrm{D}$ & $\begin{array}{l}\text { Spectral overlay, } \pm 3 \mathrm{~s} \text { of ratio } \\
\text { intensities }\end{array}$ & 4 \\
\hline XRF-E & $\mathrm{I}$ & $\mathrm{D}$ & $\begin{array}{l}\text { Spectral overlay, } \pm 3 \mathrm{~s} \text { of ratio } \\
\text { intensities }\end{array}$ & 6 \\
\hline XRF-F & $\mathrm{I}$ & $\mathrm{D}$ & $\begin{array}{l}\text { Spectral overlay, } \pm 3 \mathrm{~s} \text { of ratio } \\
\text { intensities }\end{array}$ & 6 \\
\hline XRF-G & $\mathrm{I}$ & $\mathrm{D}$ & $\begin{array}{l}\text { Spectral overlay, } \pm 2 \mathrm{~s} \text { of ratio } \\
\text { intensities }\end{array}$ & 7 \\
\hline H-LIBS & $\mathrm{I}$ & $\mathrm{D}$ & $\mathrm{t}$-test $(\mathrm{p}=0.05)$ & 6 \\
\hline ICP-A & I & $\mathrm{D}$ & $\mathrm{t}$ test $(0.05)$ of concs and ratios & 18 \\
\hline ICP-B & $\mathrm{I}$ & $\mathrm{D}$ & $\pm 2 \mathrm{~s}$ of ratios & 18 \\
\hline ICP-C & $\mathrm{I}$ & $\mathrm{D}$ & Modified \pm 4 s of concs & 18 \\
\hline ICP-D & $\mathrm{I}$ & $\mathrm{D}$ & $\mathrm{t}$ test $(0.05)$ of concs & 18 \\
\hline ICP-F & $\mathrm{I}$ & $\mathrm{D}$ & $\pm 3 \mathrm{~s}$ of concs & 18 \\
\hline ICP-G & I & $\mathrm{D}$ & Range overlap of ratios & 16 \\
\hline ICP-H & $\mathrm{I}$ & $\mathrm{D}$ & Modified \pm 4 s of concs & 16 \\
\hline ICP-I & I & $\mathrm{D}$ & $t$ test $(0.05)$ of concs & 16 \\
\hline
\end{tabular}




\subsection{Results reported for the third interlaboratory test}

The purpose of this third study was to evaluate the capabilities of each method to discriminate samples manufactured at the same plant at different time intervals. Samples with similar refractive indices but distinctive elemental compositions were selected for this exercise.

Samples were manufactured at the same plant on dates that were weeks, months, and years apart from each other. The dates of manufacture and the elemental profile of each of the samples as recorded in the FIU glass database are shown in Table 34 . The mean concentrations shown were obtained following the ASTM method for acid digestion and solution-based ICP-MS analysis (E330-04). The values shown are reported in parts per million $\left(\mu \mathrm{gg}^{-1}\right)$.

Samples manufactured only weeks or months apart have small, but significant differences in their elemental composition, e.g., K1 and Q1. However, most of the differentiating elements are present at low trace levels and it was therefore expected that only the more sensitive methods might detect some of the differences in compositions. The comparison results reported by the participants and the respective match criteria used to arrive at those conclusions are summarized in Tables 44 and 45 . 
Table 44 XRF and LIBS results for the inter-laboratory test 3 sample comparisons as reported by each participant using their match criteria

\begin{tabular}{|c|c|c|c|c|c|c|c|c|}
\hline Lab ID & $\begin{array}{ll}\text { K1 } & \text { vs } \\
\text { Q2 } & \\
\end{array}$ & K1 vs Q3 & $\begin{array}{ll}\text { K2 } & \text { vs } \\
\text { Q1 } & \\
\end{array}$ & $\begin{array}{ll}\text { K1 } & \text { Vs } \\
\text { Q1 } & \end{array}$ & $\begin{array}{ll}\mathbf{K} 2 & \mathbf{V s} \\
\mathbf{Q} 2 & \\
\end{array}$ & $\begin{array}{ll}\text { K2 } & \text { vs } \\
\text { Q3 } & \\
\end{array}$ & Reported match criteria & $\begin{array}{l}\text { No. of } \\
\text { elements } \\
\text { or ratios }\end{array}$ \\
\hline $\begin{array}{l}\text { Time } \\
\text { interval }\end{array}$ & $\begin{array}{l}\text { 3years, } \\
\text { 3months }\end{array}$ & $\begin{array}{l}\text { 3years, } \\
\text { 1month }\end{array}$ & $\begin{array}{l}\text { 3years, } \\
\text { 4months }\end{array}$ & 2weeks & 1month & 3months & & \\
\hline XRF-A & $\mathrm{D}$ & $\mathrm{D}$ & $\mathrm{D}$ & I & $\mathrm{D}$ & I & Spectral overlay & 9 \\
\hline XRF-B & $\mathrm{D}$ & $\mathrm{D}$ & $\mathrm{D}$ & I & $\mathrm{D}$ & I & $\begin{array}{l}\text { Spectral overlay, } \pm 3 \mathrm{~s} \text { of ratio } \\
\text { intensities }\end{array}$ & 8 \\
\hline XRF-C & $\mathrm{D}$ & $\mathrm{D}$ & $\mathrm{D}$ & I & $\mathrm{D}$ & I & $\begin{array}{l}\text { Spectral overlay, } \pm 3 \text { s of ratio } \\
\text { intensities }\end{array}$ & 7 \\
\hline XRF-E & $\mathrm{D}$ & $\mathrm{D}$ & $\mathrm{D}$ & $\mathrm{I}$ & $\mathrm{I}$ & I & $\begin{array}{l}\text { Spectral overlay, } \pm 3 \text { s of ratio } \\
\text { intensities }\end{array}$ & 7 \\
\hline XRF-F & $\mathrm{D}$ & $\mathrm{D}$ & $\mathrm{D}$ & I & $\mathrm{D}$ & I & $\pm 3 \mathrm{~s}$ of ratio intensities & 8 \\
\hline XRF-H & $\mathrm{D}$ & $\mathrm{D}$ & $\mathrm{D}$ & $\mathrm{I}$ & $\mathrm{D}$ & I & $\begin{array}{l}\text { Spectral overlay, } \pm 3 \text { s of ratio } \\
\text { intensities }\end{array}$ & 6 \\
\hline XRF-I & $\mathrm{D}$ & $\mathrm{D}$ & $\mathrm{D}$ & I & $\mathrm{D}$ & $\mathrm{I}$ & Spectral overlay, range overlap & 10 \\
\hline ICP-A & $\mathrm{D}$ & $\mathrm{D}$ & $\mathrm{D}$ & I & $\mathrm{D}$ & I & $\begin{array}{l} \pm 2 \mathrm{~s} \text { (for } 10 \text { elements, allows } \\
\text { one element to be different) }\end{array}$ & 10 \\
\hline LIBS-H & $\mathrm{D}$ & $\mathrm{D}$ & $\mathrm{D}$ & $\mathrm{D}$ & $\mathrm{D}$ & $\mathrm{D}$ & $\begin{array}{l}\text { Elemental ratios, } \\
\mathrm{p}=0.05, \quad \text { t-test } \\
\mathrm{p}=0.05\end{array}$ & 6 \\
\hline LIBS-I & I & $\mathrm{D}$ & $\mathrm{D}$ & I & $\mathrm{D}$ & I & PLS algorithm & 7 \\
\hline
\end{tabular}


Table 45. ICP results for the inter-laboratory test 3 sample comparisons as reported by each participant using their match criteria.

\begin{tabular}{|c|c|c|c|c|c|c|c|c|}
\hline ICP-B & $\mathrm{D}$ & $\mathrm{D}$ & $\mathrm{D}$ & $\mathrm{D}$ & $\mathrm{D}$ & $\mathrm{D}$ & $\pm 2 \mathrm{~s}$ and $\pm 3 \mathrm{~s}$ & 18 \\
\hline ICP-C & $\mathrm{D}$ & $\mathrm{D}$ & $\mathrm{D}$ & $\mathrm{D}$ & $\mathrm{D}$ & $\mathrm{D}$ & Modified $\pm 4 \mathrm{~s}$ & 18 \\
\hline ICP-D & $\mathrm{D}$ & $\mathrm{D}$ & $\mathrm{D}$ & $\mathrm{D}$ & $\mathrm{D}$ & $\mathrm{D}$ & $\begin{array}{l}\mathrm{t} \text { test (Bonferroni } \\
\mathrm{p}=0.05, \quad \text { correction), } \\
\mathrm{p}=0.05\end{array}$ & 18 \\
\hline ICP-E & $\mathrm{D}$ & $\mathrm{D}$ & $\mathrm{D}$ & $\mathrm{I}$ & $\mathrm{D}$ & $\mathrm{D}$ & $\begin{array}{l}t \quad \text { test } p=0.05 \text { and ANOVA } \\
(p=0.05)\end{array}$ & 18 \\
\hline ICP-F & $\mathrm{D}$ & $\mathrm{IC}$ & $\mathrm{D}$ & I & $\mathrm{D}$ & $\mathrm{IC}$ & Range overlap and $\pm 3 \mathrm{~s}$ & 16 \\
\hline ICP-H & $\mathrm{D}$ & $\mathrm{D}$ & $\mathrm{D}$ & $\mathrm{D}$ & $\mathrm{D}$ & $\mathrm{D}$ & Modified $\pm 4 \mathrm{~s}$ & 16 \\
\hline
\end{tabular}

$\mathrm{I}=$ Indistinguishable

$\mathrm{D}=$ Distinguishable

$\mathrm{IC}=$ inconclusive 
There were three pairs of samples that were produced over three years apart; $\mathrm{K} 1 / \mathrm{Q} 2, \mathrm{~K} 1 / \mathrm{Q} 3$, and $\mathrm{K} 2 / \mathrm{Q} 1$. Based on the results of pre-distribution analysis shown in Table 33, these sample pairs have differences in elemental compositions that were expected to be recognized using sensitive analytical methods.

All sixteen respondents correctly reported that items K2 and Q1, manufactured 3 years and 4 months apart and items K1 and Q2, manufactured 3 years and 3 months apart were distinguishable. An exception was observed for one of the LIBS participants who reported item K1 and Q2 to be indistinguishable. Fifteen of the sixteen respondents correctly reported that items $\mathrm{K} 1$ and Q3, samples that were manufactured 3 years and 1 month apart were distinguishable. The participant that used solution-based ICP-MS reported an inconclusive result as consequence of some uncontrolled problems during the digestion of sample Q3. Thus, each of the participants that completed the analysis was able to correctly discriminate between samples that were manufactured approximately 3 years apart in the same manufacturing plant, despite their indistinguishable refractive indices and physical properties. The only LIBS participant that reported a false inclusion in this sample subset used a proprietary algorithm as match criteria. After re-analysis of their raw data using other match criteria reported by the rest of the participants, no significant differences were observed.

The match criteria that were used by the participating forensic glass examiners included spectral overlay, range overlap, several different forms of confidence intervals, the t-test, and ANOVA. These criteria were used in various forms either individually or in combinations. 
Test 3 also contained three pairs of samples that were produced several weeks to months apart; K1/Q1, K2/Q2, and K2/Q3. The results of pre-distribution analysis shown in Table 34 indicate that these sample pairs have very similar elemental compositions with relatively small differences in the concentrations of some elements. It was expected that these differences could only be detected by those techniques that have good precision of the measurements and low limits of detection.

Only five of the sixteen respondents reported that item K1 was distinguishable from item Q1. Four of these respondents used LA-ICP-MS methods and one used LIBS to arrive at that conclusion. As reported in Table 34, these samples were manufactured at the same plant 2 weeks apart and therefore their elemental compositions are very similar. The discriminating elements reported by the few laboratories that found significant differences between $\mathrm{K} 1$ and Q1 were Ba (by three of the four laboratories using LA-ICPMS and by the LIBS lab) and Mn, K, Zr, Fe, Sr, Sn or Rb. Of the latter, the only other element that was common to two of the LA-ICP-MS laboratories was Zr. Table 34 shows that these elements were present in those samples at concentrations ranging from $<2$ to $30 \mathrm{ugg}^{-1}$ and therefore only sensitive methods with excellent precision between measurements would be able to detect those differences in concentration. For example, the reported Ba concentration difference between the two samples is approximately 2.5 $\mathrm{ugg}^{-1}$. Iron, the trace element having the largest difference in concentration, was reported as significantly different in the two samples by only one of the LA-ICP-MS laboratories. This result is consistent with the fact that not only the differences in mean element concentrations, but also the variations of the measured data within a sample, are important in defining the ability of a method to distinguish two different sources of glass. 
Fifteen of the sixteen respondents reported that item K2 was distinguishable from item Q2. The only respondent that could not distinguish between item K2 and item Q2 used $\mu$-XRF. However, after discussion of the results, this respondent re-examined their data and found significant differences in the Fe/Mn peak intensity ratios that were missed during the test. These samples were manufactured at the same plant 1 month apart and their elemental compositions are similar, but significant differences were detected for some elements, in particular $\mathrm{Mn}$ and $\mathrm{Ti}$ for $\mu$-XRF measurements, between 2 to 4 ratios by LIBS and between 6 to 12 elements for the ICP measurements.

Six of the sixteen respondents reported that item K2 was distinguishable from item Q3. None of the seven $\mu$-XRF users were able to differentiate these two samples. Only one LIBS user was able to differentiate these samples. The participants that were able to detect differences between these samples used laser ablation techniques (LA-ICPMS or LIBS). Two of the ICP-MS users did not differentiate this pair. Lab ICP-A was unable to differentiate the samples probably as a consequence of their smaller number of elements measured, and their match criteria that allows one element to differ and still call the results indistinguishable. Lab ICP-F, who used solution-based ICP-MS, reported an inconclusive result as a consequence of problems with the digestion of sample Q3. Samples K2 and Q3 were manufactured at the same plant 3 months apart. However, the elemental compositions of $\mathrm{K} 2$ and Q3 are more similar than those of $\mathrm{K} 2$ and Q2, which were manufactured only one month apart. The concentrations of discriminating elements were present at levels below $30 \mathrm{ugg}^{-1}$ in the glass.

This third interlaboratory test allowed the study of the ability of the different analytical methods to discriminate among samples that shared very similar composition. 
All techniques were able to differentiate samples manufactured three years apart in the same plant, regardless of the match criteria employed by each respondent. Samples manufactured weeks to months apart could only be differentiated in some instances by the more sensitive analytical techniques.

\subsection{Results reported for the fourth interlaboratory test}

The EAWG members felt that the results of the third interlaboratory test were encouraging, particularly in the excellent ability of the ICP-MS methods to discriminate glass sources produced over fairly short time periods. However, the high degree of source discrimination could lead to the incorrect source exclusion of glass fragments that came from the same source. To address this, a fourth interlaboratory test was designed and carried out. The set of samples for this test was selected primarily with the aim of studying type 1 errors, although one sample was also included to evaluate type 2 errors on samples produced in the same manufacturing plant at different times. There were twenty-one participants in this test, including two additional LIBS participants and one who used an additional technique, LA-ICP-OES.

Samples K1, K2, Q2 and Q3 all originated from glass manufactured at the Pilkington plant on 03/03/10. Sample Q1 was manufactured at the Pilkington plant on 02/18/2010. As shown in Table 33, the pre-distribution analysis indicated that the composition of Q1 is significantly different from that of the other samples. To simulate typical casework, known samples K1 and K2 consisted of three small full thickness fragments, while questioned samples were each three small irregular fragments of approximately $0.5-1 \mathrm{~mm}$ in size. The participants were instructed to make a comparison 
and reach an opinion concerning possible source for each Q fragment separately, rather than grouping them as was done in the prior tests. The participant (ICP-F) who used solution-based ICP-MS was unable to analyze the small Q fragments individually as a consequence of the sample size requirements in the ASTM method, and thus combined the three fragments for digestion and analysis. The results of comparisons made by the participants in the fourth interlaboratory test are shown in Table 46 for $\mu$-XRF methods, table 47 for ICP methods and table 48 for the LIBS labs.

Seventeen of twenty-one respondents correctly reported that all of the Q1 fragments were distinguishable from items $\mathrm{K} 1$ and $\mathrm{K} 2$ (see Tables 46, 47, 48). Although these samples were manufactured only 2 weeks apart on the same float line, significant differences exist in composition for $\mathrm{Fe}, \mathrm{Al}$ and $\mathrm{Ti}$ and several trace elements that were readily detected by all participant methods. One of the ICP participants, designated as ICP-L, does not conduct glass comparisons on a routine basis at their laboratory and therefore only reported their measured concentration data and did not make a decision of association or exclusion. Their data were only utilized for comparison of match criteria in the next part of this study. Likewise, three out of the four LIBS participants do not conduct glass examinations in a regular basis and reported either inconclusive results or false inclusions between some fragments of K1 and K2 vs Q1.

All of the K1, K2, Q2, and Q3 fragments came from the same pieces of a single glass sheet, so they should have been associated by the participants. Using their selected match criteria, all seven respondents that used $\mu$-XRF correctly reported that each fragment labeled as item Q2 or Q3 were indistinguishable from both $\mathrm{K} 1$ and $\mathrm{K} 2$. Therefore, all participants who used $\mu$-XRF were correct in both their distinguishable and 
indistinguishable conclusions in this fourth interlaboratory test. It is noteworthy that by the completion of this fourth interlaboratory test most $\mu$-XRF participants agreed on the selection of match criteria for their comparisons, based on previous results and discussion from the interlaboratory tests. All participants used spectral overlay as a preliminary assessment of similarity followed by a \pm 3 s criterion for comparison of intensity ratios with the exception of one laboratory that used range overlap.

As shown in Table 47, of the 100 reported comparisons for these four samples made by the ten participants using ICP-based methods, there were 16 incorrect discriminations of fragment pairs. Labs A, E, H, and $\mathrm{K}$ correctly found each of the Q2 and Q3 fragments to be indistinguishable from both $\mathrm{K} 1$ and $\mathrm{K} 2$. Lab C had only one incorrect result for a K1/Q3 comparison. Lab F, the one that used solution-based ICPMS had one incorrect result, but it was out of only four comparisons because the limited fragment size forced grouping of the fragments for each sample for digestion. The majority of incorrect exclusions were made by Lab D with six and Lab J with eight. These two participants used the t-test with Bonferroni correction for their match criterion. These false exclusion results raised a flag for further discussion by the EAWG members concerning the appropriate match criteria for ICP-based methods. Past experience of ICP-MS and ICP-OES users was that false exclusions rarely occur when an appropriate number of elements are used with reasonable match criteria. The observed rate of false exclusions, particularly for Labs $\mathrm{D}$ and $\mathrm{J}$ were unexpectedly high. It was felt that this high false exclusion rate was a result of participants using match criteria that were too narrow when considering the relatively large number of elements measured. Therefore, further data analysis was conducted to assess the error rates for a number of match 
criteria with the aim of finding an optimum match criterion that would simultaneously minimize both type 1 and type 2 errors. The results of these studies are discussed in the following section.

As shown in Table 48, of the 48 reported comparisons for these four samples made by the four participants using LIBS methods, there were 16 incorrect discriminations of fragment pairs and 13 results reported as inconclusive.

This fourth tests was the first inter-laboratory trial for some of the LIBS participants thus it was not surprising that LIBS data showsed drastic inconsistencies among participants. This could be a consequence of the lack of a standardized LIBS method for data acquisition and statistical treatment of the data as well as significant differences in the instrument configuration and optimized parameters. Because LIBS is not established yet in forensic laboratories as a method of analysis, it is noteworthy that contrary to the rest of participants (XRF and ICP users) none of the LIBS participants are experienced glass examiners and therefore their respective methods of analysis still have potential for improvement and optimization. One of the participant LIBS laboratories has spent several years of research on optimizing the method for glass analysis; their results are more comparable to ICP-participants. For this reason, the study on the effect of match criteria on error rates will not be discussed in the following sections for the LIBS data. Standardization of data reduction and method optimization across the different laboratories is recommended for LIBS measurements prior the evaluation of comparison methods and match criteria. 
Table 46. Inter-laboratory test 4 results as reported by each $\mu$ XRF participant using their selected match criteria

\begin{tabular}{|c|c|c|c|c|c|c|c|c|c|c|c|}
\hline $\begin{array}{l}\text { Lab } \\
\text { ID }\end{array}$ & $\begin{array}{l}\text { K1 vs } \\
\text { Q1-1 }\end{array}$ & $\begin{array}{l}\text { K1 vs } \\
\text { Q1-2 }\end{array}$ & $\begin{array}{l}\text { K1 vs } \\
\text { Q1-3 }\end{array}$ & $\begin{array}{l}\text { K1 vs } \\
\text { Q2-1 }\end{array}$ & $\begin{array}{l}\text { K1 vs } \\
\text { Q2-2 }\end{array}$ & $\begin{array}{l}\text { K1 vs } \\
\text { Q2-3 }\end{array}$ & $\begin{array}{l}\text { K1 vs } \\
\text { Q3-1 }\end{array}$ & $\begin{array}{l}\text { K1 vs } \\
\text { Q3-2 }\end{array}$ & $\begin{array}{l}\text { K1 vs } \\
\text { Q3-3 }\end{array}$ & $\begin{array}{l}\text { Match } \\
\text { Criteria }\end{array}$ & $\begin{array}{l}\text { No. of } \\
\text { ratios } \\
\text { used }\end{array}$ \\
\hline XRF-A & $\mathrm{D}$ & $\mathrm{D}$ & $\mathrm{D}$ & $\mathrm{I}$ & I & I & I & $\mathrm{I}$ & I & spectral overlay & 6 \\
\hline XRF-B & $\mathrm{D}$ & $\mathrm{D}$ & $\mathrm{D}$ & $\mathrm{I}$ & I & I & I & I & I & spectral overlay, $\pm 3 \mathrm{~s}$ & 7 \\
\hline XRF-C & $\mathrm{D}$ & $\mathrm{D}$ & $\mathrm{D}$ & I & I & I & I & I & I & spectral overlay, $\pm 3 \mathrm{~s}$ & 6 \\
\hline XRF-D & $\mathrm{D}$ & $\mathrm{D}$ & $\mathrm{D}$ & $\mathrm{I}$ & $\mathrm{I}$ & I & $\mathrm{I}$ & $\mathrm{I}$ & $\mathrm{I}$ & $3 \mathrm{~s}$ & 5 \\
\hline XRF-F & $\mathrm{D}$ & $\mathrm{D}$ & $\mathrm{D}$ & $\mathrm{I}$ & $\mathrm{I}$ & I & $\mathrm{I}$ & $\mathrm{I}$ & $\mathrm{I}$ & spectral overlay, $\pm 3 \mathrm{~s}$ & 6 \\
\hline XRF-H & $\mathrm{D}$ & $\mathrm{D}$ & $\mathrm{D}$ & $\mathrm{I}$ & $\mathrm{I}$ & I & $\mathrm{I}$ & $\mathrm{I}$ & $\mathrm{I}$ & $\pm 3 \mathrm{~s}$ & 6 \\
\hline XRF-I & $\mathrm{D}$ & $\mathrm{D}$ & $\mathrm{D}$ & I & I & I & I & I & I & spectral overlay, range overlap & 8 \\
\hline Lab ID & $\begin{array}{l}\text { K2 vs } \\
\text { Q1-1 }\end{array}$ & $\begin{array}{l}\text { K2 vs } \\
\text { Q1-2 }\end{array}$ & $\begin{array}{l}\text { K2 vs } \\
\text { Q1-3 }\end{array}$ & $\begin{array}{l}\text { K2 vs } \\
\text { Q2-1 }\end{array}$ & $\begin{array}{l}\text { K2 vs } \\
\text { Q2-2 }\end{array}$ & $\begin{array}{l}\text { K2 vs } \\
\text { Q2-3 }\end{array}$ & $\begin{array}{l}\text { K2 vs } \\
\text { Q3-1 }\end{array}$ & $\begin{array}{l}\text { K2 vs } \\
\text { Q3-2 }\end{array}$ & $\begin{array}{l}\text { K2 vs } \\
\text { Q3-3 }\end{array}$ & $\begin{array}{l}\text { Match } \\
\text { criteria }\end{array}$ & \\
\hline XRF-A & $\mathrm{D}$ & $\mathrm{D}$ & $\mathrm{D}$ & I & I & I & $\mathrm{I}$ & I & $\mathrm{I}$ & spectral overlay & 6 \\
\hline XRF-B & $\mathrm{D}$ & $\mathrm{D}$ & $\mathrm{D}$ & $\mathrm{I}$ & $\mathrm{I}$ & I & $\mathrm{I}$ & $\mathrm{I}$ & $\mathrm{I}$ & spectral overlay, $\pm 3 \mathrm{~s}$ & 7 \\
\hline XRF-C & $\mathrm{D}$ & $\mathrm{D}$ & $\mathrm{D}$ & $\mathrm{I}$ & $\mathrm{I}$ & $\mathrm{I}$ & $\mathrm{I}$ & $\mathrm{I}$ & $\mathrm{I}$ & spectral overlay, $\pm 3 \mathrm{~s}$ & 6 \\
\hline XRF-D & $\mathrm{D}$ & $\mathrm{D}$ & $\mathrm{D}$ & $\mathrm{I}$ & $\mathrm{I}$ & $\mathrm{I}$ & $\mathrm{I}$ & $\mathrm{I}$ & $\mathrm{I}$ & $\pm 3 \mathrm{~s}$ & 5 \\
\hline XRF-F & $\mathrm{D}$ & $\mathrm{D}$ & $\mathrm{D}$ & $\mathrm{I}$ & $\mathrm{I}$ & $\mathrm{I}$ & $\mathrm{I}$ & $\mathrm{I}$ & $\mathrm{I}$ & spectral overlay, $\pm 3 \mathrm{~s}$ & 6 \\
\hline XRF-H & $\mathrm{D}$ & $\mathrm{D}$ & $\mathrm{D}$ & $\mathrm{I}$ & $\mathrm{I}$ & $\mathrm{I}$ & $\mathrm{I}$ & $\mathrm{I}$ & $\mathrm{I}$ & $\pm 3 \mathrm{~s}$ & 6 \\
\hline XRF-I & $\mathrm{D}$ & $\mathrm{D}$ & $\mathrm{D}$ & I & I & I & I & I & $\mathrm{I}$ & spectral overlay, range overlap & 8 \\
\hline
\end{tabular}


Table 47. Interlaboratory test 4 results as reported by each ICP participant using their selected match criteria.

\begin{tabular}{|c|c|c|c|c|c|c|c|c|c|c|c|}
\hline $\begin{array}{l}\text { Lab } \\
\text { ID }\end{array}$ & $\begin{array}{l}\text { K1 vs } \\
\text { Q1-1 }\end{array}$ & $\begin{array}{l}\text { K1 vs } \\
\text { Q1-2 }\end{array}$ & $\begin{array}{l}\text { K1 vs } \\
\text { Q1-3 }\end{array}$ & $\begin{array}{l}\text { K1 vs } \\
\text { Q2-1 }\end{array}$ & $\begin{array}{l}\text { K1 vs } \\
\text { Q2-2 }\end{array}$ & $\begin{array}{l}\text { K1 vs } \\
\text { Q2-3 }\end{array}$ & $\begin{array}{l}\text { K1 vs } \\
\text { Q3-1 }\end{array}$ & $\begin{array}{l}\text { K1 vs } \\
\text { Q3-2 }\end{array}$ & $\begin{array}{l}\text { K1 vs } \\
\text { Q3-3 }\end{array}$ & Match criteria & $\begin{array}{l}\text { No. of } \\
\text { elements }\end{array}$ \\
\hline ICP-A & $\mathrm{D}$ & $\mathrm{D}$ & $\mathrm{D}$ & $\mathrm{I}$ & I & $\mathrm{I}$ & $\mathrm{I}$ & $\mathrm{I}$ & I & $\pm 2 \mathrm{~s}$ interval, 9 of 10 & 11 \\
\hline ICP-B & $\mathrm{D}$ & $\mathrm{D}$ & $\mathrm{D}$ & $\mathrm{IC}$ & IC & $\mathrm{IC}$ & $\mathrm{IC}$ & IC & IC & $\pm 2 \mathrm{~s}, \pm 3 \mathrm{~s}$ & 18 \\
\hline ICP-C & $\mathrm{D}$ & $\mathrm{D}$ & $\mathrm{D}$ & $\mathrm{I}$ & $\mathrm{I}$ & $\mathrm{I}$ & $\mathrm{I}$ & $\mathrm{I}$ & $\mathrm{D}$ & modified $4 \mathrm{~s}$ & 11 \\
\hline ICP-D & $\mathrm{D}$ & $\mathrm{D}$ & $\mathrm{D}$ & $\mathrm{I}$ & $\mathrm{D}$ & $\mathrm{D}$ & I & $\mathrm{D}$ & $\mathrm{D}$ & t-test / Bonferroni & 17 \\
\hline ICP-E & $\mathrm{D}$ & $\mathrm{D}$ & $\mathrm{D}$ & $\mathrm{I}$ & $\mathrm{I}$ & $\mathrm{I}$ & $\mathrm{I}$ & $\mathrm{I}$ & $\mathrm{I}$ & $\pm 2 \mathrm{~s}$ & 16 \\
\hline ICP-F & $\mathrm{D}$ & - & - & $\mathrm{D}$ & - & - & $\mathrm{I}$ & - & - & $\pm 3 \mathrm{~s}$, grouped Qs & 17 \\
\hline ICP-H & $\mathrm{D}$ & $\mathrm{D}$ & $\mathrm{D}$ & I & I & $\mathrm{I}$ & $\mathrm{I}$ & I & $\mathrm{I}$ & modified $\pm 4 \mathrm{~s}$ & 16 \\
\hline ICP-J & $\mathrm{D}$ & $\mathrm{D}$ & $\mathrm{D}$ & $\mathrm{D}$ & $\mathrm{D}$ & $\mathrm{D}$ & $\mathrm{D}$ & $\mathrm{I}$ & $\mathrm{D}$ & t-test / Bonferroni & 10 \\
\hline ICP-K & $\mathrm{D}$ & $\mathrm{D}$ & $\mathrm{D}$ & $\mathrm{I}$ & $\mathrm{I}$ & $\mathrm{I}$ & $\mathrm{I}$ & I & I & $\pm 4 \mathrm{~s}$ & 17 \\
\hline ICP-L & - & - & - & - & - & - & - & - & - & - & 17 \\
\hline $\begin{array}{l}\text { Lab } \\
\text { ID }\end{array}$ & $\begin{array}{l}\text { K2 vs } \\
\text { Q1-1 }\end{array}$ & $\begin{array}{l}\text { K2 vs } \\
\text { Q1-2 }\end{array}$ & $\begin{array}{l}\text { K2 vs } \\
\text { Q1-3 }\end{array}$ & $\begin{array}{l}\text { K2 vs } \\
\text { Q2-1 }\end{array}$ & $\begin{array}{l}\text { K2 vs } \\
\text { Q2-2 }\end{array}$ & $\begin{array}{l}\text { K2 vs } \\
\text { Q2-3 }\end{array}$ & $\begin{array}{l}\text { K2 vs } \\
\text { Q3-1 }\end{array}$ & $\begin{array}{l}\text { K2 vs } \\
\text { Q3-2 }\end{array}$ & $\begin{array}{l}\text { K2 vs } \\
\text { Q3-3 }\end{array}$ & Match criteria & $\begin{array}{l}\text { No. of } \\
\text { elements }\end{array}$ \\
\hline ICP-A & $\mathrm{D}$ & $\mathrm{D}$ & $\mathrm{D}$ & $\mathrm{I}$ & $\mathrm{I}$ & $\mathrm{I}$ & $\mathrm{I}$ & $\mathrm{I}$ & $\mathrm{I}$ & \pm 2 s interval, 9 of 10 & 11 \\
\hline ICP-B & $\mathrm{D}$ & $\mathrm{D}$ & $\mathrm{D}$ & $\mathrm{IC}$ & $\mathrm{IC}$ & $\mathrm{IC}$ & $\mathrm{IC}$ & IC & IC & $\pm 2 \mathrm{~s}, \pm 3 \mathrm{~s}$ & 18 \\
\hline ICP-C & $\mathrm{D}$ & $\mathrm{D}$ & $\mathrm{D}$ & I & $\mathrm{I}$ & $\mathrm{I}$ & I & $\mathrm{I}$ & I & modified 4s & 11 \\
\hline ICP-D & $\mathrm{D}$ & $\mathrm{D}$ & $\mathrm{D}$ & $\mathrm{I}$ & $\mathrm{I}$ & $\mathrm{D}$ & $\mathrm{I}$ & $\mathrm{D}$ & $\mathrm{I}$ & t-test / Bonferroni & 17 \\
\hline ICP-E & $\mathrm{D}$ & $\mathrm{D}$ & $\mathrm{D}$ & $\mathrm{I}$ & $\mathrm{I}$ & $\mathrm{I}$ & $\mathrm{I}$ & $\mathrm{I}$ & $\mathrm{I}$ & $\pm 2 \mathrm{~s}$ & 16 \\
\hline ICP-F & $\mathrm{D}$ & - & - & $\mathrm{I}$ & - & - & $\mathrm{I}$ & - & - & $\pm 3 \mathrm{~s}$, grouped Qs & 17 \\
\hline ICP-H & $\mathrm{D}$ & $\mathrm{D}$ & $\mathrm{D}$ & $\mathrm{I}$ & $\mathrm{I}$ & $\mathrm{I}$ & $\mathrm{I}$ & $\mathrm{I}$ & $\mathrm{I}$ & modified $\pm 4 \mathrm{~s}$ & 16 \\
\hline ICP-J & $\mathrm{D}$ & $\mathrm{D}$ & $\mathrm{D}$ & $\mathrm{D}$ & I & $\mathrm{D}$ & $\mathrm{D}$ & I & I & t-test / Bonferroni & 10 \\
\hline ICP-K & $\mathrm{D}$ & $\mathrm{D}$ & $\mathrm{D}$ & I & I & I & I & I & I & $\pm 4 \mathrm{~s}$ & 17 \\
\hline ICP-L & - & - & - & - & - & - & - & - & - & - & 17 \\
\hline
\end{tabular}

D:distinguishable I:indistinguishable IC:inconclusive $\quad$-: data not measured/not reported 
Table 48. Round robin $4^{\text {th }}$ results as reported by each LIBS participant using their selected match criteria.

\begin{tabular}{|c|c|c|c|c|c|c|c|c|c|c|c|}
\hline $\begin{array}{l}\text { Lab } \\
\text { ID }\end{array}$ & $\begin{array}{l}\text { K1 vs } \\
\text { Q1-1 }\end{array}$ & $\begin{array}{l}\text { K1 vs } \\
\text { Q1-2 }\end{array}$ & $\begin{array}{l}\text { K1 vs } \\
\text { Q1-3 }\end{array}$ & $\begin{array}{l}\text { K1 vs } \\
\text { Q2-1 }\end{array}$ & $\begin{array}{l}\text { K1 vs } \\
\text { Q2-2 }\end{array}$ & $\begin{array}{l}\text { K1 vs } \\
\text { Q2-3 }\end{array}$ & $\begin{array}{l}\text { K1 vs } \\
\text { Q3-1 }\end{array}$ & $\begin{array}{l}\text { K1 vs } \\
\text { Q3-2 }\end{array}$ & $\begin{array}{l}\text { K1 vs } \\
\text { Q3-3 }\end{array}$ & $\begin{array}{l}\text { Match } \\
\text { criteria }\end{array}$ & $\begin{array}{l}\text { \# elements } \\
\text { / ratios }\end{array}$ \\
\hline LIBS-H & $\mathrm{D}^{\mathrm{a}}$ & $\mathrm{D}^{\mathrm{a}}$ & $\mathrm{D}^{\mathrm{a}}$ & $\mathrm{I}^{\mathrm{b}}$ & $\mathrm{D}^{\mathrm{a}}$ & $\mathrm{D}^{\mathrm{a}}$ & $\mathrm{D}^{\mathrm{a}}$ & $I^{b}$ & $\mathrm{I}^{\mathrm{b}}$ & $\begin{array}{ll}\text { ttest } & / \\
\text { bonferoni }\end{array}$ & $\begin{array}{l}8 \text { elements, } \\
11 \text { ratios }\end{array}$ \\
\hline LIBS-I & $\mathrm{I}^{\mathrm{b}}$ & $\mathrm{I}^{\mathrm{b}}$ & $\mathrm{I}^{\mathrm{b}}$ & $\mathrm{D}^{\mathrm{a}}$ & $\mathrm{D}^{\mathrm{a}}$ & $\mathrm{I}^{\mathrm{b}}$ & $\mathrm{I}^{\mathrm{b}}$ & $\mathrm{I}^{\mathrm{b}}$ & $\mathrm{I}^{\mathrm{b}}$ & $\begin{array}{l}\mathrm{t} \text {-test } \\
\mathrm{p}=0.01)\end{array}$ & $\begin{array}{l}7 \text { elements, } \\
6 \text { ratios }\end{array}$ \\
\hline LIBS-J & $\mathrm{IC}^{\mathrm{c}}$ & $\mathrm{IC}^{\mathrm{c}}$ & $\mathrm{IC}^{\mathrm{c}}$ & $\mathrm{IC}^{\mathrm{c}}$ & $\mathrm{IC}^{\mathrm{c}}$ & $\mathrm{IC}^{\mathrm{c}}$ & $\mathrm{IC}^{\mathrm{c}}$ & $\mathrm{IC}^{\mathrm{c}}$ & $\mathrm{IC}^{\mathrm{c}}$ & $\begin{array}{l}\text { PLS-DA and } \\
\text { SIMCA }^{\text {e }}\end{array}$ & spectra \\
\hline LIBS-K & $\mathrm{D}^{\mathrm{a}}$ & $\mathrm{D}^{\mathrm{a}}$ & $\mathrm{I}^{\mathrm{b}}$ & $\mathrm{D}^{\mathrm{a}}$ & $\mathrm{D}^{\mathrm{a}}$ & $\mathrm{D}^{\mathrm{a}}$ & $\mathrm{I}^{\mathrm{b}}$ & $\mathrm{I}^{\mathrm{b}}$ & $\mathrm{I}^{\mathrm{b}}$ & $\begin{array}{l}\mathrm{t} \text {-test } \\
\mathrm{p}=0.01\end{array}$ & $\begin{array}{l}8 \text { elements, } \\
14 \text { ratios }\end{array}$ \\
\hline $\begin{array}{l}\text { Lab } \\
\text { ID }\end{array}$ & $\begin{array}{l}\text { K2 vs } \\
\text { Q1-1 }\end{array}$ & $\begin{array}{l}\text { K2 vs } \\
\text { Q1-2 }\end{array}$ & $\begin{array}{l}\text { K2 vs } \\
\text { Q1-3 }\end{array}$ & $\begin{array}{l}\text { K2 vs } \\
\text { Q2-1 }\end{array}$ & $\begin{array}{l}\text { K2 vs } \\
\text { Q2-2 }\end{array}$ & $\begin{array}{l}\text { K2 vs } \\
\text { Q2-3 }\end{array}$ & $\begin{array}{l}\text { K2 vs } \\
\text { Q3-1 }\end{array}$ & $\begin{array}{l}\text { K2 vs } \\
\text { Q3-2 }\end{array}$ & $\begin{array}{l}\text { K2 vs } \\
\text { Q3-3 }\end{array}$ & $\begin{array}{l}\text { Match } \\
\text { criteria }\end{array}$ & $\begin{array}{l}\text { \# elements } \\
\text { / ratios }\end{array}$ \\
\hline LIBS-H & $\mathrm{D}^{\mathrm{a}}$ & $\mathrm{D}^{\mathrm{a}}$ & $\mathrm{D}^{\mathrm{a}}$ & $\mathrm{I}^{\mathrm{b}}$ & $\mathrm{D}^{\mathrm{a}}$ & $\mathrm{D}^{\mathrm{a}}$ & $\mathrm{D}^{\mathrm{a}}$ & $\mathrm{I}^{\mathrm{b}}$ & $\mathrm{D}^{\mathrm{a}}$ & $\begin{array}{l}\text { t-test } \\
\text { bonferoni }\end{array}$ & $\begin{array}{l}8 \text { elements, } \\
11 \text { ratios }\end{array}$ \\
\hline LIBS-I & $\mathrm{I}^{\mathrm{b}}$ & $\mathrm{I}^{\mathrm{b}}$ & $\mathrm{D}^{\mathrm{a}}$ & $\mathrm{I}^{\mathrm{b}}$ & $\mathrm{D}^{\mathrm{a}}$ & $I^{b}$ & $\mathrm{I}^{\mathrm{b}}$ & $\mathrm{I}^{\mathrm{b}}$ & $\mathrm{I}^{\mathrm{b}}$ & $\begin{array}{l}\mathrm{t} \text {-test } \\
\mathrm{p}=0.01)\end{array}$ & $\begin{array}{l}7 \text { elements, } \\
6 \text { ratios }\end{array}$ \\
\hline LIBS-J & $\mathrm{IC}^{\mathrm{c}}$ & $\mathrm{IC}^{\mathrm{c}}$ & $\mathrm{IC}^{\mathrm{c}}$ & $\mathrm{IC}^{\mathrm{c}}$ & $\mathrm{IC}^{\mathrm{c}}$ & $\mathrm{IC}^{\mathrm{c}}$ & $\mathrm{IC}^{\mathrm{c}}$ & $\mathrm{IC}^{\mathrm{c}}$ & $\mathrm{IC}^{\mathrm{c}}$ & $\begin{array}{l}\text { PLS-DA and } \\
\text { SIMCA }^{\text {e }}\end{array}$ & spectra \\
\hline LIBS-K & $\mathrm{IC}^{\mathrm{c}}$ & $\mathrm{IC}^{\mathrm{c}}$ & $\mathrm{I}^{\mathrm{b}}$ & $\mathrm{D}^{\mathrm{a}}$ & $\mathrm{D}^{\mathrm{a}}$ & $\mathrm{D}^{\mathrm{a}}$ & $\mathrm{IC}^{\mathrm{c}}$ & $\mathrm{I}^{\mathrm{b}}$ & $\mathrm{I}^{\mathrm{b}}$ & $\begin{array}{l}\mathrm{t} \text {-test } \\
\mathrm{p}=0.01)\end{array}$ & $\begin{array}{l}8 \text { elements, } \\
14 \text { ratios }\end{array}$ \\
\hline
\end{tabular}




\subsubsection{Evaluation of performance of different match criteria}

In order to evaluate how the choice of match criterion affects error rates, the data provided by each participant was used to assess the error rates for the following criteria for the $\mu$-XRF methods: range overlap, t-tests ( $\mathrm{p}=0.05,0.01$ and Bonferroni correction to $0.05)$, confidence intervals $( \pm 2 \mathrm{~s}, 3 \mathrm{~s}, 4 \mathrm{~s})$, Hotelling $\mathrm{T}^{2}$, and for the ICP-based methods: these plus modified confidence intervals ( $\pm 2 \mathrm{~s}, 3 \mathrm{~s}, 4 \mathrm{~s}, 5 \mathrm{~s}, 6 \mathrm{~s}$ with minimum $3 \% \mathrm{RSD})$.

The calculations of error rates were performed for data collected for the second, third and fourth interlaboratory tests. The data from each of the individual Q fragments were used when making the comparison to the known sample for the purpose of this error rate analysis. Therefore, each $\mathrm{K} / \mathrm{Q}$ comparison was made between nine or more measurements from the $\mathrm{K}$ sample and three measurements from the $\mathrm{Q}$ sample. The result of a comparison was declared as indistinguishable when the values for all measured variables met the match criterion, otherwise the samples were deemed to be distinguishable.

The second test had one K/Q pair that originated from the same source (K1 vs. Q1), which allowed the evaluation of false exclusions, or type 1 errors and one pair of samples that originated from different sources (K1 vs. Q2), which allowed the evaluation of false inclusions or type 2 errors. The third test had five glass items, 2 known samples and 3 questioned samples, all of them originating from the same plant manufactured on different dates. Because this test did not have pairs of samples that originated from the same source, it did not have the possibility for type 1 errors. There were six sample pair comparisons that could result in false associations, or type 2 errors; (K1/Q1, K1/Q2, $\mathrm{K} 1 / \mathrm{Q} 3, \mathrm{~K} 2 / \mathrm{Q} 1, \mathrm{~K} 2 / \mathrm{Q} 2$, and $\mathrm{K} 2 / \mathrm{Q} 3$ ). The fourth test had five glass items, two known and 
3 questioned samples. Two K/Q comparison pairs allowed the evaluation of type 2 errors (K1/Q1 and K2/Q1) and 4 K/Q sample pairs (K1/Q2, K1/Q3, K2/Q2, and K2/Q3) were used to evaluate the rate of type 1 errors. For each sample pair, the number of errors was determined three times for the individual fragments of each Q sample and summed across all participants reporting results for that sample pair. All reported sample pairs were used to calculate the number of incorrect associations using each of the tested match criteria.

\subsection{Error rates for $\mu$-XRF data}

The summary results of error rate analyses obtained using $\mu$-XRF data for different match criteria expressed as the percentages of incorrect associations or exclusions are shown in Table 49. The number of comparisons used to calculate each percentage is given in the footnote to the table. False inclusions, or type 2 errors, were determined for the data from all three interlaboratory tests. The rate of false inclusions on this test was very low regardless of the match criteria employed for $\mu$-XRF data. For the 68 sample pair comparisons made for the second and fourth interlaboratory tests, only one pair resulted in a type 2 error. This error only occurred for the $t$-test at $\mathrm{p}=0.01$, the $\mathrm{t}$ test with Bonferroni correction, and the $4 \mathrm{~s}$ test for the second test. The sample pairs used for the evaluation of type 2 error rates on the second and fourth interlaboratory tests were manufactured in the same plant more than 2 years apart and 2 weeks apart, respectively. Their elemental composition was fairly distinctive and significant differences were detectable using $\mu$-XRF methods. 
Table 49. Results for the application of different match criteria on data acquired by XRF methods

\begin{tabular}{|c|c|c|c|c|c|c|}
\hline Match criteria & \multicolumn{3}{|c|}{ Type 1 error rate (\%) } & \multicolumn{3}{c|}{ Type 2 error rate (\%) } \\
\hline & Test 2 $^{\mathbf{a}}$ & Test 3 $^{\mathbf{b}}$ & Test 4 $^{\mathbf{c}}$ & Test 2 $^{\text {d }}$ & Test 3 $^{\text {e }}$ & Test 4 $^{\text {f }}$ \\
\hline Range & 11 & - & 19 & 0 & 21 & 0 \\
\hline t-test .05 & 52 & - & 60 & 0 & 6 & 0 \\
\hline t-test .01 & 22 & - & 30 & 4 & 15 & 0 \\
\hline t-test Bonf. & 15 & - & 26 & 4 & 21 & 0 \\
\hline $\pm 2 \mathrm{~s}$ & 41 & - & 24 & 0 & 18 & 0 \\
\hline $\pm 3 \mathrm{~s}$ & 11 & - & 6 & 0 & 27 & 0 \\
\hline $\pm 4 \mathrm{~s}$ & 7 & - & 0 & 4 & 36 & 0 \\
\hline Hotellings T & 15 & - & 9.5 & 0 & 26 & 0 \\
\hline
\end{tabular}

a percent rate calculated out of 27 comparisons from 9 laboratories.

${ }^{\mathrm{b}}$ design of the round robin 3 did not account for estimation of type 1 errors.

${ }^{c}$ percent rate calculated out of 84 comparisons from 7 laboratories.

${ }^{d}$ percent rate calculated out of 26 comparisons from 9 laboratories.

${ }^{\mathrm{e}}$ percent rate calculated out of 124 comparisons from 7 laboratories.

${ }^{\mathrm{f}}$ percent rate calculated out of 42 comparisons from 7 laboratories. 
As expected, the type 2 error rates on the third interlaboratory test are larger than for the other tests because the samples for this test were manufactured on the same float line and, in some cases, at relatively short date intervals. As a result, these samples have only minor differences in elemental composition. The t-test at the 0.05 and 0.01 levels resulted in the lowest numbers of type 2 errors in this set, $6 \%$ and $15 \%$, respectively.

Type 1 error rates (false exclusions) were determined for the second and fourth tests. At least one false exclusion was observed for all of the match criteria except for $4 \mathrm{~s}$ in the fourth test. The number of type 1 errors when using the narrower match criteria of the t-tests and the $2 \mathrm{~s}$ test are generally quite high. The range, $3 \mathrm{~s}, 4 \mathrm{~s}$, and Hotelling's $\mathrm{T}^{2}$ tests, with their wider match criteria, result in more acceptable type 1 error rates. The high number of type 1 errors is somewhat surprising considering that $\mu$-XRF measurements have repeatability values of $10 \%$ or greater for elements present at lower concentrations, such as $\mathrm{Ti}, \mathrm{Sr}$, and $\mathrm{Zr}$. The most likely reason as to why all pairs of samples from the same source are not correctly associated is that the irregular shapes and small sizes of the Q fragments result in biases in measured intensities when compared to the data from the larger, multiple $\mathrm{K}$ fragments. It is also significant that the conclusions reported by individual participants in the interlaboratory tests were all correct. There are several possible reasons for the better performance by the participants than that indicated by the various match criteria. First, the participants used spectral overlay as a pretest prior to comparison of analytical data. As a result, they may have removed some elements that were present at close to limits of quantitation from further quantitative comparison. Some of the false exclusion errors seen here result from comparisons of ratios involving these barely detectable elements which are more prone to sample size 
and orientation errors than elements present at higher concentrations. The second reason for the lower number of type 1 error rates for individual participant is that they grouped the data for $\mathrm{Q}$ fragments in Test 2, which improved the error rates compared with treating fragments individually.

For a compromise between type 1 and type 2 error rates, the optimum match criteria were $3 \mathrm{~s}$, range overlap, and Hotellings $\mathrm{T}^{2}$. As shown in Table 48, 3s and Hotellings $\mathrm{T}^{2}$ criteria had higher rates of false inclusions than range overlap for the data from the third test, which employed samples having very similar elemental compositions. However, the range overlap criterion had a significantly greater false exclusion rate than the $3 \mathrm{~s}$ or Hotellings $\mathrm{T}^{2}$ criteria for the small irregular shaped fragments encountered in the fourth test. One advantage of $\mu$-XRF data is that the typical number of variables (6-8 ratios) allows the fulfillment of the requirement of Hotellings $\mathrm{T}^{2}$ to have more replicate measurements than variables (i.e., at least 5 to 7 replicate measurements for the known sample and at least 3 for each questioned sample). However, in instances with small Q fragments such as debris cases, it may not be practical, or even possible, to collect the required number of replicate measurements on each fragment unless the position of the $\mathrm{x}$ ray beam remains stationary between measurements. Spectral overlay was not included in the tested match criteria because it is a qualitative comparison. However, based on the experience of EAWG members and the results reported by the participants in the interlaboratory tests, spectral overlay is one of the best match criteria. A protocol for $\mu$ XRF that has been submitted to ASTM for consideration as a standard test method recommends the use of spectral overlay followed by either a $3 \mathrm{~s}$ or range overlap match criterion using element intensity ratios. Although the results of this study cannot be 
applied directly to other manufacturers or even other dates for the float lines studied, they should be generally applicable. That is, the $\mu$-XRF methods are capable of detecting differences in composition of flat glass from the same line within a float glass plant when they are produced over time periods of weeks to months apart.

\subsection{Error rates for ICP data}

The summary of error rates obtained for ICP data for different match criteria are shown in Table 50. Because of the good precision of most ICP data, additional broader match criteria were included in this study $(5 \mathrm{~s}, 6 \mathrm{~s}$ and modified confidence intervals with minimum of $3 \%$ RSD)[15]. False inclusions or type 2 errors were estimated for the three tests. The only type 2 error that was made for the samples of the second and fourth interlaboratory tests was from the t-test with Bonferroni correction for one fragment from one participant in the second test. The samples used for the evaluation of type 2 error rates on these sets were manufactured in the same plant more than 2 years apart or 2 weeks apart, respectively. However, differences in their elemental composition as measured by ICP methods are detectable by any of the match criteria.

The type 2 error rate in the third interlaboratory test was expected to be larger than the other tests because the samples were purposely selected to be closer in manufacture date and also very similar in elemental compositions. In spite of this, the false inclusion rate was very low. All the K/Q pairs that showed false inclusions came from the pair of samples manufactured only 2 weeks apart, demonstrating that the sensitivity and precision of ICP data allows for the discrimination of samples 
manufactured at the same plant during short time intervals. Confidence intervals greater than $5 \mathrm{~s}$ provided the largest number of type 2 errors in this set.

Type 1 error rates, or false exclusions, were determined for the second and fourth tests. Some false exclusions were observed for the majority of the match criteria, with lower rates provided by broader match criteria $(>4 \mathrm{~s})$. Failure to associate samples with the same origin was observed in the second test only for 2 out of 7 participant laboratories and in all cases the differences were found only for one out of the 16-18 elements monitored. Repeatability between measurements in the discriminating element was lower than $2 \% \mathrm{RSD}$. The larger number of type 1 errors on the fourth test is attributed mainly to the atypical heterogeneity discovered in the samples, which is discussed in more detail in the following section.

The best performance for a compromise between type 1 and type 2 error rates is found for $4 \mathrm{~s}$ and modified $4 \mathrm{~s}$ interval. Using these broader match criteria reduced significantly the Type 1 errors without sacrificing the capability to discriminate samples (type 2 errors). Hotellings $\mathrm{T}^{2}$ is not as practical for ICP data as for the $\mu$-XRF data because of the larger number of variables measured (16-18 elements). However, Hotellings $T^{2}$ could be applied in cases where the questioned sample is large enough to allow the requisite number of replicate measurements. Since that was not the case in these studies, no statement can be made as to the error rates that might result when using Hotelling's $\mathrm{T}^{2}$ with ICP data. 
Table 50. Results for the application of different match criteria on data acquired by ICP methods.

\begin{tabular}{|c|c|c|c|c|c|c|}
\hline \multirow[b]{2}{*}{ Match criteria } & \multicolumn{3}{|c|}{ Type 1 error rate $(\%)$} & \multicolumn{3}{|c|}{ Type 2 error rate $(\%)$} \\
\hline & Test $2^{a}$ & Test $3^{b}$ & Test $4^{\mathrm{c}}$ & Test $2^{d}$ & Test $3^{\mathrm{e}}$ & Test $4^{f}$ \\
\hline Range & 42 & - & 81 & 0 & 0 & 0 \\
\hline t-test .05 & 74 & - & 93 & 0 & 1 & 0 \\
\hline t-test .01 & 53 & - & 84 & 0 & 1 & 0 \\
\hline t-test Bonf. & 53 & - & 69 & 0 & 2 & 0 \\
\hline $\pm 2 \mathrm{~s}$ & 53 & - & 85 & 0 & 0 & 0 \\
\hline $\pm 2 \mathrm{~s}(\mathrm{~s}>3 \%)$ & 26 & - & 75 & 0 & 0 & 0 \\
\hline $\pm 3 \mathrm{~s}$ & 42 & - & 66 & 0 & 2 & 0 \\
\hline $\pm 3 \mathrm{~s}(\mathrm{~s}>3 \%)$ & 0 & - & 47 & 0 & 2 & 0 \\
\hline $\pm 4 \mathrm{~s}$ & 26 & - & 42 & 0 & 5 & 0 \\
\hline $\pm 4 \mathrm{~s}(\mathrm{~s}>3 \%)$ & 0 & - & 28 & 0 & 5 & 0 \\
\hline $\pm 5 \mathrm{~s}$ & 11 & - & 30 & 0 & 9 & 0 \\
\hline $\pm 5 \mathrm{~s}(\mathrm{~s}>3 \%)$ & 0 & - & 18 & 0 & 11 & 0 \\
\hline $\pm 6 \mathrm{~s}$ & 11 & - & 27 & 0 & 12 & 0 \\
\hline $\pm 6 \mathrm{~s}(\mathrm{~s}>3 \%)$ & 0 & - & 13 & 0 & 15 & 0 \\
\hline
\end{tabular}

${ }^{a}$ percent rate calculated out of 19 comparisons from 7 laboratories.

${ }^{b}$ design of the round robin 3 did not account for estimation of type I errors.

${ }^{\mathrm{c}}$ percent rate calculated out of 120 comparisons from 10 laboratories.

${ }^{\mathrm{d}}$ percent rate calculated out of 19 comparisons from 7 laboratories.

${ }^{\mathrm{e}}$ percent rate calculated out of 126 comparisons from 7 laboratories.

${ }^{\mathrm{f}}$ percent rate calculated out of 60 comparisons from 10 laboratories

The need to widen the match criteria for ICP measurements is a consequence of the high precision of the measurements (typically less than $2 \%$ RSD). Using the broader criteria, the ICP methods were still able to correctly discriminate between samples with 
similar elemental profiles that originated from the same plant and were manufactured more than 2 weeks apart. It should be noted here that the significant factor affecting changes in composition of float glass is not time, per se, but rather changes in the compositions of raw materials and internal processes within the manufacturing plant that occur over time. Again, the results of this study cannot be applied directly to other manufacturers or even other dates for the float lines studied. However, they should be generally applicable in that the ICP-based methods, when applied to many major, minor, and trace elements, are capable of detecting differences in composition of flat glass originating from one plant over time periods of weeks to months.

\subsection{Homogeneity study: Pilkington and Cardinal plants}

The samples selected for the fourth interlaboratory test originated from a Pilkington glass manufacturing plant that experienced changes in the formulation of the glass as a consequence of market requirements. Figure 48 shows the variation of concentration of iron in glass samples collected over a 2-month period. Error bars represent the variation (as standard deviation) obtained from 5 replicates of a single sample measured by LA-ICP-MS. Drastic concentration changes in iron content were observed in glass manufactured between February 25, 2010 and March 19, 2010. Nevertheless, the plant reported that their "transition period", where the glass was not released to the market, was between March 14, 2010 and April 16, 2010.

Samples selected for the interlaboratory test were manufactured approximately two weeks and one month before the transition period, respectively. As a result of the unexpectedly high rates of false exclusions found in the fourth interlaboratory test by 
ICP-based methods, it was suspected that one cause for the occurrence of this type of error could be an atypical heterogeneity at the micro-scale of the samples submitted for analysis.

To test this hypothesis, homogeneity studies were conducted on the original source samples from the Pilkington plant. In addition, a set of glass samples from another plant was included for comparison purposes. The Cardinal sample manufactured on August 17, 2001, which was used as K1 for the third interlaboratory test, was selected for this study because in that interlaboratory test none of the participants reported false exclusion errors in their findings. The homogeneity study was designed to compare the variation: a) between fragments from the same source (i.e. 6-7 fragments from the same source, 3 replicates each) and b) within fragments (spatial variation, i.e. float side. nonfloat side, and different areas through a cross section of the glass)

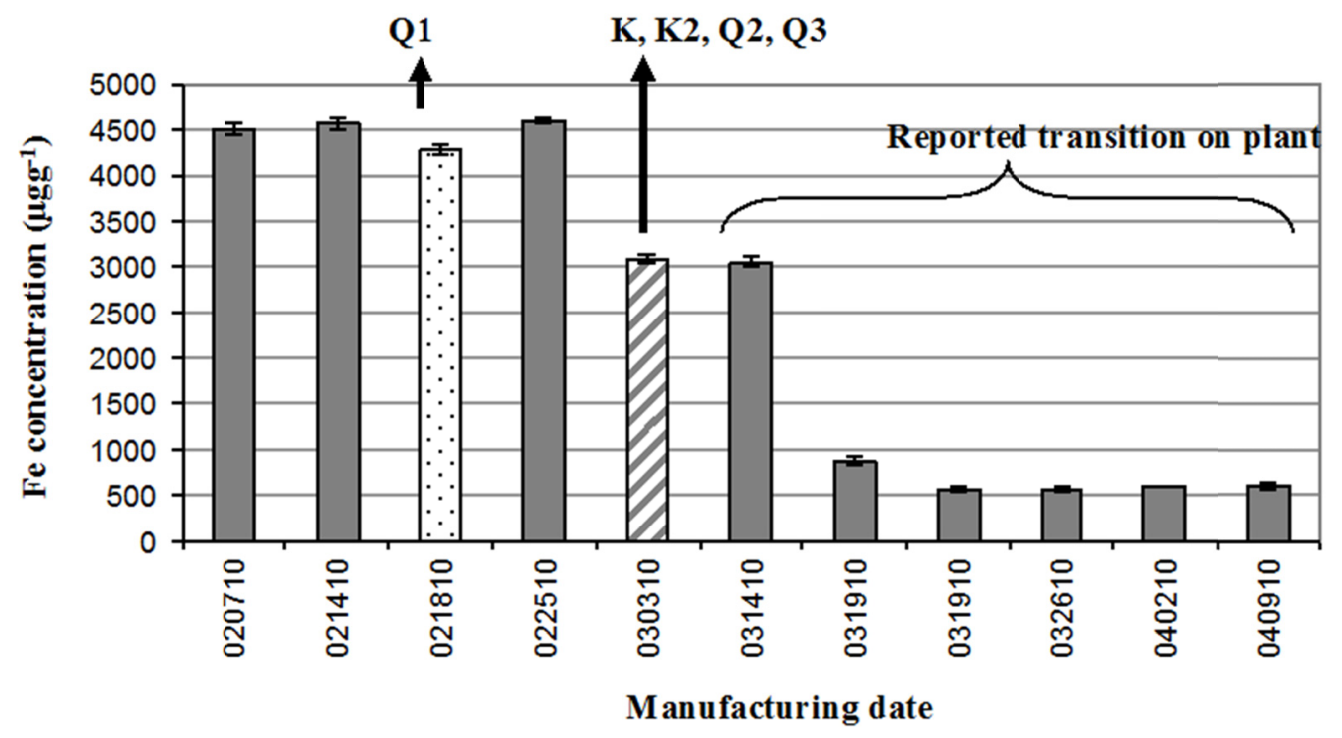

Figure 48. Elemental variation of iron composition between samples manufactured at the Pilkington plant from $02 / 07 / 10$ to $04 / 09 / 10$. 
4.2.2.2.3.1 Variation between fragments from the same source (non-float sides only)

Six fragments were randomly selected from each sample, 3 replicates were conducted on each of the non-float original surfaces of the fragments for a total of 18 measurements per sample.

Comparisons between the six fragments versus each other were conducted using ANOVA with Tukeys post-hoc test. The results show more heterogeneity in samples from the Pilkington plant than in the samples from the Cardinal plant. Significant differences for 7 out of 18 elements monitored (Mn, Al, K, Ca, Ti, Fe and $\mathrm{Sr}$ ) were observed between fragments from the Pilkington glass manufactured on February 18, 2010 and for 3 out of the 18 elements monitored (Al, Ca and Hf) for the Pilkington sample manufactured on March 3, 2010. In contrast, no significant differences were observed between any of the fragments sampled from the Cardinal glass using the same criterion.

In order to simulate the statistical treatment given to the data during the fourth interlaboratory test, the comparison between fragments was also conducted by randomly choosing 3 of the fragments to act as the Known sample $(\mathrm{K})$ and the remaining fragments as independent Questioned samples (Q), with 3 measurement replicates each. Only nonfloat surfaces were analyzed during this experiment.

In general, the Cardinal glass sample showed evidence of uniform distribution of elemental composition among non-float surfaces. No significant differences were detected between fragments using different match criteria (except t-test $\mathrm{p}=0.05$ ). On the other hand, the Pilkington samples showed more heterogeneity, as evidenced by more false exclusions than the Cardinal sample. The false exclusions were reduced to zero for 
the three Pilkington subsets when applying broader match criteria, such as $\pm 4 \mathrm{~s}$ and modified $\pm 4 \mathrm{~s}$ (minimum 3-5\% RSD).

4.2.2.3.3.2 Variation between original surfaces and across the thickness of the fragment

Figure 49 shows the sampling scheme used to study spatial variation within a single fragment. Five replicate analyses were conducted on each of the sampling sites (original surfaces such as float versus non-float side, and fracture surfaces as different areas across the thickness of the fragment).

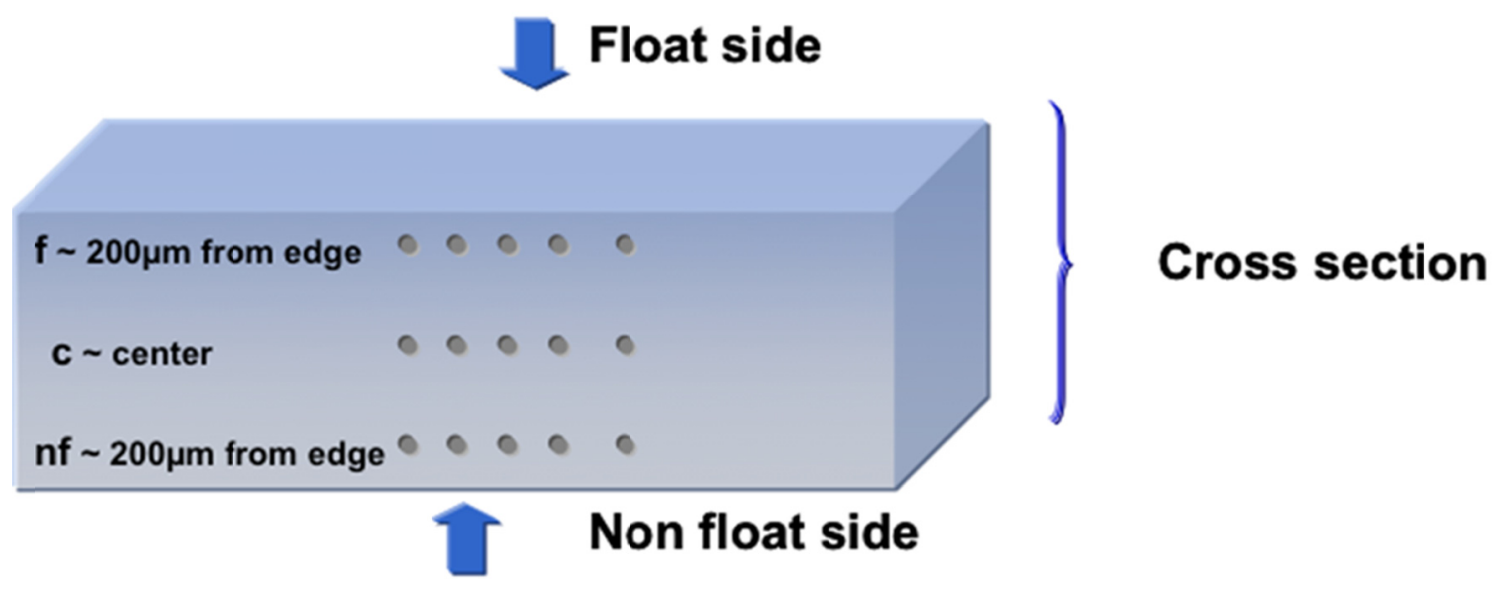

Figure 49. Sampling diagram used for the analysis of spatial elemental variation within a fragment.

Significant differences in composition were found between float and non-float surfaces on all tested samples (Cardinal and Pilkington) using all match criteria. Differences between the surfaces were detected not only for the content of Sn, but also for other elements, such as $\mathrm{Al}, \mathrm{Ca}, \mathrm{Sr}, \mathrm{Zr}$, Ti and Fe. 
These results highlight the relevance of sampling. Whenever possible, sampling from fracture surfaces is preferred over original surfaces. Otherwise, if analyzing original surfaces, either all non-float surfaces or all float surfaces should be used for the comparisons of known and questioned sources. An easy way to detect if the analysis is being done on the float side is to monitor the content of Sn, which will typically be 1-2 orders of magnitude larger on the float side of the glass. This observation can be done insitu during the analysis and the sample can be easily turned to the non-float side if needed.

The study of elemental variability across the thickness of the interior portion of glass fragments also revealed more heterogeneity in the Pilkington samples. Significant differences were detected, depending on the match criteria, particularly close to the nonfloat surface $(<200 \mu \mathrm{m})$. This variability was detected regardless of the match criteria applied to sample PK030310, which was manufactured close to the time of the reported transition in $\mathrm{Fe}$ formulation. This sample was the one selected for the fourth interlaboratory test to examine false exclusion errors.

Significant differences across the thickness of the sample were also detected for the Cardinal sample, depending on the match criteria. Nevertheless, no significant differences were detected using $\pm 4 \mathrm{~s}$ or modified $\pm 4 \mathrm{~s}$ match criteria. Figure 50 shows the variability of the iron content observed between different sampling areas of the fragments for one of the Pilkington samples (PK03010) and the Cardinal sample.

The results of this study demonstrate that the heterogeneity between fragments is more pronounced for the Pilkington samples than for the Cardinal samples. As consequence of the shape and small fragment size chosen for the Q samples on the fourth 
interlaboratory test, it is likely that participants received, Q samples from different areas across the thickness of the fragment and encountered heterogeneous compositions. This could have contributed to the elevated number of false exclusions obtained with sensitive ICP-based methods.

Consequently, based on post distribution experiments and various statistical evaluations of the data, the rate of false exclusions found in the fourth test for ICP-based methods is attributable to several factors: a) the limited number of replicates for questioned samples, a common casework concern, b) unusual heterogeneity of the samples of Pilkington glass, and c) match criteria too sensitive for methods achieving very high precision between replicates.

In the fourth interlaboratory test, participants were asked to compare the known fragments to each of the individual questioned fragments (instead of grouping all questioned fragments). This approach was selected to be a more realistic simulation of a case where small, irregular fragments recovered from surface debris must be treated as individual fragments. As a result of the small size of the fragments submitted for analysis, only 3 replicates were requested per questioned fragment. As a result, for the sensitive ICP-based methods that have high precision, only some of the fragments were correctly identified as indistinguishable from the known sources. The precision and sensitivity of $\mu-\mathrm{XRF}$ techniques, in combination with the selected match criteria, were shown to be appropriate for these types of samples. 

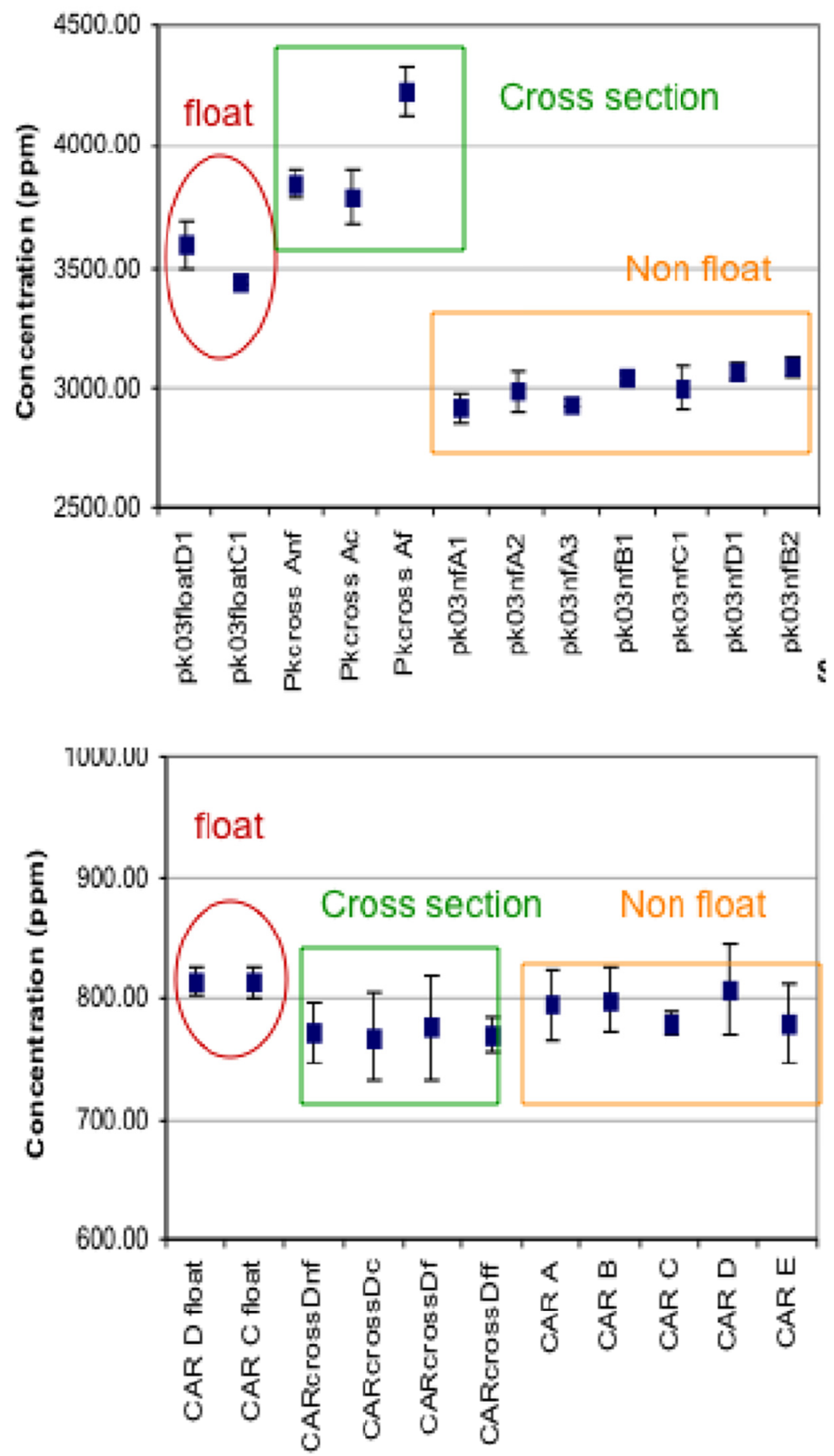

Figure 50. Variation of iron content across different sampling areas within a single fragment. Top: glass manufactured at Pilkington plant on 03/03/10. Bottom: glass manufactured at Cardinal plant on 08/17/01. 
The heterogeneity observed on the Pilkington samples, both within a fragment and between fragments originating from a single source is atypical of what has been observed in the float glass encountered in several manufacturing plant studies analyzed by solution ICP-MS and LA-ICPMS at FIU over the last decade. Heterogeneity of these samples is also inconsistent with previous within-sheet homogeneity studies conducted at FIU, the BKA, and the FBI. Nevertheless, as with any commercial product, the variability of its elemental composition is dependent on market requirements and the manufacturing history of the specific plant. For these reasons, samples such as those encountered in this fourth interlaboratory test may be present in a real case and should be taken into account during the selection of match criteria and interpretation of the data.

4.3 Conclusions for the evaluation of the performance of different match criteria for the comparison of elemental composition of glass

These interlaboratory studies allowed for a direct comparison between four of the most sensitive methods currently available for the forensic elemental analysis of glass samples (LA-ICP-MS, solution ICP-MS, LIBS and $\mu$-XRF). The methods were compared in terms of analytical performance and discrimination capability.

ICP-based methods (ICP-MS and LA-ICP-MS) are the most sensitive methods, with limits of detection on the order of sub-ppm in the solid material. Advantages of these methods are that they are fairly standardized among participant laboratories, they are currently used in forensic laboratories and they have been accepted in court. A standardized ASTM method already exists for the digestion and analysis by ICP-MS (ASTM E2330) [34] and the EAWG is currently working on developing a standardized 
method for LA-ICP-MS. Both methods are fairly mature with several publications previously reporting the evaluation of their capabilities and limitations. In addition, laser ablation sampling has unique advantages over digestion-based methods, such as reducing the sample consumption from milligrams to just few a hundred nanograms, reducing the time for analysis and eliminating the use of hazardous digestion reagents. Interlaboratory comparisons of glass reference standard materials demonstrated that ICP-methods provide accurate and precise quantitative data with deviations lower than $10 \%$ for nearly all elements measured in the studies.

Important findings from LA-ICP-MS methods include: a) the detection and report of heterogeneity of Ce and La close to the rim on FGS standards $(<250 \mu \mathrm{m})$ and $\mathrm{b})$ the awareness that possible differences between surface and bulk composition in compared glasses may lead to false exclusions if sampling and data interpretation are not carefully evaluated.

XRF methods provided consistent data among participants after normalization with a reference standard material such as SRM NIST 1831. The EAWG is also using the experience gained from these interlaboratory tests to work towards the standardization of a $\mu$-XRF method for the elemental analysis of glass. Limits of detection are 2-3 orders of magnitude higher than ICP-based methods; therefore, the number of trace elements typically detected in glass samples is more limited. Nevertheless, good performance was also observed among XRF laboratories. The measurement of LODs provided a better understanding of the capabilities of the technique and permitted a means of quantitatively comparing the performance of different instrument configurations. 
Relevant observations derived from the studies include: a) the use of normalized data to a glass standard such as SRM NIST 1831 provide a means to account for differences among instrumental configurations and to conduct interlaboratory comparisons, b) the use of a glass standard as a "control" glass is recommended to check method performance prior to analysis, and c) the use of $\mathrm{K}$ and $\mathrm{Q}$ fragments with similar size and shape is necessary to improve precision and thus increase discrimination power.

Although LIBS is not as mature as the other techniques evaluated in this work, the results suggest that LIBS offers potential for the forensic analysis of glass samples. Advantages of this method are its micro-destructive nature, speed of analysis, lower instrumental and maintenance costs and versatility. Limits of detection and precision of the measurements are comparable to those obtained by LA-ICP-MS and are generally superior to those obtained by XRF. Inter-lab optimization and validation of instrumental parameters, data reduction and element list will be crucial to improve the agreement of results between laboratories.

Mock case samples allowed an inter-method comparison of the capabilities to associate samples that originated from the same source and to discriminate among samples that were manufactured in the same plant line at different time periods. Excellent agreement between laboratories was achieved in the first interlaboratory tests with $100 \%$ correct conclusions. These first interlaboratory tests also provided an excellent opportunity for participants to fine-tune their methods and protocols and cross-validate their methodology.

The study revealed that a wide variety of match criteria are currently employed by forensic laboratories to conduct statistical comparisons of elemental composition data. 
Extensive discussions between the group members led to the design of additional interlaboratory tests to address the interpretation of evidence and the systematic selection of match criteria for elemental comparisons of glasses, based on simultaneously minimizing the frequency of both false exclusions and false inclusions.

Based on results obtained in the interlaboratory tests, it is concluded that the match criteria for comparison of elemental composition of glass fragments should be carefully selected based on the technique used for analysis as well as the number of replicates that are conducted to characterize the variability of the known and questioned samples.

For $\mu$-XRF analysis, the following observations are derived from the studies. Spectral overlay, \pm 3 s, range overlap, and Hotellings $\mathrm{T}^{2}$ performed well in terms of both false exclusions and inclusions. Excellent consistency of reported comparison results among participants was achieved for all the interlaboratory tests, not only for comparison conclusions but also for the elements reported to be responsible for discrimination. Participants who used $\mu$-XRF methods were able to detect significant differences between fragments of glass that were manufactured in the same plant within short periods of time. That period of time is dependent on the variability of the formulation of the glass within a plant. For instance, participants who used $\mu$-XRF were able to detect differences in samples manufactured a month apart at the Cardinal plant. Differences were not detected between samples manufactured at this plant 2 weeks apart and 3 months apart when their elemental compositions were extremely similar. However, all participants were able to detect significant differences between samples manufactured 2 weeks apart at the Pilkington plant. Users of $\mu$-XRF must take into consideration that 
small, irregularly shaped fragments may result in false exclusions when they are compared to larger fragments, particularly when they are thin enough that high energy xrays penetrate completely through them.

For ICP-based methods (digestion ICP-MS, LA-ICP-MS and LA-ICP-OES), the following conclusions are derived from the studies. Most participants reported precisions between replicates of $2 \% \mathrm{RSD}$ or less. This good analytical precision may be one of the factors that contribute to higher false exclusion rates when sensitive match criteria such as the t-test or a low multiple of standard deviations are used. Due to the sensitivity of the method, the capability of multi-elemental analysis of trace elements, the typical high precision, and the concerns for heterogeneity, the use of broader match criteria such as $\pm 4 \mathrm{~s}$ is recommended, either with or without minimum precision values depending on the reproducibility within replicates. These match criteria still allow detection of significant differences between samples manufactured in the same plant over short time intervals, even for samples with quite similar elemental profiles. The performance of these match criteria is in agreement with recent published data [Weis et al., 2011]. As with $\mu$-XRF methods, the time interval over which samples cannot be distinguished depends upon the variability of the formulation of the glass within a plant. For instance, ICP participants were able to detect differences in samples from the same float line at the Cardinal plant manufactured a month apart and some participants detected differences of samples manufactured 2 weeks apart.

In terms of interpretation of elemental comparisons of glass, it can be concluded from the study that glass samples that are manufactured in different plants, or even at the same plant years apart, are clearly differentiated by elemental composition when $\mu$-XRF 
or ICP-based methods are used for analysis. Samples produced in the same plant over time intervals of weeks to months may also be differentiated. This level of differentiation can be used to add significance to an association, when one is found, and to assist in assigning recovered fragments to a source when selecting among several potential sources. 


\subsection{OVERALL CONCLUSIONS}

Elemental analysis is a very powerful tool for the identification, characterization and/or differentiation of many man-made materials that could become a critical piece of information of a forensic investigation. The proper assessment of the value of an elemental profile depends on a) a full knowledge of the capabilities and limitations of the analytical technique(s) used for the acquisition of the measurements and b) an understanding of any effect that the nature of the material, its composition and/or its manufacture could have in the overall estimation of the discrimination potential.

The work presented in this dissertation aim to offer the forensic community more information on both of these aspects for three matrices of interest: ink, paper and glass.

In the case of ink and paper, forensic applications of LA-ICP-MS and LIBS were developed for the first time and therefore an exhaustive evaluation of the analytical capabilities of the methods is reported.

In the case of glass, LA-ICP-MS and LIBS methods have been already developed and optimized. Hence, the main focus was to evaluate the significance of its elemental composition in forensic comparisons. To accomplish this, both laser ablation methods were compared to other techniques such as digestion-ICP-MS and UXRF through a series of inter-laboratory studies conducted by 31 forensic examiners representing 22 different laboratories in the US and outside the US (Mexico, Canada and Germany).

In the first part of this work, laser ablation methods (LA-ICP-MS and LIBS) were developed, optimized and validated for the elemental analysis and forensic comparison of paper and inks in documents. The overall evaluation of its forensic utility was performed in terms of a) analytical performance of the method, b) homogeneity of the material at a 
micro-scale, c) capabilities to differentiate samples manufactured at different plants or time periods and d) capabilities to correctly associate a material to its source of origin.

Within this context, the results presented here for ink and paper analysis revealed that both laser ablation methods performed as fit for purpose and can be applied for the forensic comparison of paper and inks (writing inks, inkjets and toner). More specifically:

a) Both laser ablation methods offer good analytical performance. LA-ICP-MS and LIBS measurements showed good linearity, good selectivity and repeatability between measurements better than 15\% RSD. Nonetheless, LA-ICP-MS showed superior sensitivity than LIBS with limits of detection 10-1000 times better than LIBS, depending on the element of interest.

b) LA-ICP-MS showed superior performance to LIBS particularly for its better sensitivity and selectivity. LIBS also offers the advantages of affordability, reduced complexity and more versatility than LA-ICP-MS.

c) Both methods provide simple sampling, fast analysis and convenient microremoval of the material (0.3-28ug), leaving the document almost unaltered to the naked eye.

Homogeneity studies show smaller variation of elemental compositions within a single source (i.e sheet of paper, pen, ink cartrige) than variations between different sources (i.e brands, models, batches).

Significant and detectable differences were observed between multipurpose white paper from different sources (discrimination of $\sim 97-99 \%$ depending on the sample set under investigation and the laser ablation method applied). These differences of the elemental composition of paper were detected between papers of different brands, paper 
manufactured at different mills/plants and batches of paper manufactured at the same mill at times intervals ranging from few days to three months, depending on the variability of the raw materials and the recycled contents.

Significant and detectable differences were observed between black gel inks, blue gel inks, ballpoint inks, toners and inkjets from different sources (discrimination ( $\sim 87$ $100 \%)$ and low error rates ( $<0.4$ false exclusions; $1.2-12.8$ false inclusions) depending on the sample set under investigation and the method applied. Differentiation of inks was possible at the brand, model, type and batch level for all the printing inks and writing inks studied here.

The main recommendations for the elemental analysis of ink and paper by LAICP-MS or LIBS derived from this study are:

a) It is very important to characterize the natural variability of the elemental composition of multiple sheets from a single ream or multiple pages from the comparison document before doing comparison to the questioned document. The number of sheets to be sampled should be according to the expected plant stacking policies, but it should be at least 4-6 sheets per ream.

b) For LIBS analysis, comparison of spectral overlay by regions of interest is an attractive alternative to quantitative comparisons of inks. Broad-band spectrometers are more practical than Czerny-Turner, reducing not only the time of analysis but the amount of sample required per replicate.

c) Laser ablation-ICP-MS could be the method of choice for those laboratories that have an ICP-MS or that already use the technique for forensic analysis of other evidence such as glass, paint and for the determination of provenance of materials. 
d) Differences in the chemistry of the inks and ink-paper interaction required optimization of methods that were specific to the ink-type. Thus, a preliminary method optimization is recommended for any different type of ink than the ones studied here.

e) Mass removal studies revealed that there is a considerable amount of paper substrate removed along with the ink during the ablation process and therefore the identification of the contribution of the paper has to be part of the analytical approach prior comparison of the elemental ink profile.

f) Further studies that incorporate the feedback from the ink industry are recommended to fully assess the value of elemental composition of inks and to evaluate whether these methods can be used to identify the inks by country of origin and/or brand type.

These laser ablation methods now present an attractive analysis alternative for forensic examiners to increase the informing power in comparisons and identification of ink and paper.

Finally, the second part of this dissertation describes a series of interlaboratory that allowed for a direct comparison between four of the most sensitive methods currently available for the forensic elemental analysis of glass samples (LA-ICP-MS, solution ICPMS, LIBS and $\mu-\mathrm{XRF})$.

The interlaboratory studies were conducted specifically on glass materials by members of the NIJ-funded scientific working group EAWG. Design of the experiments and data processing was part of this dissertation. This grant made possible the fusion of several forensic experts to standardize their methods of analysis, cross-validate the analytical protocols and evaluate the interpretation of elemental data. 
Important findings from LA-ICP-MS methods for glass include:

a) The detection and report of heterogeneity of Ce and La close to the rim on FGS standards $(<250 \mu \mathrm{m})$

b) The awareness that possible differences between surface and bulk composition in compared glasses may lead to false exclusions if sampling and data interpretation are not carefully evaluated.

c) As a result of the sensitivity of the method, the capability of multi-elemental analysis of trace elements, the typical high precision, and the concerns for heterogeneity, the use of broader match criteria such as $\pm 4 \mathrm{~s}$ is recommended, either with or without minimum precision values depending on the reproducibility within replicates.

d) These wide match criteria still allow detection of significant differences between samples manufactured in the same plant over short time intervals, even for samples with quite similar elemental profiles. The time interval over which samples cannot be distinguished depends upon the variability of the formulation of the glass within a plant. For instance, ICP participants were able to detect differences in samples from the same float line at the Cardinal plant manufactured a month apart and some participants detected differences of samples manufactured 2 weeks apart.

Important outcomes for XRF methods include:

a) The use of normalized data to a glass standard such as SRM NIST 1831 provide a means to account for differences among instrumental configurations and to conduct interlaboratory comparisons.

b) The use of a glass standard as a "control" glass is recommended to check method performance prior to analysis, 
c) Spectral overlay, $\pm 3 \mathrm{~s}$, range overlap, and Hotellings $\mathrm{T} 2$ performed well in terms of both false exclusions and inclusions.

d) Participants who used $\mu-\mathrm{XRF}$ methods were able to detect significant differences between fragments of glass that were manufactured in the same plant within short periods of time. That period of time is dependent on the variability of the formulation of the glass within a plant. Users of $\mu$-XRF must take into consideration that small, irregularly shaped fragments may result in false exclusions when they are compared to larger fragments, particularly when they are thin enough that high energy xrays penetrate completely through them

Although LIBS is not as mature as the other techniques evaluated in this work, the results suggest that LIBS offers potential for the forensic analysis of glass samples. LIBS has analytical capabilities close to those obtained by LA-ICP-MS and better than $\mu$-XRF. Further inter-lab optimization and validation of the analytical protocols is believed to be key to improve the agreement of results between laboratories.

In summary, based on results obtained in the interlaboratory tests, it is concluded that the match criteria for comparison of elemental composition of glass fragments should be carefully selected based on the technique used for analysis as well as the number of replicates that are conducted to characterize the variability of the known and questioned samples.

It can be concluded from the glass study that glass samples that are manufactured in different plants, or even at the same plant years apart, are clearly differentiated by elemental composition when $\mu$-XRF or ICP-based methods are used for analysis. Samples produced in the same plant over time intervals of weeks to months may also be 
differentiated. This level of differentiation can be used to add significance to an association, when one is found, and to assist in assigning recovered fragments to a source when selecting among several potential sources

The inter-laboratory experience demonstrated to be a very efficient method to validate forensic methods and to assess the significance of the evidence and therefore they are recommended in the future for other matrices such as ink and paper.

It is expected that the results disclosed in this dissertation will be very informative to the forensic community in the assessment of the evidential value of elemental analysis of glass, ink and paper. 


\section{REFERENCE LIST}

ACS Committee on Environmental Improvement. Guidelines for Data Acquisition and Data Quality Evaluation in Environmental Chemistry (1980) Analytical Chemistry, 52: $2242-2248$

Almirall JR, Buckleton J, Curran JM, Hicks TN (2000) In: Curran JM, Champod TNH, Buckleton JS (eds, Forensic Interpretation of Glass Evidence Examination of glass, CRC Press, Florida

Almirall JR, Trejos T (2006) Advances in forensic analysis of glass fragments with a focus on refractive index and elemental analysis. Forensic Sci Review 18, 2: 74-96

Almirall JR, Trejos T (2010) Forensic applications of mass spectrometry, In: Beauchemin D (ed) Encyclopedia of Mass Spectrometry, $1^{\text {st }}$ edn. Elsevier, 5: 705-717

Almirall JR, Trejos T, Hobbs A, Furton K (2003) In: Carapezza EM (ed), Elemental analysis of glass and paint samples of forensic interest by ICP-MS using laser ablation solid sample introduction, Sensors, and Command, Control, Communications, and Intelligence (C3I) Technologies for Homeland Defense and Law Enforcement II, Proceedings of the International Society for Optical Engineering (SPIE), 5071: 193-196

American Society for Testing and Materials ASTM Practice E177 (2004) Standard Practice for the use of the terms precision and bias in ASTM methods, American Society for Testing and Materials, West Conshohocken, PA

American Society for Testing and Materials Method E2330-04 (2004), Standard test method for determination of trace elements in glass using inductively couple plasma mass spectrometry (ICP-MS), in: ASTM Annual Book of ASTM Standards, 14.02, American Society for Testing and Materials, West Conshohocken, PA

Andrasko J, Machly A (1978) The Discrimination Between Samples of Window Glass by Combining Physical and Chemical Techniques. J Forensic Sci 22: 250-262

ASTM C162-03 (2003) Standard terminology of glass and glass products Annual Book of ASTM Standards. Vol. 15.02 ASTM: West Conshohocken 
ASTM E1422-01 (2005) Standard guide for Test Methods for Forensic Writing Ink Comparison, 14.02, ASTM International, Pensilvania

ASTM E1789-04 (2004) Standard Guide for Writing Ink Identification, 14.02, ASTM International, Pensilvania

ASTM E2331-04 (2004 ) Standard Guide for Examination of Altered Documents, 14.02, ASTM International, Pensilvania

Bajic S, Aeschliman D, Staetveit NJ, Baldwin DP, Houk RS (2005) Analysis of glass fragments by laser ablation-inductively coupled plasma-mass spectrometry and principal component analysis. J Forensic Sci 50: 1123-1127

Becker S, Gunaratman L, Hicks T, Stoecklein W, Warman G (2001) The differentiation of float glass using refractive index and elemental analysis: Comparisons of techniques. Problems of Foren Sci 47:80-92

Becker S, Watzke P, Dücking M, Stoecklein W (2003) Laser ablation in forensic glass analysis: The use of matrix matched standards for quantitative float glass analysis. Forensic Sci Int 136, 1: 361

Ben-Mushe M, Magdassi S (2011) unique inkjet ink systems, In: Magdassi S (ed) The Chemistry of inkjet inks, World Scientific Publishing, NJ

Berends-Montero S et al (2006) Forensic analysis of float glass using laser ablation inductively coupled plasma mass spectrometry (LA-ICP-MS): validation of a method. J Anal Atom Spectrom. 21, 11: 1185-1193.

Biermann CJ (1993) Essentials of Pulping \& Papermaking, Academic Press, California Bridge CM et al (2006) Characterization of automobile float glass with laser-induced breakdown spectroscopy and laser ablation inductively coupled plasma mass spectrometry. Appl Spectrosc 60, 10: 1181-1187

Brozel-Mucha Z, Zadora G (1998) Differentiating between various types of glass using SEM-EDX elemental analysis: a preliminary study. Problems of Foren Sci 37: 68-89 
Brunelle RL, Crawford KR (2003) Advances in the Forensic Analysis and Dating of Writing Ink, Charles C Thomas, Illinois

Buscaglia J (1994) Elemental analysis of small glass fragments in forensic science. Anal Chim Acta 288: 17-24

Cahoon EM, Almirall JR (2010) Wavelength dependence on the forensic analysis of glass by nanosecond $266 \mathrm{~nm}$ and $1064 \mathrm{~nm}$ laser induced breakdown spectroscopy. Applied Optics 49, 13: C49-C57

Carvalho DN. Forty centuries of ink, The worldwide school TM, 1999, USA, http://www.worldwideschool.org/library/books/tech/printing/FortyCenturiesofInk/toc.ht $\underline{\mathrm{ml}}$

Castro W, Trejos T, Naes B, Almirall JR (2008) Comparison of high resolution and dynamic reaction cell ICP-MS capabilities for the forensic analysis of iron in glass. Anal Bioanal Chem 392: 663-672

Catterick T, Hickman DA (1981) The quantitative analysis of glass by inductively coupled plasma-atomic-emission spectrometry: A five-element survey. Forensic Sci Int 17: $253-263$

Clark Jd'A (1985) Pulp technology and treatment of paper, $2^{\text {nd }}$ ed, Miller Freeman Pub, CA

Coleman RF, Goode GC (1973) Comparison of glass fragments by neutron activation analysis. J Radiol Chem 15: 367- 372

Copley GJ (2001) The comparison and Manufacture of Glass and its Domestic and Industrial Applications. In: Forensic Examination of Glass and Paint. Caddy B (ed), Taylor \& Francis, London, 27-46

Cremers DA, Radziemski LJ, Handbook of Laser-Induced Breakdown Spectroscopy, John Wiley and sons, 2006, England 
Donelly S, Marrero JE et al (2010)= Analysis of pigmented Inkjet Printer Inks and Printed Documents by Laser/Desorption/Mass Spectrometry. J Forensic Sci 55, 1: 129135

Donnet JB, Bansal RC, Wang MJ (1993) Carbon Black: Science and Technology, $2^{\text {nd }}$ ed, Marcel Dekker Inc, NY

Duckworth DC, Morton SJ, Bayne K, Montero S, Koons RD, Almirall JR (2002) Forensic glass analysis by ICP-MS: A multi-element assessment of discriminating power via analysis of variance and pairwise comparisons. J Anal At Spectrom 17: 662-668

Duckworth DC, Bayne CK, Morton SJ, Almirall JR (2000) Analysis of variance of forensic glass analysis by ICP-MS: Variance within the method. J Anal At Spectrom15: $821-828$

Dudley RJ, Howden CR, Taylor TJ, Smalldon KW (1980) The discrimination and classification of small fragments of window and non-window glasses using energydispersive X-ray fluorescence spectrometry. X-Ray Spectrom 9:119-122

Eberlin LS et al (2010) Instantaneous chemical profiles of banknotes by ambient mass spectrometry. Analyst 135: 2533-2539

Edison SE (2011) Formulating UV curable inkjet inks, In: Magdassi S (ed), The Chemistry of inkjet inks, World Scientific Publishing Co, NJ

Ernst T, Berman T, Buscaglia J, et al. (submitted 2012) Signal to noise ratios in forensic glass analysis by micro $\mathrm{x}$-ray fluorescence spectrometry. Journal x-Ray Spectrom

Evans E, Day J, Palmerc C (2010) Atomic spectrometry update, advances in atomic spectrometry and related techniques. J Anal At Spectrom 25, 760-784

Ferrero JL, Roldan C et al (1999) Application of XRF analysis to the cultural patrimony of the comunidad Valenciana (Spain): painting, metal and paper. J Radioanal Nuclear Chem 240: 523-528 
Gallidabino M, Weyermann C, Marquis R (2010) Differentiation of blue ballpoint pen inks by positive and negative mode LDI-MS. Forensic Sci Int 204, 1-3: 169-178

Gernandt Mn, Urlaub JJ (1996) An introduction to gel pen. J Forensic Sci, 41,3: 503-504 Gonzalez J et al (2002) Comparison of 193,213 and 266nm laser ablation ICP-MS. J Anal At Spectrom 17: 1108-1113

Gornushkin I, Panne U (2010) Radiative models of laser induced plasma and pump-probe diagnostics relevant to laser induced breakdown spectroscopy. Spectochim Acta B 65:345-359

Grassi N, Giuntini L, Mando PA, Massi M (2007) Advantages of scanning-mode ion beam analysis for the study of cultural heritage, Nucl Instr Meth B 256: 712-178

Grim DM, Siegel J, Allison J (2001) Evaluation of desorption/ionization mass spectrometric methods in the forensic applications of the analysis of inks on paper. $J$ Forensic Sci 46: 1411-1420

Grundeman L, Fischer N, Scholl S (2009) From macro batch to micro-conti manufacturing: a new eco-friendly production process for writing ink employing microprocess engineering. Chem Eng \& Techn 32,11: 1748-1756

Hickman EP, Mackenzie MJ, Smith HG (1993) In: The printing ink manual, Leach Re, Pierce RJ (eds), fifth ed, Blueprint, UK

Hicks T, Monard Sermier F, Goldmann T, Brunelle A, Champod C, Margot P (2003) The classification and discrimination of glass fragments using nondestructive energy dispersive X-ray $\mu$ fluorescence. Forensic Sci Int 137: 107-118

Hoffman R (2004) Modeling and Simulation of an Electrostatic Image Transfer, Technischen Universität München, dissertation, http://tumb1.biblio.tumuenchen.de/publ/diss/ei/2004/hoffmann r.pdf

Horn I et al (2001) Wavelenght dependent ablation rates for metals and silicate glasses using homogeneized laser beam profiles-implications for LA-ICP-Ms. Appl Surf Sci 182: 91-102 
Howden CR, Dudley RJ, Smalldon KW (1978) The analysis of small glass fragments using energy dispersive x-ray fluorescence spectrometry. J Forensic Sci Soc 18: 99-112

Hubbe M (2012) Mini-encyclopedia of paper making wet-end chemistry, North Carolina State University, http://www4.ncsu.edu/ hubbe/MiniEncy.htm

Hudd A (2011) Inkjet printer technologies. In: Magdassi Shlomo (ed), The Chemistry of inkjet inks, World Scientific Publishing Co, NJ

Hughes JC, Catterick T, Southear G (1976) The quantitative analysis of glass by atomic absorption spectroscopy. J Forensic Sci 8: 217-227

Hutchinson I (2011) Raw materials for UV curable inks, In: Magdassi S (ed), The Chemistry of inkjet inks, World Scientific Publishing Co, NJ

Ifa DR, Gumaelius L, Eberlin Ls, Manicke NE, Cooks RG (2007) Forensic analysis of inks by imaging desorption electrospray ionization (DESI) mass spectrometryAnalyst 132: $461-467$

Imbert JL,Telouck P (1993) Application of laser ablation ICP-MS to elemental analysis of glasses. Microchim Acta 110: 151-160

International Union of Pure and Applied Chemistry (IUPAC) (1976) Commission on Spectrochemical and Other Optical Procedures for Analysis. Pure \& Appl Chem 45:99103.

Isogai A, Kitaoka C, Onabe F (1997) Effects of carboxyl groups in pulp on retention of alkylketene dimer. J Pulp Paper Sci 23,5: J215

Jones RW, Cody RB, McClelland JF (2006) Differentiating writing inks using direct analysis in real time mass spectrometry. J Forensic Sci 51,4: 915-918

Koch J, Gunther D (2011) Review of the state of the art of laser ablation inductively coupled plasma mass spectrometry. Appl Spectrosc 65,5: 155A-162A 
Koons RD, Buscaglia J (2001) Distribution of refractive index values in sheet glasses, Forensic Science Commun 3,1 http://www.fbi.gov/hq/lab/fsc/current/ index.htm.

Koons RD, Buscaglia, J, Bottrell M, Miller ET (2002) Forensic glass comparisons. In: Saferstein R (ed) Forensic Science Handbook, Volume 1, 2nd ed. Upper Saddle River, Prentice Hall, NJ, 161-214

Koons RD, Fiedler C, Rawalt C (1988) Classification and discrimination of sheet and container glasses by inductively coupled plasma atomic emission spectrometry and pattern recognition. J Forensic Sci 33:49-67

Koons RD, Peters CA, Rebbert PS (1991) Comparison of refractive index, energy dispersive X-ray fluorescence and inductively coupled plasma atomic emission spectrometry for forensic characterization of sheet glass fragments. J Anal At Spectrom 6: $451-456$

Koons RD, Peters CA, Rebbert PS (1991) Comparison of refractive index, energy dispersive X-ray fluorescence and inductively coupled plasma atomic emission spectrometry for forensic characterization of sheet glass fragments. J Anal At Spectrom 6: $451-456$

Krüsemann H (2001) SEMs and Forensic Science. Problems in Forensic Science XLVII: $110-121$

Kuisma-Kursula P (2000) Accuracy, precision and detection limits of SEM-WDS, SEMEDS and PIXE in the multi- elemental analysis of medieval glass. X-Ray Spectrom 29: $111-118$

Kuptsov AH (1994) Applications of Fourier transform Raman spectroscopy in forensic science. J Forensic Sci 39: 305 -319

Kyrils A, Shim A (2008) Designing pigments for optimal performance in chemical toners, NIP24 and digital fabrication 2008 proceedings, society for imaging science and technology, $72-74$

Lalli PM, Sanvido GB et al (2010) Fingerprint and aging of ink by easy ambient sonicspray ionization mass spectrometry. Analyst 135:745-750 
Latkoczy C, Dücking M, Becker S et al. (2005) Evaluation of a standard method for the quantitative elemental analysis of float glass samples by LA-ICP-MS. J Forensic Sci 50:1327-1341

Lewis JA (1996) Thin layer chromatography of writing inks -quality control considerations. J Forensic Sci 27: 874-877

Liu C et al (2005) Particle size dependent chemistry for laser ablation of brass. Anal Chem 77: 6687-6691

Liu YZ, Yu J, Xie MX, Chem Y, Jiamg GY, Gao Y (2006) studies of the degradation of blue gel pen dyes by ion-paring high performance liquid chromatography and electrospray tandem mass spectrometry. J Chrom A 1125: 95-103

Liu YZ, Yu J, Xie MX, Lui Y, Han H, Jing TT (2006) classification and dating of black gel pen ink by ion-paring high-performance liquid chromatography. J Chrom A 1135:5764

Lukens HR, Schlesinger HL, Settle DM, Guinn VP (1970) Forensic Neutron Activation Analysis of Paper, USAEC report Ca-10113, United States Atomic Energy Commision

Magdassi S (2011) Ink requirements and formulation guidelines, In: Magdassi Shlomo (ed), The Chemistry of inkjet inks, World Scientific Publishing Co, NJ

Maind SD, Chattopadhyay N, Gandhi Ch, Kumar SC, Suderanan M (2008) Quantitative evaluation of europium in blue ballpoint inks offset printing inks tagged with europium thenoylfluoroacetonate by spectrofluorometry and ICP-AES, Sci \& Justice 48: 61- 66

Maind SD, Kumar SA, Chattopadhyay N, Gandhi Ch, Suderanan M (2006) Analysis of Indian blue ballpoint pen inks tagged with rare earth thoeylfluoroacetonates by ICP-MS and instrumental NAA. Forensic Sci Int 159: 32-42

Malzer W, Hahn O, Kanngeisser B (2004) A fingerprint model for inhomogeneous inkpaper layer systems measured with $\mu$-XRF analysis. X-ray Spectrom 33: 229-233 
Manso M, Carvalho ML (2009) Application of spectroscopic techniques for the study of paper documents: a survey. Spectrochim Acta B 64: 482-490

Mao X, Bol'shakov A, Choi I, McKay C, Perry D, Sorkhabi O and Russo R (2011) Laser Ablation Molecular Isotopic Spectrometry: Strontium and its isotopes. Spectrochim Acta B 66: 767-775

Mao X, Bol'shakov A, Choi I, McKay C, Perry D, Sorkhabi O and Russo R (2011) Laser Ablation Molecular Isotopic Spectrometry: parameter influence on boron isotope measurements. Spectrochim Acta B 66: 604-609

Mazzella WD, Khanmy-Vital A (2003) A study to investigate the evidential value of blue gel inks, J Forensic Sci 48: 419-424

McGaw EA, Szymanski DW, Smith RW (2009) Determination of trace elemental concentrations in document paper for forensic comparisons using ICP-MS. J Forensic Sci 54,5:1163-1170

Melessanaki K, Papadakis V, Balas C, Anglos D (2001) Laser induced breakdown spectroscopy and hyper spectral imaging analysis of pigments on an illuminated manuscript, Spectrochim. Acta B 56: 2337-2346

Miller JN, Miller JC (2000) Statistics and Chemometrics for Analytical Chemistry, $4^{\text {th }}$ ed., Pearson Education Limited, U.K.

Moenke-Blankenburg L, Schumann T, Günther D, Kuss HM, Paul M (1992) Quantitative analysis of glass using ICP-AES and ICP-MS, laser micro-analysis ICP-AES and laser ablation ICP-MS, J Anal At Spectrom 7: 251-254

Mokgalaka NS, GArdea-Torresdey JL (2006) Laser ablation inductively coupled plasma mass spectrometry: principles and applications. Appl Spectros Rev 41, 131-150

Montero S, Hobbs A, French T, Almirall JR (2003) Elemental analysis of glass fragments by ICP-MS as evidence of association: analysis of a case. J Forensic Sci 48: 1101-1107 
Naes B, Umpierrez S, Ryland SG, Barnett C, Almirall JR (2008) A comparison of laser ablation inductively coupled plasma mass spectrometry, micro X-ray fluorescence spectroscopy, and laser induced breakdown spectroscopy for the discrimination of automotive glass, Spectrochim Acta Part B 63,10: 1145-1150

Naes, B, (2009) Elemental Analysis of Glass and Ink by Laser Ablation Inductively Coupled Plasma Mass Spectrometry (LA-ICP- MS) and Laser Induced Breakdown Spectroscopy (LIBS), FIU Electronic Theses and Dissertations. Paper 207. http://digitalcommons.fiu.edu/etd/20

NRC report (2009) Committee on Identifying the Needs of the Forensic Sciences Community, National Research Council, Strengthening Forensic Science in the United States: A Path Forward, National Academic Press, Washington DC

Oujja M, Vila ARebollar E et al (2005) Identification of inks and structural characterization of contemporary artistic prints by laser-induced breakdown spectroscopy, Spectrochim Acta B 60: 1140-1148.

Pachuta SJ, Staral JS (1994) Non-destructive analysis of colorants in paper by time-offlight secondary ion mass spectrometry. Anal Chem 66:276-284

Paper on Web (2010) Pulp and paper resources and information site http://www.paperonweb.com/index.htm

Parouchais T, Warner IM, Palmer LT, Kobus H (1996) The analysis of small glass fragments using inductively coupled plasma mass spectrometry. J Forensic Sci 41: 351360

Pearce NJ, Perkins WT, Westgate JA, Gorton MP, Jackson SE, Neal CR (1996) A compilation of new and published major and trace element data for NIST SRM 610 and NIST SRM 612 glass reference materials. Geostandard Newsletter 1: 115-144

Pfefferli P (1983) Application of microspectrometry in document examination. F SCi Int 23: $129-136$ 
Pierre C (1993) Complementarity between two dewatering and retention microparticle systems: 'cationic starch/anionic colloidal silica,' and 'potato starch/aluminum salts, 1993 papermakers conference proceedings, TAPPI Press, Atlanta

Polk DE, Attard AE, Giessen BC (1977) Forensic characterization of papers II determination of batch differences by SEM elemental analysis of the inorganic components. J Forensic Sci 22: 524-533

Reeve V, Mathiesen J, Fong W (1976) Elemental analysis by energy dispersive X-ray: A significant factor in the forensic analysis of glass. J Forensic Sci 21: 291-306

Rodriguez-Celis EM et al (2008) Laser induced breakdown spectroscopy as a tool for discrimination of glass for forensic applications. Anal Bioanal Chem 391, 5: 1961-1968

Roedel TC, Bronk H, Haschke M (2003) Investigation of the influence of particle size on the quantitative analysis of glasses by energy-dispersive micro $\mathrm{x}$-ray fluorescence spectrometry. X-Ray Spectrom. 31: 16-26

Roux C, Novotny M, Evans I, Lennard C (1999) A study to investigate the evidential value of blue and black ballpoint inks in Australia. F Sci Int 101: 167-176

Rozic M, Rozmaric M, Orescanin MV (2005) Elemental analysis of office papers by EDXRF spectrometry. Nucl Instr Meth B 229: 117-122

Russo RE et al (2011) Laser ablation molecular isotopic spectrometry. Spectrochim Acta B, 66: 99-104

Russo RE, Suen TW, Bol'shakov AA, Yoo J, Sorkhabi O, Mao X, Gonzalez J, Oropeza D, Zorba V (2011) Laser plasma spectrochemistry. J Anal At Spectrom 26: 1596-1603

Ryland S (1986) Sheet or container? Forensic glass comparisons with an emphasis on source classification. J Forensic Sci 31: 1314-1329 
Ryland S (2011) Discrimination of flat (sheet) glass specimens having similar refractive indices using micro X-ray fluorescence spectrometry. Journal of the American Society of Trace Evidence Examiners 2:1:2-12

Sakanayagi M et al (1999) Analysis of ballpoint inks by field desorption mass spectrometry. J Forensic Sci, 44,6: 1204-1214.

Samuel S, Edwards P (2011) Solvent- based inkjet inks, In: Magdassi S (ed) The Chemistry of inkjet inks, World Scientific Publishing Co, NJ

Sarkar A, Aggarwal SK, Alamelu D (2010) Laser Induced Breakdown Spectroscopy for rapid identification of different types of paper for forensic application. Anal Methods 2: $32-36$

Schmid C (2011), Formulations and properties of waterborne inkjet inks, In: Magdassi S (ed), The Chemistry of inkjet inks, World Scientific Publishing Co, NJ

Scott WE (1996) Principles of Wet End Chemistry, TAPPI Press, Atlanta

Sensi CA, Cantu A (1982) Infrared luminescence: is it a balid method to differentiate among inks?. J Forensic Sci 27: 196-199

Shakhnovich A, Belmont J (2011) Pigments for inkjet applications, In: Magdassi S (ed,) The Chemistry of inkjet inks, World Scientific Publishing Co, NJ

Shetty CS, Greer CS, Laubach GD (1994) A likely mechanism for pitch deposition control. Tappi J 77,10: 91-94

Sinor T, Wilde J, Everse K, Mensel E (1986) Lasers and optical spectroscopy in questioned document examination. J Forensic Sci 31,3: 825-839

Smook GA (1992) Handbook for Pulp \& Paper Technologists, Bellingham: Angus Wilde Publications Inc, Canada 
Spence LD, Francis RB, Tinggi U (2002) Comparison of the elemental composition of office document paper: evidence in a homicide case. J Forensic Sci 47: 648-651

Spence LD, Spence AT, Baker JP (2000) Characterization of document paper using elemental compositions determined by inductively coupled plasma mass spectrometry. J Anal At Spectrom 15: 813-819

Suzuki Y, Sugita R, Suzuki S, Marumo Y (2000) Forensic discrimination of bottle glass by refractive index measurement and analysis of trace elements with ICP-MS. Anal Sci 16: $1195-1198$

The Center for paper business and industry studies (2012) Mills online http://www.cpbis.gatech.edu/data/mills-online-new mills on line

Trejos T, Almirall (2010) Laser Ablation Inductively Coupled Plasma Mass Spectrometry in Forensic Science, In: Patonay G (ed) Encyclopedia of Analytical Chemistry (Forensic Analytical Chemistry Volume) Wiley, 1-26

Trejos T, Almirall JR (2005) Sampling strategies for the analysis of glass fragments by LA-ICPMS. Part I. Microhomogeneity study of glass and its application to the interpretation of forensic evidence. Talanta 67: 388-395

Trejos T, Almirall JR (2005) Sampling strategies for the analysis of glass fragments by LA-ICPMS. Part II. Sample size and shape considerations. Talanta 67: 396-401

Trejos T, et al (submitted) Forensic elemental analysis of glass by $\mu$-XRF, ICP-MS and LA-ICP-MS - Part II: Evaluation of the performance of different match criteria for elemental composition

Trejos T, et al (submitted) Forensic elemental analysis of glass by $\mu-\mathrm{XRF}$, ICP-MS and LA-ICP-MS - Part I: Method standardization

Trejos T, Flores A, Almirall JR (2010) Micro-spectrochemical analysis of document paper and gel inks by laser ablation inductively coupled plasma mass spectrometry and laser induced breakdown spectroscopy. Spectrochim Acta B 65: 884-895 
Trejos T, Montero S, Almirall JR (2003) Analysis and comparison of glass fragments by laser ablation inductively coupled plasma mass spectrometry (LA-ICP-MS) and ICPMS). Anal BioAnal Chem 376, 8: 1255-1264

Trejos T, Montero S, Almirall JR (2003) Analysis and comparison of glass fragments by laser ablation inductively coupled plasma mass spectrometry (LA-ICP-MS) and ICPMS). Anal BioAnal Chem 376, 8: 1255-1264

van Es A, de Koeijer J, van der Peijl G (2009) Discrimination of document paper by XRF, LA-ICP-MS and IRMS using multivariate statistical tools. Sci \& Justice 49: 120126

Weis P, Dücking M, Watzke P, Menges S, Becker S (2011) Establishing a match criterion in forensic comparison analysis of float glass using laser ablation inductively coupled plasma mass spectrometry. J Anal At Spectrom 26: 1273-1284

Wen SB et al (2007) Laser ablation induced vapor plume expansion into a background gas. J Appl Phys 102: 103-

Weyerman C, Bucher L, Majcherczyk P (2010) A statistical methodology for the comparison of blue gel pen inks analysed by laser desorption ionization mass spectrometry. Sci \& Justice 51,3: 122-130

Weyerman C, Bucher L, Majcherczyk P, Mazella W (2012) Statistical discrimination of black gel pen inks analyzed by LDI-MS. Forensic Sci Int 217 (1-3): 127-133

Williams MR, C. Moody, L.A Arceneaux, C. Rinke, K. White, M. Sigman, Analysis of black writing ink by electrospray ionization mass spectrometry, Forensic Sci Int 191 (2009) 97-103.

Wilson JF, LaPorte GM, Cantu AA (2004) Differentiation of black gel inks using optical and chemical techniques. J Forensic Sci 49: 364-370

Wolnik KL, Gaston CM,. Fricke FL (1989) Analysis of glass in product tampering investigations by ICP-AES with a hydrofluoric acid resistant torch. J Anal At Spectrom 4:27-31 
Wood and paper (2010) http://www.global-production.com/wood-pulppaper/news/index.htm

Zieba-Palus J, Borusiewicz R, Kunicki M (2008) PRAXIS- combined $\mu$ Raman and $\mu X R F$ spectrometers in the examination of forensic samples. Forensic Sci Int 175: 1-10

Zieba-Palus J, Kunicki M (2006) Application of the micro-FTIR spectroscopy, Raman spectroscopy and XRF method examination of inks. Forensic Sci Int 158: 164-172.

Zimmerman J, Mooney D (1988) Laser examination as an additional non destructive method of ink differentiation. J Forensic Sci 33: 310-318

Zurhaar A, Mullings L (1990) Characterization of forensic glass samples using inductively coupled mass spectrometry. J Anal At Spectrom 5: 611-617 
VITA

Tatiana Trejos

2003

1998

2012

$2005-2012$
Master of Science in Forensic Science, Florida International University

Licentiature in Chemistry, Universidad de Costa Rica

Interpol-EDEWG, Young Scientist Presentation Award Coordinator of Research Programs and TEAF Facilty Manager, FIU

\section{PUBLICATIONS}

Trejos T et al., Performance of standardized methods for the forensic elemental analysis of glass by $\mu$ XRF, ICP-MS, LA-ICP-MS and LIBS, PART I, submitted J. Anal. Bional. Chemistry, 2012

Trejost $\mathrm{T}$ et al., Performance of standardized methods for the forensic elemental analysis of glass by $\mu$ XRF, ICP-MS, LA-ICP-MS and LIBS, PART II, submitted J. Anal. Bional. Chemistry, 2012

Elemental Analysis Working Group (EAWG): ASTM method for the elemental analysis of glass by LA-ICP-MS, submitted 2012

Elemental Analysis Working Group (EAWG) ASTM method for the elemental analysis of glass by $\mu \mathrm{XRF}$, submitted 2012

Trejos T, Flores A and Almirall JR., Micro-spectrochemical analysis of document paper and gel inks by laser ablation inductively coupled plasma mass spectrometry and laser induced breakdown spectroscopy, Spectrochimica Acta Part B: Atomic Spectroscopy, 65B (11), 884-895, 2010

Arroyo L, Trejos T, Hosick T, Machemer S, Almirall JR, Gardinali PR. Analysis of soils and sediments by laser ablation ICP-MS: an innovative tool for environmental forensics, Environ. Forensics, 11: 4, 315- 327, 2010

Trejos T, Almirall JR, Laser Ablation Inductively Coupled Plasma Mass Spectrometry in Forensic Science in Wiley Encyclopedia of Analytical Chemistry (Forensic Analytical Chemistry Volume) G. Patonay, Ed., a9103, 1-26, 2010

Almirall JR, Trejos T, Forensic applications of mass spectrometry in Encyclopedia of Mass Spectrometry, Vol. 5, Diane Beauchemin, Ed., 705-717, 2010 


\section{SELECTED PRESENTATIONS}

October 2012, Trejos T, L Kamandulis and JR Almirall, Application of laser-based spectrochemical analysis for the analysis of questioned documents, SCIX meeting, Kansas, MO

September 2012, Trejos T and JR Almirall, Characterization of the elemental composition of printing inks using laser-based microspectrochemical techniques (LAICP-MS and LIBS), Interpol $7^{\text {th }}$ EDEWG meeting, Lyon France, (invited oral, Young Scientist Presentation Award)

June 2012, J. Almirall and T. Trejos. Evidential Value of the Elemental Composition of Glass, Ink and Paper by LA-ICP-MS, $11^{\text {th }}$ European Workshop on Laser Ablation, Spain

March 2012, T. Trejos, L Kamandulis, JR Almirall. Micro-chemical identification of printing and writing inks using laser-based methods (LIBS and LA-ICP-MS), Pittsburgh Conference, Orlando, FL (Poster)

August 2011, T. Trejos et al. Evaluation of the performance of different match criteria for the comparison of elemental composition of glass by uXRF, ICPMS, LAICPMS and LIBS, Trace Evidence Symposium, Kansas City, MO

December 2010, J. Almirall and T. Trejos, Advances in forensic chemical analysis of materials using LIBS, PACIFICHEM, Honolulu, HI (Invited Oral)

December 2010, T. Trejos and J. Almirall, Microchemical characterization of questioned documents using elemental analysis determined by laser-based methods (LIBS and LAICP-MS), PACIFICHEM, Honolulu, HI (Invited Poster)

May 2010, T.Trejos and J. Almriall, Importancia del perfil elemental en el análisis e interpretación de evidencia traza: discusión de casos, III Conferencia Internacional Educativa en Ciencias Forenses CAD-IAI, Costa Rica, (Invited Oral)

May 2010, T. Trejos and J. Almirall, Uso de rayos laser para el analisis de perfiles elementales en Ciencias Forenses, Universidad de Costa Rica, San Jose, Costa Rica

March 2010, T. Trejos; R. Hark; Luci East and José R. Almirall, PITTCON, Comparison of the capabilities of LIBS and LAICPMS for the forensic analysis of paper and gel ink

February 2010, J R. Almirall, Tatiana Trejos; Richard R. Hark; Luci East; Richard Russo. AAFS Meetting, Forensic analysis of inks by LIBS and LA-ICP-MS

February 2009, T Trejos, Naes B, Rodriguez Y, Almirall, JR $61^{\text {st }}$ Annual Meeting, AAFS. Denver Co, Evaluation of capabilities of LA-ICP-MS for the forensic analysis of gel pen inks 